\title{
Die Subjektivierung der allgemeinen Völkerrechtsregeln im Sinne des Artikel 25 Satz 2 GG
}

\author{
Dissertation \\ zur Erlangung des Doktorgrades der Juristischen Fakultät der Georg-August- \\ Universität Göttingen vorgelegt \\ von
}

Sören E. Hennies

aus Elze (Han)

Göttingen 2021 
Erstgutachter: Prof. Dr. Frank Schorkopf

Zweitgutachter: Prof. Dr. José Martínez

Tag der mündlichen Prüfung: 2. Dezember 2020 
Für Kristina und meine Familie 



\section{$\underline{\text { Inhaltsverzeichnis }}$}

Abkürzungsverzeichnis $\quad$ IV

$\S 1$ Der Konflikt um die Subjektivierung der allgemeinen Völkerrechtsregeln 1

$\S 2$ Die Entstehungsgeschichte des Art. 25 (Satz 2) GG als Hindernis einer generellen Subjektivierung 5

1. Historische Aspekte des Art. 25 Satz 2 GG 5

2. Setzt Art. 19 Abs. 4 eine Klagebefugnis für die allgemeinen Völkerrechtsregeln voraus?

2.1 Inhaltlicher Geltungsbereich des Art. 19 Abs. 4 GG 10

2.2 Die Trennung von Individualrecht und Rechtsschutz im nationalen Recht $\begin{array}{ll}\text { und die Erforderlichkeit der Klagebefugnis im Völkerrecht } & 12\end{array}$

2.3 Die unmittelbare Anwendbarkeit im Völkerrecht 15

2.4 Die unmittelbare Betroffenheit als Voraussetzung internationaler $\begin{array}{ll}\text { Rechtsmittel } & 17\end{array}$

2.5 Zwischenergebnis 19

3. Die Funktion des Art. 25 GG im innerdeutschen Recht 20

4. Hat Art. 25 Satz 2 GG konstitutive Wirkung? 23

5. Der Rang der allgemeinen Völkerrechtsregeln im deutschen Recht 28

6. Schließt Art. 25 GG reine Interessenklagen aus? 30

7. Fazit 33

§ 3 Völkerrechtliche Anspruchsinhaberschaft auch für Einzelne? 35

1. Normadressaten als Völkerrechtssubjekte 35

1.1 Anfänge der Betrachtung Einzelner als Völkerrechtssubjekte 35

1.2 Historische Entwicklung der Völkerrechtssubjektivität von Individuen als $\begin{array}{ll}\text { Zurechnungspunkte } & 37\end{array}$

1.3 Internationale Organisationen als Indikatoren? 43

1.4 Alleinige Inhaberschaft der Völkerrechtssubjektivität von Staaten überholt? 44

1.5 Zwischenergebnis 47

2. Fazit 48

§ 4 Völkerrechtliche Individualpflichten - Art. 25 GG am Beispiel des Völkerstrafrechts 50

1. Der Einzelne als Adressat völkerrechtlicher Pflichten 50

2. Die völkerrechtliche Verantwortlichkeit 55

3. Der IStGH als alleiniger Chefankläger 57

4. Völkerrechtsunmittelbare Strafbarkeit denkbar? 59 
5. Der Nullum-Crimen-Grundsatz als Hindernis praktischer Anwendung 61

6. Das IStGH-Statut und seine Umsetzung ins deutsche Recht 66

7. Die völkerstrafrechtliche Praxis Deutschlands 70

$\begin{array}{lll}7.1 & \text { Vor Erlass des VStGB } & 70\end{array}$

7.2 Nach Inkrafttreten des VStGB 71

$\begin{array}{lll}7.3 \text { Zwischenergebnis } & 74\end{array}$

$\begin{array}{lll}\text { 8. Fazit } & 76\end{array}$

$\S 5$ Völkerrechtliche Individualrechte - Die Literatur als Motor individueller $\begin{array}{ll}\text { Rechtsansprüche aus Art. } 25 \mathrm{GG} & 78\end{array}$

1. Die innerstaatliche Gerichtsbarkeit der allgemeinen Völkerrechtsregeln 78

2. Beispiel Fremdenrecht $\quad 80$

2.1 Der Wortlaut des Art. 25 Satz 2 GG als Indiz für Individualrechte? 82

2.2 Der fremdenrechtliche Individualanspruch aus Art. $25 \mathrm{GG} 83$

2.3 Art. 25 GG und Art. 3 GG als Grundsätze des innerstaatlichen Fremdenrechts 83

2.4 Die „Erzeugung“ von Rechten und Pflichten nach Art. 25 Satz 2 GG 84

2.5 Rang und Vorrang des Art. GG im Fremdenrecht 85

$\begin{array}{ll}2.6 \text { Zwischenergebnis } & 89\end{array}$

3. Beispiel Migrationsrecht 90

3.1 Bisherige Praxis in Deutschland anhand fiktiver Beispiele 91

3.2 Rechtsprinzipien als allgemeine Rechtsgrundsätze im Sinne des

3.3 Die Rechtsprinzipien im Rahmen des Art. 25 GG 97

3.4 Stellungnahme zur nationalen Rechtslage 98

$\begin{array}{lll}3.5 & \text { Zwischenergebnis } & 100\end{array}$

4. Individualentschädigungs- und Wiedergutmachungsansprüche des Völkerrechts und Kriegsvölkerrechts

4.1 Anwendbarkeit des Staatshaftungsrechts auf bewaffnete Konflikte 105

4.2 Art. 25 Satz 2 GG als Anspruchsgrundlage auf Unterlassung und auf Entschädigung

4.3 Ein völkerrechtlicher Unterlassungsanspruch in Deutschland 106

4.4 Der Entschädigungsanspruch bei Kriegsschäden 110

4.5 Die ,faktische Betroffenheit“ als zusätzliche Anspruchsvoraussetzung 114

$\begin{array}{ll}4.6 \text { Zwischenergebnis } & 119\end{array}$

5. Fazit 120

$\S 6$ Die Entwicklung und Rolle der allgemeinen Völkerrechtsregeln und Art. 25 GG In der Rechtsprechung 
$\begin{array}{ll}\text { 1. Internationaler Vergleich } & 125\end{array}$

1.1 Italien und Griechenland 126

$\begin{array}{lll}1.2 & \text { Japan } & 128\end{array}$

1.3 Die Vereinigten Staaten von Amerika 131

$\begin{array}{lll}1.4 & \text { Zwischenergebnis } & 135\end{array}$

2. Auffassung der deutschen Rechtsprechung 138

2.1 Allgemeine Völkerrechtsregeln als direkte Anspruchsgrundlage? 140

2.2 Art. 25 (Satz 2) GG als individuelles Recht? 143

2.3 Ursprünglich generell keine Subjektivierung der allgemeinen $\begin{array}{ll}\text { Völkerrechtsregeln } & 144\end{array}$

2.4 Jüngere Tendenzen und Entspannung der Sicht der Gerichte 145

2.5 Zwischenergebnis 158

3. Fazit 160

§ 7 Sichtweise der Rechtsprechung zu Art. 25 Satz 2 GG als
unmittelbare Rechtsgrundlage

1. Politische Aspekte zu den allgemeinen Völkerrechtsregeln als Individualrechte 163

2. Eine Frage der bisherigen Durchsetzbarkeit? 165

3. Keine eigenständige Rechtsgrundlage mit Art. 25 Satz 2 GG 167

4. Art. 25 Satz 2 GG als mittelbare Anspruchsgrundlage? 170

4.1 Art. 2 Abs. 1 und Abs. 2 GG in Verbindung mit Art. 25 (Satz 2) GG 170

4.2 Beispiele weiterer spezieller Verfassungsrechte und spezialgesetzliche
Rechtsgrundlagen

4.3 Zwischenergebnis 181

5. Das Normenverifikationsverfahren nach Art. 100 Abs. 2 GG 182

6. Fazit 186

$\begin{array}{lll}\S & \text { Abschließende Bewertung } & 188\end{array}$

Literaturverzeichnis $\quad$ IX 


\section{$\underline{\text { Abkürzungsverzeichnis }}$}

a. A. - andere Ansicht

Abs.- Absatz

AEUV - Vertrag über die Arbeitsweise der Europäischen Union

AJIL - American Journal of International Law

AnwB1. - Anwaltsblatt

AöR - Archiv des Öffentlichen Rechts

Art. - Artikel

ATCA - Alien Tort Claims Act

AufenthG - Aufenthaltsgesetz

AVR - Archiv des Völkerrechts

Az. - Aktenzeichen

Bd. - Band

BdDGfV - Band der Berichte der Deutschen Gesellschaft für Völkerrecht

BFHE - Entscheidungen des Bundesfinanzhofs

BGB - Bürgerliches Gesetzbuch

BGB1. - Bundesgesetzblatt

BGE - Entscheidungen des Schweizerischen Bundesgerichts

BGH - Bundesgerichtshof

BGHSt - Entscheidungen des Bundesgerichtshofs in Strafsachen

BGHZ - Entscheidungen des Bundesgerichtshofs in Zivilsachen

BPolG - Bundespolizeigesetz

BRD - Bundesrepublik Deutschland

bspw. - beispielsweise

BT-Drs. - Bundestag-Drucksache

BVerfG - Bundesverfassungsgericht

BVerfGE - Bundesverfassungsgerichtsentscheidungsband

BVerfGG - Bundesverfassungsgerichtsgesetz

BVerfGK - Kammerentscheidungen des Bundesverfassungsgerichts

BVerwG - Bundesverwaltungsgericht

BVerwGE - Bundesverwaltungsgerichtsentscheidungsband

bzgl. - bezüglich

CEDEAO - Communauté Economique des Etats de l'Afrique de l'Ouest 
CIA - Central Intelligence Agency

CONV - Convent

Ders. - derselbe

Doc. - Document

Dok. - Dokument

DÖV - Die Öffentliche Verwaltung

DVB1. - Deutsches Verwaltungsblatt

ECCHR - European Center for Constitutional and Human Rights

ECOWAS - Economic Community of West African States

EGMR - Europäischer Gerichtshof für Menschenrechte

EJIL - European Journal of International Law

EMRK - Europäische Menschenrechtskonvention

EU - Europäische Union

EuGH - Europäischer Gerichtshof

EuGRZ - Europäische Grundrechte-Zeitschrift

EWCA - England and Wales Court of Appeal

EWHC - High Court of England and Wales

EWS - Europäisches Wirtschafts- und Steuerrecht

f. - folgende

GG - Grundgesetz

GVG - Gerichtsverfahrensgesetz

GYIL - German Yearbook of International Law

HdStR - Handbuch des Staatsrechts

HFR - Humboldt Forum Recht

Hrsg. - Herausgeber

HSR - Human Security Report

HUDOC - European Court of Human Rights

HuV-I - Humanitäres Völkerrechts-Institut

IAGMR - Interamerikanischer Gerichtshof für Menschenrechte

ICC - International Chamber of Commerce

ICLQ - International Comparative Law Quaterly

ICJ - International Court of Justice

ICLR - The International Construction Law Review

ICTR - International Criminal Tribunal for Rwanda 
ICTY - International Criminal Tribunal for Yugoslavia

IGH - Internationaler Gerichtshof

ILA - International Law Association

ILC - International Law Commission

IntStR - Internationales Strafrecht

IPBPR - Internationaler Pakt über bürgerliche und politische Rechte

IStGH - Internationaler Strafgerichtshof

IStGHG - IStGH-Gesetz

i. V. m. - in Verbindung mit

JA - Juristische Arbeitsblätter

JAIL - Japanese Annual of International Law

JuS - Juristische Schulung

$\mathrm{JZ}$ - JuristenZeitung

LG - Landgericht

LJIL - Leiden Jorunal of International Law

LQR - Law Quaterly Review

NATO - North Atlantic Treaty Organization

NBV - Verfassung des Norddeutschen Bundes

NGO - Non Governmental Organization

NJW - Neue Juristische Woche

NRW - Nordrhein-Westfalen

NSDAP - Nationalsozialistische Deutsche Arbeiterpartei

NStZ - Neue Zeitschrift für Strafrecht

NWVB1. - Nordrhein-Westfälische Verwaltungsblätter

OHCHR - UN Office of the High Commissioner for Human Rights

OLG - Oberlandesgericht

OLGR - Oberlandesgericht Report

OVG - Oberverwaltungsgericht

PCIJ - Permanent Court of International Justice

PRLPJ - Pacific Rim Law and Policy Journal

RGB1. - Reichsgesetzblatt

RGDIP - Revue Générale de Droit International Public

RGZ - Entscheidungssammlung der Entscheidungen des Reichsgerichts in Zivilsachen

$\mathrm{Rn}$ - Randnummer 
SchwJIR - Schweizerisches Jahrbuch für Internationales Recht

Slg. - Sammlung

sog. - sogenannte

SRÜ - Seerechtsübereinkommen der Vereinten Nationen

SS - Schutzstaffel

StGB - Strafgesetzbuch

StiftungsG - Stiftungsgesetz

StIGH - Ständiger Internationaler Gerichtshof

StPO - Strafprozessordnung

u. a. - unter anderem

UKHL - United Kingdom House of Lords

UN - United Nations

UN Doc/Dok - United Nations Document

UNHRC - United Nations Human Rights Council

UNTS - United Nations Treaty Series

USA - United States of America

US - United States

VG - Verwaltungsgericht

vgl. - vergleiche

VO - Verordnung

VStGB - Völkerstrafgesetzbuch

VVE - Vertrag über eine Verfassung für Europa

VwGO - Verwaltungsgerichtsordnung

WRV - Weimarer Reichsverfassung

WTO - World Trade Organisation

ZaöRV - Zeitschrift für ausländisches öffentliches Recht und Völkerrecht

ZfWG - Zeitschrift für Wett- und Glücksspielrecht

ZIS - Zeitschrift für Internationale Strafrechtsdogmatik

ZP-I - Zusatzprotokoll I zu den Genfer Abkommen

ZRP - Zeitschrift für Rechtspolitik

ZStW - Zeitschrift für die gesamte Strafrechtswissenschaft 


\section{$\S 1$ Der Konflikt um die Subjektivierung der allgemeinen Völkerrechtsregeln}

Der Ausgangspunkt der vorliegenden Dissertation sind jüngere Verfahren vor deutschen Gerichten, in denen einzelne Bürger Ansprüche wegen Verletzungen der allgemeinen Regeln des Völkerrechts geltend $\mathrm{zu}$ machen versuchten. Hinsichtlich der allgemeinen Regeln des Völkerrechts gibt es bisher kaum praktische Erfahrungen, so dass die Beurteilung des inhaltlichen Gehalts und praktischen Umfangs weiterhin höchst umstritten ist. So gibt es vielfältige Ansätze $\mathrm{zu}$ bestehenden und nicht bestehenden Anspruchsinhaberschaften Einzelner, welche in den folgenden Kapiteln vorgestellt werden, und ob diese unmittelbar oder mittelbar auf Art. 25 Satz 2 GG gestützt werden können.

In der Vergangenheit gab es Klagen einzelner Nachbarn militärisch genutzter Flughäfen in Deutschland, mittels derer sie bewaffnete Drohneneinsätze ausländischer Militärkräfte überwachen und untersagen lassen wollten. Die Nutzung der US-Airbase Ramstein etwa erfolgt aufgrund des Vertrags vom 23. Oktober 1954, mit dem der Aufenthalt ausländischer Streitkräfte in Deutschland geregelt wird, dem NATO-Truppenstatut vom 19. Juni 1951, sowie dem Zusatzabkommen zum NATO-Truppenstatut vom 3. August $1959^{1}$. Im Falle der Verweigerung einer solchen Überwachung der Anlage sollte die weitere Nutzung der Einrichtung durch die USA untersagt werden. Die Kläger wollten erreichen, dass sämtliche Unterstützungsleistungen der Bundesrepublik Deutschland an die US-Truppen im Rahmen der Operation „Enduring Freedom“ rechtswidrig sind. ${ }^{2}$ Sie vertraten, ihnen stünde eine Klagebefugnis bei einer drohenden Verletzung des völkerrechtlichen Gewaltverbots nach Art. 2 Abs. 4 der UN-Charta ${ }^{3}$ und des Verbots des gezielten oder unterschiedslosen Angriffs auf Zivilpersonen nach humanitärem Völkerrecht zu. Auch wenn dieses grundsätzlich nur Staaten bindet, soll mit Art. 25 Satz 2 GG ein Rechtsgrund bestehen, der unmittelbar für die Bewohner des Bundesgebietes Rechte und Pflichten erzeugt. Außerdem seien die Behörden und Gerichte Deutschlands durch die Rechtsprechung des BVerwG zu Art. 25 GG daran gehindert, an Handlungen nichtdeutscher Hoheitsträger mitzuwirken, die gegen die allgemeinen Völkerrechtsregeln verstoßen. ${ }^{4}$

\footnotetext{
${ }^{1}$ BGBl. 1961 II, S. 1183, 1190; S. 1183, 1218

${ }^{2}$ BVerwGE 154, 328 (329); OVG Münster, Urteil vom 04.11.2014, Az. 4 A 1058/13, in: DVB1. 8/2015, S. 514-520 (Leitsatz und Gründe), Rn 2 f. nach juris.

${ }^{3}$ BGB1. 1973 II S. 430.

${ }^{4}$ BVerwGE 154, 328 (329); OVG Münster, Urteil vom 04.11.2014, Az. 4 A 1058/13, in: DVBl. 8/2015, S. 514-520 (Leitsatz und Gründe), Rn 5 nach juris.
} 
Das BVerwG und die Vorinstanzen hatten sowohl die Klagebefugnis als auch die Anspruchsinhaberschaft aus Art. 25 GG abgelehnt. Die allgemeinen Völkerrechtsregeln erzeugten zwar Rechte und Pflichten nach Art. 25 Satz 2 GG für die Bewohner des Bundesgebietes. Allerdings sei keine individuelle Rechtsverletzung des völkerrechtlichen Gewaltverbots oder des Verbots eines Angriffskriegs auszumachen gewesen. Das BVerwG stellte fest, dass sich aus Art. 25 Satz 2 GG nicht ableiten lässt, dass jede allgemeine Völkerrechtsregel unabhängig ihres mittelbaren oder unmittelbaren völkerrechtlichen Adressatenkreises für die Bewohner des Bundesgebietes subjektive Rechte begründet. Dabei hielt das BVerwG, ebenso wie die Vorinstanzen, einen Unterlassungsanspruch unmittelbar aus dem Gewaltverbot in Verbindung mit Art. 25 Satz 2 GG für möglich. ${ }^{5}$

Im Laufe der Bearbeitung wird die These untersucht, dass sich die Völkerrechtslage international und national seit Inkrafttreten des Grundgesetzes verändert hat und über Art. 25 Satz 2 GG die Entwicklung ins deutsche Recht einfließt. Natürliche Personen sind kein völkerrechtliches Nullum mehr. Ihnen stehen Rechte zu, ihnen obliegen aber auch Pflichten. Fraglich ist, inwiefern Rechte und Pflichten auf völkerrechtlicher Ebene im deutschen Recht verortet sind, und ob Art. 25 Satz 2 GG mit seiner Formulierung ,[...] und erzeugen Rechte und Pflichten unmittelbar [...]“ darüber hinaus auf nationaler Ebene den Rechtsund Pflichtenkreis erweitert. Der Fokus dieser Arbeit ist der innerstaatliche Status natürlicher Personen im Kontext national eventuell durchsetzbarer völkerrechtlicher Ansprüche. Hauptsächlich wird der Charakter des Art. 25 GG als Rechts- und Anspruchsgrundlage für Einzelne untersucht. Es gibt unterschiedliche Ansätze der Betrachtung, in denen überwiegend sowohl mit der Historie der Verhandlungen des Konvents von Herrenchiemsee als auch mit dem normativen Sinn und Zweck des Art. 25 GG für sowie gegen eine generelle Subjektivierung der allgemeinen Völkerrechtsregeln argumentiert wird. Daran lässt sich die Notwendigkeit einer intensiveren Auseinandersetzung mit dem Sachverhalt ableiten. Die vorliegende Dissertation befasst sich zum einen mit der Stichhaltigkeit der von den Gerichten angelegten Argumentation als auch mit weiteren rechtlichen und auch sozialpolitischen Blickpunkten, um die Tragbarkeit der dargelegten Sichtweisen des Art. 25 GG nach heutigem Standard nachvollziehen und eventuell neu beurteilen zu können. Zu Beginn werden deshalb zunächst die Normgeschichte und Dogmatik des Art. 25 GG (§ 2) rekapi-

${ }^{5}$ BVerwGE 154, 328 (341 f.); OVG Münster, Urteil vom 04.11.2014, Az. 4 A 1058/13, in: DVBl. 8/2015, S. 514-520 (Leitsatz und Gründe), Rn 87, 99, 103 nach juris. 
tuliert. Es ist von Bedeutung für den weiteren Verlauf der Arbeit, dass die bekannten normativen Grundlagen und Grundsätze des Art. 19 Abs. 4 GG vorgestellt werden, auf welche auch noch regelmäßig Bezug zu nehmen sein wird. Aufgegriffen werden im Weiteren ( $\S$ 3-4) die Entwicklungen völkerrechtlicher Individualrechte und -pflichten und die Völkerrechtssubjektivität Einzelner im internationalen Bereich. Am konkreten Beispiel des Völkerstrafrechts werden völkerrechtliche Individualpflichten näher beleuchtet und die Umsetzung völkerrechtlicher Verpflichtungen ins nationale Recht durch Art. 25 GG analysiert. Den Hauptteil der Untersuchung bildet die Betrachtung verschiedener Literaturstimmen ( 5), welche teils eine deutlich weitere Auslegung des Art. 25 GG befürworten, und der Rechtsprechung (§ 6). Sowohl in Kapitel $\S 5$ als auch $\S 6$ wird jeweils kritisch betrachtet, ob sich einerseits Entwicklungen des Schrifttums an den Voraussetzungen einer praktischen Durchsetzbarkeit messen lassen und andererseits, ob über die Jahre deutsche Instanzgerichte auch mit vorgenannten Literaturmeinungen kritisch auseinandersetzen oder diese Wirkung auf die deutsche Rechtsprechung entfalten. Nach kurzer Darstellung ausländischer Entscheidungen zu allgemeinen Völkerrechtsregeln wird deren Bedeutung sowie die des Art. 25 GG in der deutschen Rechtspraxis betrachtet. Dabei ist relevant zu erfahren, inwiefern deutsche Gerichte die allgemeinen Völkerrechtsregeln anwenden, und vor allem, ob Art. 25 GG als Rechts- und Anspruchsgrundlage anerkannt und angewendet wird. Schließlich werden alternative Anspruchsgrundlagen, insbesondere Art. 2 Abs. 1 und 2 GG, auf ihren Charakter als umfassende Stütze individueller Anspruchsbegehren geprüft (§ 7), um die Behelfsmöglichkeiten vor deutschen Gerichten auffassen zu können.

Die Auffassung der Rechtsprechung gegen eine generelle Subjektivierung durch Art. 25 Satz 2 GG ist nicht ohne Kritik. So beziehen sich die Richter mitunter auf prominente Auffassungen des Schrifttums und stellen diese auf die praktische Probe, inwiefern eine generelle oder zumindest teilweise vorgenommene Subjektivierung allgemeiner Völkerrechtsregeln bestehen kann. Ob auch die Entstehungsgeschichte, der Sinn und Zweck und die bisherige Entwicklung der Tragweite der allgemeinen Völkerrechtsregeln nicht doch ein anderes Ergebnis zwingend gefordert hätten, wird in den folgenden Kapiteln näher analysiert und beurteilt. Das BVerfG vertrat etwa jahrzehntelang die stetige Auffassung, Satz 2 des Art. 25 GG wirke ausschließlich deklaratorisch hinsichtlich der durch Satz 1 der Norm eingegliederten Rechtssätze. ${ }^{6}$ Die Entwicklungen der Rechtsprechung und des Schrifttums

${ }^{6}$ BVerfGE 15, 25 (33 f.); 18, 441 (448); 27, 253 (273 f.); 41, 126 (160); 46, 342 (362 f., 403 f.); 63, 343 (373). 
werden deshalb im Folgenden untersucht und Tendenzen mit Blick auf die Zukunft bewertet.

Diese Gesamtbearbeitung widmet sich den unbeantworteten Rechtsfragen, ob die allgemeinen Völkerrechtsregeln durch Art. 25 Satz 2 GG unter heutiger Betrachtung der Völkerrechtslage generell eine konstitutive Wirkung entfaltet, und ob Art. 25 Satz 2 GG selbst eine taugliche Rechtsgrundlage für deutsche Verwaltungs- oder Verfassungsrechtswege darstellt.

Mit Blick auf den möglichen Anspruchscharakter des Art. 25 Satz 2 GG wird ferner der These nachgegangen, dass eine praktische Umsetzung vor deutschen Gerichten geringe Erfolgsaussichten hätte. 


\section{$\S 2$ Die Entstehungsgeschichte des Art. 25 (Satz 2) GG als Hindernis einer generellen Subjektivierung}

In der Literatur und der Rechtsprechung werden hinsichtlich des Sinns und Zwecks der allgemeinen Völkerrechtsregeln nach Art. 25 Satz 2 GG unterschiedliche Auffassungen vertreten. Die vorliegende Bearbeitung sucht nicht danach, die bekannten Auffassungen der Geschichte und Literatur zu wiederholen. Die Herangehensweise und die Ergebnisse sind hier jedoch aus Gründen der Vollständigkeit und der Nachvollziehbarkeit noch folgender Argumentationen zu benennen.

\section{Historische Aspekte des Art. 25 Satz 2 GG}

Art. 25 GG und die allgemeinen Völkerrechtsregeln werden mit Blick auf ihre Relevanz im Grundgesetz und die sich daraus ergebende Bedeutung für Individuen vorgestellt. Es wird gezeigt wie das Völkerrecht mit den allgemeinen Völkerrechtsregeln nach dem Konvent von Herrenchiemsee über Art. 25 GG in das deutsche Recht eingegliedert wurde und welche Folgen dies für die Bewohner des Bundesgebietes hat.

Die an die Darstellung der Entstehungsgeschichte anknüpfende Auslegung des Wortlauts und Inhalts des Art. 25 GG ist erforderlich, um die anschließende Diskussion des Rangs der allgemeinen Völkerrechtsregeln im innerdeutschen Recht in Kontext bringen zu können. Sowohl nach dem Ersten als auch nach dem Zweiten Weltkrieg wurde die verfassungsrechtliche Ordnung in Deutschland neugeschaffen. Die Weimarer Reichsverfassung von 1919 war die erste demokratisch begründete Verfassung im Deutschen Reich und trat am 14. August 1919 in Kraft. Nach der Machtübernahme der NSDAP am 30. Januar 1933 galt die die Weimarer Reichsverfassung formell fort, auch wenn sie materiell größtenteils außer Kraft gesetzt ${ }^{7}$ wurde. Dem heutigen Art. 25 GG ging der Art. 4 Weimarer Reichsverfassung (WRV) voraus, welcher lautete:

\footnotetext{
${ }^{7}$ Die sog. „Reichstagsbrandverordnung“ (Verordnung des Reichspräsidenten zum Schutz von Volk und Staat) vom 28.02.1933 (Reichsgesetzblatt I/1933, S. 83) folgte auf den Brand des Reichstagsgebäudes und war ein wichtiger Schritt zur Machtergreifung Adolf Hitlers. Durch sie wurden nach Art. 48 WRV die Bürgerrechte der Weimarer Verfassung außer Kraft gesetzt. Mehr dazu in Gruchmann, Justiz im Dritten Reich, 2009. Mit dem Gesetz zur Behebung der Not von Volk und Reich vom 24.03.1933 (Reichsgesetzblatt I/1933, S. 41) wurde die gesetzgebende Gewalt im Grunde vollständig auf Adolf Hitler übertragen. Dieses Gesetz stellte später die Grundlage für die Festigung der nationalsozialistischen Diktatur dar. Mehr dazu
} 
„Die allgemeinen anerkannten Regeln des Völkerrechts gelten als bindende Bestandteile des deutschen Reichsrechts.“

Die Formulierung ,anerkannte Regeln des Völkerrechts“ machte damals noch deren umfassende Geltung von der Akzeptanz durch Deutschland abhängig. ${ }^{8}$ Mit den Frankfurter Dokumenten vom 1. Juli 1948 forderten die drei westlichen Besatzungsmächte nach dem Zweiten Weltkrieg die Ministerpräsidenten der westlichen Besatzungszonen Deutschlands auf eine neue Verfassung zu erlassen. Dies sollte die zweite neue deutsche Verfassung innerhalb von 30 Jahren sein und international die Bereitschaft Deutschlands demonstrieren dem Völkerrecht höhere Bedeutung beizumessen. ${ }^{9}$ In der Folge tagte der Verfassungskonvent von Herrenchiemsee vom 10. bis zum 23. August 1948 im Alten Schloss auf der Herreninsel in Bayern. Dort standen sich, geführt von den Abgeordneten Schmid und von Mangoldt, zwei unterschiedliche Lager gegenüber, die über die Bedeutung, Formulierung und rechtliche Einordnung der allgemeinen Völkerrechtsregeln ins innerstaatliche Recht stritten. Schmid vertrat die Ansicht, dass es fortschrittlicher wäre, wenn Deutschland als erstes Land das Völkerrecht nicht nur eine Rechtssphäre „,irgendwo“ sein ließe, sondern als eine Rechtssphäre im deutschen Bundesrecht berücksichtigte, die auch das innerstaatliche Rechtsleben für Individuen bedingen und bestimmen würde. Auch sollten die deutschen Richter nicht nur deutsche Rechtsquellen, sondern auch das Völkerrecht praktisch anwenden. ${ }^{10}$ Der Abgeordnete Eberhard pflichtete dieser Auffassung bei und fügte hinzu, dass die Deutschen verpflichtet wären, über Weimar hinauszuwachsen und die Missachtung des Völkerrechts im Dritten Reich dessen Aufnahme in die Verfassung notwendig gemacht hätte. ${ }^{11}$ Eben diese Überlegungen führten dazu, dass im Verfassungsausschuss darauf geachtet wurde, die Völkerrechtsklausel so zu gestalten, dass sie auch in der Praxis Anwendung findet. Dazu wurde überlegt, die allgemeinen Völkerrechtsregeln zum Bestandteil des Bundesrechts zu machen und diese sowohl Rechte als auch Pflichten für alle Bewohner des Bundesgebiets erzeugen zu lassen. ${ }^{12}$

in Raithel/Strenge, Die Reichstagsbrandverordnung. Grundlegung der Diktatur mit den Instrumenten des Weimarer Ausnahmezustandes, in: Vierteljahrshefte für Zeitgeschichte, Bd. 48/2000, S. 413-460.

${ }^{8}$ Walz, Völkerrecht und staatliches Recht, S. 308.

${ }^{9}$ Vgl. Stumpfe, Die allgemeinen Regeln des Völkerrechts, S. 5

${ }^{10}$ Der Parlamentarische Rat: 1948-1949, Fünfte Sitzung des Hauptausschusses vom 18.11.1948 bzgl. Art. 29 des Herrenchiemsee Entwurfs (später Art. 25 GG), S. 160, mit Verweis auf den undatierten Bericht des Unterausschusses I des Verfassungskonvents auf Herrenchiemsee vom 21.08.1948, näher in: Der Parlamentarische Rat, Band 2, Dok. Nr. 6, S. 206 mit Fn 61.

${ }^{11}$ Ders., S. 162; vgl. auch Stumpfe, Die allgemeinen Regeln des Völkerrechts, S. 6.

${ }^{12}$ So zumindest in Der Parlamentarische Rat: 1948-1949, Fünfte Sitzung des Hauptausschusses vom 18.11.1948 bzgl. Art. 29 des Herrenchiemsee Entwurfs (später Art. 25 GG), S. 158, 159. 
Der Unterausschuss legte folgenden Entwurf als Art. 29 des Herrenchiemseer Entwurfs (späterer Art. 25 GG) vor:

„Die allgemeinen Regeln des Völkerrechts sind Bestandteil des Bundesrechts und erzeugen Rechte und Pflichten für alle Bewohner des Bundesgebietes.“

Der Entwurf wich deutlich vom bisherigen Art. 4 WRV ab. Die allgemeinen Völkerrechtsregeln sollten zum Bestandteil des Bundesrechts werden, während die Weimarer Reichsverfassung lediglich die ,anerkannten“ allgemeinen Völkerrechtsregeln zum Bestandteil des Reichsrechts erklärt hatte. Schmid initiierte die Formulierung des Art. 29 des Herrenchiemseer Entwurfs. Die Vertreter seiner Ansicht wollten vor allem die Voraussetzung der Anerkennung aus dem neuen Verfassungstext streichen, da zu Zeiten der Weimarer Republik die Anerkennung oftmals bezweifelt wurde, um eine Anwendung des Völkerrechts zu vermeiden. ${ }^{13}$ Auf diese Weise sollte auch gezeigt werden, dass es nicht auf eine Anerkennung der allgemeinen Völkerrechtsregeln durch Deutschland ankäme, sondern die neue Völkerrechtsklausel generell Geltung erführe. ${ }^{14}$ Art. 29 des Herrenchiemseer Entwurfs setzte nicht die Anerkennung allgemeiner Völkerrechtsregeln voraus, um sie anwenden zu können, sondern erkennt grundsätzlich deren Existenz an. ${ }^{15}$ Dazu kam nach Schmids Auffassung, dass die allgemeinen Völkerrechtsregeln als stilles Übereinkommen der Menschen des abendländischen Rechtskreises leichter festzustellen und anzuwenden wären. ${ }^{16}$

Auf der anderen Seite standen von Mangoldt und seine Befürworter, die die Meinung vertraten, die Formulierung des Art. 4 WRV sollte beibehalten werden. Er verwies dazu bewusst auf die von Deutschland bestenfalls anzuwendende angloamerikanische Praxis, in der der Satz ,international law is a part of the law of the land“ so verstanden würde, dass einem Völkerrechtssatz niemals der Vorzug zu gewähren sei, wenn eine Norm des eigenen Rechts entgegenstehe. ${ }^{17}$

\footnotetext{
${ }^{13}$ Stumpfe, Die allgemeinen Regeln des Völkerrechts, S. 9; Der Parlamentarische Rat: 1948-1949, Fünfte Sitzung des Hauptausschusses vom 18.11.1948 bzgl. Art. 29 des Herrenchiemsee Entwurfs (später Art. 25 GG), S. 160, mit Verweis auf den undatierten Bericht des Unterausschusses I des Verfassungskonvents auf Herrenchiemsee vom 21.08.1948, näher in: Der Parlamentarische Rat, Band 2, Dok. Nr. 6, S. 206 mit Fn 61.

${ }^{14}$ Stumpfe, Die allgemeinen Regeln des Völkerrechts, S. 9; Der Parlamentarische Rat: 1948-1949, Fünfte Sitzung des Hauptausschusses vom 18.11.1948 bzgl. Art. 29 des Herrenchiemsee Entwurfs (später Art. 25 GG), S. $162 \mathrm{f}$.

${ }^{15}$ Vgl. Cremer, in: HdStR Bd. 11, § 235 Rn 4.

${ }^{16}$ Vgl. Schorkopf, Staatsrecht der internationalen Beziehungen, § 3 Rn 6; Der Parlamentarische Rat: 19481949, Fünfte Sitzung des Hauptausschusses vom 18.11.1948 bzgl. Art. 29 des Herrenchiemsee Entwurfs (später Art. 25 GG), S. $161 \mathrm{f}$.

${ }^{17}$ Vgl. Stumpfe, Die allgemeinen Regeln des Völkerrechts, S. 9, 10.
} 
Es sollte jedoch nach der vergangenen völkerrechtsfeindlichen Zeit die bis dato geltende Praxis abgelegt werden, dass nur Staaten und nicht Individuen die Adressaten von Völkerrechtssätzen sein sollten. Danach war der Einzelne nur dann an völkerrechtliche Normen gebunden oder durch diese berechtigt, wenn diese durch Transformationsakte ins Landesrecht aufgenommen werden. ${ }^{18}$ Der Staat sollte nicht mehr die Möglichkeit haben, allgemeine Völkerrechtsregeln durch einfaches Bundesgesetz außer Kraft zu setzen. Schmid wollte damit eine Schwelle überspringen und den „Weg in eine bessere Zukunft eröffnen“. Er konnte seine Auffassung letztlich durchsetzen ${ }^{19}$, so dass der Art. 29 des Herrenchiemseer Entwurfs heute als Art. 25 GG lautet:

„Die allgemeinen Regeln des Völkerrechts sind Bestandteil des Bundesrechts. Sie gehen den Gesetzen vor und erzeugen Rechte und Pflichten unmittelbar für die Bewohner des Bundesgebietes.“

Deutschland wollte und sollte mit besserem Beispiel nach zwei verlorenen Weltkriegen vorangehen und dem Staat sollte völkerrechtlich keine alleinige Adressatenstellung zukommen. Eine solche Formulierung bestand bis zum Inkrafttreten des Grundgesetzes auch nicht in Art. 4 WRV. Eine vergleichbare Rechtslage hat nach Art. 4 WRV zwar bereits bestanden, ist aber mit Art. 25 GG erstmals konkret geregelt worden. Bereits die Entstehungsphase des neuen Grundgesetzes und die letztgenannte Ansicht lassen erkennen, dass die Inklusion von Individuen in den Adressatenkreis von Völkerrechtssätzen früh bedacht wurde. Auch das BVerwG hat festgehalten, dass der Wille der damaligen Verfassungsgeber gewesen sei, den allgemeinen Völkerrechtsregeln eine höhere innerstaatliche Bedeutung beizumessen als Art. 4 WRV, so dass diese unmittelbar gelten. ${ }^{20}$

Strittig in Theorie und Praxis ist bereits die Auslegung des Wortlauts. So stellte sich das BVerwG zwar der Klägeransicht, bereits aus dem Wortlaut könne ein unmittelbarer Individualanspruch abgeleitet werden, entgegen, man habe nicht auf das Erfordernis der individuellen Betroffenheit verzichten und so entgegen des Zwecks des Art. 19 Abs. 4 GG han-

\footnotetext{
${ }^{18}$ Schorkopf, Staatsrecht der internationalen Beziehungen, § 3 Rn 3; Preuß, Reich und Länder, S. 86 f.; Cremer, in: HdStR Bd. 11, § 235 Rn 8 .

${ }^{19}$ Vgl. Stumpfe, Die allgemeinen Regeln des Völkerrechts S. 10; Der Parlamentarische Rat: 1948-1949, Fünfte Sitzung des Hauptausschusses vom 18.11.1948 bzgl. Art. 29 des Herrenchiemsee Entwurfs (später Art. 25 GG), S. $160 \mathrm{f}$.

${ }^{20}$ BVerwGE 154, 328; vgl. auch Der Parlamentarische Rat: 1948-1949, Fünfte Sitzung des Hauptausschusses vom 18.11.1948 bzgl. Art. 29 des Herrenchiemsee Entwurfs (später Art. 25 GG), S. 160 f.
} 
deln wollen. Für etwas anderes ergäben sich aus den Gesetzgebungsmaterialien keine Anhaltspunkte. ${ }^{21}$ Schmid und Eberhard führten als Beispiele für die unmittelbare Rechtserzeugung den Briand-Kellogg-Pakt ${ }^{22}$ von 1928 und die Haager Landkriegsordnung von $1907^{23}$ an, in denen zum einen der Verzicht auf einen Angriffskrieg und zum anderen das humanitäre Völkerrecht normiert wurden. Das BVerwG vertrat allerdings auch, die Bewohner Deutschlands können sich auch auf die allgemeinen Völkerrechtsregeln berufen wie sie beispielsweise in den genannten völkerrechtlichen Verträgen enthalten sind. Das BVerwG hat auch offengelassen, ob Anwohner eines Militärflughafens Verstöße gegen das völkerrechtliche Gewaltverbot als individuelle Rechte im Verfahren zur Erteilung der Einflugerlaubnisse geltend machen könnten, sollte Art. 25 Satz 2 GG unmittelbare Rechte erzeugen. $^{24}$

Anders als durch das BVerwG kann die Entstehungsgeschichte des Art. 25 GG nicht nur zugunsten einer Adressatenstellung von Staaten aufgefasst werden. Es gibt auch Interpretationsmöglichkeiten zugunsten einer unmittelbaren Adressatenstellung Einzelner. Die Verhandlungen von Herrenchiemsee als Vorarbeit zur Verfassungsgebung durch den Parlamentarischen Rat sind daher in ihrer Argumentation interessant und bieten eine erste Einschätzung bezüglich der Betrachtung der Stellung natürlicher Personen. Es ist zu prüfen, ob diese Vorarbeit ihren Niederschlag derart gefunden hat, dass Einzelne heute aus Art.2 5 Satz 2 GG individuelle Rechte ableiten und geltend machen können.

\section{Setzt Art. 19 Abs. 4 GG eine Klagebefugnis für die allgemeinen Völkerrechtsregeln voraus?}

In den eingangs erwähnten Entscheidungen hatten die Kläger mit Rechtsbehelfen wegen Verstößen gegen allgemeine Völkerrechtsregeln mangels individueller Klagebefugnis nach Art. 19 Abs. 4 GG keinen Erfolg. Die Gesetzgebungsmaterialien zu Art. 25 GG gäben keinen Hinweis darauf, dass auf das Erfordernis verzichtet hätte werden sollen. ${ }^{25}$

\footnotetext{
${ }^{21}$ BVerwGE 154, 328 (341, 343, 347).

${ }^{22}$ Mehr dazu in Roscher, Der Briand-Kellogg-Pakt von 1928: Der „Verzicht auf den Krieg als Mittel nationaler Politik“ im völkerrechtlichen Denken der Zwischenkriegszeit, 2004.

${ }^{23}$ Deutsches Reichsgesetzblatt 1910, S. 5 ff.; mehr dazu in Gasser, Humanitäres Völkerrecht. Eine Einführung., 2007.

${ }^{24}$ BVerwGE 127, 302 (316, 343 f.); 131, 316 (343), vertiefter hierzu in Kapitel $§ 8$.

${ }^{25}$ Vgl. dazu BVerwGE 154, 328 (343).
} 
Auf der anderen Seite scheint es allerdings auch keine Anhaltspunkte dafür zu geben, dass dieses Erfordernis zwingend auch bei den allgemeinen Völkerrechtsregeln einzuhalten ist. Es ist daher wichtig, ob sich aus dem Sinn und Zweck und der inhaltlichen Ausgestaltung des Art. 19 Abs. 4 GG durch Literatur und Rechtsprechung in Bezug auf die allgemeinen Völkerrechtsregeln oder aus dem Sinn und Zweck des Art. 25 GG entnehmen lässt, ob die allgemeinen Völkerrechtsregeln in ihrer Geltung nicht von Zulässigkeitsvoraussetzungen abhängen sollen.

\subsection{Inhaltlicher Geltungsbereich des Art. 19 Abs. 4 GG}

Art. 19 GG umfasst mehrere Bestimmungen, die, ohne selbst Grundrechtscharakter zu haben, den Schutz der Grundrechte gewährleisten. Art. 19 Abs. 1 GG beinhalten das Verbot des grundrechtseinschränkenden Einzelfallgesetzes und das Zitiergebot. Die Wesensgehaltsgarantie ist in Abs. 2 geregelt und Abs. 3 erweitert den Kreis der begünstigten Grundrechtsträger neben natürlichen auch auf inländische juristische Personen. ${ }^{26}$ Die in Rede stehende Rechtsschutzgarantie gewährleistet Art. 19 Abs. 4 GG und regelt damit die gerichtliche und lückenlose Überprüfbarkeit aller behaupteten rechtswidrigen Eingriffe der öffentlichen (Exekutiv-)Gewalt in subjektive Rechte. ${ }^{27}$ Die Grundsatznorm gilt im Verfassungsgefüge des Grundgesetzes für die gesamte nationale Rechtsordnung, solange es nicht zwischen den Streitparteien an einem Über-Unterordnungsverhältnis mangelt. ${ }^{28}$

Art. 25 Satz 1 GG macht die allgemeinen Völkerrechtsregeln zu einfachem Bundesrecht mit Zwischenrang zur Bundesverfassung. Rein nach dem Wortlaut des Art. 19 Abs. 4 GG und des Art. 25 Satz 1 GG gilt die Rechtsweggarantie auch für die allgemeinen Völkerrechtsregeln, sofern man diesen den Charakter eines subjektiven Individualrechts einräumt. Die „öffentliche Gewalt“ in Satz 1 meint die Akte der deutschen öffentlichen Gewalt, denn nur diese ist an das deutsche Grundgesetz gebunden. Art. 19 Abs. 4 GG setzt die mögliche Verletzung eigener subjektiv-öffentlicher Rechte voraus, um sogenannte Popularklageverfahren oder Verbandsklagen zu vermeiden. Es wird jedoch herausgestellt, dass das Grundgesetz der Einführung solcher Popularklageverfahren durch den Gesetzgeber grundsätzlich

\footnotetext{
${ }^{26}$ Repräsentativ Burghart, in: Leibholz/Rinck, Grundgesetz für die Bundesrepublik Deutschland, Art. 19 GG, Rn 11, 41 f., 66 f., 91 f., 216 f.

${ }^{27}$ BVerfGE 22, 106 (110); 58, 1 (40); 103, 142 (156); Sachs, in: Sachs, Art. 19 GG, Rn 113 f., 118 f., 133 ; Antoni, in: Hömig/Wolff, Art. 19 GG, Rn 1, 12.

${ }^{28}$ Antoni, in: Hömig/Wolff, Art. 19 GG, Rn 12, 13.
} 
nicht entgegensteht, sofern es sich dabei nicht um Rechte im Sinne des Art. 19 Abs. 4 GG handelt. ${ }^{29}$ Einklagbare Rechte im Sinne des Art. 19 Abs. 4 Satz 1 GG sind Verfassungsrechte, förmliche Gesetze, Rechtsverordnungen, autonome Satzungen und auch das Gewohnheitsrecht. Nicht ausreichend sind allerdings rein wirtschaftliche Interessen oder Verstöße gegen Rechtsnormen, die lediglich Allgemeininteressen schützen und keinen subjektiven Rechtsraum schaffen. ${ }^{30}$

In der Literatur wird der Geltungsbereich des Art. 19 Abs. 4 GG auf innerstaatliche Normen sehr ausführlich benannt und für alle subjektiv-öffentlichen Rechte die Klagebefugnis als Zulässigkeitsanforderung vorgeschrieben. Es wird allerdings die Möglichkeit für die Gesetzgebung eingeräumt Popularklagen zuzulassen. ${ }^{31}$ Das BVerwG hat bezüglich Art. 25 GG argumentiert, die Entstehungsgeschichte des Art. 25 GG sehe keinen Verzicht auf eine Klagebefugnis vor. ${ }^{32}$ Das bedeutet, dass mit einer allgemeinen Völkerrechtsregel ein subjektives Recht i. S. d. Art. 19 IV GG bestehen muss, um sich als Einzelner darauf berufen zu können.

Teilweise wird die Ansicht des Gerichts vor dem Hintergrund begrüßt, dass auch politisch motivierte Klagehäufungen kontrolliert werden sollten. ${ }^{33}$ Allerdings ist durchaus zu bezweifeln, dass die konkreten Beispiele Klimaschutz-, Eurorettungs- oder Migrationspolitik $^{34}$ der Bundesregierung mit den allgemeinen Völkerrechtsregeln wie dem allgemeinen Gewaltverbot nach Art. 2 Abs. 4 der UN-Charta und dem Verbot des gezielten oder unterschiedslosen Angriffs auf Zivilpersonen nach dem humanitären Völkerrecht vergleichbar seien. Einen angemessenen Rahmen zu schaffen und nicht jede politisch motivierte Interessenklage zuzulassen ist durchaus vernünftig und weiter aufrecht zu erhalten. Allerdings sollte auf der Ebene des Völkerrechts aufgrund der weiter reichenden Folgen für die internationale Gemeinschaft ein anderer Maßstab angelegt werden als bei der Vermeidung innenpolitisch unliebsamer Privatklagen und untersucht werden, ob diese zur Wahrung des völkerrechtskonformen Miteinanders nach Sinn und Zweck des Art. 25 GG nicht möglicherweise doch gewollt und sinnvoll sind. Die Eröffnung der Möglichkeit Popularklagen

\footnotetext{
${ }^{29}$ BVerfGE 13, 132 (151); 27, 297 (305); 31, 33 (39); 51, 176 (185); näheres dazu vgl. Sachs, in: Sachs, Art. 19 GG, Rn 126.

${ }^{30}$ Antoni, in: Hömig/Wolff, Art. 19 GG, Rn 15; Sachs, in: Sachs, Art. 19 GG, Rn 126 f.; Burghart, in: Leibholz/Rinck, Grundgesetz für die Bundesrepublik Deutschland, Art. 19 GG, Rn 332.

${ }^{31}$ Sachs, in: Sachs, Art. 19 GG, Rn 126.

${ }^{32}$ BVerwGE 154, 328 (341 f.)

${ }^{33}$ So Gärditz, in: DVBl. 13/2016, S. 849 (858).

${ }^{34}$ Gärditz, in: DVBl. 13/2016, S. 849 (858); Gärditz nannte diese Bereiche der Bundespolitik beispielhaft als Diskussionsfelder in der Bevölkerung, welche nicht impulsiv ohne individuelle Betroffenheit vor Gericht gebracht werden können sollten.
} 
durch den Gesetzgeber zuzulassen wird noch mit der Betrachtung des Sinns und Zwecks des Art. 25 GG näher betrachtet.

Ein subjektives internationales Recht ist nicht automatisch ein subjektives öffentliches Recht im Sinne des Grundgesetzes, mit der Folge, dass Art. 19 Abs. 4 GG anwendbar wäre, da sich die Qualität eines subjektiven öffentlichen Rechts nach den Kriterien des nationalen Verfassungs- und Verwaltungsrechts richtet. Dieser gäbe einen Verfassungsrechtsanspruch auf Rechtsschutz, für den die Verfassungsbeschwerde das richtige Rechtsmittel ist. ${ }^{35}$ Aus dem Grundsatz der Völkerrechtsfreundlichkeit des Grundgesetzes ${ }^{36}$ in Verbindung mit der Bindung der Rechtsprechung an Recht und Gesetz gem. Art. 20 Abs. 3 in Verbindung mit Art. 59 Abs. 2 GG ergibt sich die Pflicht deutscher Gerichte, ,die einschlägige Judikatur der für Deutschland zuständigen internationalen Gerichte zur Kenntnis zu nehmen und sich mit ihnen auseinanderzusetzen“. 37

\subsection{Die Trennung von Individualrecht und Rechtsschutz im nationalen Recht und die}

\section{Erforderlichkeit der Klagebefugnis im Völkerrecht}

Traditionell wurde der Mensch als natürliche Person nur dann auch als Völkerrechtssubjekt angesehen, sofern ihm auch die selbstständige Durchsetzung seiner Rechte vor internationalen Gerichten oder ähnlichen Instanzen möglich war, da er ansonsten maximal ein potentielles Völkerrechtssubjekt wäre. ${ }^{38}$ Auch die deutsche juristische Debatte verknüpfte materielle und prozessuale Aspekte des subjektiven Rechts und geht dabei auf die Jellineksche Definition zurück, die das subjektive öffentliche Recht als die Fähigkeit bezeichnet, Rechtsnormen im individuellen Interesse in Bewegung zu setzen. ${ }^{39}$ Jellinek meinte mit ,in Bewegung setzen“ jedoch die Durchsetzbarkeit einer Norm, beispielsweise vor Behörden, und nicht die Klagbarkeit als Bedingung der Rechtsexistenz. Die Existenz eines subjektiven öffentlichen Rechts sollte unabhängig von der prozessualen Durchsetzbarkeit vor Gerichten bestehen können. ${ }^{40}$ Heute werden in den meisten staatlichen Rechtssystemen materielle und prozessuale Rechte unterschieden. Das Grundgesetz trennt beides mit Art. 19 Abs. 4

\footnotetext{
${ }^{35}$ Schmidt-Aßmann, in: Maunz/Dürig, Art. 19 Abs. 4 GG, Rn 152 f.

${ }^{36}$ Nach der ständigen Rechtsprechung seit BVerfGE 6, 309 (362); 18, 112 (121); 41, 88 (120).

${ }^{37}$ BVerfGK 9, 174 (189, 191 f.).

${ }^{38}$ Kelsen, Priciples of International Law, S. 234.

${ }^{39}$ Jellinek, System der subjektiven öffentlichen Rechte, S. 51, 351.

${ }^{40}$ Jellinek, System der subjektiven öffentlichen Rechte, S. 51, 351.
} 
GG deutlich und regelt: „Wird jemand durch die öffentliche Gewalt in seinen Rechten verletzt, so steht ihm der Rechtsweg offen." Die Verfassungsnorm, die für das nationale Recht die Rechtsweggarantie regelt und in Absatz 4 die Klagebefugnis als notwendige Voraussetzung zur Geltendmachung eigener Rechte vorschreibt, wäre nach zutreffender Meinung überflüssig, käme die Klagebefugnis bereits im Begriff des subjektiven Rechts vor. ${ }^{41}$ Andere wiederum sehen die gerichtliche Durchsetzbarkeit eines Rechts nicht als seine Voraussetzung, sondern lediglich als rechtliche Wirkung an. ${ }^{42}$ Auf den Punkt der Trennung des materiellen Rechts und prozessualen Rechtsschutzes kommt es hier nicht an, sondern auf das Aufgreifen der Klagebefugnis nach Art. 19 Abs. 4 GG im Kontext des Völkerrechts, und ob diese als Voraussetzung für die den völkerrechtlichen Prozess erforderlich ist.

Peters vertritt beispielsweise, dass die prozessuale Konzeption der Völkerrechtspersönlichkeit inkonsequent sei. ${ }^{43}$ Die traditionelle Verknüpfung von Rechtspersönlichkeit und der individuellen Klagebefugnis müsse aufgelöst werden. Sie führt an, die prozessuale Konzeption unterschlage die Durchsetzung von Rechten auf verschiedenen Ebenen. Diese könne sowohl national, als auch international stattfinden. Die dezentrale Durchsetzung der Individualrechte durch nationale Institutionen aufgrund der Anerkennung einer unmittelbaren Anwendbarkeit individualschützender Völkerrechtsnormen steigere die Effektivität der subjektiven internationalen Rechte. Die Koppelung unterschätze die Bedeutung der nationalen Institutionen für die Durchsetzung des Völkerrechts. Die systematische Funktion sei normativ gewollt, da das allgemeine Rechtsprinzip der Subsidiarität respektiere und implementiere. ${ }^{44}$ Im Jahr 1995 ging Higgins allerdings noch nicht so weit, die Verknüpfung von materiellem Recht und Klagebefugnis zu verwerfen und stellte die Frage: „Is [...] a right without a remedy [...] virtually no legal right at all? Or is that something that international lawyers, operating in a decentralized system, are not allowed to think? [...] Is the statement that international law is about inter-state obligations only the consequence of a procedural disability under which the individual labours, or is it the cause of that procedural disability? “45

Auch der IGH sah die Befugnis zur Geltendmachung eigener Rechte als notwendigen Bestandteil der Rechtspersönlichkeit: ,, whether the Charter has given the origanization such a position that it possesses, in regard to its Members, rights which it is entitled to ask them

\footnotetext{
${ }^{41}$ Saurer, Der Einzelne im europäischen Verwaltungsrecht, S. 138.

${ }^{42}$ Siehe Peters, Jenseits der Menschenrechte, S. 39.

${ }^{43}$ Vgl. Peters, Jenseits der Menschenrechte, S. 42.

${ }^{44}$ Vgl. Peters, Jenseits der Menschenrechte, S. 42.

${ }^{45}$ Siehe Higgins, Problems and Process, S. 52 f.
} 
to respect [...].“46 Die Richter haben im LaGrand-Fall ohne weiteres angenommen, dass das Wiener Übereinkommen über konsularische Beziehungen ein individuelles Recht erzeuge, dass jedoch nur vom Heimatstaat geltend gemacht werden könne. ${ }^{47}$ Die Koppelung geht zurück auf das Streben nach völkerrechtlicher Effektivität. Danach erfordern viele Rechtsinstitute des Völkerrechts die Übereinstimmung der Norm mit den realen Verhältnissen als Tatbestandsmerkmal. Dabei wird der Sinn verfolgt, das Auseinanderfallen von Rechtswirklichkeit und Rechtsanspruch zu verhindern. Eine fehlende Realisierbarkeit würde völkerrechtliche Ansprüche entwerten, also soll es besser sein, nicht effektive Titel gar nicht erst als Recht anzuerkennen. ${ }^{48}$

Schließt man sich zum Beispiel Peters Auffassung an und fordert die Trennung der Rechtspersönlichkeit und der Klagebefugnis, und dass letzteres auch national-rechtlich geklärt werden könnte, besteht mit Art. 19 Abs. 4 GG eine entsprechende Norm, die die Klagebefugnis als notwendige Voraussetzung zur Geltendmachung eines Individualrechts aus dem Völkerrecht vor nationalen Gerichten vorschreibt. Die Notwendigkeit einer unmittelbaren Betroffenheit wäre somit in Bezug auf die streitige Entscheidung des BVerwG zu bestätigen und der Entscheidung des Gerichts in diesem Punkt zuzustimmen. Folgt man ihr nicht, bedeutet dies folglich jedoch nicht die Ablehnung der Erforderlichkeit einer Klagebefugnis zur Geltendmachung völkerrechtlicher Individualrechte. Auf die Diskussion über eine wenigstens begriffliche Einordnung kommt es hier damit nicht an. Sie zeigt aber die für die Frage relevante Antwort auf, dass eine Klagebefugnis als Prozessvoraussetzung im Völkerrecht vorhanden und anerkannt ist. Auch völkerrechtliche Individualrechte sollen dann nur mit einer individuellen Klagebefugnis geltend gemacht werden können.

\footnotetext{
${ }^{46}$ IGH, Judgement of 11.04.1949, Reparation for Injuries suffered in the Service of the United Nations, Advisory Opinion, ICJ Report 1949, S. 178.

${ }^{47}$ IGH, Judgement of 27.6.2001, LaGrand Case (Germany v. United States of America), ICJ Reports 2001, S. 466, vgl. auch StIGH, Peter Pàzmàny University Case, PCIJ Ser. A/B, No. 61 (1935), S. 231; IAGMR, Judgement of 28.08.2001, Judicial Condition and Human Rights of the Child, Advisory Opinion OC17/02, Concurring Opinion of Antonio Augusto Cancado Trindade, Ser. A Nr. 17, S. 79.

${ }^{48}$ Peters, Jenseits der Menschenrechte, S. 41.
} 


\subsection{Die unmittelbare Anwendbarkeit im Völkerrecht}

Die unmittelbare Anwendbarkeit wird sowohl vom jeweiligen nationalen Recht, als auch vom Völkerrecht geregelt und hat eine ,gemischte internationale/innerstaatliche Qualität “. ${ }^{49}$ Traditionell war die Frage der unmittelbaren Anwendbarkeit Sache des nationalen Rechts, deren Beantwortung allein den entsprechenden Gerichten überlassen wurde. Begründet wurde dies damit, dass es dabei um die Umsetzung von Völkerrecht gehe. Dieses verlange seine Umsetzung, überlasse jedoch den Staaten hinsichtlich der Art und Weise einen eigenen Spielraum, so dass es in die Entscheidung der jeweiligen Staaten falle, ob Völkerrecht unmittelbar oder nur mittelbar angewendet wird. ${ }^{50}$ Andere Ansichten sehen in der unmittelbaren Anwendbarkeit stattdessen eine Frage der Auslegung völkerrechtlicher Normen. Dabei hängt die Entscheidung vom jeweiligen Norminhalt ab, und dieser ist durch Auslegung zu ermitteln. ${ }^{51} \mathrm{Ob}$ eine völkerrechtliche Norm nun unmittelbar anwendbar ist oder nicht, entscheiden die nationalen Behörden und Gerichte. Dies entspricht soweit auch dem Normalfall der völkerrechtlichen Rechtsanwendung. Teils darf auch von internationalen Gerichten entschieden werden, wie es um die unmittelbare Anwendbarkeit steht. ${ }^{52}$ Die Anwendung völkerrechtlicher Normen durch internationale und nationale Instanzen soll kompatiblen Regeln folgen, da beide Ebenen durch das Local-Remedies-Erfordernis wechselseitig verknüpft sind. ${ }^{53}$

Die unmittelbare Anwendbarkeit von Völkerrechtsnormen ist von der Existenz materieller Individualpflichten und -rechte zu unterschieden. Aufgrund des Unterschieds zwischen der Unmittelbarkeit völkerrechtlicher Normen und ihres individualrechtlichen Charakters kann beispielsweise aus der begrenzten Einklagbarkeit verschiedener Menschenrechte keine mangelnde Qualität als subjektives Recht gefolgert werden. Der UN-Sozialausschuss sieht die Möglichkeit der direkten Anwendung gewisser Vorschriften durch nationale Gerichte ${ }^{54}$

\footnotetext{
${ }^{49}$ Siehe Nollkaemper, National Courts and the International Rule of Law, S. 127.

${ }^{50}$ EuGH, Urteil vom 23.11.1999, Portugal vs Rat, Rs. C-149/96, Slg. 1999, I-8395, Rn 35 (anerkennend zur internationalen unmittelbaren Anwendung des WTO-Rechts).

${ }^{51}$ BGE, Urteil vom 04.05.2010, Az. 136 I, S. 290-295, S. 443 f..; Nollkaemper, National Courts and the International Rule of Law, S. 129.

${ }^{52}$ EuGH, Urteil vom 05.02.1963, van Gend vs Loos, Rs. 26/62, Slg. 1963, S. 1.

${ }^{53} \mathrm{Vgl}$. Koller, Die unmittelbare Anwendbarkeit völkerrechtlicher Verträge und des EWG-Vertrages im innerstaatlichen Bereich, S. 114-124; siehe auch Verhoeven, in: Revue Belge de droit international 2/1980, S. 243 (258 f.); dazu auch StIGH, Advisory Opinion of 03.03.1928, Jurisdiction of the Courts of Danzig, Series B, No 15.

${ }^{54}$ OHCHR - Committee on Economic, Social and Cultural Rights, General Comment No. 3 1991, Rn 4-6.
} 
und der StIGH betrachtet die Gewähr von Rechten und deren Durchsetzbarkeit vor staatlichen Gerichten als einen Komplex. ${ }^{55}$ Beide Aspekte in Verbindung drängen sich in Konstellationen auf, die im jeweiligen Staatsrecht als verwaltungs-, verfassungsrechtlich oder zivilrechtlich qualifiziert werden. Im Zivilrecht ist die Durchsetzung normalerweise an einen materiellen Anspruch gebunden, und auch das öffentliche Recht vieler Staaten knüpft die Verwaltungsrechtsschutzmöglichkeiten von Individuen oft an die Existenz materieller subjektiver Rechte des Individuums. So ist gut nachvollziehbar, dass die staatlichen Gerichte vielfach für die unmittelbare Anwendbarkeit einer Vorschrift die tatsächliche Rechtseinräumung für Einzelne als Vorbedingung fordern. ${ }^{56}$

Die unmittelbare Anwendbarkeit kann jedoch rechtssystematisch nicht mit der Gewähr subjektiver Individualrechte gleichgesetzt werden. ${ }^{57}$ Man könnte diese daher als einen weiteren Filter beschreiben, der die praktische Wirksamkeit des völkerrechtlichen Rechtsstatus des Individuums einschränken kann, und für dessen Einsatz die Gerichte deshalb von vornherein materielle Rechte des Individuums betrachten. ${ }^{58}$ Auch Teile der neueren internationalen Literatur vermuten positiv die regelmäßige und unmittelbare Anwendung völkerrechtlicher Normen. ${ }^{59}$

Es gab bisher auch Ansätze zu grenzüberschreitenden Zivilprozessen, um mit Musterverfahren möglicherweise den Weg zu mehr Recht zu ebnen. ${ }^{60}$ Dabei wurden auch die Prozessführungsbefugnis oder Klagebefugnis im Prozessrecht hinsichtlich möglicher Zivilprozesse aufgrund von Menschenrechtsverletzungen erwähnt. Koch verwies auf die völkerrechtlichen Normen zum Schutze der Menschenrechte und der allgemeinen Völkerrechtsregeln, die über Art. 25 GG in Deutschland gelten. ${ }^{61}$ Dabei fehlte es jedoch an einer

${ }^{55} \mathrm{StIGH}$, Advisory Opinion of 03.03.1928, Jurisdiction of the Courts of Danzig, Series B, No 15, Fn 9.

${ }^{56}$ Für die Schweiz BGE, Urteil vom 22.09.2000, - Studiengebühren ZH II, Az. 126 I 240, S. 242 E. 2.b. (2000); für die USA der US Supreme Court, Judgment of 1884, Head Money Cases, 112 US 580, S. 598 f.; für Deutschland RGZ 117, 280 (I 13/27), Urteil vom 18.06.1927, S. 447; 117, 284 (I 372/26), Urteil vom 18.06.1927, S. $450 \mathrm{f}$.

${ }^{57}$ EuGH, Urteil vom 22.06.1989, Fediol vs. Kommission, Rs. 70/87, Slg. 1989, S. 1797 f. (Schlussanträge des Generalanwalts Walter van Gerven); Buchs, Anwendbarkeit völkerrechtlicher Vertragsbestimmungen, S. 40, 89; Geiger, Grundgesetz und Völkerrecht (4. Auflage 2009), S. 143, unverändert in der aktuellen 7. Auflage 2018 unter dem Titel „Staatsrecht III: Bezüge des Grundgesetzes zum Völker- und Europarecht, S. 146; Nollkaemper, National Courts and the International Rule of Law, S. $121 \mathrm{f}$.

${ }^{58}$ Klar unterscheidend dazu beispielsweise BVerfGE 46, 342 (362 f).

${ }^{59}$ Lagrange, in: Collected Courses of the Hague Academy of International Law 356/2012, S. 372 (448).

${ }^{60}$ Koch, in: AnwB1. 6/2015, S. $454(459,460)$.

${ }^{61}$ Ders.

Um die Problematik des Völkerrechts und der Menschenrechte im Rahmen von zivilrechtlichen Ansprüchen soll es hier nicht gehen. Die Parallele ist jedoch interessant für die vorliegende Bearbeitung mit Hinblick auf die praktische Geltendmachung völkerrechtlicher Normen. 
deutlichen Klarstellung, ob dafür nun eine Prozessbefugnis erforderlich oder bereits ,unmittelbar" durch Art. 25 Satz 2 GG vermittelt ist. ${ }^{62}$

Art. 25 GG regelt die unmittelbare Anwendbarkeit hinsichtlich des Umfangs einer Geltendmachung nicht, ebenso wenig die materiell-rechtliche Frage des subjektiven Rechts. Besagt wird lediglich, dass die allgemeinen Völkerrechtsregeln dieselben Rechtswirkungen für und gegen Einzelne haben wie auch sonstiges innerstaatliches Recht. ${ }^{63}$ Deutsche Gerichte sind also gehalten, innerstaatliches Recht nicht völkerrechtsverletzend anzuwenden. Zumindest anhand des Wortlauts gibt Art. 25 GG im Ganzen zunächst anhand der Formulierung einer „unmittelbaren“ Geltung noch kein subjektives materielles Recht her, so dass Einzelne hierauf prozessual zurückgreifen könnten. Die etwaige Qualität des Art. 25 Satz 2 GG als individuelles subjektives Recht mit dem Charakter einer Anspruchsgrundlage wird im späteren Verlauf der Bearbeitung noch genauer zu betrachten sein.

\subsection{Die unmittelbare Betroffenheit als Voraussetzung internationaler Rechtsmittel}

Nach Art. 263 Abs. 4 AEUV können sowohl natürliche als auch juristische Personen Individualklage erheben, wenn die Einzelpersonen durch Handlungen oder Rechtsakte mit Verordnungscharakter unmittelbar betroffen sind, auch wenn dabei Menschenrechte verletzt werden. Auch hier zeigt sich, dass die unmittelbare Betroffenheit eines subjektiven Rechts vorausgesetzt wird. Um Popularklagen auszuschließen, wird eine erweiterte Relation des Klägers zum Klagegegenstand gefordert. ${ }^{64}$ Die angegriffene Handlung muss den Kläger daher entweder unmittelbar und individuell betreffen oder an ihn gerichtet sein. ${ }^{65}$

Das Unmittelbarkeitskriterium in Art. 263 Abs. 4 AEUV soll Personen, die lediglich potentiell von einer Unionshandlung betroffen sind, von der Klagemöglichkeit ausschließen. Anders als bei der deutschen Verwaltungsklagebefugnis nach $\S 42$ Abs. 2 VwGO ist das Merkmal der Betroffenheit auf europäischer Ebene nicht mit der möglichen Verletzung subjektiver Rechte des Klägers gleichzusetzen. Vielmehr ist bereits die Feststellung einer

\footnotetext{
${ }^{62}$ Koch, in: AnwB1. 6/2015, S. 454 (459, 460).

${ }^{63}$ Siehe Geiger, Staatsrecht III, S. $151 \mathrm{f}$.

${ }^{64}$ Vgl. Ehricke, in: Streinz, Art. 263 AEUV, Rn 58; Gaitanides, in: v. der Groeben/Schwarze/Hatje, Art. 263 AEUV, Rn 60.

${ }^{65}$ EuGH, Urteil vom 15.07.1963, Plaumann \& Co. Vs EU-Commission, Rs. 25-62, Slg. 1963, 213 (238); Ehricke, in: Streinz, Art. 263 AEUV, Rn 57, 58 f.
} 
Verletzung rechtlich relevanter Interessen ausreichend. Dieser muss lediglich ein Interesse an der Aufhebung des angefochtenen Rechtsakts darlegen können. ${ }^{66}$

Nach der Auffassung des EuGHs ist ein Kläger durch Unionshandlungen unmittelbar betroffen, wenn die Handlung selbst und ohne weiteren Durchführungsakt den Interessenkreis des Klägers berührt (formelle Unmittelbarkeit) oder wenn es wahrscheinlich ist, dass ein späterer Durchführungsakt den Interessenkreis berühren wird (materielle Unmittelbarkeit). Letzteres ist der Fall, wenn die nationale Maßnahme eine zwingende Folge der Unionshandlung ist und dem Mitgliedsstaat kein Ermessen bei der Umsetzung einräumt. ${ }^{67}$ Der EuGH hat die unmittelbare Betroffenheit von Unternehmen beispielsweise durch die Tabakwerberichtlinie verneint, weil diese keine Rechtspflichten für Einzelne begründe. Entscheidend soll nach der Rechtsprechung im Fall Japan Tobacco sein, ob die einzelnen Mitgliedsstaaten ein Ermessen bei der Richtlinienumsetzung ausüben dürfen oder nicht. ${ }^{68}$

Das Individualitätsmerkmal bei der Voraussetzung der individuellen Betroffenheit wurde bereits im vormals ausgearbeiteten, aber nicht in Kraft getretenen, Art. III-365 Abs. 4 VVE $^{69}$ betont. Der heute geltende Art. 263 Abs. 4 AEUV fordert ebenso eine Betroffenheit einzelner Personen durch Handlungen oder Rechtsakte mit Verordnungscharakter. ${ }^{70}$

Die unionsrechtliche Konzeption, die das Erfordernis einer Klagebefugnis weicher formuliert, sollte jedoch nicht - wie teilweise gefordert ${ }^{71}$ - im deutschen Verfahren zugunsten individueller Ansprüche aus den allgemeinen Völkerrechtsregeln für anwendbar gehalten werden. Art. 263 Abs. 4 GG enthält keinen „Anwendungszwang“ für die Mitgliedsstaaten, ihren Verwaltungsrechtsschutz betreffend unions- oder völkerrechtliche Normen auch entsprechend auszugestalten. Zudem kollidiert die Norm national nicht mit $§ 42$ Abs. 2 VwGO, so dass es auch theoretisch keinen Anwendungsvorrang zugunsten von Art. 263 Abs. 4 AEUV gibt. ${ }^{72}$ Es bleibt somit, ob national- oder europarechtlich, bei der durchgehenden

\footnotetext{
${ }^{66}$ Schwarze/Voet van Vormizeele, in: Schwarze: Art. 263 AEUV, Rn 38, 39; Ehricke, in: Streinz, Art. 263 AEUV, Rn 59, 70; Sodan, in: Sodan/Ziekow, § 42 VwGO, Rn 365.

${ }^{67}$ EuGH, Urteil vom 13.05.1971, International Fruit Company, Rs. 41-44/70, Slg. 1971, Rn 16 f.; PiraikiPatraiki, Rs. 11/82, Slg. 1985, Rn 7 f.

${ }^{68}$ EuGH, Beschluss vom 10.09.2002, Japan Tobacco, Slg. 2002, Rs. T-223/01 II-3259, Rn 45 f.; vgl. auch Fredriksen, in: ZEuS 1/2005, S. 99 (116).

${ }^{69}$ Der Verfassungsvertrag für Europa, unterzeichnet von den europ. Staats- und Regierungschefs am 29.10.2004 (nie in Kraft getreten), sollte eine Reformation des politischen Systems der EU werden. Durch gescheiterte Referenden in Frankreich und den Niederlanden, konnte der Vertrag nicht am geplanten 01.11.2006 in Kraft treten, und stattdessen schlossen die europäischen Staats- und Regierungschefs den am 01.12.2009 in Kraft getretenen Vertrag von Lissabon.

${ }^{70}$ Näheres dazu vgl. Ehricke, in: Streinz, Art. 263 AEUV, Rn 59 f.

${ }^{71}$ Fischer-Lescano, Militärbasen und militärisch genutzte Flughäfen in Deutschland, S. 15.

${ }^{72}$ Kessler/Salomon, in: DÖV 7/2014, S. 283 (284).
} 
Voraussetzung der individuellen Betroffenheit von Individualpflichten oder -rechten als Klagebefugnis.

\subsection{Zwischenergebnis}

Das Erfordernis einer individuellen Betroffenheit zur Geltendmachung einer Rechtsverletzung regelt das Grundgesetz in Art. 19 Abs. 4 GG. Zurecht beriefen sich die Gerichte bisher darauf, dass Kläger mit ihren Begehren vor deutschen Gerichten über Art. 25 GG grundsätzlich eine unmittelbare Betroffenheit durch die infrage stehende Rechtsverletzung geltend machen müssen. Die bisherige Untersuchung hat gezeigt, dass es auch auf völkerrechtlicher Ebene die Voraussetzung einer Klagebefugnis oder einer notwendigen Betroffenheit gibt, so dass Kläger vor Gericht an dieser Voraussetzung gemessen werden müssen. ${ }^{73}$ Die Darstellung des Sinns und Zwecks des Art. 25 GG und die Herausstellung der Bezüge zu Individualinteressen und einer möglicherweise von den Verfassungsgebern gewollten Klagebefugnis durch unmittelbare Betroffenheit zeigt, dass der Auffassung des BVerwG in seiner Entscheidung aus 2016 zur US-Airbase Ramstein diesbezüglich zuzustimmen ist. Zwar weist das Gericht ohne weitere Ausführungen auf die Entstehungsgeschichte des Art. 25 GG hin und verweist auf den Mangel an Erkenntnissen aus den Gesetzgebungsmaterialien, dass die allgemeinen Völkerrechtsregeln mit Popularklagen hätten geltend gemacht werden sollen können. ${ }^{74}$ Auch $§ 42$ Abs. 2 VwGO regelt, dass der Kläger eine Rechtsverletzung geltend machen müssen, soweit gesetzlich nichts anderes bestimmt sei. Dass Art. 25 Satz 2 GG im Wortlaut „unmittelbare“ Rechte und Pflichten bestimmt, wurde ebenfalls erläutert. Könnte sich jedoch jeder Bürger auf die allgemeinen Völkerrechtsregeln berufen, würde die Problematik, ob diese Bestandteil des geltenden objektiven Rechts sind, mit der Frage vermengt, inwiefern der Einzelne oder ein deutsches Staatsorgan aus den allgemeinen Regeln Rechte oder Pflichten ableiten könnte. Dieser kritische Aspekt wurde durch das BVerwG 2016 nicht deutlich geklärt.

\footnotetext{
${ }^{73}$ So bspw. für Drittstaaten vgl. IGH, Judgment of 23.01.2020, Application of the Convention on the Prevention and Punishment of the Crime of Genocide, Gambia vs. Myanmar, Preliminary Order, $\S 41 \mathrm{ff}$.

${ }^{74}$ BVerwGE 154, 328 (343).
} 


\section{Die Funktion des Art. 25 GG im innerdeutschen Recht}

Bevor der Sinn und Zweck des Art. 25 GG dargestellt werden, ist zunächst die gesamte Norm in ihrer Bedeutung zu beleuchten, inhaltlich und im Verhältnis zum innerstaatlichen Recht. Art. 19 Abs. 4 GG schreibt das Erfordernis der Klagebefugnis für Klagebegehren im gesamten deutschen Rechtssystem vor. Das BVerwG hat zurecht den Art. 25 GG am Erfordernis einer Klagebefugnis nach $\S 42$ Abs. 2 VwGO und Art. 19 Abs. 4 GG gemessen. ${ }^{75}$ Das Erfordernis gilt nur dann nicht, soweit im Sinne des - dem Art. 19 IV GG grundsätzlich nachgeordneten $-\S 42$ Abs. 2 VwGO einfachgesetzlich etwas anderes für den Verwaltungsrechtsweg bestimmt ist. Wichtig ist somit, ob die in Art. 25 Satz 2 GG enthaltene Regelung bei der Auslegung und Anwendung von § 42 Abs. 2 VwGO zu berücksichtigen ist. Denkbar ist auch, dass Art. 25 Satz 2 GG kraft verfassungsrechtlicher Anordnung eine eigene Klagebefugnis eröffnet. ${ }^{76}$

Im Rahmen des Kapitels soll auch erläutert werden, inwiefern eine noch im weiteren Verlauf zu betrachtende Subjektivierung der allgemeinen Völkerrechtsregeln sich nur auf individualgerichtete oder auch bloß staatengerichtete Völkerrechtsregeln beziehen kann.

Art. 25 Satz 1 GG macht die allgemeinen Völkerrechtsregeln zum Bestandteil des Bundesrechts. Art. 25 GG, in Verbindung mit Art. 20 Abs. 3 GG, hält nicht nur Gerichte und Behörden zur Konformität zwischen allgemeinen Völkerrechtsregeln und deutschem Recht an, sondern kontrolliert auch die Gesetzgebung über das mögliche Normenverifikationsverfahren nach Art. 100 Abs. 2 GG. ${ }^{77}$

Die monistische Lehre sieht Völker- und Landesrecht als Teile einer einheitlichen Rechtsordnung, wobei heutzutage dem Völkerrecht als Primat der Vorrang eingeräumt wird. Nach strengerer Sicht ist völkerrechtswidriges innerstaatliches Recht stets nichtig, gemäßigte Meinungen des Monismus belassen es bei einem Anwendungsvorrang des Völkerrechts. ${ }^{78}$ Die dualistische Lehre sieht das Völker- und Landesrecht als selbstständige Rechtsordnungen. Die früher vertretene radikale Ansicht hat eine Kollision der beiden Rechtsordnungen schon per Definition ausgeschlossen. Sie konnten im Falle einer Kollision nebeneinander fortgelten. Die gemäßigte Ansicht erkennt jedoch eine Überschneidung beider Rechtskreise

\footnotetext{
${ }^{75}$ So Deiseroth, in: DVB1 16/2017, S. 985 (991); BVerwGE 154, 328 (339 f.).

${ }^{76}$ Deiseroth, in: DVB1. 16/2017, S. 985 (991).

${ }^{77}$ BVerfGE 23, 288 (316); 75, 1 (18 f.); 109, 13 (26); 109, 38 (52); und auch BVerfG, Dreierausschussbeschluss vom 11.10.1985, Az. 1 BvR 336/85, in: NJW 22/1986, S. 1425 f.

${ }^{78}$ Streinz, in: Sachs, Art. 25 GG, Rn 12; v. Heinegg, in: Epping/Hillgruber, Art. 25 GG, Rn 13; Schweitzer/Dederer, Staatsrecht, S. 12 Rn 41 f.
} 
an. ${ }^{79}$ Etwaige Kollisionen werden durch entsprechende Normen gelöst. Völkerrechtswidriges nationales Recht gilt danach nur vorläufig, denn die Staaten sind verpflichtet, ihre nationalen Rechtsordnungen völkerrechtskonform auszugestalten. Monismus und Dualismus vertreten in ihren gemäßigten Formen, dass sich die Staaten nicht unter Berufung auf entgegenstehendes nationales Recht ihren völkerrechtlichen Verpflichtungen entziehen dürfen. Sie sind verpflichtet, in ihren Rechtsordnungen eine dem Völkerrecht entsprechende Lage zu schaffen, haben dabei jedoch ein eigenes Ermessen. ${ }^{80}$ Art. 25 GG kann sowohl den Dualismus, als auch den Monismus darstellen. Für ersteren sprechen unter anderem die Entstehungsgeschichte und die Begrenzung auf ,allgemeine Regeln“ des Völkerrechts, welcher dem das gesamte Völkerrecht erfassenden Monismus zuwiderläuft. ${ }^{81}$ Art. 25 GG wählt allerdings nicht zwischen Dualismus oder Monismus. Die gemäßigten Ansichten der beiden Lehren favorisieren beide einen Vorrang des Völkerrechts, so dass entgegenstehendes Landesrecht zumindest vorläufig wirksam bleibt und eine Entscheidung nicht erforderlich ist. ${ }^{82}$ Eine Entscheidung zugunsten einer der etablierten vertretenen Ansichten ist deshalb für die Bearbeitung nicht erforderlich.

Mit Art. 25 GG hat Deutschland mittels Eingliederung das Völkerrecht zu einem Teil des deutschen Rechts gemacht. ${ }^{83}$ Dabei ist es jedoch nicht die Aufgabe des Art. 25 GG, mit den allgemeinen Völkerrechtsregeln die Lücken des innerstaatlichen Rechts zu füllen, sondern die Rechtsordnung Deutschlands enger und fester an das Völkerrecht zu binden. ${ }^{84}$ Dieser Aspekt wird in Kapitel $\S 4$ und $\S 7$ der Arbeit bei der Frage nach einer national-rechtlichen Rechts- und Anspruchsgrundlage zu berücksichtigen sein. Die allgemeinen Regeln des Völkerrechts bleiben stets den Grundbedingungen für den Bestand des Völkerrechts unterworfen, so dass diese von der deutschen Gesetzgebungsmacht ausgeschlossen sind. ${ }^{85}$

Zur Zeit der Weimarer Reichsverfassung ging die überwiegende Ansicht im Verfassungsausschuss des Deutschen Reiches dahin, dass Art. 4 WRV nur die Regeln anspricht, die das

\footnotetext{
${ }^{79}$ Streinz, in: Sachs, Art. 25 GG, Rn 13; v. Heinegg, in: Epping/Hillgruber, Art. 25 GG, Rn 13; Schweitzer/Dederer, Staatsrecht, S. $13 \mathrm{Rn} 47 \mathrm{f}$.

${ }^{80}$ Streinz, in: Sachs, Art. 25 GG, Rn 13, 14; v. Heinegg, in: Epping/Hillgruber, Art. 25 GG, Rn 14; Schweitzer/Dederer, Staatsrecht, S. 15 Rn $51 \mathrm{f}$.

${ }^{81}$ Hillgruber, in: Schmidt-Bleibtreu/Hofmann/Henneke, Art. 25 GG, Rn 1 f.

${ }^{82}$ Vgl. Streinz, in: Sachs, Art. 25 GG, Rn 20; Schweitzer/Dederer Staatsrecht, S. 15 Rn 51.

${ }^{83}$ Stumpfe, Die allgemeinen Regeln des Völkerrechts S. 18; Koenig/König, in: v. Mangoldt/Klein/Starck, Art. 25 GG, Rn 45.

${ }^{84}$ Stumpfe, Die allgemeinen Regeln des Völkerrechts S. 43, 44; a. A. Echterhölter, in: JZ 22/1955, S. 689 (690)

${ }^{85}$ Walz, Völkerrecht und staatliches Recht, S. 303 f.
} 
Deutsche Reich selbst anerkannt hat. ${ }^{86}$ Für Art. 25 GG wurde bewusst auf dieses Erfordernis verzichtet, insbesondere sollte keine deutsche Anerkennung vorausgesetzt sein.

Eine allgemeine Völkerrechtsregel wird über Art. 25 GG sogar dann zu deutschem Bundesrecht, wenn Deutschland diese nicht ausdrücklich anerkennt. ${ }^{87}$ Andererseits wurde auch vertreten, dass Regeln des Völkerrechts sinngemäß schon von den Völkerrechtssubjekten anerkannt worden sein müssen, damit sie überhaupt zu Regeln erstarken könnten. ${ }^{88}$ Es sei irrelevant, ob die Regeln des Völkerrechts anerkannt oder allgemein anerkannt sein müssen, um zum Bestandteil des Bundesrechts zu werden. Allgemeine Regeln seien solche, die von allen Völkerrechtssubjekten oder der überwiegenden Mehrheit anerkannt werden. ${ }^{89}$ Grundsätzlich regelt das Völkerrecht das Verhältnis zwischen Staaten. Es ist der Sinn des Art. 25 GG, die allgemeinen Völkerrechtsregeln und damit auch das Völkergewohnheitsrecht trotz dieses Umstands zu Bestandteilen des Bundesrechts zu machen. ${ }^{90}$ Die allgemeinen Völkerrechtsregeln sind nicht nur Teil des Bundesrechts gem. Art. 25 Satz 1 GG und partizipieren an dessen Vorrang nach Art. 31 GG, sie gehen auch gem. Art. 25 Satz 2 GG den Gesetzen vor und binden die gesetzgeberische Gewalt. In Verbindung mit Art. 20 Abs. 3 GG verpflichtet Art. 25 Satz 1 GG nicht nur die Behörden und Gerichte zur Auslegung des deutschen Rechts im Einklang mit den allgemeinen Völkerrechtsregeln, sondern zeigt auch dem Gesetzgeber Grenzen auf, deren Aufgabe der Einhaltung der deutschen Judikative zukommt. ${ }^{91}$

Der Satz 1 des Art. 25 GG beinhaltet kein Individualrecht, sofern sich die übernommenen Völkerrechtssätze lediglich an Staaten richten. Eine Umformung staatengerichteter Völkerrechtsgrundsätze ist damit auch nicht möglich, da keinerlei Individualberechtigung übernommen wird. Eine Ergänzung des Völkerrechtssatzes hinsichtlich des Adressaten würde sowohl das Völkerrecht, als auch das innerstaatliche Recht verfälschen. ${ }^{92}$ Art. 25 GG machte sonst einen Völkerrechtssatz zum Bundesrecht, den das Völkerrecht jedoch gar nicht enthält. ${ }^{93}$ Eine Umdeutung des Adressaten widerspräche dem Zweck des Art. 25 Satz 1 GG, da der eigentliche Rechtsinhaber, der fremde Staat, unter Umständen eine Rechtsverletzung nicht geltend machen möchte oder diese sogar billigt.

\footnotetext{
${ }^{86}$ Walz, Völkerrecht und staatliches Recht, S. 308.

${ }^{87}$ Stumpfe, Die allgemeinen Regeln des Völkerrechts, S. 45 f.; Doehring, Fremdenrecht, S. 37 f; Cremer, in: in: HdStR Bd. 11, § 235 Rn 4 f., 32, 51 f., ${ }^{88}$ Stumpfe, Die allgemeinen Regeln des Völkerrechts, S. 45 f.

${ }^{89}$ BVerfGE 15, 25 (34); 23, 288 (316); 117, 141 (148).

${ }^{90}$ Doehring, Fremdenrecht, S. 144.

${ }^{91}$ Koenig/König, in: v. Mangoldt/Klein/Starck, Art. 25 GG, Rn 3; Streinz, in: Sachs, Art. 25 GG, Rn 38, 44.

${ }^{92}$ Koenig/König, in: v. Mangoldt/Klein/Starck, Art. 25 GG, Rn 45 f.

${ }^{93} \mathrm{Vgl}$. Doehring, Fremdenrecht, S. 146.
} 
Anders ist es bei Regeln des Völkerrechts, die bereits auf der völkerrechtlichen Ebene subjektive Individualrechte begründen. Auf diese können sich Individuen bereits aufgrund von Art. 25 Satz 1 GG berufen. Hier bedarf es schlicht der Übernahme durch Art. 25 Satz 1 GG, eine Berufung auf Art. 25 Satz 2 GG wäre falsch. Ein etwaiges Recht aus Art. 25 Satz 1 GG kann jedoch nur so weit reichen wie es die übernommene Völkerrechtsregel selbst tut.

\section{Hat Art. 25 Satz 2 GG konstitutive Wirkung?}

Im Zentrum dieser Untersuchung steht Satz 2 des Art. 25 GG und dessen etwaige konstitutive Wirkung. Dieser besagt, die allgemeinen Regeln des Völkerrechts stehen über den Gesetzen und erzeugen Rechte und Pflichten unmittelbar für alle Bewohner des Bundesgebietes.

Entgegen des Wortlauts des Art. 25 Satz 2 GG entfalten die allgemeinen Völkerrechtsregeln unmittelbar Rechte und Pflichten nicht nur für die im Bundesgebiet ansässigen natürlichen und juristischen Personen. Vielmehr sind alle Personen betroffen, die sowohl der Territorial- als auch der Personalhoheit Deutschlands unterliegen. ${ }^{94}$

Die Formulierung des Satz 2 in Art. 25 GG hat über die letzten Jahrzehnte umfassend Anlass zur Diskussion über die Deutung der daraus resultierenden Rechtsfolgen geliefert. Besonders umstritten ist dabei die Frage, ob Satz 2 sich auch auf allgemeine Völkerrechtsregeln bezieht, die sich zwar ausschließlich an Staaten als Adressaten richten, bezüglich ihres inhaltlichen Gehalts allerdings auch von Individuen in Anspruch genommen werden könnten, da diese auch den Rechtskreis des Einzelnen berühren. Auf vereinzelte Stimmen der Literatur sowie insbesondere auch auf die jüngere und aktuelle Rechtsprechung wird im Verlauf der Arbeit noch intensiv geblickt, welche Tendenzen zu einer weiterentwickelten Auslegung des Art. 25 Satz 2 GG auszumachen sind, und auch was die Subjektivität der Norm als tatsächliche Anspruchsgrundlage für Individuen betrifft.

Das BVerfG hat früh vertreten, der Art. 25 Satz 2 GG besitze lediglich deklaratorische Wirkung. ${ }^{95}$ Satz 2 der Norm entfalte deshalb keine eigene weitergehende Rechtswirkung,

\footnotetext{
${ }^{94}$ Heintschel v. Heinegg, in: Epping/Hillgruber, Art. 25 GG, Rn 32; so auch Koenig/König, in: v. Mangoldt/Klein/Starck, Art. 25 GG, Rn 57 f.

${ }^{95}$ BVerfGE 15, 25 (33); 18, 441 (448); 27, 253 (274); 41, 126 (160); 46, 342 (363, 403) unter Offenlassen der Problematik einer konstitutiven Subjektivierung durch Art. 25 Satz 2 GG; BVerfGE 63, 343 (363, 373 f.); 84, 90 (124 f.); 112, 1 (22).
} 
da die unmittelbare Anwendbarkeit der allgemeinen Völkerrechtsregeln bereits aus der Einbeziehung durch Art. 25 Satz 1 GG folge. Entweder berechtigen oder verpflichten die Regeln den Einzelnen aus ihrem entsprechenden Inhalt von selbst oder durch die Aufnahme ins deutsche Recht. ${ }^{96}$

Weitere Stimmen der Literatur vertreten heute, dass Art. 25 Satz 2 GG solche Völkerrechtsregeln einbeziehe, die bereits im völkerrechtlichen Bereich individualbezogen sind oder einen starken subjektiven Gehalt aufweisen und solche Völkerrechtsregeln nicht betreffen, die nur Rechte und Pflichten für die Staaten regeln. ${ }^{97}$ Danach soll nicht jede allgemeine Völkerrechtsregel geeignet sein, Rechte und Pflichten zu erzeugen. ${ }^{98}$ Abzustellen sei auf das Schutzinteresse der Regel, ob sie staatlichen Schutz bezwecke oder Individualinteressen das Schutzgut bilden. Sollen von Art. 25 Satz 2 GG nur die individualgerichteten allgemeinen Völkerrechtsregeln erfasst werden, laufe diese Vorschrift jedoch leer, da sie den rechtlichen Inhalt des ersten Satzes der Norm lediglich ausformuliert darstelle. Das Vorliegen eines berechtigten Schutzinteresses, das durch ein staatliches Verhalten verletzt worden sein könnte, stelle die Voraussetzung für eine zur Klage erforderliche Klagebefugnis dar. ${ }^{99}$ Nach dieser Sichtweise könnten und müssten individualschützende Interessen im Einzelfall vorliegen, die ein Kläger wiederum glaubhaft als beeinträchtigt vorbringen müsste, um allgemeine Völkerrechtsregeln nach Art. 25 GG prozessieren zu können.

Wiederum gibt es auch Vertreter der Auffassung, die Vorschrift ordne für verschiedene Arten der Völkerrechtsregeln einen Adressatenwechsel an. ${ }^{100}$ Nicht immer wird dieser als erforderlich angesehen. Die allgemeinen Völkerrechtsregeln binden danach bereits die Staatsgewalt, so dass auf diese Weise auch die einzelnen Individuen begünstigt würden. Demnach komme Art. 25 Satz 2 GG nur eine deklaratorische Wirkung zu. ${ }^{101}$

Ein differenzierter Blick auf die unterschiedlichen Adressaten des Völkerrechts gibt Aufschluss darüber, inwiefern dies eine Rolle für die rechtliche Betrachtung des Art. 25 Satz 1

\footnotetext{
${ }^{96}$ Cremer, in: HdStR Bd. 11, § 235 Rn 31 f.; Dahm, Zur Problematik des Völkerstrafrechts, S. 68.

${ }^{97}$ Herdegen, in: Maunz/Dürig, Ar.t 25 GG, Rn 89 (,,individualschützende[n] oder individualverpflichtende[n] Finalität"); Wollenschläger, in: Dreier, Art. 25 GG, Rn 36; Cremer, in: HdStR Bd. 11, § 235 Rn 32; auch BVerfGE 112, 1 (22).

${ }^{98}$ Dahm, Völkerrecht, Bd 1, S. 66 f.

${ }^{99}$ Ders.

${ }^{100}$ In verschiedenen Formen Hillgruber, in: Schmidt-Bleibtreu/Hofmann/Henneke, Art. 25 GG, Rn 20 f.; Wollenschläger, in: Dreier, Art. 25 GG, Rn 33 f., auch Cremer, in: HdStR Bd. 11, § 235 Rn 32, 59; a. A. Dazu Talmon, in: JZ 2013, S. 12 (13); die Funktion des Art. 25 Satz 2 GG eines „Adressatenwechsels“ ablehnend, da bereits die Übernahme allgemeiner Völkerrechtsregeln ins innerstaatliche Recht deren Geltung für Einzelne bedeute, und es deshalb keines Adressatenwechsels bedürfe, Hofmann, in: Umbach/Clemens, Art. 25 GG, Rn 26, deutlich gegen einen Adressatenwechsel ist Zuleeg, in: Denninger, Art. 24 Abs. 3/25 GG, Rn 11.

${ }^{101}$ Hofmann, in: Umbach/Clemens, Art. 25 GG, Rn 26.
} 
und 2 GG sowie dessen Adressatenkreis spielt. Zum einen gibt es Völkerrechtsregeln, die sich lediglich an Staaten richten und nur zwischen diesen anwendbar sind. Dies betrifft alle Organe der Exekutive, Judikative und Legislative und auch die Organe der auswärtigen Gewalt. Verwaltungsbehörden und Gerichte müssen die allgemeinen Völkerrechtsregeln als bindendes Recht im Sinne des Art. 20 Abs. 3 GG beachten, unabhängig davon, an wen sie gerichtet sind. ${ }^{102}$ Dies gilt auch dann, wenn sie für Individuen zugänglich sein sollten und ihrem materiellen Inhalt nach nicht verändert werden könnten, ohne ihren Sinn zu verlieren. Beispielsweise wäre eine Geltendmachung der staatengerichteten allgemeinen Völkerrechtsregeln durch Individuen sinnlos, weil sie auf diese schlechthin nicht anwendbar sind (beispielsweise die Regeln der räumlichen Gesetzgebungsgrenzen). ${ }^{103}$ Nochmals herauszustellen ist allerdings, dass die staatengerichteten völkerrechtlichen Normen bereits über Art. 25 Satz 1 GG Bestandteil des objektiven Bundesrechts sind. Art. 25 Satz 2 GG kann jedoch keine subjektiven Rechtssätze hervorbringen, die das Völkerrecht in der Art nicht kennt. ${ }^{104}$ Staatengerichtete völkerrechtliche Regeln, die auch nur diese ansprechen und vom innerstaatlichen Recht erst verändert werden müssten, um auch den Individuen zugänglich zu sein, werden von Art. 25 Satz 2 GG gar nicht erst berührt. Dies erfolgt allerdings nicht grenzenlos. Es werden durch individualgerichtete Regeln keine Beziehungen geregelt, die im Völkerrecht nicht bestehen oder die das Völkerrecht nicht regeln wollte. Hinsichtlich des Fremdenrechts wurde bezüglich Art. 25 Satz 2 GG vertreten, dass die Begrenzung des individuellen Anspruchs auch bedeute, dass der Fremde im Bereich des Völkerrechts nicht mehr Rechte geltend machen könne als sein Heimatstaat im Interesse des Fremden. ${ }^{105}$

Es sind jedoch im Völkerrecht auch wenige Individualrechte als zweite Gruppe von Völkerrechtsregeln anerkannt wie die praktisch weniger relevanten Menschenrechte ${ }^{106}$ oder der völkerrechtliche Mindeststandard ${ }^{107}$ oder auch der Grundsatz ,pacta sunt servanda““108 Könnte die Mehrheit der allgemeinen Regeln nur von den Staaten in Anspruch genommen

\footnotetext{
${ }^{102}$ Koenig/König, in: v. Mangoldt/Klein/Starck, Art. 25 GG, Rn 3; Streinz, in: Sachs, Art. 25 GG, Rn 38, 44.

${ }^{103}$ Koenig/König, in: v. Mangoldt/Klein/Starck, Art. 25 GG, Rn 59, 60.

${ }^{104}$ Doehring, Fremdenrecht, S. 156; v. Heinegg, in: Epping/Hillgruber, Art. 25 GG, Rn 33, 34; Herdegen, in: Maunz/Dürig, Art. 25 GG, Rn 88 f.

${ }^{105}$ Vgl. Doehring, Fremdenrecht, S. 163. Auf Doehrings Werk: „Die allgemeinen Regeln des völkerrechtlichen Fremdenrechts und das deutsche Verfassungsrecht“ aus 1963 wird in Kapitel § 6 noch vertieft eingegangen.

${ }^{106}$ Streinz, in: Sachs, Art. 25 GG, Rn 68; Rojahn, in: v. Münch/Kunig, Art. 25 GG, Rn 42.

${ }^{107}$ BVerfGE 60, 253 (303 f.); 67, 43 (63).

${ }^{108}$ Burghart, in: Leibholz/Rinck, Grundgesetz für die Bundesrepublik Deutschland, Art. 25 GG, Rn 101.
} 
werden, wäre eine Beschränkung von Art. 25 Satz 2 GG auf die völkerrechtlichen Individualrechte enttäuschend, zumal diese bereits über Art. 25 Satz 1 GG in Anspruch genommen werden können. Diese individualgerichteten Regeln erzeugen bereits auf völkerrechtlicher Ebene Rechte und Pflichten für Einzelne. ${ }^{109}$ Diesbezüglich besteht Einigkeit zwischen Literatur und Rechtsprechung. ${ }^{110}$ Das gilt insbesondere für die fundamentalen Menschenrechte, die bereits als subjektive Rechte anerkannt sind und auch zu den allgemeinen Völkerrechtsregeln gezählt werden. ${ }^{111}$

Eine dritte Gruppe der Völkerrechtsnormen bezieht sich ebenfalls auf der Verhalten der Staaten untereinander. Jedoch ist diese Gruppe der Inanspruchnahme durch das Individuum, zumindest dem Wortlaut nach, nicht vollständig entzogen. ${ }^{112} \mathrm{Zu}$ denken ist dabei an Normen betreffend die Freiheit der Hohen See, das Verbot grenzüberschreitender Umweltschäden oder das Recht auf friedliche Durchfahrt durch das Küstenmeer. ${ }^{113}$

Die Vertreter der Auffassung, dass Art. 25 Satz 2 GG nicht bloß deklaratorische Wirkung entfalte, sondern im deutschen Recht auch unmittelbar Einzelne berechtige und verpflichte, sehen die damit verbundene Umformung auf zwei Ebenen. ${ }^{114}$ Zunächst werden die staatengerichteten allgemeinen Völkerrechtsregeln ohne inhaltliche Modifikation über Art. 25 Satz 1 GG ins nationale objektive Recht eingegliedert. Art. 25 Satz 2 GG mache diese Regeln dann mit konstitutiver Wirkung zu Rechten und Pflichten und den einzelnen Bundesbewohnern zugänglich. Es finde demnach ein „Adressaten- und Inhaltswechsel“ statt. ${ }^{115}$ Dieser erfolge insbesondere automatisch durch generelle Anordnung des Verfassungsgesetzgebers bei allen allgemeinen Völkerrechtsregeln, die einer Inanspruchnahme durch Einzelne zugänglich ist. ${ }^{116}$

\footnotetext{
${ }^{109}$ Vgl. auch Doehring, Fremdenrecht, S. 158; ebenso Koenig/König, in: v. Mangoldt/Klein/Starck, Art. 25 GG, Rn 60; Rojahn, in: v. Münch/Kunig, Art. 25 GG, Rn 42 f.; Streinz, in: Sachs, Art. 25 GG, Rn 46 f.

${ }^{110}$ Repräsentativ BVerfGE 46, 342 (362); v. Heinegg, in: Epping/Hillgruber, Art. 25 GG, Rn 33; Herdegen, in: Maunz/Dürig, Art. 25 GG, Rn 85 f.

${ }^{111}$ Henkin, in: EPIL 8/1985, S. 268 f.; so auch BVerfGE 53, 332 (337); 57, 9 (25); 59, 280 (283, 286); 60, 253 (303 f.); 74, 358 (370); 75, 1 (19 f); 83, 119 (128).

${ }_{112}$ v. Heinegg, in: Epping/Hillgruber, Art. 25 GG, Rn 35; Steinberger, in: HdStR, Bd 7, § 173 Rn 69.

${ }^{113}$ Koenig/König, in: v. Mangoldt/Klein/Starck, Art. 25 GG, Rn 61.

${ }^{114}$ So zumindest Rojahn, in: v. Münch/Kunig, Art. 25 GG, Rn 46.

${ }^{115}$ Rojahn, in: v. Münch/Kunig, Art. 25 GG, Rn 46; so auch Doehring, Fremdenrecht, S. 157 f.; Tomuschat, in: ZaöRV 1968, S. 47 (63 f.).

${ }^{116} \mathrm{Vgl}$. Steinberger, in: HdStR Bd. 7, § 173 Rn 68 f.
} 
Begründet wird dies, an dieser Stelle in Kürze dargestellt, mit der Funktion des Art. 25, das Völkerrecht möglichst effektiv auszugestalten und auch innerstaatlich in Rechtszusammenhang zu bringen. ${ }^{117}$ Dazu gehöre auch die subjektiv-rechtliche Erweiterung des Adressatenkreises, die eine individuelle Einklagbarkeit der völkerrechtlichen Normen zur Folge habe. ${ }^{118}$ Auf der Seite der Erzeugung von Pflichten ist entscheidend festzuhalten, dass diese nur soweit reichen können wie sie tatsächlich von Individuen verlangt und erfüllt werden können. Die Einhaltung der staatlichen Pflichten setzt die besondere Fähigkeit zu deren faktischer Durchsetzung voraus. Die Erzeugung von Pflichten muss sich daher auf diejenigen Pflichten beschränken, die der „Natur der Sache nach zum Adressatenwechsel im beschriebenen Sinne geeignet sind“. 119

Denkbar ist, dass staatengerichtete Rechte vom Individuum selbst geltend gemacht werden. Das Rechtssystem der Europäischen Menschenrechtskonvention ist ein Beweis für die Existenz solcher Regelungen auf vertraglicher Grundlage. Die Vorschrift des Art. 25 Satz 2 GG hat zur Folge, dass die völkerrechtlichen Regeln, die im Völkerrecht selbst zwar staatengerichtet sind, jetzt aber auf Anordnung des innerstaatlichen Rechts den Individuen zugänglich gemacht werden, ohne ihren materiellen Gehalt nach Sinn und Zweck zu verändern. Den Staaten bleibt es durchaus unbenommen, den innerstaatlichen Adressatenkreis unter Beachtung des Völkerrechts zu vergrößern. ${ }^{120}$ Nach Mosler sei bei Art. 25 Satz 2 GG indes anzunehmen, dass dessen Zweck es ist, dem Art. 25 Satz 1 GG etwas hinzuzufügen, anstatt den rechtlichen Gehalt lediglich als Pleonasmus zu wiederholen. ${ }^{121}$

Allgemeine Völkerrechtsregeln erzeugen für den Einzelnen innerstaatlich jedoch nur ausnahmsweise unmittelbar Rechte und Pflichten. Die Norm muss dazu hinreichend bestimmt und unbedingt sein sowie den Interessen Einzelner dienen. ${ }^{122}$ Am Beispiel des Völkerstrafrechts in Kapitel $§ 4$ wird die inhaltliche Konkretisierung der Völkerrechtsregeln am Maßstab des nationalen Bestimmtheitsgrundsatzes nach Art. 103 Abs. 2 GG gemessen.

Dass diese subjektiven Rechte auf der Ebene des Völkerrechts überhaupt bestehen, bekräftigt die Sicht auf den Sinn und Zweck des Art. 25 Satz 2 GG: wären alle Normen des Völkerrechts sowohl staaten-, als auch individualgerichtet, hätte Art. 25 Satz 2 GG keine weitere Bedeutung, da lediglich eine bereits generell bestehende Anordnung wiederholt würde.

\footnotetext{
${ }^{117}$ Koenig/König, in: v. Mangoldt/Klein/Starck, Art. 25 GG, Rn 62.

${ }^{118}$ Rojahn, in: v. Münch/Kunig, Art. 25 GG, Rn 49.

${ }^{119}$ Siehe Doehring, Fremdenrecht, S. 164.

${ }^{120}$ v. Heinegg, in: Epping/Hillgruber, Art. 25 GG, Rn 34.

${ }^{121}$ Mosler, Das Völkerrecht in der Praxis der deutschen Gerichte, S. 38

${ }^{122}$ v. Heinegg, in: Epping/Hillgruber, Art. 25 GG, Rn 35; Koenig/König, in: v. Mangoldt/Klein/Starck, Art. 25 GG, Rn 63.
} 


\section{Der Rang der allgemeinen Völkerrechtsregeln im deutschen Recht}

Zu klären ist, ob die allgemeinen Völkerrechtsregeln im Sinne des Art. 25 GG eine Sonderrolle im deutschen Rechtsgefüge einnehmen. Stünden die allgemeinen Regeln als eine Art Schirm über der nationalen Rechtsordnung, wäre kritisch zu betrachten, ob deren praktische Wirkung vom Vorliegen verwaltungs- oder verfassungsrechtlicher Zulässigkeitsanforderungen abhängen können soll. Die besondere Relevanz völkerrechtlicher Rechtssätze, die nicht nur die Staaten, sondern auch deren Bürger berechtigen und verpflichten sollen, kämen kaum zur Geltung, würden sie durch nationale Verfahrensnormen behindert. Sollten in der Tat Bewohner des Bundesgebietes eigene Rechte geltend machen können, erwiese es sich in der Praxis als besonders schwierig. Sie müssten erst durch einen gezielten oder unterschiedslosen Angriff auf Zivilpersonen im Sinne des humanitären Völkerrechts verletzt, aber nicht getötet werden, um dadurch ,unmittelbar betroffen“ im Sinne des Art. 19 Abs. 4 GG und der Auslegung des $\mathrm{BVerwG}^{123}$ zu sein. Der Großteil der beabsichtigten Klagen gegen etwaige Verletzungen der allgemeinen Völkerrechtsregeln würde von den Gerichten daher kaum als zulässig erachtet und entschieden. Die allgemeinen Regeln könnten dadurch Gefahr laufen, für den Einzelnen in der Rechtspraxis nahezu unerreichbar zu werden. Die Vertreter von Herrenchiemsee wollten dies allerdings verhindern und das Völkerrecht sollte bis zum Einzelnen durchdringen.

Viele Autoren und Richter haben im letzten halben Jahrhundert über den Rang der allgemeinen Völkerrechtsregeln gestritten. Der Rang der allgemeinen Völkerrechtsregeln hängt vom Rang der gewohnheitsrechtlichen Normen ab, da diese überwiegend identisch sind. ${ }^{124}$ Wird ihnen ein Verfassungsrang zugesprochen, kommt den von ihnen erfassten allgemeinen Völkerrechtsregeln ebenso Verfassungsrang zu. Räumt die innerstaatliche Rechtsordnung den völkerrechtlichen Gewohnheiten Gesetzesrang ein, genießen die allgemeinen Völkerrechtsregeln Gesetzesrang. ${ }^{125}$ Ein niedrigerer Rang kann hingegen nicht ausgeschlossen werden. Eventuelle Konflikte werden relevant, wenn den allgemeinen Völkerrechtsregeln Gesetzes- oder Untergesetzesrang zugesprochen wird. Konflikte treten selte-

\footnotetext{
${ }^{123}$ BVerwGE 154, 328 (346 f.).

${ }^{124} \mathrm{Vgl}$. Papadimitriu, Die Stellung der allgemeinen Regeln des Völkerrechts im innerstaatlichen Recht, S. 88.

${ }^{125}$ Ders.
} 
ner auf, wenn ihnen Übergesetzesrang oder Verfassungsrang zukommt. Das Gebot der völkerrechtskonformen Gestaltung der innerstaatlichen Rechtsordnung und die völkerrechtskonforme Auslegung sind Bestandteil der enthaltenen Rangklausel. ${ }^{126}$

Einzelne Ansichten der Literatur befürworten einen Rang sowohl über dem Bundesrecht, als auch über der Bundesverfassung, einen sogenannten „Überverfassungsrang““127, während andere den Gleichrang der allgemeinen Regeln mit der Bundesverfassung vertreten ${ }^{128}$ oder den Vorrang der allgemeinen Regeln als Bestandteil des EU-Rechts ${ }^{129}$.

Das BVerfG vertritt die Auffassung eines Rangs der allgemeinen Völkerrechtsregeln unter der Bundesverfassung, aber auch über den Landesverfassungen, also einen sogenannten „Zwischenrang““ ${ }^{130}$ Dafür spricht, dass der Art. 25 GG nicht in der Ewigkeitsklausel des Art. 79 Abs. 3 GG als unantastbar erwähnt ist, und dass ein Vorrang der allgemeinen Völkerrechtsregeln gegenüber dem Grundgesetz als Deutschlands höchster Rechtsrangstufe ausdrücklich von dieser hätte geregelt werden müssen. ${ }^{131}$ Art. 100 Abs. 2 GG spricht dem BVerfG jedoch eine Entscheidungskompetenz in Verfahren vor den Instanzgerichten zu. Das Völkergewohnheitsrecht und die allgemeinen Rechtsgrundsätze wirken also als Rechtmäßigkeitsmaßstab für die Gesetzgebung des Parlaments. Danach verstößt ein Gesetz gegen die verfassungsmäßige Ordnung im Sinne des Art. 2 Abs. 1 GG, wenn es mit den allgemeinen Völkerrechtsregeln kollidiert. ${ }^{132}$

Teilweise wird angenommen, dass die einen Rechtsanwendungsbefehl erteilende Norm der anzuwendenden völkerrechtlichen Norm die gleiche Rangstufe zuweise. Die allgemeinen Völkerrechtsregeln hätten demnach denselben Rang wie das deutsche Grundgesetz. ${ }^{133} \mathrm{Ge}$ gen einen Gleichrang mit der Bundesverfassung spricht allerdings, dass sich zwei gleichrangige Verfassungsrechtssätze gegenüberstünden und kollidieren könnten. Zudem wären

${ }^{126}$ Vgl. Papadimitriu, Die Stellung der allgemeinen Regeln des Völkerrechts im innerstaatlichen Recht, S. 89.

${ }^{127}$ Streinz, in: Sachs, Art. 25 GG, Rn 90; Zuleeg, in: Denninger, Art. 24 Abs. 3/25 GG, Rn 24; Pernice, in Dreier, Art. 25 GG, Rn 25 f. (Vorauflage) hinsichtlich des ius cogens, a. A. in der Folgeauflage Wollenschläger, in: Dreier, Art. 25 GG, Rn 30.

${ }^{128}$ U. a. Cremer, in: HdStR Bd. 11, § 235 Rn 27; Hofmann, in: Umbach/Clemens, Art. 25 GG, Rn 22 f., der letztendlich jedoch der h.M. und einem Zwischenrang den Vorrang gibt; Maunz, in: Maunz/Dürig, Art. 25 GG (1964) Rn 24 f., mittlerweile jedoch auch den Zwischenrang befürwortend, in: Maunz/Dürig, Art. 25 GG (Stand 2016, Ergänzungslieferung aus 2019), Rn 78; Papadimitriu, Die Stellung der allgemeinen Regeln des Völkerrechts im innerstaatlichen Recht, S. 94.

${ }^{129}$ EuGH, Urteil vom 16.06.1998, Racke GmbH\&Co. vs. Hauptzollamt Mainz, Rs C-162/96, Slg. 1998 I-3655; dazu Hoffmeister, EWS 10/1998, S. 365 (366 f.).

${ }^{130}$ U.a. BVerfGE 1, 208 (233); 6, 309 (363); 37, 271 (278 f.); 111, 307 (318).

${ }^{131}$ Vgl. Koenig/König, in: v. Mangoldt/Klein/Starck, Art. 25 GG, Rn 53; Herdegen, in: Mainz/Dürig, Art. 25 GG, Rn 78.

${ }^{132} \mathrm{Vgl}$. bspw. Burghart, in: Leibholz/Rinck, Grundgesetz für die Bundesrepublik Deutschland, Art. 25 GG, Rn 51 f.; vgl. auch Schorkopf, Staatsrecht der internationalen Beziehungen, § 3 Rn 30.

${ }^{133}$ Streinz, in: Sachs, Art. 25 GG, Rn 90; ebenso Koenig/König, in: v. Mangoldt/Klein/Starck, Art. 25 GG, Rn 55. 
die allgemeinen Völkerrechtsregeln laut Art. 25 Satz 1 GG als einfaches Bundesrecht zu werten und müssten dennoch Vorrang vor der Verfassung genießen.

Früher wurde vertreten, dass die allgemeinen Völkerrechtsregeln einen „Überverfassungsrang“ innehätten. In den Beratungen des Parlamentarischen Rates wurde die Formulierung „Bundesverfassungsrecht“ entworfen, allerdings kurz vor Beratungsende wieder in „Bundesrecht" geändert. Ersteres wurde vorgenommen, um dem von vereinzelten Mitgliedern des Rats angestrebten Höchstrang der allgemeinen Völkerrechtsregeln zu entsprechen. ${ }^{134}$ Vereinzelt wurde aufgrund dieser Beratungen von Bundesgerichten die Höchstrangigkeit des Völkerrechts angenommen. ${ }^{135}$ Letztendlich wollte die Mehrheit des Parlamentarischen Rats jedoch, dass die allgemeinen Völkerrechtsregeln nur den Bundesgesetzen vorgehen. Der direkte Wortlaut des Art. 25 GG erwähnt auch nur die Bundesgesetze, welcher den Überverfassungsrang deutlich ausschließt. ${ }^{136}$ Die Vielzahl der inhaltlich unterschiedlichen Auffassungen gilt es hier nicht zu ergänzen oder inhaltlich zu bewerten. Sie sind bekannt und werden in älterer sowie aktueller Kommentierung gleichermaßen wiedergegeben. ${ }^{137}$

\section{Schließt Art. 25 GG reine Interessenklagen aus?}

Den allgemeinen Völkerrechtsregeln kommt über Art. 25 GG eine gewisse Sonderrolle zu, sollen die allgemeinen Regeln des Völkerrechts ins deutsche Rechtssystem implementieren. Die Zulassungsvoraussetzung der Klagebefugnis könnte diese Sonderrolle gefährden, wenn Kläger selbst erst unmittelbar Betroffene eines gezielten oder unterschiedslosen Angriffs auf Zivilpersonen oder völkerrechtswidriger Gewalt sein müssten. Denkbar ist auch, dass der Art. 25 GG im Grundgesetz dennoch reine Interessenklagen ausschließt, um die Aufweichung der hohen Bedeutung mittels Einschränkungen der Klagemöglichkeit oder die Lähmung des Justizapparats zu vermeiden.

\footnotetext{
${ }^{134}$ Ausführlicher in Schorkopf, Grundgesetz und Überstaatlichkeit, S. 58-61.

${ }^{135}$ BGHSt 1, 391 (399); BGHZ 3, 94 (107); BVerwG, Urteil vom 10.05.1961, Az. IV C 286.59, in: NJW 1961, S. $2225,2226$.

${ }^{136}$ Vgl. Koenig/König, in: v. Mangoldt/Klein/Starck, Art. 25 GG, Rn 52 f.; Streinz, in: Sachs, Art. 25 GG, Rn $86,87$.

${ }^{137}$ Unter anderem in: Hillgruber, in: HdStR Bd. 2, § $32 \S 32$ Rn 117; Koenig/König, in: v. Mangoldt/Klein/Starck, Art. 25 GG, Rn 49 f.; Streinz, in: Sachs, Art. 25 GG, Rn 85 f.; Wollenschläger, in: Dreier, Art. 25 GG, Rn 30; Herdegen, in: Maunz/Dürig, Art. 25 GG, Rn 78.
} 
Auch nicht einklagbare Rechte erzeugen Ordnungs- und Legitimationsfunktionen, weshalb im deutschen Recht zahlreiche Rechtsnormen eben nicht prozessierbar sind, speziell besondere Vorschriften des Grundgesetzes wie beispielsweise Art. 20 Abs. 1 oder Art. 20a GG. ${ }^{138}$ Art. 25 GG wird in der Auflistung allerdings nicht erwähnt und beinhaltet auch nach seinem Wortlaut Rechte und Pflichten.

Eine Klage vor dem VG Köln hatte ebenfalls die Duldung von Drohneneinsätzen als Streitgegenstand. Auch wenn sie als unbegründet abgewiesen wurde, hielten die Richter die Kläger immerhin für klagebefugt im Sinne des $§ 42$ Abs. 2 VwGO, da sie eine Schutzpflichtverletzung seitens der Bundesrepublik Deutschland geltend machen konnten. ${ }^{139}$ Eine inhaltliche Auseinandersetzung seitens des Gerichts erfolgte allerdings nicht. Eine Diskussion über die Notwendigkeit der unmittelbaren Betroffenheit war nicht zu führen. Das BVerwG hatte zwar ebenso über eine Leistungsklage im Sinne der $§ 43$ Abs. 2, 111, 113 Abs. 4 VwGO zu entscheiden, für die die Klagebefugnis über $§ 42$ Abs. 2 VwGO vorgeschrieben ist, allerdings ging es nicht um die Verletzung einer allgemeinen Völkerrechtsregel, deren mögliche Subjektivierung zu entscheiden gewesen wäre, sondern um eine rein staatengerichtete Völkerrechtsregel. ${ }^{140}$ Gärditz begrüßte das Vorgehen des BVerwG, die individuelle Betroffenheit zur Geltendmachung von völkerrechtlichen Individualrechten zu fordern, um so Popularklagen zu vermeiden. Er begründet seine Zustimmung mit aktuellen politischen Argumenten wie selbsternannte „Gemeinwohlwächter“, die zwecks Förderung von Klimaschutz, Migrations- oder Europapolitik immer häufiger Klagen einreichen. ${ }^{141} \mathrm{Er}$ fordert gerichtliche Zurückhaltung bei der Kontrolle der Bundesregierung hinsichtlich politisch heikler Sachverhalte. Die Klagerechte daher angemessen zu bestimmen und das personale Substrat weiterhin als Bedingung der Subjektivierung festzulegen, sei daher vom BVerwG überzeugend ausgelegt worden. ${ }^{142}$ An die Klagebefugnis hinsichtlich allgemeiner Völkerrechtsregeln werden somit wohl auch weitestgehend angenommene politische Voraussetzungen geknüpft.

Entsprechend der Argumentation des BVerwG wurde die Entstehungsgeschichte samt dem Sinnzusammenhang des Art. 25 Satz 2 GG bereits näher betrachtet. Bis auf den Mangel an

\footnotetext{
${ }^{138}$ Siehe Peters, Jenseits der Menschenrechte, S. 40.

${ }^{139}$ VG Köln, Urteil vom 27.05.2015, Az. 3 K 5625/14, in: ZD 2016, S. $402-404$ (Leitsatz und Gründe), Rn 19 nach juris.; zur Rechtsprechung es BVerwG auch Gärditz, in: DVBl. 13/2016, S. 849 (854 f.).

${ }^{140}$ BVerwGE 154, $328 \mathrm{f}$.

${ }^{141} \mathrm{Vgl}$. bereits S. 13.

${ }^{142}$ Gärditz, in: DVB1. 13/2016, S. 849 (858).
} 
Erkenntnissen aus den Gesetzgebungsmaterialien zur gewollten Vermeidung von Popularklagen macht das Gericht aber keine Ausführungen. Der Wortlaut des Art. 25 Satz 2 GG spricht den Bewohnern des Bundesgebietes ausdrücklich eine unmittelbare Berechtigung und Verpflichtung im Sinne des $\S 42$ Abs. 2 VwGO zu, also aus welchem Grund sollte ein Gericht das Erfordernis einer zweiten, zusätzlichen unmittelbaren Betroffenheit im Rahmen einer Rechtsbehelfsbefugnis verlangen dürfen?

Die knapp begründete Auffassung des BVerwG verwundert umso mehr, haben die allgemeinen Völkerrechtsregeln in der deutschen Rechtspraxis bisweilen nur geringe Anwendung und Ausführung erfahren. Deiseroth vermutet eine justizielle Kreation seitens der Rechtsprechung - die Einführung eines nicht ausdrücklich formulierten weiteren Tatbestandsmerkmals - hinter dem Vorgehen des Gerichts, um weiterhin die Entscheidung eines Falls in ,unsicherem Gelände“" vermeiden zu können. ${ }^{143}$

Dies als Standpunkt angenommen, liegt der Gedanke nicht fern, dass möglicherweise auch nur dann von bestehenden oder teilweise bestehenden Individualrechten aus Art. 25 Satz 2 GG laut Rechtsprechung ausgegangen wird, wenn der Rechtsbehelf bereits vor einer Sachentscheidung an der fehlenden, ,neu“ vorausgesetzten Zulässigkeitsanforderung nur scheitern kann. In Kapitel $\S 6$ wird die nationale Rechtsprechung intensiver untersucht auf erfolgreiche Rechtsbegehren Einzelner und etwaige Prozess- oder Anspruchshindernisse. Vorweggenommen kann bereits die Entscheidung des OVG Münsters aus 2019 angeführt werden, in welcher die Klagenden nicht nur als klagebefugt angesehen wurden, sondern auch eine behauptete Grundrechtsverletzung aus Art. 2 Abs. 2 GG infolge von Verletzungen allgemeiner Völkerrechtsregeln geltend machen konnten. ${ }^{144}$ Die Klagebefugnis als Instrument zur Vermeidung von Popularklagen steht somit einer erfolgreichen Geltendmachung von Völkerrechtsverstößen vor deutschen Instanz- und Verfassungsgerichten jedenfalls nicht entgegen, so dass auch entgegen des direkten Wortlauts des Art. 25 GG an der Verfahrensvoraussetzung einer unmittelbaren Betroffenheit festgehalten werden muss.

\footnotetext{
${ }^{143}$ Deiseroth, in: DVBl. 16/2017, S. 985 (991).

${ }^{144}$ OVG Münster, Urteil vom 19.03.2019, Az. 4 A 1361/15, in: NJW 26/2019, S. 1898 (Leitsatz). 
Die Inhaberschaft eines Rechtsanspruchs aus Art. 25 Satz 1 GG beschränkt sich naturgemäß ausschließlich auf die individualgerichteten Normen, die im Völkerrecht subjektive Individualrechte begründen. Die Struktur des Art. 25 GG setzt voraus, dass lediglich die Bestimmung in Satz 2 den Wechsel der Adressaten ausdrücklich anordnet für allgemeine Völkerrechtsregeln, die einer Subjektivierung zugänglich sind. Ein Ausdruck in Art. 25 Satz 2 GG, der nicht schon in Satz 1 der Norm vorgenommen wurde, wäre unsinnig.

Der überwiegend vertretene Zwischenrang der allgemeinen Völkerrechtsregeln zwischen Bundesrecht und Bundesverfassung ist für die weitere Bearbeitung am überzeugendsten. Zum einen ergibt sich direkt aus dem Wortlaut des Art. 25 GG, dass den allgemeinen Völkerrechtsregeln jedenfalls ein Rang über dem Bundes- und Landesrecht zukommt. ${ }^{145} \mathrm{Ob}$ die allgemeinen Völkerrechtsregeln gleich Bundesrecht, Bundesverfassungsrecht, dazwischen oder als ganz übergeordnetes EU-Recht anzusehen sind, hat einen Einfluss auf die Anspruchsnatur, beispielsweise ob eine bundesrechtliche oder verfassungsrechtliche Anspruchsgrundlage besteht. Diese unterschieden sich dann unter anderem in ihrer Gerichtsbarkeit, ihren materiellen Voraussetzungen und Zulässigkeitsanforderungen. Eine Entscheidung ist hinsichtlich der Frage nach der Erforderlichkeit einer Klagebefugnis im Sinne des Art. 19 Abs. 4 GG aus dem Sinn und Zweck des Art. 25 GG jedoch unbedeutend, da der Art. 19 GG für das gesamte nationale Recht gilt. Ob die allgemeinen Völkerrechtsregeln nun vor den deutschen Instanzgerichten oder vor dem Bundesverfassungsgericht geltend gemacht werden können, ist für das Erfordernis einer unmittelbaren Betroffenheit individueller Interessen irrelevant. Erforderlich ist jedenfalls bei beiden Varianten die Möglichkeit der Verletzung dieser Interessen.

Angenommen, dass das Erfordernis der unmittelbaren Betroffenheit bewusst für die allgemeinen Völkerrechtsregeln in Deutschland nicht vorliegt, hätte dies einen immensen Nachteil für den hohen Wert der Menschenrechte zur Folge. Das OVG Münster hat dies im Vergleich zu den nationalen Grundrechten ausgeführt. Bei ihnen komme es nicht mehr auf eine individuelle Betroffenheit an. ${ }^{146}$ Jedem Bürger stünde es offen, auf Grundlage von Art. 25 Satz 2 GG gegen jede subjektiv beurteilte Menschenrechtsverletzung vorzugehen, auch

\footnotetext{
${ }^{145}$ Den Zwischenrang in ständiger Rechtsprechung bestätigend, repräsentativ: BVerfGE, 141, 1 (17).

${ }^{146}$ OVG Münster, Urteil vom 04.11.2014, Az. 4 A 1058/13, in: DVB1. 8/2015, S. 514-520 (Leitsatz und Gründe, Rn 95 nach juris.
} 
wenn er oder sie nicht selbst betroffen wäre. Im Gegensatz dazu stünden die national garantierten Grundrechte, welche lediglich mit einer persönlichen Rechtsbeeinträchtigung geltend gemacht werden können, obwohl diese nicht in jedem einzelnen Grundrecht vorausgesetzt wird. ${ }^{147}$ Zusammenfassend ist zu bemerken, dass bei den Menschenrechten und auch den gesetzlichen Akten auf europäischer Ebene ein Individualitätserfordernis hinsichtlich des Klagewegs gegeben ist. Es wird vertreten, die Voraussetzung einer unmittelbaren Betroffenheit sei auf europäischer Ebene schwächer verankert als im deutschen Recht, allerdings hat das keinen nennenswerten Einfluss auf die Beurteilung der Sachlage. Zugrunde liegen die allgemeinen Regeln des Völkerrechts im Sinne des Art. 25 GG, also im Sinne der deutschen Verfassung und Bundesrechte. Die bisherige Rechtsprechung hat bisher auch deutlich ausgedrückt, auf das Vorliegen einer Klagebefugnis und eines Individualbezugs der allgemeinen Völkerrechtsregel keinesfalls verzichten zu wollen. Verhindert werden sollen Popularklagen sowohl auf nationaler als auch europäischer und internationaler Ebene.

Der Rechtsprechung ist im Ergebnis zuzustimmen. Dass die Formulierungen der Grundrechte und der Inkorporierungsklausel nicht das Erfordernis einer unmittelbaren Betroffenheit für die allgemeinen Völkerrechtsnormen vorschreiben, schließt dieses zwar nicht aus. Es ist aber für die personenbezogene Rechtsanwendung relevant, um eine inflationäre Geltendmachung der höchsten Rechtsgüter zu verhindern. Dies sollte jedenfalls auch für die völkerrechtlichen Menschenrechte gelten, so dass wohl entgegen des direkten Wortlauts des Art. 25 Satz 2 GG doch zusätzlich eine unmittelbare Betroffenheit verlangt werden muss, und den besprochenen Entscheidungen keine Auslegungsfehler vorgeworfen werden können.

\footnotetext{
${ }^{147}$ OVG Münster, Urteil vom 04.11.2014, Az. 4 A 1058/13, in: DVBl. 8/2015, S. 514-520, Rn 95 nach juris; vgl. auch BVerfGE 59, 280 (282 f.); 63, 332 (337); 75, 1 (19); Cremer, in: HdStR Bd. 11, § 235, Rn 40. 


\section{$\S 3$ Völkerrechtliche Anspruchsinhaberschaft auch für Einzelne?}

Im vorangegangenen Kapitel wurde aufgezeigt, dass Art. 25 GG insbesondere dahingehend umstritten ist, ob zugunsten Einzelner entsprechend des Wortlauts der Norm Rechte erzeugt werden. Folgend wird der Frage nachgegangen, inwiefern Einzelne überhaupt Adressaten völkerrechtlicher Rechte und Pflichten sein oder werden können, und ob sie eine vollumfängliche Adressatenstellung einnehmen. Die Sichtweisen zur Völkerrechtssubjektivität Einzelner haben sich im Laufe der Jahrzehnte regelmäßig geändert. Die Entwicklung soll hier näher dargestellt und deren Wirkung auf die Geltung des Art. 25 GG berücksichtigt werden.

Es ist denkbar, dass neuerliche Änderungen der völkerrechtlichen Auffassungen eine andere Betrachtung der Materie ermöglichen. Unter Umständen erzwingen sie sogar, dass die allgemeinen Völkerrechtsregeln im deutschen Recht anders behandelt werden können.

\section{Normadressaten als Völkerrechtssubjekte}

Im Folgenden wird betrachtet, ob über Art. 25 GG einzelne Personen direkt als Völkerrechtssubjekte angesprochen werden. Dabei wird unter anderem auf die Historie der Subjektsdefinition und Reichweite geschaut, wer oder was als Völkerrechtssubjekt anerkannt wurde, und welche etwaige Entwicklung in den letzten Jahrzehnten bezeugt werden konnte.

\subsection{Anfänge der Betrachtung Einzelner als Völkerrechtssubjekte}

Nach der in der allgemeinen Rechtstheorie verwendeten Definition ist Rechtssubjekt, wer Träger von Rechten und Pflichten ist. ${ }^{148}$

Völkerrechtssubjekt ist demnach der Träger völkerrechtlicher Rechten und Pflichten. ${ }^{149}$ Wenn Individuen, also natürliche Personen, nach Art. 25 Satz 2 GG Träger von Rechten

\footnotetext{
${ }^{148}$ Walter, in: Wolfrum, EPIL 9/2012, S. 634 f.; Hempel, Die Völkerrechtssubjektivität internationaler nichtstaatlicher Organisationen, S. 57, 74; Jellinek, System der subjektiven öffentlichen Rechte, S. 28; auch IGH, Reparation for Injuries Suffered in the Service of the United Nations, Advisory Opinion of 11.04.1949, ICJ Reports 1949, S. 174 (179). ${ }^{149}$ Ders.
} 
und Pflichten aus den allgemeinen Völkerrechtsregeln sein sollen, sollten sie Völkerrechtssubjekte sein.

Es wurden bereits früh unterschiedliche Arten von Zurechnungspunkten für Rechtstatbestände im Völkerrecht eingeführt. Unter dem Begriff der Völkerrechtssubjekte verstand und erklärte Knubben Zurechnungspunkte, die die völkerrechtlichen Normen und Sätze (objektives Völkerrecht) mit subjektiven Rechten und Pflichten ausstatten. Er nahm rein menschliches Verhalten jedoch aus dieser Art von Zurechnungspunkten aus, da dieses nicht an die Realisierung von Rechtsfolgen geknüpft sei, sondern lediglich zur Ausübung tatsächlicher Rechtsausübung oder Pflichtenbefolgung. Es wurden drei Unterfälle der Völkerrechtssubjektivität unterschieden: die völkerrechtliche Geschäftsfähigkeit, die völkerrechtliche Deliktsfähigkeit und die völkerrechtliche Parteifähigkeit. Die Geschäftsfähigkeit ist relevant, um durch eine eigene Willenserklärung einen völkerrechtlichen Tatbestand zu erfüllen, der auch weitere Tatbestandsmerkmale umfassen kann, an die die Rechtsfolge des Erwerbs eigener subjektiver Rechte oder Pflichten geknüpft sein könnten. Die Deliktsfähigkeit bildet die Fähigkeit, völkerrechtliche Deliktstatbestände samt deren Folgen zugerechnet zu bekommen. Dabei kann es sich um die aktive Deliktsfähigkeit handeln, wenn der Betreffende als Deliktssubjekt völkerrechtlich subjektiven Pflichten unterliegt, oder es handelt sich um die passive Deliktsfähigkeit, bei der der Betreffende als Deliktsobjekt subjektive Rechte infolge der Rechtsverletzung innehat. Die völkerrechtliche Parteifähigkeit ist die Fähigkeit, vor bestimmten internationalen Gerichten zugerechnete Tatbestände des öffentlichen Völkerrechts oder subjektive Rechte oder Pflichten geltend machen zu können. ${ }^{150}$ Das subjektive und objektive Völkerrechtsprinzip kann auch als Einteilungsprinzip aufgefasst werden. Hierbei wurde gefragt, ob die Grundlage des objektiv völkerrechtlichen Inhalts und der prinzipielle Ausgangspunkt der wissenschaftlichen Erkenntnis der durch den völkerrechtlichen Inhalt geregelten internationalen Rechtsverhältnisse subjektiv oder objektiv begründet und somit in den Mittelpunkt des Völkerrechtsinhalts die einzelne Staatsperson und deren Souveränität Völkerrechtssubjektivität gestellt werde. Im Mittelpunkt der Untersuchung stehen hier nur die Subjekte der subjektiven Erscheinungsformen des Völkerrechts, also der völkerrechtlichen subjektiven Rechte und Pflichten, während die Subjekte der objektiven Erscheinungsformen des Völkerrechts, also der Quelle des Geltungsgrunds und Völkerrechtsinhalts, nicht relevant sind.

${ }^{150} \mathrm{Vgl}$. Knubben, Die Subjekte des Völkerrechts, 1928, S. 5, 6. 


\subsection{Historische Entwicklung der Völkerrechtssubjektivität von Individuen als Zurechnungspunkte}

Der Zurechnungsinhalt einer Rechtsnorm wurde teils bereits lange vor dem Erlass des Art. 25 GG nur an die Zurechnung von tatsächlichem Verhalten von Individuen als Rechtstatbestände sowie die Zurechnung von tatsächlichem Verhalten als Rechtsakte durch Normunterworfene geknüpft. Vereinzelt wurden nur Einzelmenschen als Zurechnungspunkte der Rechtsnormbefolgung oder der Rechtsnormverfolgung und -durchsetzung anerkannt. Die Annahme wurde jedoch abgelehnt, dass nicht nur in der objektiven Erscheinungsform des Rechts ein rein gedankliches Sollen zum Ausdruck komme und nach normativer und positiver Geltung im Rechtsleben strebe, da diese subjektiven Rechte und Pflichten unnötig und kompliziert seien. Die Annahme der Fähigkeit der Individuen eine soziale Organisation zu bilden beruhe nämlich auf einer Verwechslung von Rechtsgrund und Rechtsfolge, weil die Individuen als solche nicht einfach zu einer derartigen Entscheidung fähig seien. Recht und Gesellschaft hätten sich zusammen mit dem Einzelmenschen weiterentwickelt. ${ }^{151}$

Knubben allerdings hielt fest, dass letztendlich nur die Staaten rechts- und handlungsfähig seien. Er vertrat, dass die Verleihung durch die Vertragsstaaten vollzogen werden könnte. In diesem Fall beruhe die Befugnis im Verhältnis des Individuums zum Staat lediglich auf dem einseitigen Willen des Staates, den dieser gegenüber den Individuen jederzeit landesrechtlich ändern könnte, ohne dass sich diese aber auf ihnen zustehende völkerrechtliche Rechte berufen könnten. ${ }^{152}$ Einen anderweitigen Beweis, dass Individuen konkret als Subjekte des Völkerrechts erklärt wurden, gab es im Jahr 1925 von den Autoren, die die Völkerrechtssubjektivität annahmen, jedoch nicht. ${ }^{153}$ In Europa wandelte sich die Ansicht der Völkerrechtssubjektivität von Individuen im Zeitraum vom Ersten Weltkrieg bis nach Ende des Zweiten Weltkriegs. Scelle von der Juristischen Fakultät in Paris hat 1932 die natürlichen Personen für Völkerrechtssubjekte gehalten: „Weder der Staat noch irgendeine andere Gemeinschaft kann Völkerrechtssubjekt sein; die internationalen Gemeinschaften sind Kollektive von Individuen, die Rechtssubjekte sind [...].“154 Das Einmischen der Westmächte unter dem Vorwand des Minderheitenschutzes sollte damit gerechtfertigt werden,

\footnotetext{
${ }^{151} \mathrm{Vgl}$. Lundstedt, Superstition or Rationality in Action for Peace?, S. 96-120, 161.

${ }^{152}$ Knubben, Die Subjekte des Völkerrechts, S. 305, 489, $500 \mathrm{f}$.

${ }^{153}$ So u. a. in Knubben, Die Subjekte des Völkerrechts, S. 492.

${ }^{154}$ Scelle, Précis de droit des gens, S. 42.
} 
dass Rechtssubjekte im Allgemeinen und Völkerrechtssubjekte im Besonderen nur natürliche Personen sein könnten. Der Staat sei lediglich eine Organisationsform der Völkerrechtssubjekte, also natürlichen Personen, und als Kollektiv von Individuen zu verstehen. ${ }^{155}$ Modzorjan schrieb, dass Scelles Auffassung dem Staat dadurch seinen Staatscharakter beraubt hätte, indem er ihn schlicht mit internationalen Personenverbänden gleichsetzt.

Auch andere Autoren wie Lauterpacht ${ }^{156}$, Rousseau ${ }^{157}$ oder Jessup ${ }^{158}$ kritisierten diese Auffassung, dass die Staatspersönlichkeit in den Amtspersönlichkeiten aufgehe und so die Staatssouveränität abnehme, da nicht jedem Subjekt diese Souveränität zustehen könnte. Die Autoren sahen diese Auffassung als zu unwissenschaftlich an. Nach dem zweiten Weltkrieg hingegen änderte Scelle seine Auffassung. Er beschränkte sich darauf, das Völkerrecht unklarer als Rechtsordnung der „Gemeinschaft von Völkern der friedlichen Vereinigung von Menschen“" zu bestimmen. ${ }^{159}$

Besonders in der Nachkriegszeit änderten sich also die Ansichten zur Völkerrechtssubjektivität der Individuen.

Rousseau war zu der Zeit ebenfalls der Meinung, dass die Normen des Völkerrechts auf natürliche Personen nur ausnahmsweise durch ein „innerstaatliches Verfahren“ Anwendung fänden. Es bestünde eine Reihe von Regeln, die sich unmittelbar auf die Individuen bezögen, beispielsweise über den Austausch von Bevölkerungsteilen, über das Schicksal von Staatenlosen und das Asylrecht. ${ }^{160}$ Dies sprach für ihn gegen eine Völkerrechtssubjektivität der Individuen, sondern für die der Staaten, die Vertragsverpflichtungen eingehen. Er befand deshalb, dass die natürlichen Personen damit lediglich Subjekte des nationalen Rechts seien, jedoch keine Völkerrechtssubjekte. Es seien also nicht die einzelnen Personen, sondern die Staaten, die als Völkerrechtssubjekte Abkommen und Verträge schließen. Hieraus lasse sich keine Völkerrechtssubjektivität von Einzelpersonen ableiten. ${ }^{161}$

Jessup und Lauterpacht sowie andere Autoren leiteten die Völkerrechtssubjektivität natürlicher Personen daraus ab, dass die internationalen Organisationen berufen seien, Individuen Schutz zu gewähren. Die Schutzpflicht ergebe sich dabei aus der Schutzbedürftigkeit der Menschenrechte, die über den Kompetenzbereich des Staates hinausgehe. Nach Jessup

\footnotetext{
${ }^{155}$ Vgl. Scelle, Précis de droit des gens, S. 49, 56 f.

${ }^{156}$ Lauterpacht, International Law and Human Rights, S. 69.

${ }^{157}$ Rousseau, Droit international public, S. $215 \mathrm{f}$.

${ }^{158}$ Jessup, A Modern Law of Nations, S. 2, 9 f., 17.

${ }^{159}$ Siehe Scelle, Cours de droit international public, S. 5; Peters, Jenseits der Menschenrechte, S. 8 f.

${ }^{160} \mathrm{Vgl}$. Rousseau, Droit international public, S. 215, 221.

${ }^{161}$ Knubben, Die Subjekte des Völkerrechts, S. 31.
} 
zählten dazu auch die früher für den Rechtsschutz der Minderheiten geschaffenen Organe. Er beschränkte jedoch seine Auffassung dadurch, dass es noch nicht feststehe, welche Grenzen die Machtbefugnisse der UN bezüglich der Individuen haben. ${ }^{162}$ Es sei jedoch niemand anderem möglich, besser als der Staat die Individualrechte zu gewährleisten. Verletze der Staat die Gewährleistung, habe der Bürger diese Rechte selbst geltend zu machen und wiederherzustellen. ${ }^{163}$

Dabei ist der Gedanke naheliegend, ob diese dann aber nicht doch auch auf völkerrechtlicher Ebene ihre Rechten geltend machen können sollten.

Auch Piotrowski hatte die Völkerrechtssubjektivität natürlicher Personen aus dem Recht von Staaten auf gerichtliche und diplomatische Intervention zugunsten der Bürger abgeleitet. ${ }^{164}$ Danach ist denkbar, dass die Staaten gegebenenfalls selbst den Anstoß gegeben haben, die Völkerrechtssubjektivität für natürlichen Personen zu bestätigen.

Die Befürworter einer Völkerrechtssubjektivität Einzelner stellen heraus, dass damals bereits eine Entwicklung der Rechtssubjektivität Einzelner festzustellen gewesen sei, die nicht geleugnet werden könne. Individuen würden ,in gewissem Umfang [...] als Träger völkerrechtsunmittelbarer Rechte und Pflichten behandelt“ ${ }^{465}$ Bereits in den 1960er vertrat man die formale Einschränkung, was auch heute den Einzelnen vor den Gerichten an der Durchsetzung subjektiver Rechte behindert: die fehlende Klagebefugnis vor (internationalen) Gerichten. Es lassen sich zahlreiche individuelle Völkerrechtspositionen identifizieren, die allein rechtslogisch die Völkerrechtspersönlichkeit des Einzelnen voraussetzen. ${ }^{166}$ Dabei implizierten auch die vertraglich verliehenen Rechtspositionen eine Zuerkennung der Rechtssubjektivität Einzelner. ${ }^{167}$

Doehring kritisierte die Haltung des BVerfG aus 1957 als dieses ohne weitere Begründung ausführte, völkerrechtliche Ansprüche könnten als Privatperson ohnehin nicht geltend gemacht werden. ${ }^{168}$ Er befürwortete stattdessen eine schlicht wörtliche Heranziehung des Art. 25 GG, der Rechte und Pflichten für Einzelne „erzeuge“, und sah somit keine Problematik

\footnotetext{
${ }^{162}$ Vgl. Lauterpacht, International Law and Human Rights, S. 34, 35; Jessup, A Modern Law of Nations, S. $17 \mathrm{f}$.

${ }^{163}$ Ders.

${ }^{164}$ Vgl. Piotrowski, in: Revue de Droit International de Sciences diplomatiques et politiques“, No. 1/1954, S. 31-33.

${ }^{165}$ Siehe Doehring, Fremdenrecht, S. 9, Dahm, Völkerrecht, Bd. 1, S. 418.

${ }^{166} \mathrm{Vgl}$. bspw. zum Investitionsschutzrecht, zum Konsularrecht aus Art. 36 des Wiener Übereinkommens über konsularische Beziehungen, und im diplomatischen Schutz: Peters, Jenseits der Menschenrechte, S. 257 f., 307 f., 343 f.

${ }^{167}$ Ders.

${ }^{168}$ Doehring, Fremdenrecht, S. 10, mit Verweis auf BVerfGE 6, $300 \mathrm{f}$.
} 
der Durchsetzung vor deutschen Gerichten. Völkerrecht und nationales Recht gewährten aufeinander zugehend unmittelbar die Inhaberschaft von Rechten und Pflichten.

Es hat auch Ansätze gegeben, von internationalen Organisationen auf Individuen zu schließen. So könnte für letztere wie für Organisationen eine lediglich partikuläre Völkerrechtssubjektivität anerkannt werden. Ein Menschen wäre dann etwa nur gegenüber den Vertragsparteien der UN-Pakte Träger der darin garantierten Menschenrechte. ${ }^{169}$

Vereinzelt gab es auch Kritik an der „Lockerung der absoluten Staatsunterworfenheit“ des Individuums. So wurde von Gegnern einer Völkerrechtssubjektivität Einzelner befürchtet, dass dadurch die staatliche Souveränität geschwächt werden könnte. ${ }^{170}$ Die Souveränität würde durch eine individuelle Völkerrechtssubjektivität nicht bereits dadurch berührt, wenn Individuen versuchten Rechte gegen den Staat geltend zu machen, sondern schon durch die Existenz und Unterwerfung unter mehrere Rechtsordnungen. ${ }^{171}$ Hempel führte 1998 unter anderem die Auffassung an, dass Völkerrechtssubjekte als Wirkungseinheiten verstanden werden könnten, gegen die sich völkerrechtliche Sanktionen als Haftungsobjekte richten. Begründet wurde die Ansicht mit dem in der Norm bestimmten Verhalten und dem Zweck der Norm, der das Verhüten eines bestimmten Verhaltens beinhaltet. ${ }^{172}$ Andere bestärken jedoch, dass die völkerrechtliche Deliktsfähigkeit gerade die Rechtsfähigkeit voraussetze. Nur wer rechtserhebliche handele, könne auch für sein Tun haftbar gemacht werden. Dabei würde das Haftungsmoment zu stark betont und die Völkerrechtssubjektivität zu unbestimmt dargestellt. ${ }^{173}$

Die Durchsetzbarkeit einer bestimmten Rechtsposition ist für die Begründung eines subjektiven Rechts dann nicht erforderlich. Das subjektive Recht kann zwar derart definiert werden, jedoch ist der Schluss für Hempel nicht zwingend. Gegen die Erforderlichkeit der Durchsetzbarkeit spricht vor allem, dass innerstaatlich auch von subjektiven Rechten zu sprechen ist, ohne dass es auf die Durchsetzbarkeit ankäme. Im Übrigen fehlen dazu auch

\footnotetext{
${ }^{169}$ Grundlegend in Seyersted, Objective International Personality of Intergovernmental Organizations, 1963, vgl. auch Malanczuk, Akehurst's Modern Instruction to International Law, S. 104.

${ }^{170}$ Verdross/Simma, Universelles Völkerrecht, 1984, S. 39.

${ }^{171}$ Ders., S. 39 f.

${ }^{172}$ Hempel, Die Völkerrechtssubjektivität internationaler nichtstaatlicher Organisationen, S. 71; vgl. auch Quadri, Diritto Internazionale Publico, S. 520 f.; Eustathiades, in: Collected Courses of the Hague Academy of International Law 48/1953 S. 405 (415, 426).

${ }^{173}$ Vgl. Hempel, Die Völkerrechtssubjektivität internationaler nichtstaatlicher Organisationen, S. 72; Schneider, in: AVR 2/1955/56, S. 257 (264).

Die völkerrechtliche Delitksfähigkeit bei konkreter Betrachtung des Völkerstrafrechts spielt unter Kapitel $\S 5$ noch eine stärkere Rolle.
} 
weitestgehend die Möglichkeiten im Völkerrecht. Würde ein subjektives Recht an die Erforderlichkeit der Durchsetzbarkeit gebunden, enthielte das Völkerrecht vermutlich nur wenige praktisch anwendbare subjektive Rechte. Um über die Theorie hinaus Norm und soziale Wirklichkeit weiter in Beziehung stehen zu lassen, wurde gefordert, dass die Norm tatsächliche Beachtung aufweist und die generelle Chance der Beachtung besitzt. ${ }^{174} 2014$ vertrat dann auch Peters, der umfängliche Völkerrechtssubjektivität Einzelner klar befürwortet, dass die Völkerrechtssubjektivität die Völkerrechtsfähigkeit ausmache, Träger völkerrechtlicher Rechte und Pflichten zu sein. Dies erfordere aber keine eigene Völkerrechtserzeugung durch den Akteur. Auch eine Durchsetzbarkeit der eigenen Rechte sei nicht erforderlich. Vorausgesetzt wird allerdings eine Inhaberschaft von Rechten. ${ }^{175}$ Aktuell ist es dennoch so, dass, wenn den Einzelpersonen nicht die Unterstützung ihres Heimatstaates zukommt, sie weiterhin praktisch machtlos sind. ${ }^{176}$ Sowohl Peters als auch Higgins sehen die Rechtsgrundlage der individuellen Völkerrechtssubjektivität im Völkergewohnheitsrecht. Die gewohnheitsrechtliche Norm sei in den zentralen Menschenrechten und den Garantien des humanitären Völkerrechts enthalten. Hinzu kämen auch die „Phänomene“ der umfangreichen Ausweitung internationaler Individualrechte und -pflichten. ${ }^{177}$ Ausführungen der nationalen und internationalen Gerichte zeigen laut Peters, auch wenn sie auf nähere Verweise verzichtet, dass Einwände gegen die Rechtspersönlichkeit Einzelner irrelevant geworden seien. Mehrere Staaten scheinen in ihrer Überzeugung in Richtung Akzeptanz einer nicht nur partiellen Völkerrechtssubjektivität zu tendieren. ${ }^{178}$ Wieder ist hier festzuhalten, dass damit die beiden Elemente des Völkergewohnheitsrechts Praxis und Rechtsüberzeugung vorlägen. Anhand der Menschenrechte argumentiert sie, dass, wenn diese echte subjektive Rechte darstellten und viele von ihnen als Völkergewohnheitsrecht gälten, sei die ihnen vorausgesetzte Völkerrechts-fähigkeit im Völkergewohnheitsrecht fundiert. ${ }^{179}$

Die individuellen Interessen sollten jedoch nicht überbetont werden, so müssten diese weiter mit Belangen der jeweiligen Heimatstaaten abgewogen werden und mit denen des verletzenden Staates. Individuen sind dabei keine autonomen Völkerrechtssubjekte, sondern lediglich ,passive recipients of rights and obligations in the international legal system“.

\footnotetext{
${ }^{174}$ Vgl. Hempel, Die Völkerrechtssubjektivität internationaler nichtstaatlicher Organisationen, S. 80; Alexy, Theorie der Grundrechte, S. 167.

${ }^{175}$ Peters, Jenseits der Menschenrechte, S. 50, 51.

${ }^{176}$ Näheres in Pergantis, in: ZaöRV 2006, S. 351 f.; Vermeer-Künzli, in: EJIL 1/2007, S. 37-68; eine progressive Entwicklung hinsichtlich der Stärkung der Position Einzelner befürwortend Amerasinghe, Diplomatic Protection, S. 90.

${ }^{177}$ Vgl. Peters, Jenseits der Menschenrechte, S. 371; Higgins, Problems and Process, S. 53 f.

${ }^{178}$ Siehe Peters, Jenseits der Menschenrechte, S. 372.

${ }^{179} \mathrm{Vgl}$. hierzu Peters, Jenseits der Menschenrechte, S. 372.
} 
Einzelne haben danach selbst keine Rechtserzeugungsmacht, sondern könnten nur Rechte empfangen, so dass ihre Rechtsstellung weitestgehend staatsabhängig ist. ${ }^{180}$ Sie sind Objekte bezüglich des Erwerbs von Rechten und Subjekte zwecks ihrer Ausübung. Es wird betont, dass den Einzelnen Pflichten und Rechte aufgezwungen werden können, und geht so weit, eine verstärkte staatliche Dominanz zu erblicken: „the conferral of rights and obligations on individuals - which is exclusively controlled by states - actually reinforces the dominant position of states in the international legal system" .181

Letztlich muss dennoch festgestellt werden, dass befürwortende Stimmen sich eher verhalten zu einer staatsunabhängigen Völkerrechtspersönlichkeit des Einzelnen bezogen auf gewisse Rechte äußern. McCorquodale vertritt, dass ,each State no longer has complete control over the continuance, development, and interpretation of individuals' rights, and the

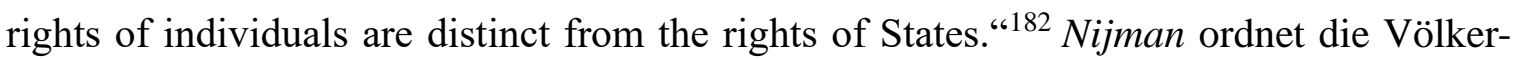
rechtspersönlichkeit als eine kosmopolitische Identität ein und erlaubt sich einen Perspektivenwechsel, dass der Einzelne eine „originary and primary international legal person“ sei ${ }^{183}$, und Portman argumentiert vor allem auf der Pflichtenseite: ,individuals possess personality in international law when international crimes and basic human rights are concerned. By implication, as a matter of fundamental legal principle, individuals are a priori international persons in this limited context. “184 Der Autor sieht die individuelle Völkerrechtspersönlichkeit nicht aufgrund positiven Rechts gegeben, sondern durch Naturrecht. ${ }^{185}$ Wenn man von der Rechtsfähigkeit Einzelner im nationalen Staatenrecht ausgeht, welche in Deutschland gem. $§ 1$ BGB mit der Geburt eintritt, ist die letztgenannte Ansicht, die als auch eine Völkerrechtssubjektivität als Naturrecht anerkennt, grundsätzlich nachvollziehbar. Bedenkt man hingegen den ursprünglichen Geltungszweck des Völkerrechts, nämlich die Schaffung einer rein unter Staaten verbindlichen internationalen Rechtsordnung, überzeugt die Ansicht, dass die Völkerrechtssubjektivität dem Einzelnen erst verliehen werden muss.

\footnotetext{
${ }^{180}$ Siehe Parlett, The Individual in the International Legal System, S. 353, 357 f., 362.

${ }^{181}$ Parlett, The Individual in the International Legal System, S. 352, 359 f., 370.

${ }^{182}$ Mc Corquodale, in: Evans, International Law, S. 284 (286).

${ }^{183}$ Nijman, in: LJIL 1/2007, S. 25 (64).

${ }^{184}$ Siehe Portman, Legal Personality in International Law, S. 272, 273.

${ }^{185}$ Ders.
} 


\section{3. . Internationale Organisationen als Indikatoren?}

Ein Blick auf die internationalen Organisationen könnte möglicherweise helfen, eine etwaige Entwicklung der Beurteilung der Völkerrechtssubjektivität im Verhältnis zwischen Einzelperson und Staat festzustellen.

Lador-Lederer erwog die Subjektivität an die Wahrnehmung internationaler Funktionen zu knüpfen, auch wenn er sich dabei besonders auf NGOs bezogen hat. Die Rechtspersönlichkeit aus der Funktion einer Wirkungseinheit soll insbesondere dann bejaht werden, wenn eine Legislativ-, Exekutiv- oder Judikativfunktion wahrgenommen wird. Andere stellten weitgehend auf die Wahrnehmung einer internationalen Sozialfunktion ab, beispielsweise werde die Internationale Handelskammer so zum Rechtssubjekt. ${ }^{186}$

Andere Stimmen setzen eine eigene Souveränität für die Völkerrechtssubjektivität voraus. Es solle dabei darauf ankommen, ob die entsprechende Wirkungseinheit eine der Staatsgewalt ähnliche Gewalt innehat, also wenn ihre Rechtsordnung autonom ist und sich nicht von einer anderen, insbesondere nicht-staatlichen, Gewalt ableitet. ${ }^{187}$ Wiederum wurde auch vertreten, dass die Inhaberschaft internationaler Organe, die nicht der Staatsautorität unterstehen und Akte im eigenen Namen ausführen, für die Völkerrechtssubjektivität sprechen. Auf einen völkerrechtlichen Vertrag soll es dabei nicht ankommen. Die Rechtssubjektivität wird mehr aus der Staatenpraxis gewohnheitsrechtlich hergeleitet. Diese Herleitung erstreckt sich auch über alle souveränen rechtlichen Gemeinschaften. Der internationalen Handlungsfähigkeit kommt dabei deutlich weniger Bedeutung zu als der souveränen Selbstregierung. Die Bestimmung der Völkerrechtssubjektivität findet demnach, so Hempel, hier über den Vergleich mit Staaten statt. ${ }^{188}$ Er kritisierte die beiden ersten Ansichten darin, dass die Definition der Völkerrechtssubjektivität mit der von Staaten vergleichbar gemacht würde. Diese sei jedoch wesentlich vielschichtiger und neben den Kriterien der Funktion und Souveränität auch weitreichender. Jedoch sei erkennbar, dass eine klare Abgrenzung des Kreises der Völkerrechtssubjekte gar nicht möglich sei. Die benannten Kri-

\footnotetext{
${ }^{186}$ Lador-Lederer, International Non-Governmental Organizations, S. 14, 210, 215; ders., in: ZaöRV 1963, S. 657 (665, 672); vgl. auch Dahlgrün, Funktion und Rechtspersönlichkeit der IHK, S. 246 f.; Imhoof, in: SchwJIR 1989, S. 98 f.

${ }^{187}$ Vgl. Köck, Die völkerrechtliche Stellung des Heiligen Stuhls, S. 32 f.; Himmels, n: FS für Walter Remmers, S. 214.

${ }^{188}$ Seyersted, Objective International Personality of Intergovernmental Organisations, S. 46 f, 91 f., 100.; Hempel, Die Völkerrechtssubjektivität internationaler nichtstaatlicher Organisationen, S. 60.
} 
terien, wie beispielsweise die ausgeübte Funktion, führten zu einer „Grauzone“, da sie einen Ermessensspielraum schüfen. ${ }^{189}$ Eine Vergleichbarkeit zur Rechtspersönlichkeit des Staates lehnen Hempel und Mosler ab. ${ }^{190}$ Einen wichtigen Punkt äußerte Rudolf 1963, dass im staatlichen Bereich aus einer Wertentscheidung heraus die Rechtspersönlichkeit zugesprochen würde, die von Epoche zu Epoche differiere. ${ }^{191}$ Letztendlich wird die Völkerrechtssubjektivität natürlicher Personen weder problematisiert, noch in Unabhängigkeit von Funktionen oder staatsungebundener Souveränität angenommen. Es zeigt sich allein aus der kurzen Darstellung, dass aufgrund von prägenden Ereignissen in der Geschichte die Einstellung und Ansicht von Völkerrechtssubjekten auch im Hinblick auf nichtstaatliche Organisationen schwankt. Portmann vertritt, dass Völkerrecht auch nichtstaatlich erzeugt werden könne, auch wenn er keine Aussage zu dessen Ursprung vornimmt. Er stellt auf rechtliche Prinzipien ab, nach denen sich auch Staaten bei ihrer Rechtsetzung richten. ${ }^{192}$

\section{4. .Alleinige Inhaberschaft der Völkerrechtssubjektivität von Staaten überholt?}

Aus Art. 34 IGH-Statut geht hervor, dass nur Staaten Parteien vor IGH sein können. Manche Stimmen fordern aber auch, dass private Vertragspartner in völkerrechtlichen Verträgen auch als solche anerkannt sein müssten. ${ }^{193}$ Teilweise wird die Anerkennung nur von Staaten als Völkerrechtssubjekte jedoch als nicht mehr zeitgemäß angesehen. Das Individuum sei teilweise Träger von Rechten und Pflichten, auch wenn die Möglichkeit der Durchsetzung fehle. ${ }^{194}$ Der IGH hat 2001 in seiner LaGrand-Entscheidung ausgeführt, dass Individuen auch dort ohne spezielle Erwähnung die Möglichkeit der Geltendmachung ihrer Rechte hätten, wo sie als Vertragsparteien ratifizierend tätig geworden sind. ${ }^{195}$ Auch Bautze stellt anhand der Rechtsprechung heraus, dass Individuen durch das Völkerrecht eigene Rechte

\footnotetext{
${ }^{189}$ Hempel, Die Völkerrechtssubjektivität internationaler nichtstaatlicher Organisationen, S. 60.

${ }^{190} \mathrm{Vgl}$. Hempel, Die Völkerrechtssubjektivität internationaler nichtstaatlicher Organisationen, S. 61; Mosler, in: ZaöRV 1962, S. 1 (21).

${ }^{191}$ Siehe Rudolf, Völkerrecht und deutsches Recht, S. 41; Hempel, Die Völkerrechtssubjektivität internationaler nichtstaatlicher Organisationen, S. 61.

${ }^{192}$ Portmann, Legal Personality in International Law, S. 275.

${ }^{193}$ Vgl. Böckstiegel, Der Staat als Vertragspartner ausländischer Privatunternehmen, S. 184f., 344; vgl. auch Hempel, Die Völkerrechtssubjektivität internationaler nichtstaatlicher Organisationen, S. 66.

${ }^{194} \mathrm{Vgl}$. Dahm/Delbrück/Wolfrum, Band I/2, S. 260.

${ }^{195}$ IGH, Judgement of 27.06.2001, LaGrand Case (Germany v. United States of America), ICJ Reports 2001, S. 466.
} 
zugesprochen werden. ${ }^{196}$ Hempel wiederum vertritt in seinem eigenen Ansatz einer Definition der Völkerrechtssubjekte die Auffassung, dass für die Begründung eines subjektiven Rechts die Durchsetzbarkeit der Rechtsposition eben nicht zwingend erforderlich sei. ${ }^{197} \mathrm{Er}$ hält dazu jedoch ergänzend fest, dass im LaGrand-Fall des IGH nicht die Brüder LaGrand ihre Rechte geltend machen konnten, sondern nur die Heimatstaaten stellvertretend für diese tätig geworden sind. Es bedürfe weiter eines nationalen Gesetzes, durch das der Vertrag ins inländische Recht übernommen wird. ${ }^{198}$ Deutschland hatte damals nicht nur die Verletzung eigener Recht des konsularischen Beistands aus der Wiener Konvention durch die USA beklagt, sondern auch eigene Rechte der Brüder LaGrand, also Individualrechte, welche nur über den diplomatischen Schutz geltend gemacht werden konnten. ${ }^{199}$ Entgegen der Ansicht der USA unterstütze der IGH die deutsche Auffassung, dass die Streitigkeit nicht über die Geltendmachung von Gewohnheitsrecht geführt würde, sondern tatsächliches Konventionsrecht verletzt worden sei. Der Sachverhalt und das Ergebnis des Verfahrens vor dem IGH sowie die Diskussion über dessen Zuständigkeit sind für die vorliegende Arbeit nicht von Bedeutung. Allerdings hat der IGH eine völkerrechtliche Klarstellung über die Völkerrechtssubjektivität natürlicher Personen getroffen, die grundlegend für die spätere Betrachtung der Subjektivierung der allgemeinen Völkerrechtsregeln ist.

Der IGH hat geprüft, ob Art. 36 Abs. 1 (b) der Konvention der betreffenden natürlichen Person ein eigenes, subjektives Recht verleiht. Art. 36 Abs. 1 (b) der Konvention spricht von der Informationspflicht der Behörden des Staates gegenüber dem Betroffenen „über seine Rechte“ und davon, dass konsularischer Beistand dann nicht gewährleistet werde, „wenn $e^{\text {“ }}$ dem ausdrücklich widerspreche. Der IGH leitete aus dem Wortlaut der Norm die Einräumung eigener Recht ab, deren Verletzung die jeweiligen Staaten für die Individuen vertretend geltend machen können. Bedeutend ist dieser Schritt, weil die Konsularrechtskonvention grundsätzlich die konsularischen Beziehungen „zwischen den Staaten“ regelt.

\footnotetext{
${ }^{196}$ Bautze, Völkerrecht, S. 68.

${ }^{197}$ Vgl. Hempel, Die Völkerrechtssubjektivität internationaler nichtstaatlicher Organisationen, S. 66.

${ }^{198}$ Dahm/Delbrück/Wolfrum, Band I/2, S. 263.

${ }^{199}$ Die deutschen Brüder Karl und Walter LaGrand, die 1982 einen Raub mit Todesfolge begingen, wurden zum Tode verurteilt, obwohl ihnen kein konsularischer Beistand nach dem Wiener Übereinkommen über konsularische Beziehungen (1963) gewährt worden war. Die USA vollstreckten später das Todesurteil trotz anfänglicher Kenntnis über die deutsche Staatsangehörigkeit. Die deutsche Regierung versuchte 1999 die Verletzung der Konvention durch den IGH feststellen und entsprechende einstweilige Maßnahmen verhängen zu lassen, um die Hinrichtung aufzuschieben. Der IGH erließ diese und verzichtete auf die mündliche Verhandlung, was trotz der Möglichkeit nach Art. 75 Abs. 1 der Verfahrensordnung erstmalig war. Der IGH machte klar, wenn auch vergeblich, dass die Anordnungen des IGH verbindlich seien.
} 
Die Entscheidung des IGH wurde deshalb auch als „Markstein“ bezeichnet. ${ }^{200}$ Die Konsularrechts-konvention entstammt den 1960er Jahren, in der natürliche Personen eine untergeordnete Rolle spielten und der Menschenrechtsschutz nicht weit fortentwickelt war. ${ }^{201}$ Bereits wenige Jahre später hat bspw. ein französisches ein Schiedsgericht nochmals bestätigt, dass Regeln zum zeitgenössischen Völkerrecht gehörten, nach denen Bestimmungen eines Vertrags subjektive Rechte für Einzelne schaffen können. ${ }^{202}$ Als gedanklicher Einwurf sei anzumerken, dass der bis heute im Wortlaut unveränderte Art. 25 GG deutlich vor dem Wiener Übereinkommen über konsularische Beziehungen, nämlich 1949, formuliert wurde und in Kraft getreten ist, und dass der Wortlaut in Satz 2 ebenso von „Rechten und Pflichten“ der Bewohner des Bundesgebietes spricht.

Der IGH stellte in seiner Entscheidung allein auf den Wortlaut des Art. 36 Abs. 1 (b) der Konvention ab. Dadurch lässt der Gerichtshof Individuen (wenigstens teilweise) die Qualität als Völkerrechtssubjekten zukommen, obwohl die Konvention zum fast ausschließlich auf Staaten bezogenen Völkerrecht gehört. Der Wortlaut ist nach Ansicht des IGH klar und deutlich und wurde deshalb individualrechtsfreundlich ausgelegt. ${ }^{203}$

Die Entscheidung des IGH, natürliche Personen nicht mehr als rechtliches Nullum im Völkerrecht anzusehen, kann nicht ohne Kritik in eine unmittelbare Anwendbarkeit des Art. 25 Satz 2 GG aufgrund des Wortlauts ausgelegt werden. Dass Individuen nun zumindest teilweise als Völkerrechtssubjekte behandelt werden, gibt zumindest keine automatischen Rückschlüsse auf die Auslegung des Normcharakters von Art. 25 Satz 2 GG als generell anwendbares Individualrecht. Sie gibt jedoch ein Indiz in Richtung einer moderneren Sichtweise der innerstaatlichen Bedeutung der allgemeinen Völkerrechtsregeln und spiegelt den Individualisierungsschub in der Rechtspraxis wider.

\footnotetext{
${ }^{200}$ Siehe Oellers-Frahm, in: EuGRZ 11-13/2001, S. 265 (265 f.); Oellers-Frahm, in: Die Rechtsstellung des Menschen im Völkerrecht, S. 21 (21 f.).

${ }^{201}$ Vgl. Oellers-Frahm, in: Die Rechtsstellung des Menschen im Völkerrecht, S. 21 (27).

${ }^{202}$ Schiedsgericht, Francaise vs. UNESCO sur la question du régime fiscal des pensions versées aux fonctionnaires retraités de l'Unesco résidant en France, Schiedsspruch vom 14.01.2003, in: RGDIP 107 (2003), Rn 82.

${ }^{203}$ Vgl. auch Hillgruber, in: JZ 1/2002, S. 94 (96). 


\section{5. . Zwischenergebnis}

Der IGH hat mit seiner Entscheidung den „Rubikon der Individualrechte überschritten“204, und manche sehen in der Entscheidung sowie der Folgerechtsprechung gar Beiträge zu einer „Humanisierung“ des Völkerrechts im Ganzen. ${ }^{205}$ Berücksichtigt man den ursprünglichen Zweck des Völkerrechts, nämlich die Beziehungen zwischen den Staaten zu regeln und auch nur die Staaten unmittelbar zu berechtigen und zu verpflichten, ist jedenfalls der Einordnung der IGH-Entscheidung als absolutes Novum von höchster Rechtsinstanz zuzustimmen.

Nach der LaGrand-Entscheidung mussten sich die deutschen Gerichte aufgrund der internationalen Berücksichtigungspflicht nach dem IGH richten. ${ }^{206}$ Die Neuheit im Konstrukt der Individualrechte zog also auch ins deutsche Recht ein. Aus der anerkannten Rechtsfähigkeit folgt allerdings ebenfalls nicht ein konkretes Recht, dieses muss erst noch verliehen werden. Die Völkerrechtsfähigkeit von Individuen und auch nichtstaatlichen Organisationen, vollumfänglich oder auch beschränkt, sagt somit erst einmal nichts Neues über die reale Rechtsposition aus. Die partielle Völkerrechtsfähigkeit des Einzelnen ist nur ein positives Indiz für die tatsächliche völkerrechtlichen Rechtsstellung Einzelner in Deutschland nach Art. 25 GG, allerdings für die Emanzipation wesentlich.

Es wurde bereits erläutert, dass es einen Individualisierungsschub gibt hinsichtlich der Beurteilung der Rechtsstellung von Individuen im Völkerrecht. Gegen eine Individualisierung des Völkerrechts am Beispiel des diplomatischen Schutzes spricht der politische Charakter dieses Instituts, dass Einzelne immer noch auf Schutz und rechtliche Unterstützung der entsprechenden Heimatstaaten angewiesen sind. Entscheidend ist für die Völkerrechtssubjektivität im Kern, dass Individuen mit Rechten und Pflichten ausgestattet werden. ${ }^{207}$

Es wurde angeführt, dass eine Subjektivierung der bewährten Rechtspositionen überflüssig sei. Begründet wurden die überzeugenden Zweifel damit, dass die ,juristische Fiktion“ aufrechtzuerhalten ist und dass auf internationaler Ebene der diplomatische Schutz lediglich

\footnotetext{
${ }^{204}$ So Milano, in: NYIL 2004, S. 85 (129).

${ }^{205}$ Siehe Mennecke, in: GYIL 2001, S. 430 (468).

${ }^{206}$ BGH, Beschluss vom 07.11.2001, Az. 5 StR 116/01, in: NStZ 2002, 168; Beschluss vom 29.01.2003, Az. 5 StR 475/02, in: NStZ-RR 2004, 5 f.; Beschluss vom 11.04.2007, Az. 5 StR 475/02, in: BGHR StPO $\S$ 24 Abs. 2; Beschluss vom 25.09.2007, Az. 5 StR 116/91, in: NStZ 2007, 159 f.; Beschluss vom 07.06.2011, Az. 4 StR 643/10, in: StV 2011, 603 f.; nachfolgend BVerfG, Beschluss vom 19.09.2006, Az. 2 BvR 2115/01, 2 BvR 2132/01, 2 BvR 348/03, in: NJW 2007, 499 f.; Beschluss vom 08.07.2010, Az. 2 BvR 2485/07, 2 BvR 2513/07, 2 BvR 2548/07, Beschluss vom 05.11.2013, Az. 2 BvR 1579/11, in: NJW 2014, $532 \mathrm{f}$.

${ }^{207}$ Meyer, Der Alien Tort Claims Act, S. 348.
} 
den Respekt eines zwischenstaatlichen Rechts geltend macht. Letztendlich läuft die Durchsetzung eines Rechts nur zwischenstaatlich ab. Der sich im Schrifttum seit längerem abzeichnende Trend bzgl. der Völkerrechtssubjektivität ist zu begrüßen, den Einzelnen im Völkerrecht nicht mehr als Nullum zu sehen und nicht nur pauschal als Adressaten völkerrechtlicher Rechte und Pflichten zu akzeptieren, sondern auch auszustatten. Gerade nach der LaGrand-Entscheidung des IGH ist dies folgerichtig.

\section{Fazit}

Die Beurteilung der Anerkennung einer individuellen Völkerrechtssubjektivität wandelte sich insbesondere in der internationalen Literatur im letzten Jahrhundert abhängig von politischen Konflikten mehrfach.

Ein Überblick über die völkerrechtlichen Teilgebiete hat zeigt, dass Individuen zunehmend internationale Rechte erwerben. Eine neue Betrachtung der aktuellen Rechtslage liegt nicht daran, dass Einzelne nun überhaupt Rechte und Pflichten innehaben können, sondern dass eine quantitative Zunahme beobachtet werden kann. Die genannten Autorenansichten können auf denselben Nenner reduziert werden, dass sie das Individuum als natürliche Person im Völkerrecht auffassen, solange eine staatsunabhängige Fundierung ihrer Völkerrechtspersönlichkeit die standfeste Grundlage hierfür bietet.

Art. 25 GG gliedert über die allgemeinen Völkerrechtsregeln sowohl das Völkergewohnheitsrecht als auch die allgemeinen Rechtsgrundsätze ins deutsche Recht ein, weshalb auch nur diese Rechtsquellen hinsichtlich ihrer Eignung als Rechtsgrundlage betrachtet werden. Die Stimmen der nationalen und internationalen Literatur, die die Völkerrechtspersönlichkeit Einzelner aufgrund des Völkergewohnheitsrechts anerkennen, verkennen allerdings oder sehen nicht als Hindernis an, dass das Element der „Übung“ durch die Rechtsauffassungen der Staaten geprägt werden. Von einer Staatsunmittelbarkeit kann somit nicht die Rede sein, hängt es doch vom staatlichen rechtspolitischen Gutdünken $a b$, ob sich die Rechtsstellung Einzelner hin zu einer Anerkennung der individuellen Völkerrechtspersönlichkeit entwickelt oder nicht.

Anfang des 20. Jahrhunderts wurde allerdings bereits über die Verleihung von völkerrechtlichen Rechten und Pflichten durch den Staat gesprochen. Die Repräsentation seitens der Staaten auf internationaler Ebene ist aus praktischen und systematischen Gründen nur noch eingeschränkt erfolgreich. Dabei kommt den Staaten eine Vormundschaft zu, weil diese 
entweder keine Demokratie vertreten oder außenpolitisch, wirtschaftlich oder fiskalisch mit Einzelinteressen kollidieren.

Hinsichtlich des Ergebnisses der Anerkennung einer Völkerrechtspersönlichkeit Einzelner ist es irrelevant wie der Entstehungsweg bestritten wurde, ob durch Verleihung durch Staaten oder von vornherein durch Naturrecht.

Die beschriebenen Entwicklungen auf internationaler Ebene geben aufschlussreiche Indizien hinsichtlich einer mittlerweile anzuerkennenden Völkerrechtssubjektivität Einzelner, denn Völkerrechtsinhaber können sich womöglich aufgrund ihrer völkerrechtlichen Adressatenstellung auf allgemeine Völkerrechtsregeln i. S. d. Art. 25 Satz 2 GG berufen.

Hat dies nun eine vollumfängliche Adressatenstellung völkerrechtlicher Normen, inklusive Art. 25 GG, der nationalen Bundesbürger vor deutschen Gerichten zur Folge?

Die Rolle natürlicher Personen hat sich im internationalen Rechtsgefüge hin zum partizipierenden Subjekt entwickelt, wenn auch noch nicht vollständig oder abschließend. Dass nun nicht mehr ausschließlich Staaten gebunden und adressiert werden (können), hat zur Folge, dass das Völkerrecht auch über die Staatsgrenzen ins nationale Rechtssystem greift und eine stärkere Bindungswirkung entfaltet. Schmid sprach im Rahmen des Konvents von Herrenchiemsee bereits davon, dass dieses nicht nur eine Rechtssphäre irgendwo dort oben sein, sondern bis nach unten auf den Einzelnen durchgreifen solle. ${ }^{208}$

Fraglich ist jedoch, ob diese (einmal unterstellte) Völkerrechtssubjektivität Einzelner auch einen praktischen Nutzen hätte. Im Fall LaGrand hat sich bereits gezeigt, dass Einzelne zwar Völkerrechtssubjekte sein sollen, allerdings den jeweiligen Herkunftsstaaten im Einzelfall die Geltendmachung der, doch den Einzelnen zustehenden, Konsularrechte zugestanden hätte. ${ }^{209}$ Es darf bereits deshalb kein voreiliger Schluss aus einer (zumindest teilweisen) Völkerrechtssubjektivität Einzelner auf eine neu begründete, umfassende Anspruchsinhaberschaft auf internationaler Ebene gezogen werden. ${ }^{210}$ Die Gesetzgebung steht im Folgen am Beispiel völkerrechtlicher Individualpflichten und spezieller am Beispiel des Völkerstrafrechts auf dem Prüfstand, um zu untersuchen, inwiefern innerhalb Deutschlands eine Völkerrechtssubjektivität Einzelner überhaupt genutzt werden könnte.

\footnotetext{
${ }^{208}$ Siehe dazu bereits in Kapitel $\S 3$.

${ }^{209}$ Vgl. IGH, Judgement of 27.06.2001, LaGrand Case (Germany v. United States of America), ICJ Reports 2001, S. 466.

${ }^{210}$ Für das Fremdenrecht wurden beispielsweise auch Verträge geschlossen, mittels derer Staaten zum Nachteil ihrer Bürger auf deren Rechte verzichtet und eine Geltendmachung ausgeschlossen haben; vgl. dazu Doehring, Fremdenrecht, S. 105.
} 


\section{$\S 4$ Völkerrechtliche Individualpflichten-Art. 25 GG am Beispiel des Völker- strafrechts}

Dieses Kapitel untersucht die Umsetzung völkerrechtlicher Verpflichtungen Deutschlands am konkreten Beispiel des Völkerstrafrechts. Art. 25 Satz 2 GG erklärt auch, dass die allgemeinen Völkerrechtsregeln Pflichten begründen, die für die Bewohner des Bundesgebietes unmittelbar gelten sollen. Um auch diesen einen Platz im Rahmen dieser Untersuchung einzuräumen, wird versucht, die unmittelbare Geltung völkerrechtlicher Pflichten in ein helleres Licht zu rücken und deren Bedeutung für das deutsche Rechtsgefüge zu erläutern, wenigstens aber abzuleiten. Überwiegend ist das Völkerstrafrecht völkervertraglich geregelt, dennoch entspringt es teils dem Völkergewohnheitsrecht, so dass mit der nationalen Implementierung über Art. 25 GG auch das völkergewohnheitsrechtliche Strafrecht Einzug in deutsches Bundesrecht findet. Art. 25 GG gliedert jedoch nicht das Völkervertragsrecht rein. Beinhaltete das Völkergewohnheitsrecht individuelle Rechtsgrundlagen, gehörten diese über Art. 25 GG auch zum deutschen Bundesrecht. Die Betrachtung soll Aufschluss über die Relevanz des Völkergewohnheitsstrafrechts im deutschen Recht und der deutschen Rechtspraxis geben. Die erarbeiteten Ergebnisse sollen Aufschlüsse geben hinsichtlich der tatsächlichen Praxis und etwaigen Bezugnahmen nationalen Rechts auf völkergewohnheitsrechtliche Regeln, die mit der deutschen Gesetzgebung und gerichtlichen Durchsetzbarkeit völkerrechtlicher Normen aufkommen.

\section{Der Einzelne als Adressat völkerrechtlicher Pflichten}

So wie im weiteren Fortgang hinsichtlich der Rechtsstellung Einzelner auf einige Literaturbeispiele zu völkerrechtlichen Individualrechten geschaut wird, wird im Folgenden zunächst im Allgemeinen auf die Völkerrechtspflichten geblickt und zur Vertiefung im nächsten Kapitel auf das Völkerstrafrecht als Spezialfall völkerrechtlicher Pflichten.

Aus der Völkerrechtsfähigkeit leitet sich neben den individuellen Rechten auch die juristische Möglichkeit ab, einzelnen Personen völkerrechtsunmittelbare Pflichten aufzuerlegen. $\mathrm{Zu}$ Beginn sei gleich gesagt, dass trotz der Entwicklungen bei Individualrechten auch die völkerrechtlichen Individualpflichten näher betrachtet werden sollen, um eine umfassende Betrachtung und Bewertung zu ermöglichen. Die Betrachtung der Völkerrechtspflichten 
könnte allerdings ein bedeutendes Indiz zur Beurteilung der allgemeinen Völkerrechtsregeln sein, werden sie doch ebenfalls vom Wortlaut des Art. 25 Satz 2 GG erfasst und für die Bewohner des Bundesgebietes unmittelbar geregelt.

Individualpflichten sind vor allem Unterlassungspflichten, beispielsweise die Pflicht, keinen Völkermord und keine Kriegsverbrechen zu begehen oder militärische Aktivitäten zu unterlassen (beispielsweise Art. I der Völkermordkonvention). Auch Handlungspflichten sind zugehörig, wie etwa zur Mitwirkung an der Bekämpfung des Drogenschmuggels, welche sowohl natürliche, als auch juristische Personen als potentielle Pflichtenträger binden können. ${ }^{211}$ Bei der Existenz von Individualpflichten kommt es nicht auf deren tatsächliche Durchsetzbarkeit auf prozessualer Ebene an. Durchgesetzt werden könnten sie dann jedenfalls vor nationalen und auch internationalen Gerichten. Auch wenn die Existenz der Individualpflichten unabhängig von deren Durchsetzbarkeit ist, ist diese für deren Legitimation von Bedeutung. Je effektiver eine völkerrechtliche Rechtsinstanz eine Pflicht durchsetzen kann, desto wahrscheinlicher wird die reale Beachtung der Individualpflichten, und umso größer ist deren Bedeutung. Die übrigen Völkerrechtssubjekte sind also auch zu Sanktionen unmittelbar gegenüber dem Individuum bei Nichterfüllung völkerrechtlicher Pflichten berechtigt. ${ }^{212}$

Die Staatspflichten anders als Individualpflichten sind eine Selbstbindung, denn die Individualpflichten stammen nicht aus der Hand anderer privater Personen, sondern aus der Hand öffentlicher Autoritäten. Aus diesem Grund sei das Pacta-tertiis-Prinzip nicht zur Erklärung völkerrechtlicher Pflichten heranzuziehen, da dieses die Zustimmung der rechtlich Belasteten sicherstelle. Die Staaten seien jedoch als politische Gebilde kein Selbstzweck, und sie besitzen anstatt eigener Rechte Kompetenzen, die mit den Rechten natürlicher Personen vergleichbar sind. Die Verpflichtung von Individuen müsse gerechtfertigt werden. $^{213}$

Auch die legislative Zuständigkeit ${ }^{214}$ soll kein Prinzip sein, dass die Individualpflichten begründen könnte. Wird dies bejaht, reicht eine Erzeugung von Gewohnheitsrecht zur Entstehung durch Staaten und ohne direkte Mitwirkung der Pflichtenträger. Nach dem Prinzip der legislativen Zuständigkeit und Gebiets- und Personalhoheit hat die Ratifizierung eines

\footnotetext{
${ }^{211}$ Vgl. United Nations Security Council, Statement by the President of the Security Council, UN-Doc. S/PRST/2009/32 vom 08.12.2009, S. 1-2

${ }^{212}$ Peters, Jenseits der Menschenrechte, S. 54, 55.

${ }^{213}$ Peters, Jenseits der Menschenrechte, S. $64 \mathrm{f}$.

${ }^{214}$ Sivakumaran, in: ILCQ 2/2006, S. 369 (381).
} 
Vertrags durch einen Staat zur Folge, dass er dies für alle Individuen seines Herrschaftsbereichs tut. Problematisch dabei ist, dass die Sichtweise die Frage des persönlichen Anwendungsbereichs des Vertragstextes mit seiner Umsetzung in das nationale Recht nicht klar auseinanderhält, es sich dabei jedoch um zwei getrennt zu beurteilende Aspekte handelt. Dabei wird nicht berücksichtigt, ob die gebundenen Staaten auch wirklich die Auffassungen der Bürger auf internationaler Ebene vertreten, also ob sie die Menschen nicht nur formell, sondern auch inhaltlich vertreten. Es liegt nach Ansicht mancher nahe, dass eine mittelbare Verpflichtung der Individuen durch das Völkerrecht nicht ausreicht, um die völkerrechtlichen Regelungsziele zu erreichen. Wie auch bei den Individualrechten besteht das Bedürfnis nach einer Möglichkeit der Ansprache des Einzelnen, um der Gefahr entgegenzutreten, dass Einzelstaaten Völkerrechtsvorschriften nicht oder nicht ordnungsgemäß umsetzen können oder wollen. Globale Güter würden auf diese Weise nicht umfassend geschützt. Individualpflichten aus dem Völkerrecht sind daher zur Schließung von Lücken in der völkerrechtlichen Regulierung erforderlich. ${ }^{215}$

Es ist denkbar, dass eine nur mittelbare Verpflichtung Einzelner durch den Staat nicht ausreicht und durch völkerrechtsunmittelbare Pflichten für Individuen „horizontal“ ergänzt werden muss. Der praktische Nutzen der völkerrechtsunmittelbaren Individualpflicht soll die Legitimationsbedenken zu überwiegen haben, welcher darin besteht, dass eine Individualpflicht entsteht, existiert und durchgesetzt werden kann. Der Nutzen überwiegt die gegenläufigen Erwägungen dann, wenn die entsprechende Pflicht so inhaltlich wichtig ist, dass das Interesse an der zuverlässigen, lückenlosen Erfüllung gesteigert besteht. ${ }^{216}$ Die staatlichen Pflichten müssten zum einen außerordentlich bedeutsam und zum anderen besonders schlecht für eine nur staatliche Durchsetzung nach nationalem Recht sein. Erst dann kann sie als völkerrechtsunmittelbare Individualpflicht anerkannt werden. ${ }^{217}$ Als Beispiel kann das Völkerstrafrecht herangezogen werden. Die Missachtung des Schutzes zentraler Menschenrechte und die Anwendung militärischer Gewalt stellen oft gleichzeitig Straftaten dar. Ist das geschützte Rechtsgut vom Völkerrecht selbst unmittelbar geschützt, ist der Zweck der Norm an den Einzelnen als Unterlassungspflicht unstreitig. Die indivi-

\footnotetext{
${ }^{215}$ Peters, Jenseits der Menschenrechte, S. 68, in diese Richtung auch Knox, Horizontal Rights Law, in: AJIL 1/2008, S. 1 (30).

${ }^{216}$ Peters, Jenseits der Menschenrechte, S. 68, 69; Herdegen, Die Befugnisse des UN-Sicherheitsrates, S. 32 f.

${ }^{217}$ Knox, in: AJIL 1/2008, S. 1 (30).
} 
duelle strafrechtliche Verantwortung sei ungeachtet einer Pseudolegalisierung durch völkerrechtswidriges staatliches Recht anerkannt. ${ }^{218}$ Für den innerstaatlichen Bereich akzeptiert der EGMR, dass ebenso nicht kodifizierte Regeln des „common law“ mögliche Rechtsgrundlagen für staatliche Maßnahmen sein können. ${ }^{219}$ Der EGMR hat beispielsweise für die Erfüllung der Anforderungen der Freiheitsentziehung nach Art. 5 EMRK vorausgesetzt, dass dieser „rechtmäßig“ und nach „der gesetzlich vorgeschriebenen Weise“ erfolgen müsse und hat dazu eine völkerrechtliche Rechtsgrundlage für die Freiheitsentziehung und die damit einhergehende Duldungspflicht ausreichen lassen. ${ }^{220}$ Auch das Statut des Internationalen Strafgerichtshofs drückt aus, dass alle klassischen Rechtsquellen des Völkerrechts nicht nur als Grundlage von Individualpflicht, sondern auch der Individualstrafbarkeit sein können. 221

Im Ergebnis setzen die Anforderungen des Legalitätsprinzips den völkerrechtsunmittelbaren Individualpflichten klare Grenzen. Durch die geforderte Bestimmtheit und Zugänglichkeit einer Norm wird diese vorhersehbar, zudem darf die Pflicht einer Norm nur entnommen werden, wenn der Schutz wichtiger Rechtsgüter erforderlich ist. ${ }^{222}$ Die Einhaltung des Legalitätsprinzips ist allerdings nicht der einzige Eckpfeiler, der beachtet werden muss. Auch die Rechtsgrundlagen der völkerrechtsunmittelbaren Individualpflichten sind zu betrachten. Das Sekundär- und Richterrecht ist für die Untersuchung der Subjektivierung allgemeiner Völkerrechtsregeln uninteressant. Der EGMR hat gewohnheitsrechtliche Normen des Rechts des bewaffneten Konflikts als Rechtsgrundlage einer Unterlassungspflicht gelten und sogar als Grundlage der Strafbarkeit ausreichen lassen. Der Gerichtshof hielt besonders die Strafbarkeit der Kriegsverbrechen einer Partisanengruppe der Roten Armee gegen Bewohner eines lettischen Dorfes im Jahr 1944 allein aus dem Völkerrecht für ausreichend zugänglich und vorhersehbar im Sinne des Art. 7 EMRK. ${ }^{223}$ In einem anderen Fall machte der IGH hinsichtlich eines Sicherheitsratsbeschlusses dennoch klar, dass eine Intention bestehen müsse, eine bestimmte Unterlassungs- oder Handlungspflicht an bestimmte Akteure richten zu wollen: „There is no indication, in the text of Security Council

\footnotetext{
${ }^{218}$ Siehe hierzu bereits Prinzipien II und IV, Formulation of the Nürnberg Principles, Report of the International Law Commission on its Second Session of 05.06.-29.07.1950, ORGA, $5^{\text {th }}$ Session Supplement No. 12 (A/1316), YB ILC 1950 II, S. 374-378; dazu auch Peters, Jenseits der Menschenrechte, S. 70.

${ }^{219}$ EGMR, Judgement of 26.04.1979, Sunday Times vs United Kingdom, Nr. 6538/74, Rn 46-53.

${ }^{220}$ EGMR, Judgement of 29.03.2010, Medvedyev vs Frankreich, Nr. 3394/03, Rn 79, 80.

${ }^{221}$ U. a. Burghart, in: Leibholz/Rinck, Grundgesetz für die Bundesrepublik Deutschland, Art. 25 GG, Rn 63 f.

${ }^{222}$ EGMR, Judgement of 29.03.2010, Medvedyev vs Frankreich, Nr. 3394/03, Rn 49; Judgement of 23.09.1998, Petra vs. Rumänien, Nr. 27273/95, Rn 37.

${ }^{223}$ EGMR (Große Kammer), Judgment of 17.05.2010, Kononov vs Lettland, Nr. 36376/04, Rn 236.
} 
resolution 1244 (1999), that the Security Council intended to impose, beyond that, a specific obligation to act or a prohibition from acting, addressed to such other actors“. Der Anhaltspunkt drückt nach Ansicht des Gerichts aus, dass eine den Umständen nach erkennbare, nicht zwingend präzise Verpflichtung möglich wäre. ${ }^{224}$

Am Beispiel des Kosovo-Konflikts sieht man zugunsten der Unmittelbarkeit völkerrechtlicher Pflichten, dass bewaffnete nicht-staatliche Gruppen im Konflikt direkter Adressat sein müssen, wenn eine Sicherheitsresolution die Friedensschaffung zum Ziel hat. ${ }^{225}$ Es wäre nicht zielführend und unzureichend, forderte der Sicherheitsrat die jeweiligen Staaten nur dazu auf, die militärischen Aktivitäten der Opposition zu beenden und nach dem nationalen Strafrecht zu behandeln. Das Risiko einer Durchsetzungs- und Regulierungslücke ist offensichtlich, so dass die Pflicht zur Auferlegung völkerrechtsunmittelbarer Individualpflichten erfüllt ist. Streitgegenstand des Verfahrens vor dem IGH - wie auch unter anderem im der Untersuchung zugrundeliegenden Verfahren des BVerwG aus 2016 - war das völkerrechtliche und staatengerichtete Gewaltverbot nach Art. 2 Abs. 4 UN-Charta. Am Beispiel dieser Resolutionen zeigt sich, dass der Sicherheitsrat es für ungenügend hielt, sich allein auf deren nationale Umsetzungen zu verlassen. Staaten haben nicht immer die Möglichkeit, ihr eigenes Recht durchzusetzen, wenn sie der Gewalt nichtstaatlicher Akteure ausgesetzt sind. Nach Herdegen legen Sicherheitsratsresolutionen den Akteuren keine neuen Rechtspflichten auf, sondern setzen vertraglich und gewohnheitsrechtlich begründete Pflichten durch. ${ }^{226}$ Das normale völkerrechtliche Regulierungsschema besteht aus der indirekten Verpflichtung von Individuen durch völkerrechtliche Staatspflichten zum Erlass staatlicher Ge- und Verbote, die wiederum private Akteure ansprechen. Die völkerrechtsunmittelbaren Pflichten sollen nur anerkannt werden, wenn es einen tatsächlichen Regulierungsbedarf gibt und das Legalitätsprinzip eingehalten wird. Sind diese Bedingungen erfüllt, sollen Individualpflichten unter anderem auch durch Völkergewohnheitsrecht und allgemeine Rechtsgrundsätze, also durch allgemeine Völkerrechtsregeln, etabliert werden. ${ }^{227}$

\footnotetext{
${ }^{224} \mathrm{IGH}$, Advisory Opinion of 22.07.2010, Accordance with International Law of the Unilateral Declaration of Independence in Respect of Kosovo, ICJ Reports 2010, S. 403.

${ }^{225}$ Ders.; vgl. auch Peters, Jenseits der Menschenrechte, S. $87 \mathrm{f}$.

${ }^{226} \mathrm{Vgl}$. Herdegen, Befugnisse des UN-Sicherheitsrats, S. 32.

${ }^{227} \mathrm{Vgl}$. Herdegen, Befugnisse des UN-Sicherheitsrats, S. 32.
} 


\section{Die völkerrechtliche Verantwortlichkeit}

Die internationale völkerrechtliche Verantwortung von Individuen ist laut Tomuschat, entgegen der von Staaten und internationalen Organisationen, noch nicht abschließend anerkannt. Einzelne Personen können sich auf andere Weise als Staaten völkerrechtlich verantwortlich machen und auf der Sekundärebene verantwortlich sein. ${ }^{228}$ Tomuschats Ausführungen sind jedoch nicht exklusiv für staatliche Bedienstete. Die individuelle völkerrechtliche Strafbarkeit einzelner Personen ist als völkergewohnheitsrechtliches Prinzip anerkannt. Gut etabliert ist dabei das Völkerstrafrecht. Es wird angenommen, dass es eine über die völkerstrafrechtliche Verpflichtung hinausgehende Fähigkeit gebe, völkerrechtlich verantwortlich gemacht werden zu können. ${ }^{229}$ Die Entwicklung der individuellen Verantwortlichkeit habe von Nürnberg bis Den Haag mit Art. 25 Abs. 1 und 2 IStGH-Statut ihren Abschluss gefunden. ${ }^{230}$ Die individuelle völkerrechtliche Verantwortlichkeit ist systematisch und funktional gesehen zwingend. ${ }^{231}$ Als Argument kann die Deliktsfähigkeit Einzelner herangezogen werden. Die Rechtspraxis erkennt individualgerichtete Primärpflichten als Rechtspflichten an, dies impliziert gleichzeitig die individuelle Fähigkeit, völkerrechtlich verantwortlich sein zu können ${ }^{232}$, und auch in der Literatur werden Individualpflichten hinsichtlich ihrer innewohnenden Sekundärpflicht in „strafrechtliche“ und ,zivilrechtliche“ Pflichten unterteilt. ${ }^{233}$ Jede Völkerrechtsverletzung lässt sich auf das Verhalten von Individuen zurückführen. Das Völkerstrafrecht schützt auch vor einer Strafentziehung staatlicher Organe durch Immunität oder staatlicher Souveränität. Die Immunität von Diplomaten ist völkervertraglich geregelt, aber auch Staatsoberhäupter und sonstige Regierungsmitglieder sind erfasst, die ihre Staaten im Ausland repräsentieren. Die Wichtigkeit des Schutzes einzelner Personen unterstreicht ebenfalls ein Heranrücken an die staatliche Relevanz im Völkerrecht. Ihnen kommt auf internationalem Parkett eine gefestigte Rechtsstellung zu. Eine Strafverfolgung vor nationalen Gerichten soll jeweils nach Ende der

\footnotetext{
${ }^{228}$ Tomuschat, in: The Law of International Responsibility, S. 317 (320).

${ }^{229}$ Hecker, Europäisches Strafrecht, § 2 Rn 82; Ambos, Internationales Strafrecht, § 5 Rn 1; Satzger, Internationales Strafrecht, § $12 \mathrm{Rn} 1$.

${ }^{230} \mathrm{Ambos}$, Internationales Strafrecht, § $10 \mathrm{Rn} 10$.

${ }^{231}$ Peters, Jenseits der Menschenrechte, S. 103.

${ }^{232}$ Vgl. für die Deliktsfähigkeit Dörr, in: JZ 60/2005, S. 905 (913 f.); Hecker, Europäisches Strafrecht, § 10 Rn 102

${ }^{233}$ Zum Beispiel Clapham, in: EJIL 1/2010, S. 25-30; Crawford, in: The Law of International Responsibility, S. 17 (19).
} 
Amtszeiten möglich sein - was jedoch nicht kritiklos ist -, davor schützt jedoch auch keine funktionelle Immunität. ${ }^{234}$

Es wird argumentiert, völkerrechtliche Verbrechen seien stets individuelle Verbrechen, so dass sie nicht als hoheitliche Handlungen den Staaten zugerechnet werden können. Andere wiederum sehen in der Strafverfolgung eine völkergewohnheitsrechtliche Ausnahme der individuellen Immunität. ${ }^{235}$

Das völkerrechtliche Deliktsrecht begründet allein für Völkerrechtssubjekte die schuldunabhängige Verantwortlichkeit für die Völkerrechtsverstöße, die ihnen zugerechnet werden können. Der völkerrechtlich Verantwortliche muss dann den völkerrechtskonformen Zustand wiederherstellen. ${ }^{236}$ Das Völkerstrafrecht konstituiert hingegen die individuelle strafrechtliche Verantwortlichkeit des unmittelbar handelnden Täters für ein völkerrechtliches Verbrechen. In der Völkerrechtswissenschaft wird das Modell der individuellen Zurechnung kritischer gesehen. Aufgrund unterschiedlicher Strafrechtskonzeptionen unterscheidet sich die Zurechnung eines bestimmten Geschehens bei der völkerstrafrechtlichen Makrokriminalität schwieriger als bei der innerstaatlichen Allgemeinkriminalität. Auch stehen die Taten in einem Gesamtzusammenhang, welcher die Isolierung der zurechenbaren Anteile einer Tat erschwert. ${ }^{237}$ Unterschiedliche Ansätze gibt es bezüglich möglicher Zurechnungsmodelle. Zum einen kann die altbekannte individuelle Zurechnung zur Person um das kollektive Element der Zurechnung zur kriminellen Organisation ergänzt werden mit normativer Überbrückung des individualistischen Kausalitätserfordernisses. ${ }^{238}$ Andererseits wird auch eine doppelte Zurechnung vertreten, in der die beiden vorgenannten Zurechnungen nebeneinanderstehen, jedoch nicht ohne in Verbindung miteinander zu stehen. Kollektiviert betrachtet der Ansatz die Gesamttat aller Beteiligten, und einzelne Teile des Ganzen werden einzelnen Beteiligten zugerechnet. In welcher Reihenfolge dies geschieht soll dabei

\footnotetext{
${ }^{234}$ Peters, Jenseits der Menschenrechte, S. 103.

${ }^{235} \mathrm{UK}$ House of Lords, Opinions of the Lords of Appeal for Judgement in the Cause Bartle, Evans and Others, and the Commissioner of Police for the Metropolis and Others vs. Ex Parte Pinochet, Az. [2000] 1 AC 147, [1999] 2 ALL ER 97, [1999] 2 WLR 827, [1999] UKHL 17, from 24.3.1999; dazu Sands, in: LJIL 1/2003, 37 (45 f.); Akande/Shah, EJIL 4/2010, 815 (828); Kreicker, ZIS 4/2012, 107 (117 f.); Näheres zur Immunität in: Ambos, Internationales Strafrecht, § 7 Rn. 101 f.; in dieselbe Richtung einer Ausnahme der Immunität auch Hecker, Europäisches Strafrecht, § 10 Rn 82

${ }^{236}$ Dörr, in: Ipsen, Völkerrecht, § 29 Rn. 2, 4 f.

${ }^{237}$ Ambos, Internationales Strafrecht, § $10 \mathrm{Rn} 11$.

${ }^{238}$ So u. a. Bock, in: ZIS 7-8/2017, S. 410 (425 f.).
} 
vom Einzelfall abhängen. ${ }^{239}$ Anders als im nationalen Strafrecht bezieht sich die völkerstrafrechtliche Zurechnung immer auch auf die Organisation oder das gesamte System. ${ }^{240}$ Es zeigt sich, dass eine individuelle Zurechenbarkeit auf völkerstrafrechtlicher Ebene vorliegt, jedoch die Auffassungen über die inhaltliche Gestaltung und vor allem praktische Umsetzung divergieren.

\section{Der IStGH als alleiniger Chefankläger}

Das IStGH-Statut sieht bislang nur die Strafbarkeit natürlicher Personen vor (Art. 25 Abs. 1 IStGH-Statut), ein Vorschlag Frankreichs zur Heranziehung juristischer Personen des Privatrechts und Personenvereinigungen hat sich nicht durchsetzen können. ${ }^{241}$ Das Individuum wird also, gemessen am jeweiligen Schuld- und Strafausspruch, deutlich in seiner Verantwortlichkeit ernst genommen und unmittelbar am Völkerrecht gemessen.

Der IStGH untersucht nicht ausschließlich vereinzelte oder mehrere bestimmte Fälle, sondern bezieht sich auf Situationen, sogenannte „trigger mechanisms“. Darunter ist die Gesamtheit aller rechtlichen und tatsächlichen Geschehnisse eines Landes zu verstehen, die für denjenigen, der dem IStGH eine Situation vorlegt, einen Verdacht begründen, dass Verbrechen nach IStGH-Statut begangen worden sind. ${ }^{242}$ Der IStGH kann als Chefankläger auch selbst nach Art. 13 c), 15 Abs. 1 IStGH-Statut „von Amts wegen“ Untersuchungen beginnen. Schließlich kann der UN-Sicherheitsrat einen Beschluss gem. Kapitel VII der UN-Charta dem Gerichtshof betreffend eine bestimmte Situation vorlegen, vgl. Art. 13 b) IStGH-Statut.

Der gewünschte präventive Effekt der Einrichtung eines solchen Gerichts ${ }^{243}$ setzt weiter dessen Effektivität voraus. Zu berücksichtigen ist, dass der IStGH auf die Mitwirkung der

\footnotetext{
${ }^{239}$ Werle/Jeßberger, Völkerstrafrecht, S. 467 Rn 466; zur doppelten Zurechnung ebenso auch Bock, in: ZIS 7-8/2017, S. 410 (424 f.).

${ }^{240}$ Ambos, Internationales Strafrecht, § 7 Rn 12.

${ }^{241}$ Vgl. u. a. Ambos, Internationales Strafrecht, § 7 Rn 10

Auf europäischer Ebene steht der Erlass eines Unternehmensstrafrechts bevor, welches die Strafbarkeit im europäischen Recht erweitert, für die Pläne eines Unternehmensstrafrechts auf nationaler Ebene siehe https://www.handelsblatt.com/politik/deutschland/unternehmenssanktionen-bundesjustizministeriumplant-mehr-arbeitnehmerschutz/24463366.html?ticket=ST-1757917-azVH24x5YZD1Hfa5JBYf-ap4. Das Bundesministerium der Justiz und für Verbraucherschutz hat mit Bearbeitungsstand vom 16.06.2020 ein Gesetz zur Stärkung der Integrität der Wirtschaft bereits entworfen.

${ }^{242}$ Satzger, Internationales und Europäisches Strafrecht, § 14 Rn 12; zu den verschiedenen Mechanismen, die ein Verfahren auslösen können, vgl. Ambos, Internationales Strafrecht, § 8 Rn 7, 20 f; Werle/Jeßberger, Völkerstrafrecht, S. 310 Rn 310.

${ }^{243}$ Vgl. Absatz 5 der Präambel des IStGH-Statuts.
} 
Staaten angewiesen ist, beispielsweise beim Vollzug von Haftbefehlen, bei der Zulassung von Ermittlungen vor Ort oder bei der Vorlage von Beweismitteln. Delikat ist dabei, dass der IStGH zur Vollstreckung der Strafe gerade auf die Zusammenarbeit derjenigen Staaten angewiesen ist, die unfähig oder unwillig sind, die Strafverfolgung selbst voranzutreiben. Für diese Fälle eröffnet das Komplementaritätsprinzip die Zuständigkeit des IStGH. ${ }^{244} \mathrm{Im}$ IStGH-Statut ist die vorrangige Gerichtsbarkeit nationaler Strafgerichte vor der des IStGH festgelegt. Danach ist es dem IStGH möglich, seine Gerichtsbarkeit auch bei Vorliegen schwerster Verbrechen nicht auszuüben, wenn ein nationales Strafverfahren stattgefunden hat oder stattfindet. Dieser Grundsatz kennt jedoch zwei wichtige Ausnahmen: trotz des vorrangigen nationalen Strafverfahrens darf der IStGH seine Gerichtsbarkeit ausüben, wenn der betroffene Staat nach Art. 17 IStGH-Statut „nicht willens oder nicht in der Lage“ ist, die Strafverfolgung ernsthaft zu betreiben.

Es werden folgend vornehmlich speziell die Umsetzung des Völkerstrafrechts in Deutschland und die deutsche Gerichtsbarkeit genauer betrachtet. Die moderne Praxis hat gezeigt, dass den allgemeinen Rechtsgrundsätzen immer weniger Relevanz beigemessen wird. Dies liegt an dem dichteren Netz aus Völkervertragsrecht, welches überwiegend das Völkerstrafrecht regelt, und auch dem Völkergewohnheitsrecht. ${ }^{245}$ Es zeigt sich, dass eher international- und national-rechtliche Alternativen geschaffen werden, welche konkreter formuliert und für die jeweils zustimmenden Beteiligten in ihrer Anwendung verbindlicher sind, als dass unkonkrete und praktisch schwierig zu beurteilende allgemeine Rechtsgrundsätze herangezogen werden. Im Völkerstrafrecht erlangen die allgemeinen Rechtsgrundsätze jedoch höhere Bedeutung, insbesondere bezüglich des allgemeinen Teils, wobei die Grenzen zum Völkergewohnheitsrecht verschwimmen. ${ }^{246}$ Zum Völkergewohnheitsrecht zählen in Teilen auch die Statuten des Tokioter Militärgerichtshofs und der Ad-hoc-Gerichtshöfe ICTY und ICTR, denn bei diesen handelt es sich nicht um völkerrechtliche Verträge. ${ }^{247}$ Art. 67 des IStGH-Statuts gewährt den Angeklagten eigene Rechte während des Verfahrens. Dabei handelt es sich um Prozessmaxime wie beispielsweise das Recht auf ein Urteil ohne

\footnotetext{
${ }^{244}$ Satzger, Internationales und Europäisches Strafrecht, § 14 Rn 39; Hecker, Europäisches Strafrecht, § 2 Rn 87.

${ }^{245}$ Vgl. Frau, in: Ipsen, Völkerrecht, § 35 Rn 1.

${ }^{246}$ Vgl. Werle/Jeßberger, Völkerstrafrecht, S. 185 Rn. 184.

${ }^{247}$ Repräsentativ ICTY, Appeals Chamber Judgement of 29.10.1997, Prosecutor vs. Blaskic, Case No. IT-9514, Rn 41; Judgement of 15.07.1999, Prosecutor vs. Tadic, Case No. IT-94-1AR108, Decision on the Defence Motion for Interlocutory Appeal on Jurisdiction, Rn 295; ICTR, Judgement of 18.07.1997, Prosecutor v. Kanyabashi, Case N. ICTR-96-15-T, Decision on the Defence Motion on Jurisdiction; vgl. auch Ambos, Internationales Strafrecht, $\S 8$ RN 1 f., 19 f.
} 
unangemessene Verzögerung (Abs. 1 c)), das Recht auf anwaltliche Vertretung (Abs. 1 d)), oder das Zeugnisverweigerungsrecht (Abs. $1 \mathrm{~g}$ )). Vergleichbare Rechte wurden durch die Statuten des ICTY (Art. 21) und ICTR (Art. 20) geregelt. Vergleichbar sind diese Rechte mit den Grundsätzen der deutschen Strafprozessordnung (Beschleunigungsgebot nach $\S \S$ 121, 229 StPO, anwaltliche Vertretung $§ § 137$ f., 387 StPO und das Zeugnisverweigerungsrecht nach $\S \S 52$ f. StPO). Mögliche Verletzungen der Rechte des Angeklagten des IStGHStatuts werden durch die Rechtsbeistände gerügt. Diese Rechte beschränken sich jedoch ausschließlich auf das Verfahren vor dem IStGH und drücken keine besondere Rechtsstellung natürlicher Personen im Völkerstrafprozess aus. Die Regelungen des Statuts weisen deutlich auf, dass eine natürliche Person im Verfahren vor dem IStGH entweder die Rolle des Opfers oder des Angeklagten einnimmt, nicht jedoch die des Berechtigten. Eine Frage nach Umfang und Grenzen einer Klagebefugnis stellt sich hier nicht, da es nicht möglich ist, eine Situation vor dem IStGH beispielsweise seitens eines Opfers vorzulegen. Nach Art. 68 Abs. 3 IStGH-Statut kommt den Opfern von Völkerrechtsverbrechen im Rahmen der Verfahren vor dem IStGH mehr als nur die Rolle des Zeugen zu. Es ist in jeder Phase des Verfahrens möglich, dass sie ihre „Sichtweisen und Belange“ einbringen, sofern die Kanzlei dem Antrag auf Zulassung als Opfer im Prozess zugestimmt wurde. Opfern ist es möglich, sich von einem eigenen Anwalt vertreten zu lassen. ${ }^{248}$ So bleibt der IStGH jedoch ein Gericht „über“ den Einzelnen, nicht „für“ den Einzelnen. Das Einbringen von „Sichtweisen und Belangen“" wird den Opfern seitens der Kanzlei gewährt, sie haben also keine anfängliche individuelle Berechtigung im Prozess. Die Prozessstellung wird erst nachträglich erzeugt.

\section{Völkerrechtsunmittelbare Strafbarkeit denkbar?}

Hinsichtlich eines direkten Rückgriffs auf das Völkerrecht als Rechtsgrundlage einer konkreten Strafe und der Strafandrohung hat das Sondertribunal für den Libanon festgestellt: „,as a general rule, international norms criminalising conduct are 'non-self-executing', for their implementation requires national legislation defining the crime and the relevant penalty“'249. Das Tribunal entschied sich also gegen die unmittelbare Geltung, aber für die

\footnotetext{
${ }^{248}$ Satzger, Internationales und Europäisches Strafrecht, § 14 Rn 35.

${ }^{249}$ Special Tribunal for Lebanon, Appeals Chamber, Judgement of 16.02.2011, Interlocutory Decision on the Applicable Law, Case No. STL-11-01/1, Rn 76.
} 
nationale Anwendbarkeit und Ausgestaltung durch die Gerichte. Die Verbotsdurchsetzung vollziehen somit internationale und auch staatliche Instanzen. Unterschieden werden von der möglichen individuellen Pflichtenstellung muss aber die rechtliche Frage der Durchsetzbarkeit. Besonders die Existenz völkerrechtsunmittelbarer Pflichten soll, unerheblich der Verfügbarkeit internationaler Durchsetzungsinstanzen, Bestand haben. ${ }^{250}$

Das Völkerrecht ist als Rechtsgrundlage einer individuellen strafrechtlichen Verantwortung laut vereinzelter Stimmen des allgemeinen Völkerrechts denkbar und sollte nicht kategorisch ausgeschlossen werden. Es sei nicht anzunehmen, dass lediglich die Staaten dazu animiert werden, staatliche Strafnormen zu erlassen und die Durchsetzung der Befolgung den staatlichen Instanzen zu überlassen. ${ }^{251}$ Vielfach wird die Gegenauffassung vertreten, dass völkerrechtliche Regeln wie die Genfer Konvention nicht durch staatliche Gerichte angewendet werden und insbesondere keine Rechtsgrundlage für Strafurteile sein können. Stattdessen müsse eine konkretisierte innerstaatliche Strafnorm vorliegen und eine Unterlassungspflicht anordnen, gegen die verstoßen werden müsste. ${ }^{252}$ Als Quelle einer prinzipiellen völkerrechtsunmittelbaren Straffähigkeit wird in der Literatur das Völkergewohnheitsrecht diskutiert. Portman formulierte dazu, dass ,there is a rebuttable presumption that individuals possess personality in international law when international crimes and basic human rights are concerned. [...]. It follows that there is no need to separately establish whether international crimes bind individual human beings: they automatically do so on the basis of legal principle [...] indicating so“. Seiner Meinung nach ist dies ,just a matter of them being individual human beings and as such under an obligation to respect fundamental international norms". 253

Die Konsequenz der Fundierung einer völkerrechtlichen Strafbarkeit des Individuums im allgemeinen Völkerrecht ist die fehlende Reversibilität durch einzelne Staaten. Folgt man den benannten Ansichten und erkennt eine generelle Strafbarkeit Einzelner aus dem Völkergewohnheitsrecht an, gehörten die entsprechenden Rechtsgrundlagen auch zu den allgemeinen Völkerrechtsregeln, die Art. 25 GG ins deutsche Bundesrecht aufnimmt. Dies ist

\footnotetext{
${ }^{250}$ Bleckmann, Völkerrecht, S. 46; Kempen/Hillgruber, Völkerrecht, § 59 Rn 1.

${ }^{251} \mathrm{Vgl}$. Peters, Jenseits der Menschenrechte, S. 112.

${ }^{252}$ So u. a. Hecker, Europäisches Strafrecht, § 2 Rn 2; Berber, Lehrbuch des Völkerrechts, S. 242-244; Bothe, in: Swinarski, Studies and Essays on International Humanitarian Law and Red Cross Principles in Honour of Jean Pictet, S. 301 (302); zweifelnd allerdings auch Randelzhofer, in: Randelzhofer/Tomuschat, State Responsibility and the Individual, S. 231 (241).

${ }^{253}$ Roland Portman, Legal Personality in International Law, S. 273; auch Parlett, The individual in the international legal system, S. 258.
} 
deshalb zu begrüßen, da es weltweit einen einheitlichen Standard schafft, an dem Individuen in (völker-)strafrechtlicher Sicht gemessen werden können und müssen, ohne dass es auf die Anerkennung einzelner Staaten abhinge In der weiteren Bearbeitung wird der These nachgegangen, dass sich das Völkerrecht, insbesondere das Völkergewohnheitsrecht, als unmittelbare Rechtsgrundlage in Deutschland nicht durchgesetzt hat, sondern in speziellen Fällen einfach-gesetzlich konkretisiert worden sind.

Näher betrachtet wird im Folgenden der Bestimmtheitsgrundsatz des deutschen Rechts gem. Art. 103 Abs. 2 GG, an dem internationale Rechtsquellen gemessen werden müssen.

\section{Der Nullum-Crimen-Grundsatz als Hindernis praktischer Anwendung}

Im Sinne des Art. 15 Abs. 2 des Internationalen Pakts über bürgerliche und politische Rechte und des Art. 7 Abs. 2 EMRK sind das Völkergewohnheitsrecht und die allgemeinen Rechtsgrundsätze als ,allgemeine Regeln“ unmittelbare Quellen der Individualstrafbarkeit. $^{254}$

Die staatlichen Gerichte müssen jedoch bei der Anwendung des Völkergewohnheitsrechts und der allgemein anerkannten Rechtsgrundsätze das Nullum-Crimen-Prinzip (kein Verbrechen ohne Gesetz) ${ }^{255}$ bewahren. ${ }^{256}$ Dieses ist eine Ausprägung des Rechtsstaatsprinzips, das BVerfG verbietet die Aushebelung eines ,strengen Parlamentsvorbehalts“. ${ }^{257}$ Dies ist auch ein Konflikt zwischen Völkerrecht und nationalem Verfassungsrecht. Deutsche Gerichte befanden sich beispielsweise im Rahmen der Mauerschützenprozesse in diesem Konflikt. ${ }^{258}$ Art. 103 Abs. 2 GG fordert, dass eine Tat nur bestraft werden kann, wenn diese

\footnotetext{
${ }^{254}$ Art. 21 Abs. 1 IStGH-Statut wendet nach lit. b) an: „Grundsätze und Regeln des Völkerrechts“ und nach lit. c) dann wieder: ,,allgemeine Rechtsgrundsätze, die der Gerichtshof [...] abgeleitet hat.“

${ }^{255} \mathrm{Vgl}$. Wessels/Beulke/Satzger, Strafrecht AT, S. 20, Rn. 72 f.; Rengier, Strafrecht AT, Rn. 26 f.

${ }^{256}$ Die Bundesrepublik Deutschland hat im Jahr 2001 ihren bei der Ratifikation zu Art. 7 Abs. 2 EMRK vorgebrachten Vorbehalt zurückgezogen, wonach die Anwendung der Konvention nur in den Grenzen des Art. 103 Abs. 2 GG geschehen werde. Da die allgemeinen Rechtsgrundsätze und das Völkergewohnheitsrecht jedoch die Bestrafungen nur erlauben, jedoch nicht vorschreiben, bedeutet dies jedoch nicht, dass eine Bestrafung nach den allgemeinen Völkerrechtsregeln nun möglich sei, vgl.: Innerstaatliche Umsetzung von Menschenrechtsstandards, Antwort der Bundesregierung, BT-Drs. 14/3892, vom 14.07.2000, S. $2 \mathrm{f}$.

${ }^{257}$ BVerfGE 95, 96 (130, 131); 78, 374 (382). Ebenso sehen es hinsichtlich der unmittelbaren Übernahme völkergewohnheitsrechtlicher Regeln ins nationale Recht durch Art. 25 GG, ohne dass auf den Gesetzesvorbehalt verzichtet würde Steinberger, in: HdStR Bd. 7, § 173, Rn 68; Herdegen, in: Maunz/Düring, Art. 25 GG, Rn 87; Rojahn, in: v. Münch/Kunig, Art. 25 GG, Rn 28; Kunig, in: Vitzthum/Proelß, Völkerrecht, S. 128 Rn 183; Streinz, in: Sachs, Art. 25 GG, Rn 6.

${ }^{258}$ Unter anderem in BVerfGE 95, 96 (132 f.); BVerfG, Kammerbeschluss vom 12.07.1995, Az. 2 BvR 1130/95, in: NStZ 10/1995, S. 490 (Leitsatz und Gründe), Rn 14 nach juris.
} 
gesetzlich vor der Tatbegehung bestimmt war. Fraglich ist damit, ob es dem Bestimmtheitsgrundsatz widerspräche, wegen Zuwiderhandlungen gegen allgemeine Völkerrechtsregeln eine Sanktion verhängen zu wollen. ${ }^{259}$ Dieser Vorbehalt darf weder durch Art. 25 GG umgangen werden ${ }^{260}$ noch dürfen Lücken des nationalen Strafrechts durch Rückgriff auf das Völkergewohnheitsrecht geschlossen werden. Art. 103 Abs. 2 steht einer „Internationalisierung des deutschen Strafrechts durch die Hintertür des Art. 25 GG entgegen“. ${ }^{261}$

Satzger schreibt, dass eine Entwicklung des Völkerstrafrechts ohne das Völkergewohnheitsrecht nicht möglich gewesen sei, so dass das Gesetzlichkeitsprinzip des Art. 103 Abs. 2 GG nur eingeschränkt gelten könne. ${ }^{262}$ Peters ist der Meinung, dass die Strafbarkeit der Kernverbrechen wie Völkermord, Kriegsverbrechen und solche gegen die Menschlichkeit direkt aus dem Völkergewohnheitsrecht fließen und somit eine völkerrechtsunmittelbare Strafbarkeit des Einzelnen begründet. ${ }^{263}$ Dafür sprächen die entsprechenden Abkommen wie beispielsweise die Präambel des Rom-Statuts. Dort werden die Kernverbrechen als „schwerste Verbrechen, welche die internationale Gemeinschaft als Ganzes berühren“, und als ,,internationale Verbrechen“ bezeichnet. Art. I der Völkermordkonvention von $1948^{264}$ besagt: „Die vertragsschließenden Parteien bestätigen, dass Völkermord, ob im Frieden oder im Krieg begangen, ein Verbrechen gemäß internationalen Rechts ist, zu dessen Verhütung und Bestrafung sie sich verpflichten." Nach dem Gesetzlichkeitsprinzip aus Art.103 Abs. 2 GG sind die allgemeinen Völkerrechtsregeln allerdings ungeeignet als konkrete Rechtsgrundlagen, verglichen zu vertraglich festgesetzten Regeln, da diese identifizierbarer und dadurch vorhersehbarer sind. Das Gesetzlichkeitsprinzip entfaltet somit nicht nur eine beschränkende Wirkung zulasten des Staates hinsichtlich unbestimmter Rechtsgrundlagen, sondern auch eine individualschützende Sperre gegen die umfängliche Geltung unspezifischen Völkergewohnheitsrechts.

\footnotetext{
${ }^{259}$ Diese Frage warf auch Tomuschat auf, in: HdStR Bd. 7, § 172 Rn 16.

${ }^{260}$ Vgl. Tomuschat, in: HdStR Bd. 7, § 172 Rn 16; auch Kunig, in: Vitzthum/Proelß, Völkerrecht, S.118 f. Rn 153; Rojahn, in: v. Münch/Kunig, Art. 25 GG, Rn 29, 45.

${ }^{261}$ Siehe Talmon, in: JZ 1/2013, S. 12 (19); vgl. dazu auch Kolb/Neumann/Salomon, in: ZaöRV 2011, S. 191 (211 f.).

Hier sind hingegen Art. 7 Abs. 2 EMRK und Art. 15 Abs. 2 des Internationalen Pakts über bürgerliche und politische Rechte als Teilausnahme zu beachten, wonach allgemeine Völkerrechtsregeln dennoch als Strafbarkeitsgrundlage herangezogen werden können.

${ }^{262}$ Satzger, Internationales und Europäisches Strafrecht, § 12 Rn 6.

${ }^{263} \mathrm{Vgl}$. Peters, Jenseits der Menschenrechte, S. 135.

${ }^{264}$ UN Doc. A/RES/3/260 (1948), auch BGB1. 1954 II S. 729.
} 
Eine spezifische völkerrechtsunmittelbare Strafbarkeit könnte danach, unter Beachtung des Nullum-Crimen-Prinzips, möglicherweise aus dem Völkergewohnheitsrecht und aus allgemeinen Rechtsgrundsätzen abgeleitet werden, wobei der Konkretisierung der konkreten Straftatbestände durch Richterrecht eine erhebliche Relevanz hinsichtlich Praxis und Legitimation zukommt. Art. 22 Abs. 3 des IStGH-Statuts gibt diese Möglichkeit theoretisch ebenfalls auf, da die Vorschrift eine völkerrechtliche Strafbarkeit, die auf Völkergewohnheitsrecht und allgemeinen Rechtsgrundsätzen beruht, unberührt lässt. Dies hat sich in der bisherigen und auch neueren Rechtsprechung jedoch schwieriger gestaltet. Der IStGH kann diese ungeschriebenen Tatbestände eben nicht anwenden, die diese dem IStGH-Statut gegenüber subsidiär sind, vgl. Art. 22 Abs. 1 IStGH-Statut. ${ }^{265}$ Mit Erlass des IStGH-Statuts und auch der nationalen Umsetzung, welche unter dem Folgepunkt noch deutlich näher betrachtet wird, erübrigt sich die Frage der unmittelbaren Geltung allgemeiner Völkerrechtsregeln als Rechtsgrundlage völkerstrafrechtlicher Verfahren jedenfalls für die Zuständigkeit des IStGH. Die Völkerrechtswissenschaft steht einer Bestrafung auf der Grundlage ungeschriebenen Völkerrechts auf europäischer Ebene (nulla poena sine lege scripta) jedoch auch offen gegenüber. So soll das Gesetzlichkeitsprinzip nach Art. 7 EMRK nicht entgegenstehen, sondern nur eine „Straftat nach nationalem oder internationalem Recht" unabhängig der Kodifikation verlangen. Eine Bestrafung aufgrund strafrechtlichen Gewohnheitsrechts ist somit nicht mit Art. 7 Abs. 1 EMRK unvereinbar. ${ }^{266}$

Ambos betont für das deutsche Strafrecht, dass das Gesetzlichkeitsprinzip der EMRK in seiner Regelungswirkung hinter dem des Art. 103 Abs. 2 GG zurückstehe. ${ }^{267}$ Art. 103 Abs. 2 GG wird auch im Zusammenhang mit dem VStGB noch betrachtet werden.

Abhängig von der Konkretisierung anerkannten Völkerrechts fallen die Einschätzungen hoher Gerichte in einzelnen Entscheidungen auseinander. Das Jugoslawientribunal hat sich mit dem Legalitätsprinzip und Völkergewohnheitsrecht als Strafrechtsgrundlage befasst und ist zu dem Ergebnis gekommen, dass die individuelle, völkerrechtsunmittelbare Strafbarkeit aufgrund von Vertragsrecht oder Völkergewohnheitsrecht möglich sei, denn ,the violation of the rule must entail [...] the individual criminal responsibility of the person breaching the rule“. Die bereits genannten Elemente des Völkergewohnheitsrechts, Rechtsüberzeugung und Praxis, sind gegeben: „the clear and unequivocal recognition of

\footnotetext{
${ }^{265}$ Ambos, Internationales Strafrecht, $§ 5$ Rn 5 f., zur allgemeinen Problematik, siehe Rn 7 f., $\$ 7$ Rn 8.

${ }^{266}$ Ambos, Internationales Strafrecht, $\S 10$ Rn 126; Frowein, in: Frowein/Peukert, Art. 7 EMRK, Rn 4; Gollwitzer, Art. 7 EMRK, Rn 9; Satzger, Internationales und Europäisches Strafrecht, § 11 Rn 84.

${ }^{267}$ Ambos, Internationales Strafrecht, § $10 \mathrm{Rn} 126$.
} 
the rules of warfare in international law and State practice indicating an intention to criminalize the prohibition, $[\ldots]$ as well as punishment of violations by national courts and military tribunals“ ${ }^{268}$ Das Element der Praxis liegt bereits durch die tatsächliche Ahndung durch Gerichte vor. Das BVerfG hat das Rückwirkungsverbot aus dem Grundgesetz völkerrechtskonform ausgelegt und in den Mauerschützenfällen den Vertrauensschutz bei einem „offensichtlichen, unerträglichen Verstoß gegen elementare Gebote der Gerechtigkeit und gegen völkerrechtlich geschützte Menschenrechte“ eingeschränkt. Eine völkerrechtsunmittelbare Strafbarkeit stellte offensichtlich partiell auch ohne formelles Parlamentsgesetz zumindest keinen Verstoß gegen Art. 103 Abs. 2 GG dar. ${ }^{269}$ Die Praxis legte das Nullum-Crimen-Prinzip also großzügig aus, was die Effizienz einer auch internationalen Strafbarkeit Einzelner fördernd war, ohne an nationalen (Verfassungs-)Schranken zu scheitern. ${ }^{270} \mathrm{Zu}$ berücksichtigen ist hier jedoch, dass die besagten Entscheidungen vor dem Erlass des VStGB im Jahr 2002 gefallen sind.

Jüngere Entscheidungen internationaler Gerichte befanden jedoch Bestrafungen durch nationale Gerichte auf Grundlage ungeschriebener, allgemeiner Regeln nicht immer als zulässig. Das Gericht der westafrikanischen Wirtschaftsgemeinschaft befasste sich beispielsweise mit der Verurteilung des ehemaligen Präsidenten des Tschad wegen Verbrechen gegen die Menschlichkeit durch nationale Gerichte, obwohl solche Strafbestände erst nachträglich ins nationale Recht einführt wurden. Den Vorwurf des Verstoßes gegen das Rückwirkungsverbot bestätigte das ECOWAS-Gericht und befand die unmittelbare Anwendung der allgemeinen Rechtsgrundsätze als Grundlage zur Bestrafung wegen des Tatbestands des Verbrechens gegen die Menschlichkeit für unzulässig. ${ }^{271}$

Für die im Raum stehende Untersuchung einer unmittelbaren Anwendbarkeit des Art. 25 (Satz 2) GG wäre dieser Umstand herausfordernd, besagt Satz 2 der Norm doch wörtlich, dass die allgemeinen Völkerrechtsregeln Rechte und Pflichten erzeugen, die unmittelbar gelten.

Auf einen Sachverhalt können Normen aller Rechtsquellen Anwendung finden. Die Inkorporation gewohnheitsrechtlicher Normen in völkerrechtliche Verträge ändert nichts an deren gleichzeitiger gewohnheitsrechtlicher Geltung. Es bestehen also völkervertragliche und

\footnotetext{
${ }^{268}$ ICTY, Appeals Chamber, Judgement of 02.10.1995, Prosecutor vs. Dusko Tadic, Decision on the Defence Motion for Interlocutory Appeal on Jurisdiction, Case No IT-94-1-AR72, Rn 94.

${ }^{269}$ BVerfGE 95, 96 (135): Die Rechtsprechung bezog sich nicht unmittelbar auf eine Bestrafung ohne Gesetzesgrundlage, sondern auf die vom DDR-Recht gestützte Rechtfertigung des Schießbefehls.

${ }^{270}$ So auch Ferdinandusse, Direct Application of International Criminal Law in National Courts, S. 270-272.

${ }^{271}$ Cour de Justice de la Communauté Economique des Etats de l'Afrique de l'Ouest (CEDEAO/ECOWAS), of 18.11.2010, Hissein Habré vs Senegal, Rn 57 f.
} 
völkergewohnheitsrechtliche Normierungen. Das BVerfG befand dies am Beispiel des Völkermordverbots (Art. I der Völkermordkonvention) im Jahr 2000. ${ }^{272}$ Art. 25 GG verhindert nicht, den zulässigen völkerrechtlichen Verträgen, die den allgemeinen Völkerrechtsregeln nicht voll entsprechen, die Kraft innerstaatlichen Rechts durch Gesetz zu verschaffen. Dabei ist das Völkergewohnheitsrecht nachgiebiges Recht. Dass die allgemeinen gewohnheitsrechtlichen Regeln des Völkerrechts dem völkerrechtlichen Vertragsrecht vorrangig wären, ist dem allgemeinen Völkerrecht fremd. ${ }^{273}$

Positiv bewertet hat die Ableitung einer Strafbarkeit aus dem Völkergewohnheitsrecht wiederum der EGMR im Jahr 2010. Bestimmungen des humanitären Völkerrechts wie der Haager Landkriegsordnung von 1907 waren schon 1944 nicht nur als Völkergewohnheitsrecht anerkannt, sondern als solches auch strafbewehrt. Über das Völkergewohnheitsrecht waren beispielsweise Misshandlungen von Kriegsgefangenen als Kriegsverbrechen strafbar. $^{274}$

Die Betrachtung der höchstrichterlichen Rechtsprechung zeigt, wie uneinheitlich die Anwendung des Völkergewohnheitsrechts als Rechtsgrundlage des Völkerstrafrechts gesehen wird.

Nach Fassbender ist das Völkerrecht weit genug entwickelt, um neben der völkerrechtsunmittelbaren strafrechtlichen Verantwortung ebenso die nicht-strafrechtliche Verantwortung ableiten zu können. „Der fortgeschrittene Prozess der 'Humanisierung' des Völkerrechts würde sicher eine derartige Verantwortung nahelegen. Jedoch waren Staaten bisher nicht bereit, sich darauf zu einigen.“275 Ergäbe sich das Prinzip der Individualverantwortung bereits aus der aktuellen Praxis als gewohnheitsrechtliche Norm, von einer erkennbaren Rechtsüberzeugung begleitet, wäre eine explizite Normierung nicht erforderlich. Dafür sind bisher allerdings überschaubare Ansätze vorhanden. ${ }^{276}$ Satzger schreibt, dass eine Entwicklung des Völkerstrafrechts ohne das Völkergewohnheitsrecht nicht möglich gewesen

\footnotetext{
${ }^{272}$ BVerfG, Nichtannahmebeschluss vom 12.12.2000, Az. 2 BvR 1290/99, in: NJW 25/2001, S. 1848-1853 (Leitsatz und Gründe), Rn 16 nach juris.

${ }^{273}$ BVerfGE 18, 441 (448); sowie Wengler, Völkerrecht, S. 483; Dahm, Völkerrecht, Bd. 1 S. 67; Bertram, in: Partsch, Berichte der Deutschen Gesellschaft für Völkerrecht 6/1964, S. 68

${ }^{274}$ EGMR (Große Kammer) Judgement of 17.05.2010, Kononov vs Lettland, Nr. 36376/04, Rn 202 f.; EGMR (Kammer), Judgement of 24.07.2008, Kononov vs Lettland, Nr. 36376/04, Rn 120, bezweifelt von den Richtern Costa u. a., Annex Rn 11.

${ }^{275}$ Siehe Fassbender, in: JICJ 2/2008, S. 347 (369), bezüglich staatlicher Offizieller, die dem Staat zugerechnet werden können

${ }^{276} \mathrm{Vgl}$. Peters, Jenseits der Menschenrechte, S. 151.
} 
sei, so dass das Gesetzlichkeitsprinzip des Art. 103 Abs. 2 GG nur eingeschränkt gelten könne. ${ }^{277}$

Die rechtliche Möglichkeit, Einzelnen neben primären auch sekundäre völkerrechtliche Pflichten auferlegen zu können, ist sowohl abstrakt, als auch prinzipiell zu begrüßen. Eine derartige beidseitige Entwicklung auf Seiten der völkerrechtlichen Pflichten bringt eine fortlaufende Entfaltung der Individualrechte hervor und reicht einer Festigung des Rechtsstatus des Individuums zum primären Völkerrechtssubjekt zum Vorteil. Hinsichtlich der individuellen Verantwortlichkeit allerdings fehlte es bisher an einer entsprechenden, auch die Rangfolge der Haftung regelnden, Definition im Völkerrecht. ${ }^{278}$

Für Art. 25 GG und dessen Betrachtung bedeutet dies bisher, dass die eingegliederten Völkergewohnheitsrechte und Rechtsgrundsätze den deutschen Rechtsgrundsätzen für die praktische Umsetzung grundsätzlich nicht voll umfassend standhalten und entsprechen können. Die Rechtsprechung hat in Einzelfällen, siehe die Mauerschützenfälle des BVerfG, die Grundsätze zur Unterstützung der Praktikabilität weiter ausgelegt. Dennoch zeigt diese allgemeine Problematik die, zumindest für das Völkergewohnheitsstrafrecht, geringe praktische Konkretisierung, so dass Art. 25 GG als rechtliche Grundlage einer völkerstrafrechtlichen Verantwortlichkeit in Frage gestellt werden muss. Im nächsten Abschnitt wird deshalb für Deutschland auf eine gesetzliche Neuschaffung geblickt, und ob diese eine vorteilhaftere Grundlagenalternative darstellen könnte, so dass Art. 25 für völkerrechtliche Pflichten oder Verbote nicht herhalten müsste, oder sogar dürfte.

\section{Das IStGH-Statut und seine Umsetzung ins deutsche Recht}

Das IStGH-Statutgesetz ist das deutsche Zustimmungsgesetz nach Art. 59 II GG und erlangt somit den Rang einfachen Rechts. Im Jahr 2002 ist das Gesetz zur Ausführung des Römischen Statuts des IStGH von 1998 in Kraft getreten. Der Kern dieses Artikelgesetzes ist das Gesetz über die Zusammenarbeit mit dem Internationalen Strafgerichtshof. ${ }^{279}$ Das IStGHG regelt die Zusammenarbeit zwischen dem IStGH und den deutschen Behörden. Darin geregelt werden unter anderem die Überstellung von Verdächtigen, die Rechtshilfe bei Entscheidungen und Anordnungen des Gerichtshofs durch Vollstreckung und sonstige

\footnotetext{
${ }^{277}$ Satzger, Internationales und Europäisches Strafrecht, § 12 Rn 5, 6.

${ }^{278}$ Dieser Meinung u.a. auch Peters, Jenseits der Menschenrechte, S. 151.

${ }^{279}$ BGB1. I 2002, S. 2144 f.
} 
Rechtshilfesachen, wobei das Strafverfahren vor dem IStGH den Verfahren vor nationalen Strafgericht nachrangig ist. ${ }^{280}$ Die Umsetzung des Statuts ist für die Bearbeitung deshalb von Relevanz, da das VStGB völkerrechtliche Strafnormen abbilden und konkretisieren sollte. Es geht aus diesem hervor. In den kommenden Punkten wird die Praktikabilität der neuen Normen beleuchtet als für Gerichte und Behörden vorteilhaftere Alternative zur Berufung auf Art. 25 GG hinsichtlich unmittelbar geltender völkerrechtlicher Pflichten.

Das VStGB passt das deutsche materielle Strafrecht an das Römische Statut des IStGH an und spiegelt als ein überwiegend eigenständiges Regelungswerk die Entwicklung des humanitären Völkerrechts und des Völkerstrafrechts in Deutschland wider, indem es Verbrechen gegen das Völkerrecht unter Strafe stellt. ${ }^{281}$ Der Erlass des VStGB zielt darauf ab, dass Deutschland in der Lage sein soll, Verbrechen selbst zu verfolgen, die in die Zuständigkeit des IStGH fallen.

Einige Defizite der Rechtslage vor Inkrafttreten des VStGB zeigen auf, dass ohne ein Tätigwerden des deutschen Gesetzgebers eine selbstständige Strafverfolgung nicht zu gewährleisten war. So wies das deutsche Strafrecht gegenüber dem Rom-Statut einige Lücken auf, bezüglich derer wegen des Komplementaritätsprinzips eine Modifikation erforderlich war. Dies betraf beispielsweise die Tatbestände der Art. 8 Abs. 2 lit. a und b IStGH-Statut. ${ }^{282}$ Das allgemeine deutsche Strafrecht litt derweil noch an qualitativen Mängeln als es die Verhaltensweisen des Rom-Statuts zwar als „einfache“ Vergehen oder Verbrechen unter Strafe stellte, den ursprünglichen völkerrechtlichen Unrechtsgehalt jedoch nicht erfasste. ${ }^{283}$ Mit Erlass des nationalen VStGB hat Deutschland das materielle Strafrecht an die Bestimmungen des IStGH-Statuts angepasst und das sogenannte „deutsche Völkerstrafrecht“ geprägt, und das, obwohl das IStGH-Statut die Vertragsstaaten nicht zur Implementierung von Völkerstraftatbeständen verpflichtet. Das Gesetzlichkeitsprinzip nach Art. 103 Abs. 2 GG verbietet eine Strafverfolgung der völkergewohnheitsrechtlich anerkannten Straftatbestände des IStGH-Statuts, solange diese nicht formell-gesetzlich geregelt sind. ${ }^{284}$ Im letzten Abschnitt wurde festgestellt, welche Schwierigkeiten das Gesetzlichkeitsprinzip bezüglich

\footnotetext{
${ }^{280}$ Vgl. zu dem Regierungsentwurf: MacLean, ZRP 6/2002, 260 f.

${ }^{281}$ Gesetzentwurf der Bundesregierung - Völkerstrafgesetzbuch, BR-Drucks. 29/0

${ }^{282}$ Diese regeln die völkerstrafrechtlich relevante Rechtsverweigerung, jedenfalls bei ausländischen Tätern (lit. a) oder die völkerrechtswidrige Überführung eines Teils der Zivilbevölkerung einer Besatzungsmacht in besetztes Gebiet (lit. b).

${ }^{283}$ Satzger, Internationales und Europäisches Strafrecht, $\$ 17$ Rn 8 f.

${ }^{284}$ Vgl. hierzu nur Satzger, in: NStZ 3/2002, S. 125 (126); Satzger, in: JuS 11/2004, S. 943 f.; Satzger, Internationales und Europäisches Strafrecht, § 17 Rn. 12.
} 
der praktischen Geltendmachung völkergewohnheitsrechtlicher Inhalte enthaltender Normen entfaltet. Der deutsche Gesetzgeber wollte jedoch in Achtung des Komplementaritätsprinzips sicherstellen, dass die in die Zuständigkeit des IStGH fallenden Verbrechen durch Deutschland selbst verfolgt werden können.

Die aufgezeigten Lücken konnten auch nicht mit einer Regelung ausgeglichen werden, die eine unmittelbare Anwendung völkerrechtlicher Verbrechenstatbestände erlaubt. Spiegeln die völkerrechtlichen Verbrechenstatbestände das Völkergewohnheitsrecht wider, erlangt dieses durch Art. 25 Satz 1 GG als allgemeine Völkerrechtsregel Eingang ins deutsche Recht. Dieses geht dann deutschem Verfassungsrecht vor. ${ }^{285}$ Die völkergewohnheitsrechtlichen Tatbestände müssen allerdings auch dem Gesetzlichkeitsprinzip nach Art. 103 Abs. 2 GG genügen, welches eine rein gewohnheitsrechtliche Begründung einer individuellen Strafbarkeit verbietet. Vor dem Hintergrund des daraus abzuleitenden Verbots einer gewohnheitsrechtlichen Begründung einer Strafbarkeit darf die deutsche Strafverfolgung nicht unmittelbar aufgrund Völkerrechts erfolgen. ${ }^{286}$

Die klaren und bestimmt formulierten Straftatbestände fördern das Ziel „,durch Normierung in einem einheitlichen Regelungswerk die Rechtsklarheit und Handhabbarkeit in der Praxis zu fördern“. 287 Dazu gehört auch, dass stets „Tragweite und Anwendungsbereich der Straftatbestände zu erkennen sind und sich durch Auslegung ermitteln lassen“. ${ }^{288}$ Das BVerfG hat sich allerdings für ein weites Verständnis der Bestimmtheits-anforderungen ausgesprochen, da der Gesetzgeber ohne normative, allgemeine und wertausfüllungsbedüftige Begriffe „,nicht in der Lage wäre, der Vielgestaltigkeit des Lebens Herr zu werden“. ${ }^{289}$ Die Völkerrechtsfreundlichkeit des Grundgesetzes muss zu einem gewissen Privileg im Hinblick auf den anzuwendenden Grundsatz der Bestimmtheit führen. Zumindest insoweit, wie der Rechtsunterworfene das Risiko der Strafbarkeit erkennt und die Rechtsprechung problemlos in die Lage versetzt wird, die Konkretisierung der Tatbestände durch Auslegung zu erreichen, sollten die Vorschriften des VStGB als hinreichend bestimmt erachtet werden. ${ }^{290}$ Einwendungen gegen die Ausgestaltung des VStGB können vor dem Hintergrund des Art. 103 Abs. 2 GG erhoben werden, soweit die Straftatbestände mehr oder weniger pauschal

\footnotetext{
${ }^{285}$ BVerfGE 6, 309 (363); vgl. auch Satzger, Internationales und Europäisches Strafrecht, § 17 Rn 12 f.

${ }^{286} \mathrm{Vgl}$. Hecker, Europäisches Strafrecht, § $10 \mathrm{Rn} 33$; Kreß, Vom Nutzen eines deutschen Völkerstrafgesetzbuchs, S. 10; Hermsdörfer, in: HuV-I 1/1999, S. 22 f.; Werle, JZ 18/2001, 885 (889); Blanke/Molitor, AVR 2/2001, S. 142 (165). Demgegenüber sind jedoch die ,,allgemeinen Regeln des Völkerrechts“ unmittelbar für die Frage der Rechtswidrigkeit von Bedeutung, vgl. dazu Werle, in: ZStW 4/1997, 808 (825).

${ }^{287}$ Siehe die Begründung des Gesetzentwurfs der Bundesregierung, BR-Drucks. 29/02, S. 23.

${ }^{288}$ Siehe u. a. BVerfGE 25, 269 (285); 55, 144 (152); 75, 329 (340 f.).

${ }^{289}$ BVerfGE 11, 234 (237).

${ }^{290}$ Satzger, in: JuS 11/2004, S. 943 f.; Satzger, Internationales und Europäisches Strafrecht, § 17 Rn 32.
} 
auf das Völkergewohnheitsrecht Bezug nehmen. Als Beispiel kann hier $§ 7$ Abs. 1 Nr. 4 VStGB herangezogen werden. Die Formulierung ,allgemeine Regeln des Völkerrechts“ bezieht sich auf Art. 25 GG und verweist somit insbesondere auf das Völkergewohnheitsrecht. ${ }^{291}$

Völkergewohnheitsrechtliche Regelungen werden also dynamisch in den Tatbestand des $\S$ 7 Abs. 1 Nr. 4 VStGB mit einbezogen.

Die benannte Auffassung der Literatur und die direkte Bezugnahme des $§ 7$ Abs. 1 Nr. 4 VStGB zeigen, dass Art. 25 GG weniger unmittelbar als mittelbar in Erscheinung tritt, gerade was die Anwendung des Völkergewohnheitsrechts betrifft. Hierdurch kommt genau der Eindruck auf, dass die Inkorporierung des Völkergewohnheitsrechts und der anerkannten Rechtsgrundsätze über Art. 25 GG dazu genutzt wird, andere spezifische Gesetze zu erlassen, die sich direkt auf konkretes Gewohnheitsrecht beziehen und dieses in unmittelbar anwendbares nationales Recht aufnehmen. Demnach wäre nicht Art. 25 Satz 1 oder Satz 2 GG die unmittelbare Rechtsgrundlage, sondern hier die Normen des VStGB.

Weiter ist es für Bürger und Richter schwierig, den Inhalt des Völkergewohnheitsrechts zu greifen, auszulegen und praktisch anzuwenden. ${ }^{292}$ Es ist außerdem zu bedenken, dass Verbote der Strafvorschriften vom aktuellen Stand des Völkergewohnheitsrechts abhängen und damit eine dynamische Verweisung auf ungeschriebenes und sich laufend fortentwickelndes Recht vorliegt. Eine solche Verweisung ist bereits im allgemeinen Strafrecht problematisch, im Rahmen des Völkerstrafrechts kann eine solche dynamische Verweisung allerdings nicht akzeptiert werden. Der deutsche Gesetzgeber ist daher gezwungen, das nationale Völkerstrafrecht und die Voraussetzungen der Strafbarkeit genauer zu formulieren. Eine Umsetzung ${ }^{293}$ des Rom-Statuts ins deutsche Strafrecht ist aus völkerrechtlicher Sicht nicht geboten und ließe sich mit den Anforderungen der deutschen Verfassung nach Art. 103 Abs. 2 GG nicht vereinbaren. ${ }^{294}$

Von der Überarbeitung des deutschen Strafrechts kann nicht automatisch auf die allgemeinen Völkerrechtsregeln in Deutschland geschlossen werden. Vor dem Hintergrund des Geltungsbereichs des Art. 25 GG ist aber denkbar, dass die Inkorporierungsklausel des Art. 25 GG nicht unbewusst seit dem Inkrafttreten unverändert blieb und nicht um Regelungen

\footnotetext{
${ }^{291}$ Siehe dazu die Begründung des Gesetzentwurfs der Bundesregierung, BR-Drucks. 29/02, S. 46.

${ }^{292}$ Kritisch auch Gropengießer/Kreicker in: Nationale Strafverfolgung völkerrechtlicher Verbrechen, S. 126 f.; a.A. offenbar Werle/Burchards, in: Münchener Kommentar, § 7 VStGB, Rn. 68; Kuhli, in: ZIS 4/2012, 124 (129 f.).; zur Deutungsobliegenheit mancher Straftatbestände des Gewohnheitsrechts auch BVerfG, Nichtannahmebeschluss vom 12.12.2000, Az. 2 BvR 1290/99, in: NJW 25/2001, 1848 f.

${ }^{293}$ Werle, in: JZ 18/2001, 885 (887).

${ }^{294}$ Satzger, Internationales und Europäisches Strafrecht, S. § 17 Rn 34, 35.
} 
ergänzt oder konkretisiert wurde. Die materiellen Änderungen und das Hinzufügen spezieller, aus dem Völkergewohnheitsrecht abgeleiteter, Straftatbestände zum nationalen (Völker-)Strafrecht legen diesen Gedanken nahe.

\section{Die völkerstrafrechtliche Praxis Deutschlands}

Hinsichtlich der Verantwortung im Völkerrecht wird zwischen zwei unterschiedlichen Regimen der Staatenverantwortlichkeit und der individuellen strafrechtlicher Verantwortlichkeit unterschieden, welche sich nur teilweise überschneiden. ${ }^{295}$ Auch internationale Strafgerichte müssen das Völkergewohnheitsrecht unmittelbar anwenden. Im Rahmen einer weltweiten Anwendung des Völkerrechts lässt sich keine gleichmäßige Bestrafung erreichen. Eine indirekte Durchsetzung kann nicht verhindern, dass Völkerstraftaten teils überhaupt nicht geahndet oder überhaupt verfolgt werden. Dies hängt von der Bereitschaft einzelner Staaten ab, Straftatbestände des Völkerrechts in ihre Rechtsordnungen aufzunehmen und umzusetzen. ${ }^{296}$ Für die vorliegende Untersuchung

\subsection{Vor Erlass des VStGB}

Vor Inkrafttreten des VStGB im Jahr 2002 ergingen nationale Urteile wegen Völkerstrafrechtsverletzungen noch auf Grundlage des StGB. So bestand bis 2002 der $§ 220$ a StGB a. F., der den Völkermord ahndete. Der BGH hat 1999 im Rahmen eines Verfahrens wegen im Ausland begangenen Völkermordes auf $\S 6$ Nr. 1 StGB, sowie $\S 220$ a Abs. 1 Nr. 1 StGB und direkt auch Art. 1 der Völkermordkonvention abgestellt. ${ }^{297}$ Bei der Völkermordkonvention (oder Genozid-Konvention) handelt es sich um kodifiziertes Völkergewohnheitsrecht. $^{298}$

\footnotetext{
${ }^{295}$ Bianchi in: Cassese, The Oxford Companion to International Criminal Justice, S. 18; Werle/Jeßberger, Völkerstrafrecht, S. 142 Rn 142 f.

${ }^{296}$ Satzger, Internationales und Europäisches Strafrecht, § 12 Rn 8.

${ }^{297}$ BGHSt 45, $65 \mathrm{f}$.

${ }^{298}$ Deiseroth, in: Das Recht in guter Verfassung?, S. 25 (35).
} 
Bei zwischen Völkerrechtssubjekten geschlossenen völkerrechtlichen Verträgen kann es sich auch um allgemeine Völkerrechtsregeln im Sinne des Art. 25 GG, soweit die Rechtsnormen des ius cogens oder des Völkergewohnheitsrechts ihren Niederschlag finden. ${ }^{299} \S$ 6 Nr. 1 StGB ist zusammen mit $§ 220$ a StGB mit Erlass des VStGB aufgehoben worden. Vorher wurde Völkermord laut Weltrechtsprinzip (jetzt in $§ 1$ VStGB verankert) auch unabhängig vom Recht des Tatorts vom deutschen Strafrecht erfasst, auch wenn er im Ausland begangen wurde. ${ }^{300}$ Entsprechend der völkerrechtlichen Verwurzelung ist $\S 220$ a StGB, anders als die national-rechtlichen Kapital- und Körperverletzungsdelikte, keine Individualrechtsgüter schützende Strafnorm, sondern dient dem Schutz der Existenz einer verfolgten rassischen, nationalen oder religiösen Gruppe. ${ }^{301}$

Durch Gesetz vom 9. August 1948 wurde $§ 220$ a StGB über den Beitritt der BRD zur Genozid-Konvention vom 9. Dezember 1948 über die Verhütung und Bestrafung des Völkermordes ins StGB eingefügt. Der Bundesgesetzgeber hat den Wortlaut des $§ 220$ a StGB bewusst an Art. II der Genozid-Konvention angelehnt, indem die subjektiven und objektiven Merkmale des Völkermords tatbestandlich umschrieben wurden. ${ }^{302}$ Interessant ist an dieser Stelle, dass sich der Art. 25 GG bereits seit 1949 im deutschen Grundgesetz befindet, welcher die allgemeinen Völkerrechtsregeln ins deutsche Bundesrecht aufnimmt. Dennoch sah der Gesetzgeber die Notwendigkeit, den Wortlaut des Strafgesetzes (und 2002 auch des VStGB) an das Gewohnheitsrecht anzupassen, statt sich im jeweiligen Einzelfall über Art. 25 GG direkt auf das Gewohnheitsrecht zu berufen.

\section{2. $\quad$ Nach Inkrafttreten des VStGB}

Nach Inkrafttreten des VStGB in 2002 wurden bis Mitte 2016 ca. 50 Ermittlungsverfahren wegen VStGB-Verletzungen eingeleitet. ${ }^{303}$ Zwischen 2017 und 2019 wurden dann allerdings - auch wenn ein großer Teil eingestellt worden ist - über 100 Ermittlungsverfahren

\footnotetext{
${ }^{299}$ BVerwGE 127, 302 (316); vgl. dazu näher u.a. Jescheck, in: Bundeswehr und Recht, S. 63 (71).

${ }^{300}$ Fassung des $\S 6$ Nr. 1 StGB bis zum 30.06.2002.

${ }^{301}$ BGHSt 45, 65 (81).

${ }^{302}$ BGHSt 45, 65 (79); vgl. zum Gesetzgebungsverfahren des $\$ 220$ a StGB a. F.: Campbell, § 220 a StGB, S. $160 \mathrm{f}$.

${ }^{303}$ Anhörung des Bundestagsrechtsausschusses zu einem Antrag der Grünen - BT-Drucksacke 18/6341.
} 
auf Grundlage des VStGB eröffnet. ${ }^{304}$ Ein Grund für die geringe Praxis des Völkerstrafrechts in Deutschland sollen Hemmnisse des Verfahrensrechts sein. Die ohnehin herausfordernde Aufgabe, gerichtsfeste Beweise vorzulegen, werde im Völkerstrafrecht erschwert. $^{305}$ Ab 2011 fand erst knapp zehn Jahre nach Erlass des Völkerstrafgesetzbuchs der erste VStGB-Prozess vor dem OLG Stuttgart statt, in dem sich der Ruander Ignace Murwanashvaka wegen Kriegsverbrechen im Rahmen der sogenannten Vorgesetztenverantwortlichkeit und Verbrechen gegen die Menschlichkeit im Kongo nach $\S 8$ Abs. 1 Nr. 1, Abs. 6 Nr. 2, § 9 Abs. 1 VStGB verantworten musste. Das Urteil über 13 Jahre Freiheitsstrafe erging 2015. ${ }^{306}$ Im Jahr 2014 fällte das OLG Frankfurt gegen den Ruander Onesphore Rwabukombe unter anderem wegen des im Jahre 1994 in Ruanda nach $§ 6$ Abs. 1 Nr. 1 VStGB begangenen Völkermordes in erster Instanz ein Urteil über eine Freiheitsstrafe von 14 Jahren wegen Beihilfe zum Völkermord. ${ }^{307} 2015$ dann entschied der BGH im Revisionsverfahren, dass es sich statt Beihilfe zum Völkermord um Mittäterschaft gehandelt hat. Der BGH hat der Revision des Generalbundesanwaltes jedoch stattgegeben und eine Mittäterschaft des Völkermordes bejaht. ${ }^{308}$

Das BVerfG hat 2015 erst mit Blick auf das VStGB zum Kunduz-Fall ausgeführt, bei dem zwecks eines Präventivschlags auf durch die Taliban gestohlene Tanklaster zahlreiche Zivilisten zu Tode kamen, dass neben dessen Geltung auch ,über Art. 25 GG das gesamte Konfliktvölkerrecht zur Anwendung“" kommt, unabhängig von einer einzelfallbezogenen Einordnung des Konfliktbeginns. ${ }^{309}$ Auf die Streitfrage des Beschlusses der Verfassungsrichter kommt es hier nicht an. Relevant ist allerdings, dass die Richter Art. 25 GG als Implementierungsnorm benennen und parallel zum VStGB die Heranziehung ermöglichen. Die sich seit 2015 in Deutschland häufenden Gerichtsverfahren wegen versuchter Teilnahmen Einzelner an den völkerrechtswidrigen Gewaltakten des sogenannten „Islamischen Staates“, der Taliban oder anderer als Terrororganisationen eingestuften Vereinigungen ste-

\footnotetext{
${ }^{304}$ Antwort der Bundesregierung auf die Kleine Anfrage der Fraktion BÜNDNIS 90/DIE GRÜNEN - Drucksacke 19/11480 und 19/12354 vom 12.08.2019.

305 https://web.archive.org/web/20160430205259/http://rsw.beck.de/aktuell/meldung/anhoerung-expertendiskutieren-anwendungsdefizit-des-voelkerstrafgesetzbuchs (zuletzt aufgerufen am 26.03.2018).

${ }^{306}$ Siehe dazu Safferling/Kirsch, in: JA 7/2012, S. 481, (485 f.); OLG Stuttgart, Urteil vom 28. September 2015, Az. 5 - 3 StE 6/10, Rn 1875 nach juris.

${ }^{307}$ OLG Frankfurt a. M., Urteil vom 18.02.2014, Az. 5-3 StE 4/10-4-3/10, Rn 4 nach juris.

${ }^{308}$ BGHR VStGB $\S 6$ Mittäter (Gründe), Rn 9 f. nach juris.

${ }^{309}$ BVerfG, Nichtannahmebeschluss vom 19. Mai 2015, Az. 2 BvR 987/11, in: NJW 49/2015, S. 3500-3503 (Leitsatz und Gründe), Rn 6 f. nach juris.
} 
hen neben den Normen des StGB für Kapitalverbrechen ( $§ 212$ f. StGB) auch auf Grundlage derer des VStGB (vornehmlich $\S \S 8,9,12,13$ VStGB). ${ }^{310}$ In jüngster Vergangenheit hat es jedoch auch schon abschließende Urteile in VStGB-Prozessen gegeben. So entschieden beispielsweise das OLG Frankfurt 2016 und der BGH 2017 über Leichenschändungen im Sinne des $\S 8$ Abs. 1 Nr. 9 VStGB, die teils auch durch deutschstämmige Kämpfer des „Islamischen Staats“ begangen wurden, zu Freiheitsstrafen über jeweils achteinhalb und zwei Jahren verurteilt. ${ }^{311}$

Zwischen 2004 und 2007 wurden in Frankreich und Deutschland mehrere Strafanzeigen gegen US-Regierungsmitglieder gestellt, in denen unter anderem der damalige Verteidigungsminister Donald Rumsfeld wegen Kriegsverbrechen, Folter und anderen Straftaten in den Gefangenenlagern Guantanamo und Abu Ghraib beschuldigt wurden. Die zuständigen Anklagebehörden verzichteten auf Ermittlungsaufnahmen, und auch dagegen gerichtete Rechtsmittel blieben ohne Erfolg. ${ }^{312}$ Die Strafanzeigen stützten sich auf das in Frankreich und Deutschland etablierte Weltrechtsprinzip und Normen des VStGB, wonach die Verbrechensverfolgung auch in Drittstaaten möglich ist, auch wenn schwerste Verbrechen in anderen Ländern begangen worden sind. ${ }^{313}$ Die stellvertretende Direktorin des amerikanischen Geheimdienstes CIA, Gina Haspel, die von US-Präsident Trump 2017 ernannt wurde, soll 2002 die Folter von Gefangenen gebilligt und überwacht haben. Bereits Ende 2014 wurde vom „European Center for Constitutional and Human Rights“ Strafanzeige gestellt, die dem Generalbundesanwalt seitdem vorliegt. Strafanzeige wurde auch gegen George Tenet, den ehemaligen CIA-Chef, Donald Rumsfeld und weitere Mitglieder der ehemaligen Bush-Regierung erhoben. Wie bei den bereits zwischen 2004 und 2007 angestrebten Verfahren stütze sich die 2014 erhobene Klage auf $§ 8$ Abs. 1 Nr. 3 VStGB. ${ }^{314}$

\footnotetext{
${ }^{310} \mathrm{BGH}$, Beschluss vom 06.10.2016, Az. AK 52/16, Rn 2 nach juris; Beschluss vom 20.12.2016, Az. 3 StR 435/16, in: NStZ 2/2017, S. 699; Beschluss vom 01.06.2017, Az. 20-24/17 u.a., Rn 2 nach juris; Beschluss vom 14.11.2017, Az. 4 BGs 156/17, in: NStZ 3/2018, S. 154 f.; Beschluss vom 19.12.2017, Az. 72/17, in: NStZ-RR 3/2018, S. 75; Beschluss vom 11.01.2018, Az. 74/17, Rn 1 nach juris.

${ }^{311}$ Vgl. OLG Frankfurt a. M., Urteil vom 08.11.2016, Az. 5-3 StE 4/16-4-3/16, Rn 262 nach juris; BGHSt 62, $272(272)$

${ }^{312}$ OLG Stuttgart, Beschluss vom 13.09.2005, Az. 5 Ws 109/05, in: JZ 4/2006, S. 208.

${ }^{313}$ Siehe Schreiben des Generalbundesanwaltes vom 10.03.2005, Az. 3 ARP 207/04-2, S. 2; Schreiben des Rechtsanwalts Kaleck an den Generalbundesanwalt vom 29.11.2004, S. 2, beide Schriftsätze abrufbar unter https://www.ecchr.eu/de/unsere-themen/voelkerstraftaten-und-rechtliche-verantwortung/usa/rumsfeld.html (zuletzt aufgerufen am 18.10.2018)

${ }^{314}$ Siehe die Schreiben des ECCHR an den Bundesanwalt Ritscher vom 28.06.2016, Az. GBA 3 ARP 100/144 und vom 17.12.2014 (Strafanzeige), abrufbar unter https://www.ecchr.eu/de/unsere-themen/voelkerstraftaten-und-rechtliche-verantwortung/usa/verfahren-deutschland.html (zuletzt abgerufen am 18.10.2018)
} 
Die dargestellten Entscheidungen, sowie die aktuell zahlreichen anhängigen Verfahren wegen Völkerrechtsverbrechen, stehen alle auf der Grundlage bewährter Strafnormen des StGB und vor allem des 2002 neu erlassenen VStGB. Ein direkter Zugriff auf die völkergewohnheitsrechtlichen Strafnormen oder die kodifizierten Gewohnheitsrechtsverträge wie beispielsweise die Völkermordkonvention bleibt seitens der Rechtsprechung aus. Auch die Völkerrechtsklausel des Art. 25 GG kommt im Völkerstrafrecht nicht zur Anwendung, da mit dem VStGB ein spezielleres Gesetz geschaffen wurde, welches die Einarbeitung des Völkergewohnheitsrechts und der anerkannten Rechtsgrundsätze aufweist und die aufgeworfene Problematik des Nullum-Crimen-Prinzips praxistauglich einschränkt.

Die - wenn auch quantitativ geringe - Praxis des Völkerstrafrechts in Deutschland zeigt dennoch bedeutsam, dass mit der Schaffung von konkreten Normen wie $\S 7$ VStGB ein praktikables Mittel geschaffen worden ist, dem Völkerstrafrecht in Deutschland Geltung auch für Einzelne zu verschaffen. In einem ersten Vergleich zu Art. 25 Satz 2 GG zeigt sich für die Bearbeitung, dass am Beispiel des Völkerstrafrechts ein Teil des Völkergewohnheitsrechts auch vor nationalen Gerichten geltend gemacht werden kann, wenn eine taugliche Rechtsgrundlage vorhanden ist, die den Grundsätzen des Art. 103 Abs. 2 GG genügt.

\subsection{Zwischenergebnis}

Die aufgezeigte Problematik des Gesetzlichkeitsprinzips aus Art. 103 Abs. 2 GG beeinträchtigt die praktische Anwendung des gewohnheitsrechtlichen Völkerstrafrechts sowohl auf internationaler, als auch nationaler Ebene. So theoretisch plausibel die Problematik des Gesetzlichkeitsprinzips ihrerseits angemahnt wird, so schwierig ist jedoch die praktische Umsetzung. Es erweist sich als denkbar schwierig für Bürger und auch Richter, gewohnheitsrechtliche Rechtssätze dogmatisch zu umfassen, um daraufhin begangene Verbrechen beurteilen zu können. Auch aus diesem Umstand heraus wurde das IStGH-Statut in Deutschland mit Erlass des VStGB umgesetzt. Vereinzelte Stimmen der Literatur betonen jedoch, das Nullum-Crimen-Prinzip dürfe keine absolute Barriere darstellen, die die unmittelbare Anwendbarkeit internationaler Strafnormen verhindere. ${ }^{315}$ Dennoch hat der deutsche Gesetzgeber Wert daraufgelegt, am Maßstab des IStGH-Statuts ein neues Gesetz zu erlassen, dass diesem nachkommt. Dieses findet seit seinem Erlass zunehmend Anwendung

${ }^{315}$ Vgl. Ferdinandusse, Direct Application of International Criminal Law in National Courts, S. 270-272. 
und zeigt somit, dass selbst kodifiziertes Gewohnheitsrecht wie die Völkermordkonvention, die Genfer Konvention oder die Haager Abkommen als gerichtliche Rechtsgrundlage, wenn überhaupt, nur nachrangig herangezogen wird. Auch, wenn vereinzelt Stimmen des allgemeinen Völkerrechts eine völkerrechtliche Straffähigkeit Einzelner als völkergewohnheitsrechtlich etabliert sehen ${ }^{316}$, liegt mit dem speziellen Bundesgesetz des VStGB eine ausreichende Rechtsgrundlage für Verfahren vor deutschen Gerichten vor. Auch in der Völkerrechtswissenschaft wird deshalb mit Verweis auf die strikte Regelung des Art. 103 Abs. 2 GG deutlich gemacht, dass eine „deutsche Strafverfolgung der völkergewohnheitsrechtlich anerkannten Tatbestände des IStGH-Statuts“ ausgeschlossen sei, solange diese nicht in förmlichen Gesetzen geregelt sind. Nicht nur ist die direkte Geltung des Völkergewohnheitsrechts auf strafrechtlicher Ebene schwierig, sie ist nach den Verfahrensgrundsätzen der deutschen Verfassung nicht möglich ${ }^{317}$

Die Reformierung des internationalen und nationalen Völkerstrafrechts zeigt, dass mit dem VStGB eine nationale Alternative zur direkten Heranziehung des Gewohnheitsrechts und der anerkannten Rechtsgrundsätze für das Völkerstrafrecht geschaffen wurde. Im Gegensatz zu Art. 25 GG bestehen mit beispielsweise $\S 8$ Abs. 1 Nr. 1 oder $\S 11$ Abs. 1 Nr. 1 VStGB tatsächliche Verbots- und Sanktionsnormen und für völkerstrafrechtswidriges Verhalten werden Konsequenzen angedroht.

Die Geltung der allgemeinen Regeln des Völkerstrafrechts im Sinne des Art. 25 GG hat zwar in den Grenzen der Art. 103 Abs. 2 GG, Art. 7 Abs. 2 EMRK und Art. 15 Abs. 2 des Internationalen Pakts über bürgerliche und politische Rechte zu erfolgen, ist jedoch wie gezeigt über das VStGB in Deutschland möglich. Das BVerfG hat erst 2015 eine simultane Anwendbarkeit bekräftigt. ${ }^{318}$ Wenig überraschend ist deshalb die äußerst überschaubare Rechtspraxis des Völkergewohnheitsrechts und der anerkannten Rechtsgrundsätze, auch über den Bereich des Völkerstrafrechts hinaus. Es stellt sich auch die Frage, warum über Art. 25 GG als „Einfallstor“ direkt auf Gewohnheitsrecht und Rechtsgrundsätze zurückge-

\footnotetext{
${ }^{316}$ Eine völkerrechtsunmittelbare Strafbarkeit könne sich, unter Beachtung des Nullum-Crimen-Prinzips, sowohl aus Völkergewohnheitsrecht, als auch den anerkannten Rechtsgrundsätzen und dem Völkervertragsrecht ergeben. Richterliche Konkretisierungen hätten dabei eine sowohl praktische, als auch legitimationsrelevante große Bedeutung, in: Peters, Jenseits der Menschenrechte, S. 149

${ }^{317}$ Siehe Hecker, Europäisches Strafrecht, § 2 Rn 90; vgl. so auch Satzger, Internationales und Europäisches Strafrecht, § 17 Rn 12; ders., in: JuS 11/2004, S. 943 f.

${ }^{318}$ BVerfG, Nichtannahmebeschluss vom 19.05.2015, Az. 2 BvR 987/11, in: NJW 2015, 3500 f., Rn 6 nach juris.
} 
griffen werden sollte, wenn diese doch vom Gesetzgeber in ihren Wertungen gewissermaßen „neu formuliert“, teils aber auch wortgleich, Einfluss in Spezialgesetze gefunden haben. Diese Neuregelungen schienen aber erforderlich gewesen zu sein, um das nationale Strafrecht dem IStGH-Statut entsprechend aktualisieren zu können. Wie bereits erwähnt, war eine Schließung der vor dem VStGB bestehenden Rechtslücken über Art. 25 GG direkt nicht möglich. Auch zukünftige Rückgriffe auf das Gewohnheitsrecht und die Rechtsgrundsätze würden in der Praxis wohl an Art. 103 Abs. 2 GG scheitern, wenn es konsequent um konkrete Straftatbestände und folgende Bestrafungen ginge.

Man kann und muss sagen, dass das völkerstrafrechtliche Gewohnheitsrecht im traditionellen Sinne überholt und in vereinzelten Ländern wie Deutschland durch, zwar teils wortgleiche, aber anhand jüngster politischer und geschichtlicher Geschehnisse entwickelte, speziellere Gesetze kodifiziert wurde. So wird eine praktische Anwendbarkeit vor nationalen Instanzen gewährleistet. Diese kann vor dem Hintergrund des Nullum-Crimen-Prinzips nicht durchweg garantiert werden, allerdings zeigt die deutsche Rechtspraxis der letzten 15 Jahre, dass völkerrechtliche Verbrechen zunehmend prozessiert und auch rechtskräftig erfolgreich geahndet werden.

\section{Fazit}

Der kurze Einblick in die Bedeutung und Anwendung des Völkerstrafrechts international und in Deutschland hat gezeigt, dass der Einzelne vor dem IStGH nicht die Möglichkeit hat, selbst Verfahren gegen andere Staaten oder natürliche Personen wegen Verstößen gegen das Völkerstrafrecht anzustrengen. National gab es bis zur Umsetzung des IStGH-Statuts in Form des Erlasses des VStGB nur einige wenige Paragraphen im StGB. Besonders beim Völkerstrafrecht war eine Entscheidung der Frage nach der unmittelbaren Anwendbarkeit als Rechtsgrundlage irrelevant, stößt die praktische Anwendung doch besonders am Beispiel der deutschen Rechtsordnung bei der Einhaltung des Bestimmtheitsgrundsatzes nach Art. 103 Abs. 2 GG an ihre Grenze.

Auch, wenn es in der Rechtsprechung bei der Aufarbeitung der Mauerschützenfälle der DDR Ausnahmen und Lockerungen des Bestimmtheitserfordernisses gegeben hat und im StGB vereinzelte Völkerstrafrechtstatbestände vorhanden waren, wurde im Jahr 2002 mit dem VStGB ein Gesetz geschaffen, das die vorherigen Defizite der Rechtslage ausgleichen sollte. Das Völkerstrafrecht wurde für die deutsche Rechtspraxis praktikabler gemacht, was 
sich durch die Anzahl der Verfahren und auch positiven Strafurteile bestätigt. Der deutsche Gesetzgeber ist dabei seiner Verpflichtung nachgekommen der Völkerrechtsfreundlichkeit Rechnung zu tragen.

Das VStGB und seine praktische Anwendung sind positive Beispiele dafür, dass die Eingliederung der völkergewohnheitsrechtlichen Regeln und Grundsätze gem. Art. 25 GG den deutschen Gesetzgeber dazu bringt, die nationale Rechtslage im Lichte der völkerrechtsfreundlichen Auslegung und Anwendung bundesgesetzlich für die Bewohner des Bundesgebietes zu gestalten. 


\section{$\S 5$ Völkerrechtliche Individualrechte - Die Literatur als Motor individueller}

\section{Rechtsansprüche aus Art. 25 GG}

In der Rechtslehre haben sich mehrere Autoren in spezifischen Einzelgebieten diesem Thema angenommen und untersucht, inwieweit Art. 25 Satz 2 GG unmittelbar einen individuellen Anspruch in praktischen Beispielen vermittelt. Im Folgenden werden einzelne Werke des letzten und aktuellen Jahrhunderts herangezogen und auf ihre Stichhaltigkeit untersucht, und ob aufgrund neuerer Erkenntnisse die Ansichten und Ergebnisse der Autoren noch haltbar sind. In anderen Kapiteln werden diese Werke in Bezug zu den dortigen Themen verglichen, hier soll ein differenzierter Blick auf deren Bedeutung für Art. 25 Satz 2 GG geworfen werden.

Für die Auswahl dieser Werke ist entscheidend gewesen, dass diese einerseits am Beispiel des Fremdenrechts Einblicke in die Argumentation aus den 1960er sowie 2010er Jahren gewähren und andererseits eine sozial- und gesellschaftspolitischer Betrachtung der allgemeinen Völkerrechtsregeln am Beispiel der progressiven Inklusion ermöglichen. Ein Augenmerk wird dabei deshalb auf die genannten Teile der Wissenschaft gelegt, die auch rein staatengerichtete Regeln als Individualrechte ansehen und auch Art. 25 Satz 2 GG eventuell als Rechtsgrundlage anerkennen, da in dem dieser Bearbeitung zugrundeliegenden Urteil des BVerwG gerade über die etwaige Anspruchsbegründung von staatengerichteten allgemeinen Völkerrechtsregeln entschieden wurde. Dabei werden auch vereinzelt Entscheidungen der deutschen Rechtsprechung herangezogen, die sich in ihren Urteilsbegründungen teils gezielt mit älteren und neueren Meinungen des Schrifttums auseinandergesetzt haben, um darzustellen, inwieweit diese in der praktischen Umsetzung haltbar sind.

\section{Die innerstaatliche Gerichtsbarkeit der allgemeinen Völkerrechtsregeln}

Teilweise wird von Teilen der Literatur vertreten, dass nur dann unmittelbare subjektive Rechte und Pflichten erzeugt werden, wenn die völkerrechtlichen Normen dies direkt oder indirekt vorsähen. Dies sei nur bei Normen der Fall, die beinhalten und bezwecken, in 
Rechtsverhältnisse Einzelner einzugreifen. Der ursprünglichen Rechtsprechung des BVerfG folgend wird insoweit Art. 25 Satz 2 GG als lediglich deklaratorisch angesehen. ${ }^{319}$ Es gibt auch Stimmen, die zumindest eine weitgehend individualschützende oder individualverpflichtende Finalität völkerrechtlicher Normen fordern (beispielsweise das humanitäre Kriegsvölkerrecht ${ }^{320}$, die Freiheiten der Hohen See ${ }^{321}$ oder der Mindeststandard des Fremdenrechts $\left.{ }^{322}\right)^{323}$, und den neueren Tendenzen der höchstrichterlichen Rechtsprechung entsprechen. ${ }^{324}$ Diese lehnt Deiseroth als zu „restriktiv“ ab und erklärt, sie seien weder mit dem Wortlaut, noch mit der Entstehungsgeschichte des Art. 25 GG vereinbar. Seiner Meinung nach können Bürger nach Art. 25 Satz 2 GG vor deutschen innerstaatlichen Gerichten einfordern, dass deutsche Hoheitsträger uneingeschränkt die allgemeinen Völkerrechtsregeln einhalten müssen. ${ }^{325}$

Schmid glaubte, Deutschland sollte als erstes Land mit der herrschenden Doktrin brechen und zum Ausdruck bringen, dass Völkerrecht auch im innerstaatlichen Recht den einzelnen Deutschen bedingt, bestimmt und sich unmittelbar an diesen wendet. ${ }^{326}$

Auch Deiseroth vertritt, dass daraus abzuleiten sei, jeder Einzelne könne sich in den ,entsprechenden“ Verfahren auf die Regeln des Art. 25 GG berufen, unabhängig ihrer Beachtung als objektives Recht durch die deutschen Staatsorgane. Er definiert allerdings nicht die jeweiligen Verfahren, und er äußert ebenfalls nicht, ob sich die Einzelnen nun auf Art. 25 GG als Anspruchsgrundlage oder die jeweiligen allgemeinen Völkerrechtsregeln stützen sollen. Für den Autor kommt es nicht auf die gesetzliche Konkretisierung an, die Subjektivierung bejaht er generell. Gerade dies begründe aufgrund von Art. 25 Satz 2 GG eine mögliche Verpflichtung der staatlichen Organe zur Wahrung der allgemeinen Völkerrechtsregeln. ${ }^{327}$

Ein wenig konkretisiert Deiseroth dann doch die möglichen Verfahren zu Art. 25 GG. Einzelne sollen sich über Art. 2 Abs. 1 GG, im Zweifel nach Erschöpfung des Rechtswegs, mit

\footnotetext{
${ }^{319}$ So etwa BVerfGE 63, 343 (373 f.); 112, 1 (22); restriktiv ohne weitere Begründung BVerwGE 86, 99 (119); im Schrifttum unter anderem v. Heinegg, in: Epping/Hillgruber, Art. 25 GG, Rn 35; Wollenschläger, in: Dreier, Art. 25 GG, Rn 34.

${ }^{320}$ Herdegen, in: Maunz/Dürig, Art. 25 GG, Rn 89.

${ }^{321}$ Herdegen, in: Maunz/Dürig, Art. 25 GG, Rn 89.

${ }^{322}$ Ders.

${ }^{323}$ Gegen die Drittwirkung dieser jeweiligen Regeln: v. Heinegg, in: Epping/Hillgruber, Art. 25 GG Rn 35.1.

${ }^{324}$ BVerfGE 112,1 (22 f.).

${ }^{325}$ Deiseroth, in: Das Recht in guter Verfassung?, S. 25 (36).

${ }^{326}$ Der Parlamentarische Rat: 1948-1949, Fünfte Sitzung des Hauptausschusses vom 18.11.1948 bzgl. Art. 29 des Herrenchiemsee Entwurfs (später Art. 25 GG), S. 160, 161.

${ }^{327}$ Deiseroth, in: Das Recht in guter Verfassung?, S. 25 (37); a. A. allerdings Wollenschläger, in: Dreier, Art. 25 GG, Rn 15.
} 
der Verfassungsbeschwerde gegen gerichtliche Entscheidungen wenden können, gehören die allgemeinen Völkerrechtsregeln doch zur verfassungsmäßigen Ordnung im Sinne des Art. 2 Abs. 1 GG. ${ }^{328}$

In Kapitel $\S 6$ wird diese Variante der verfahrensrechtlichen Geltendmachung thematisiert werden und es wird sich herausstellen, dass diese Option der Rechtsdurchsetzung erfolgreich ist. Interessant wäre jedoch ein tieferer Einblick Deiseroths in den vorhergehenden Instanzenzug gewesen, dort speziellere Ausführungen vor allem zur problematischen Klagebefugnis anzustrengen. Dies lässt der Autor allerdings unbegründet und ohne weitere Beachtung aus.

\section{Beispiel Fremdenrecht}

Dieser Abschnitt beschäftigt sich mit dem völkerrechtlichen Fremdenrecht und wird die Bedeutung und individuelle Schutzrichtung des Art. 25 GG untersuchen. Dieses wird vorwiegend den allgemeinen Rechtsgrundsätzen entnommen. Das Werk Doehrings zum Fremdenrecht wird als prominentestes Beispiel des subjektivierungsfreudigen Schrifttums auch heute noch als Hauptargument herangezogen. Dabei unterstützte er als Vorreiter und vor dem Hintergrund der Ausgangslage zur Zeit der Schaffung des Grundgesetzes nach dem Zweiten Weltkrieg die Anerkennung und Durchsetzung fremdenrechtlicher Individualansprüche und Einzelansprüchen aus dem völkerrechtlichen Gewaltverbot. Seiner Meinung nach ist die beschriebene Zweiteilung der (staaten- und individualgerichteten) Normen nicht ausreichend berïcksichtigt worden. Er knüpfte diese Bemerkung an Friesenhahns Arbeit, in welcher dieser feststellte, dass , ,[...] souveräne Staaten allein Rechtspersonen der Völkergemeinschaft seien, und die Einzelnen erscheinen nur als Subjekte von Rechten [...], soweit der das Völkerrecht bildende Wille der Staaten ihnen solche Rechte zuerkenne““. 329 Der Kern seiner Untersuchung lag darin, die etwaige Konkurrenz der allgemeinen Völkerrechtsregeln Art. 25 GG zum Gleichheitsgrundsatz des Art. 3 GG nahezulegen und diese systematisch aufzuklären. Dabei beachtete er unter anderem die Frage nach der Ausländereigenschaft als sachlichen Differenzierungsgrund. Zu diesem konkreten Beispiel erkannte

\footnotetext{
${ }^{328}$ BVerfGE 23, 288 (300); BVerfGK 3, 27 (28 f.); Deiseroth, in: Das Recht in guter Verfassung?, S. 25 (37); Fischer-Lescano, Militärbasen und militärisch genutzte Flughäfen, S. 18.

${ }^{329}$ Siehe Friesenhahn, Der Internationale Schutz der Menschenrechte, S. 52; Doehring, Fremdenrecht, S. 108. 
der BGH die Ausländereigenschaft bei der Amtshaftung als zu berücksichtigenden Tatbestand an. ${ }^{330}$ In jüngeren Strafentscheidungen, vor allem bei der Beurteilung der Strafzumessung, durfte die Ausländereigenschaft vor dem Hintergrund des wertzuschätzenden Gastrechts in Deutschland jedoch nicht als strafschärfend erachtet werden und wurde vom BGH auch als Verstoß gegen Art. 3 Abs. 3 GG gewertet. ${ }^{331}$ Während auch das Sozialversicherungs-recht keinen Unterschied zwischen Inländern und Ausländern bei der Beitragspflicht oder Leistungsberechtigung macht, gab es für den BGH auch im Jahr 1986 bei der Amtshaftung einen Aspekt, der solche Unterschiede zugelassen hat. Um ausländischen Staaten ein Motiv zur Gegenseitigkeit zu liefern und deutschen Staatsangehörigen eine verbesserte Rechtsstellung zu gewähren, bestand bei mangelnder Gegenseitigkeit ein Haftungsausschluss für den Staat bei Amtspflichtverletzungen. Der BGH führte indes damals schon aus, dass diese Ansicht eng auszulegen sei, denn eine engere internationale Verflechtung von Wirtschaft und Handel ließen solche Differenzierungen fragwürdig erscheinen. ${ }^{332}$ Betrachtet man die Situation 30 Jahre später unter diesem Blickpunkt, kann den Richtern nur zugestimmt werden, denn die Verflechtungen sind im Zeitalter der Globalisierung noch dichter geworden.

Insbesondere seien hier die Europäische Freizügigkeit ${ }^{333}$ und das Europäische Diskriminierungsverbot nach Art. 14 EMRK, Art. 18 AEUV erwähnt.

Doehring führte weiter aus, dass das Völkerrecht eine solche Diskriminierung nicht schlechthin verbiete. ${ }^{334}$ Darauf aufbauend werden im Weiteren seine Ausführungen näher betrachtet und ins Licht der tatsächlichen Praktikabilität allgemeiner völkerrechtlicher Regeln gerückt.

${ }^{330} \mathrm{BGH}$, Urteil vom 01.10.1956, Az. III ZR 48/55, in: NJW 49/1956, S. 1836-1837 (Leitsatz 1 und Gründe), Rn 17 f. nach juris.

${ }^{331}$ BGH, Beschluss vom 25.04.1986, Az. 2 StR 74/86, in: StV 1987, S. 20; siehe auch BGH, Beschluss vom 29.11.1990, Az. 1 StR 618/90, in: StV 1991, S. 105; Beschluss vom 10.09.1991, Az. 2 StR 375/91, in: StV 1991, S. 557; Urteil vom 23.08.2005, Az. 5 StR 195/05, in: NStZ 35/2006, S. 35 f.; OLG Hamm, Beschluss vom 22.09.2016; Az. III-5 RVs 68/16, 5 RVs 68/16, Rn 2 nach juris.

${ }^{332} \mathrm{BGHZ} 99,62$ (64).

${ }^{333}$ Gesetz über die allgemeine Freizügigkeit von Unionsbürgern, erlassen am 30.07.2004 (BGBl. I S. 1950 ff.).

${ }^{334}$ Doehring, Fremdenrecht, S. 17; mit Verweis auf die Entscheidungen Chal Chan Ping vs USA (1889) 130 U.S. 581 und Fong Yve Ting vs USA (1893) 149 U.S. 698. 


\subsection{Der Wortlaut des Art. 25 Satz 2 GG als Indiz für Individualrechte?}

Die Auslegung des Art. 25 GG machte es für den Autor unzweifelhaft möglich, Individualrechte prozessieren zu können. Dabei stützte er sich ausschließlich auf den Wortlaut des Art. 25 Satz 2 GG und dessen Entwicklung aus Art. 4 WRV. Doehring kritisiert die Betrachtung der Zuerkennung von Individualrechten in Art. 25 GG als rein deklaratorisch und beruft sich auf die Sicht der kommentierenden Literatur aus dem Jahr 1957. ${ }^{335}$ Wie bereits herausgestellt wurde und der Entstehungsgeschichte des Art. 25 GG entnommen werden kann, hat sich von Mangoldt mit seiner Auffassung im Konvent von Herrenchiemsee nicht durchsetzen können, die Formulierung des Art. 25 GG am Art. 4 WRV zu orientieren. Allerdings teilte er auch nicht die Meinung, Art. 25 GG vermittele eine deutlich andere Rechtslage als Art. 4 WRV. Er lag richtig in der Herausarbeitung der einzelnen allgemeinen Völkerrechtsregeln nach Staatenbezogenheit und Individualbezogenheit und dem Erfordernis eines Individualbezugs wie ihn auch die Rechtsprechung nach 2000 forderte. ${ }^{336}$ Weiter bemängelte der Autor in seiner Darstellung, dass die Tragweite des Umfangs der Rechte und Pflichten aus Art. 25 GG vom Gesetzgeber „,wohl kaum erkannt worden“ seien. Dabei handele es sich deshalb um ein Dilemma, weil der Art. 25 GG eine „Blankettnorm“ sei und diese eine Rechtsordnung auffasse, deren Grenzen hinsichtlich des objektiven Rechts und auch hinsichtlich der Adressaten fließend seien. Die aus der primär auf Staaten angelegten Rechtsordnung erzeugten Rechte und Pflichten im Sinne des Art. 25 Satz 2 GG gefährdeten jedoch die Rechtssicherheit als wichtigstes Merkmal des Individualschutzes. ${ }^{337}$ Mangels ausgiebiger Rechtsprechung und der streitigen Literatur kann Doehring in seiner Annahme auch über 50 Jahre nach Erscheinen seines Buches zugestimmt werden. Über die wirklichen Grenzen des Art. 25 GG und über dessen Bedeutung ist sich die Rechtspraxis auch heute uneins. Die in vorherigen Kapiteln gezeigte Entwicklung der Völkerrechtssubjektivität war bereits in den frühen Sechzigerjahren Anlass genug für Repräsentanten des Fremdenrechts, im Zusammenhang mit der Fortentwicklung allgemeiner Menschenrechte auch eine gesteigerte Festigung des fremdenrechtlichen Mindeststandards zu sehen. ${ }^{338}$

\footnotetext{
${ }^{335}$ Vgl. v. Mangoldt/Klein, Das Bonner Grundgesetz, Bd. 1, S. 682 (später ausführlich zur Problematik der Auslegung des Satz 2 von Koenig, in: v. Mangoldt/Klein/Starck, Kommentar zum Grundgesetz, Art. 25 GG, Rn 56 f.) unter Berufung auf Dahm, Zur Problematik des Völkerstrafrechts, S. 68.

${ }^{336}$ Nicht zuletzt BVerwGE 154, 328 (345 f., 348 f.); Doehring, Fremdenrecht, S. 44, 45.

${ }^{337}$ Siehe Doehring, Fremdenrecht, S. 50.

${ }^{338} \mathrm{IGH}$, Advisory Opinion of 11.04.1949, Reparations for injuries suffered in the service of the United Nations, ICJ Report 1949, S. 178; Accioly, in: Collected Courses of the Hague Academy of International Law 96/1959, S. 404 (422).
} 
Dennoch begründet allein die Rechtssubjektivität noch keine Klagebefugnis, weder im Völkerrecht, noch im innerstaatlichen Recht. ${ }^{339}$ Auch ist darauf hinzuweisen, dass bei der Nationalisierung fremden Eigentums der betroffene Einzelne, sowie auch dessen Heimatstaat, als Gläubiger von Entschädigungsforderungen angesehen werden müssen; ein Anspruch könnte wiederum nur vom Heimatstaat geltend gemacht werden, da nur dieser als Völkerrechtssubjekt anzusehen sei. ${ }^{340}$ Ähnlich argumentierte auch der IGH im LaGrandFall 2001. Auch hier ist eine Parallelität erkennbar.

\subsection{Der fremdenrechtliche Individualanspruch aus Art. 25 GG}

Der Großteil der fremdenrechtlichen Regeln begünstigen die Heimatstaaten der betroffenen Individuen. Der Rest schützt Individualinteressen und erschöpft sich in den Rechtssätzen, die sich auf allgemein anerkannte Menschenrechte beziehen und im Fremdenrecht als „Mindeststandard“ bekannt sind. ${ }^{341}$

\subsection{Art. 25 GG und Art. 3 GG als Grundsätze des innerstaatlichen Fremdenrechts}

Das völkerrechtliche Fremdenrecht beruht auf dem Völkergewohnheitsrecht und gehört damit zu den allgemeinen Völkerrechtsregeln und über Art. 25 Satz 2 GG zum deutschen innerstaatlichen Recht. Praktisch ist die Handhabung gerade dieser Rechtssätze jedoch schwierig, da sie nicht vom deutschen Gesetzgeber abhängen und das Individuum als innerstaatlicher Adressat nicht in der Lage ist, den Inhalt und damit die eigenen Rechte und Pflichten abzumessen. ${ }^{342}$ Diese Bemerkung trifft auch heute noch zu, bereiten das Gesetzlichkeitsprinzip und das Bestimmtheitsgebot aus Art. 103 GG, wie in Kapitel § 4 gezeigt, unter anderem in der Praxis des Völkerstrafrechts erhebliche Anwendungsschwierigkeiten des Völkergewohnheitsrechts.

\footnotetext{
${ }^{339}$ Jellinek, System der subjektiven öffentlichen Rechte, S. 119; siehe auch IStGH, Peter Pàzmàny University Case, PCIJ Ser. A/B, No. 61, S. 231: „It is scarcely necessary to point out that the capacity to possess civil rights does not necessarily imply the capacity to exercise those rights oneself.“

${ }^{340}$ Vannod, Fragen des internationalen Enteignungs- und Konfiskationsrechts, S. 26.

${ }^{341}$ Doehring, Fremdenrecht, S. 107.

${ }^{342}$ Dies erkennt auch Doehring selbst an: Doehring, Fremdenrecht, S. 118.
} 
Ebenso wie Peters hatte Doehring bereits die Entwicklung subjektiver Individualrechte herausgestellt, beispielsweise die Erstarkung allgemeiner Menschen- und Grundrechte, so wie auch politische und wirtschaftliche Zusammenschlüsse und auch geographische Verschiebungen. ${ }^{343}$ Hieraus ist insgesamt eine Fortentwicklung des Fremdenrechts abzuleiten. Art. 25 GG ordnet die Anwendung aller allgemeinen Völkerrechtsregeln an, einschließlich des Fremdenrechts. Art. 3 GG fordert die Gleichbehandlung aller Menschen, die sich im deutschen Hoheitsgebiet befinden. Eine Beschränkend des Anwendungsbereichs auf Deutsche gibt es nicht. Der Rechtssatz könnte daher völkerrechtlich zulässigen Differenzierungen - ein ebensolches Differenzierungsverbot gibt es im Völkerrecht nicht - entgegenstehen.

\subsection{Die „Erzeugung“von Rechten und Pflichten nach Art. 25 Satz 2 GG}

Nach Inkrafttreten des Grundgesetzes hatten sowohl Rechtsprechung als auch Literatur die Tragweite des Art. 25 Satz 2 GG lange noch nicht eingehend untersucht. Auch heute werden Reichweite und Bedeutung der allgemeinen Völkerrechtsregeln in Deutschland zwar regelmäßig behandelt. Lediglich kurze Bemerkungen zur Vorschrift und der dreifachen Unterscheidung in ausschließlich staatengerichtete, staatengerichtete und individualbezogene sowie lediglich individualbezogene Völkerrechtsregeln bekräftigen allerdings keine endgültige dogmatische Erkenntnis. Der völkerrechtliche Verweis des Grundgesetzes bleibt beiläufig erwähnt, aber inhaltlich überwiegend unberührt, obwohl sich seit der Veröffentlichung von Doehrings Werk zum Fremdenrecht mit der veränderten Stellung des Individuums und dessen Völkerrechtssubjektivität Neues ergeben hat. Nochmals zu berücksichtigen ist hier die bereits zu Beginn der Untersuchung herausgestellte Sichtweise des BVerwG zur unmittelbaren Geltung und der Voraussetzung eines konkreten, zumindest teilweisen, Individualbezugs des Betroffenen zur allgemeinen Völkerrechtsregel.

Diese neuere Ansicht steht Doehrings Auffassung nicht entgegen, der Art. 25 Satz 2 GG nach dessen Wortlaut auslegt und die „Erzeugung“ von Individualrechten für ansonsten staatengerichtete Regeln, die das Verhalten gegenüber Fremden zum Gegenstand haben, annimmt, sollten diese von Individuen in Anspruch genommen werden können. ${ }^{344}$

\footnotetext{
${ }^{343}$ Peters, Jenseits der Menschenrechte, S. 425 f.; Doehring, Fremdenrecht, S. 158.

${ }^{344}$ Doehring, Fremdenrecht, S. 158.
} 
Ansprüche gegen Kriegsgegner auf Wiedergutmachung gehören beispielsweise jedenfalls nicht dazu. Art. 25 GG kann keinesfalls eine Wirkung entfalten, dass Deutsche von ihrer Regierung die Einhaltung solcher Pflichten einfordern könnten, da es sich dabei höchstens um Pflichten gegenüber fremden Staaten handele und Art. 25 GG innerstaatlich völkerrechtmäßiges Verhalten vorschreibt. ${ }^{345}$ Doehring behauptete ferner, das völkerrechtliche Fremdenrecht gewähre dem Einzelnen jedoch nicht mehr als eine Rechtsstellung betreffend den Mindeststandard. Eine Behörde könnte sich daher gem. Art. 25 GG darauf berufen, nicht mehr als dass durch das Völkerrecht Gewährte zuzuerkennen. Die Behörde hätte zwar die Pflicht Fremde gemäß Völkerrecht zu behandeln, sie hätte aber auch die Pflicht zur Anwendung des Völkerrechts zugunsten des Aufenthaltsstaates, und diese Schutzfunktion stamme aus dem Art. 25 Satz 2 GG. ${ }^{346}$ Das Völkerrecht gewährt generell auch keinen mit dem deutschen Art. 3 GG vergleichbaren Gleichbehandlungsgrundsatz bezüglich der Einbürgerung Fremder. ${ }^{347}$

Insgesamt vertrat Doehring eine Rechtsauffassung, die bis heute nicht widerlegt werden konnte. Fremde können sich nur dann auf völkerrechtliche Rechtssätze berufen, wenn diese ausdrücklich diesem eine günstigere Position verschaffen als das ins innerstaatliche Recht übernommene Völkerrecht.

\subsection{Rang und Vorrang des Art. 25 GG im Fremdenrecht}

Entscheidend ist bei Doehrings Bearbeitung und Rechtsauffassung, dass er den allgemeinen Völkerrechtsregeln einen Gleichrang mit den anderen Normen des Grundgesetzes einräumt. Daraus entspringt, Art. 25 GG als lex specialis zu Art. 3 GG zu sehen, so dass die

\footnotetext{
${ }^{345}$ So bspw. Schack, in: DVB1. 21/1957, S. 740 (749); BVerfGE 94, 315 f.; kürzlich zur Schutzpflicht des Staates OVG Münster, Urteil vom 19.03.2019, Az. 4 A 1361/15, in: NJW 26/2019, S. 1898.

${ }^{346}$ Doehring, Fremdenrecht, S. 167.

${ }^{347}$ Doehring, Fremdenrecht, S. 169; Hauser, Die den Ausländern in der Schweiz garantierten Freiheitsrechte, S. 20: Jedoch entspringt dem Art. 25 GG kein Anspruch, Staaten beispielsweise auf die Einbürgerung Fremder zu verpflichten. Es bestünde aber auch keine staatliche Pflicht zur gerichtlichen Überprüfung ergangener Abweisungen. Ebenso erwächst Fremden kein Anspruch zur strikten Einhaltung der Gleichberechtigung bezüglich fremder Staatsangehöriger im Sinne der Inländerbehandlung aus Art. 25 GG, also auch kein Anspruch auf eine fehlerfreie Ermessensentscheidung.
} 
allgemeinen Völkerrechtsregeln Vorrang vor dem nationalen Gleichheitsgrundsatz genieBen. ${ }^{348}$ Der Autor sieht einen Sonderstatus des Fremden für die übrigen Verfassungsnormen und einfachen Gesetze. Er sieht zutreffend, dass die Frage des Ranges der allgemeinen Völkerrechtsregeln von Bedeutung für das Fremdenrecht ist, da davon auch die Auslegung und Handhabung des verfassungsrechtlichen Gleichheitssatzes abhängen. Stünde Art. 25 GG über dem Grundgesetz, würden Rechtsregeln des völkerrechtlichen Fremdenrechts dem übrigen Verfassungsrecht übergeordnet. Bei einem Verfassungsrang des Art. 25 GG stehen diese auf derselben Stufe und sind lex specialis zum Fremdenrecht. Der sogenannte „Zwischenrang“ der allgemeinen Völkerrechtsregeln zwischen Verfassung und einfachem Gesetz ordnet die restlichen Verfassungsregeln dem Art. 25 GG über, so dass nicht Art. 25 GG lex specialis die Rechtsgrundlage zulässiger Ungleichbehandlung wäre, sondern zu fragen gälte, ob und inwiefern das Fremdsein ein vernünftiger und sachlich gerechtfertigter Unterscheidungsgrund für die Anwendung des Art. 3 GG abgeben.

Doehring macht sich insgesamt für einen Gleichrang der allgemeinen Völkerrechtsregeln mit den übrigen Verfassungsnormen stark. Er erkennt die dreistufige Systematisierung der allgemeinen Völkerrechtsregeln an und widerspricht nicht der Logik, die sie ausmacht. Mosler begründet seine Ablehnung eines Verfassungsranges damit, dass das Grundgesetz diesen für die allgemeinen Völkerrechtsregeln wohl ausdrücklich bestimmt hätte, wäre dieser gewollt, allerdings sei lediglich der Vorrang vor den Bundesgesetzen geregelt worden. Doehring kritisiert daran, dass dieser „Vorrang vor den Gesetzen“ (Art. 25 Satz 2 GG) doch den Verfassungsrang meine, einen anderen Hinweis gebe der Wortlaut nicht, schon gar keine Limitierung nach oben. ${ }^{349}$

Der Autor argumentierte weiter mit dem Gleichheitssatz des Beamtenrechts. Art. 33 Abs. 5 GG genieße ebenfalls Verfassungsrang und verweise auf ,hergebrachte Grundsätze des Berufsbeamtentums“. Den Verfassungsrang sowie einen subjektiven grundrechtsähnlichen Anspruch gegen den Staat hätte das BVerfG bestätigt. ${ }^{350}$ Daraus folgerte er, das Gericht wollte damit einen Gleichrang regeln. Allerdings zieht er daraus eine Parallelität zu Art. 25

\footnotetext{
${ }^{348}$ a. A. hierzu Talmon, in: JZ 1/2013, S. 12 (18), der eine „Blankett-Legitimierung“ für zukünftige vom Völkergewohnheitsrecht gedeckte Grundrechtseingriffe nicht mit dem Grundgesetz vereinbar sieht. Die Anwendbarkeit der allgemeinen Völkerrechtsregeln bekomme durch den Gesetzesvorbehalt konkrete Grenzen gesetzt.

${ }^{349}$ Mosler, Das Völkerrecht in der Praxis der deutschen Gerichte, S. 45; Doehring, Fremdenrecht S. 182.

${ }^{350}$ BVerfGE 12, 81 (87 f.).
} 
GG, die aus heutiger Perspektive nicht ohne weiteres nachvollziehbar ist, nicht zuletzt aufgrund des Zwischenrangs der allgemeinen Völkerrechtsregeln gegenüber dem Verfassungsrang des Art. 33 Abs. 5 GG.

Ebenso argumentierte Doehring mit Art. 25 GG als Verfassungsschranke des Grundrechts auf Asyl für fremde Staatsangehörige, den allgemeinen Völkerrechtsregeln als Teil der verfassungsmäßigen Ordnung und der Klarstellung des BVerfG hinsichtlich des Art. 25 GG als „Verfassungsgrundsatz“. ${ }^{351}$ Dies sei unmittelbarer Ausdruck der Anerkennung eines durchaus gleichgestellten Ranges, eben nicht unterhalb der Grundrechte. Den fachlichen Ausführungen schloss sich Doehring vorbehaltlos an, zumindest was die rein am Wortlaut vorgenommene Interpretation des Art. 25 GG als subjektive Rechtsgrundlage betrifft.

Beruft sich das Individuum infolge staatlicher Maßnahmen darauf, durch deren Vollzug würde beispielsweise das Verbot des Angriffskrieges verletzt, so soll Art. 25 Satz 2 GG als Rechtsgrundlage anwendbar sein. ${ }^{352}$ Er führt selbst aus, dass das BVerfG den Art. 25 GG wiederum nicht als Grundrecht oder anderes gleichgestelltes Recht im Sinne eines Beschwerdegegenstands der Verfassungsbeschwerde nach $\S 90$ Abs. 1 BVerfGG ansieht. ${ }^{353}$ Auch Münch hat in einem Aufsatz die Wortwahl der Richter kritisiert, dass Art. 25 GG „keine Grund- oder gleichgestellten Rechte enthalte“. ${ }^{354}$

Den beiden Autoren muss zugestimmt werden, dass der Katalog des $§ 90$ BVerfGG allein keinen Aufschluss über den Verfassungsrang des Art. 25 GG gibt, allerdings bleibt es auch über 50 Jahre nach Erscheinen ihrer Werke bei der Rechtsprechung der Gerichte, Art. 25 GG nicht grundrechtsgleich zu behandeln. Die Ausführungen galten auch bezüglich der Pflichtenseite des Art. 25 GG: so steht auch der Staatsgewalt zu, Fremden zum Schutze des Aufenthaltsstaats Pflichten mit Verfassungsrang entgegenhalten zu können. Die Folge eines Zwischenrangs oder Gleichrangs mit Bundesrechten wäre für Doehring eine schwächere Stellung der Staatsgewalt, da diese gehindert würde, Verfassungsansprüche von Fremden etwaige Einschränkungen entgegenzuhalten, die einem Art. 25 GG als lex specialis allerdings entnommen werden könnten. ${ }^{355}$

An dieser Stelle sei bereits erwähnt, dass nach aktueller und früherer Rechtsprechung die allgemeinen Völkerrechtsregeln auch mit der allgemeine Handlungsfreiheit gem. Art. 2

\footnotetext{
${ }^{351}$ BGHSt 3, 392 (394); der BGH zu den allgemeinen Völkerrechtsregeln als Teil der ,,verfassungsmäßigen Ordnung“, BGHSt 7, 394 (402); BVerfGE 1, 208 (233); Doehring, Fremdenrecht, S. 185.

${ }^{352}$ Doehring, Fremdenrecht, S. 165 f.; Doehring, in: HdStR Bd 7, § 178 Rn 24, 25, 31.

${ }^{353}$ BVerfGE 4,110 (111 f.); so auch Cremer, in: HdStR Bd. 11, § 235 Rn 33.

${ }^{354}$ Münch, in: ZaöRV 1959, S. 186 (195).

${ }^{355}$ Doehring, Fremdenrecht, S. 187.
} 
Abs. 1 GG verknüpft geltend gemacht werden können. ${ }^{356}$ Sogenannte „Deutschen-Grundrechte“, die von fremden Staatsangehörigen nicht in Anspruch genommen werden können, werden nach der unionsrechtskonformen Auslegung inhaltlich ebenso über Art. 2 Abs. 1 GG ausgestaltet und entfalten ähnliche Schutzwirkungen.

Doehring stützte auf seine Auffassung des Gleichrangs des Art. 25 GG mit den übrigen Verfassungssätzen die Heranziehung des Art. 25 GG, wo der Gleichheitsgrundsatz des Art. 3 GG nicht zweifelsfrei die Unterscheidung zwischen Deutschen und Fremden verboten hat. So wie bei der unterschiedlichen Behandlung von Beamten auf die hergebrachten Grundsätze des Berufsbeamtentums gem. Art. 33 Abs. 5 GG zurückgegriffen werden könnte, müsste im Rahmen der Ungleichbehandlung von Fremden auf die allgemeinen Völkerrechtsregeln gem. Art. 25 GG zurückgegriffen werden. ${ }^{357}$ Danach sei es der Gleichheitssatz, der durch Art. 25 GG eingeschränkt würde, nicht umgekehrt. Das völkerrechtliche Fremdenrecht fungiere derweil als Maßstab der innerstaatlichen Auslegung des Gleichheitssatzes. Art. 25 GG wird dabei als Maßstab zur Behandlung von fremden Rechtssubjekten herangezogen, sofern nicht andere Verfassungsnormen andere vom Völkerrecht abweichende Ergebnisse fordert und soweit als lex specialis gleichen Ranges zu beachten ist. Die Fremdheit darf nicht als ausdrückliches Diskriminierungsverbot aus Art. 3 Abs. 3 GG angesehen werden, so dass die staatliche Gewalt regelmäßig berechtigt ist, sich bei der Behandlung des Art. 3 GG auf die Einhaltung des Fremdenrechts zu beschränken. Sie ist verpflichtet, den Mindeststandard des Völkerrechts zu achten und dazu berechtigt, oberhalb dieses Mindeststandards gleichermaßen zu diskriminieren wie das Völkerrecht es zulässt, das kein allgemeines Gebot zur Inländerbehandlung enthält. ${ }^{358}$ Dies stimmt auch mit der Rechtsprechung des BVerfG mit Hinblick auf Art. 3 Abs. 3 GG überein. Daraus folgt eine Pflicht zur Berücksichtigung des faktischen Tatbestands einer fremden Staatsangehörigkeit bei Art. 3 Abs. 1 GG bis zu der Willkürgrenze, die Art. 25 GG bestimmt. Ein Verbot zur Berücksichtigung dieses Unterschieds kann Art. 3 Abs. 2 GG jedoch nicht entnommen werden. ${ }^{359}$ Das BVerwG stellte fest: „Auch aus dem Gleichheitsgrundsatz des Art. 3 GG ergibt sich nichts anderes. Er verbietet dem Gesetzgeber nicht, zwischen Ausländern und Inländern sachliche Unterschiede zu machen. Ebenso wenig kann sich der Kläger auf das

\footnotetext{
${ }^{356}$ Siehe dazu insbesondere in Kapitel $§ 7$ und $§ 8$.

${ }^{357}$ Doehring, Fremdenrecht, S. 191: Er zieht u. a. H. P. Ipsen argumentativ heran, der nach seiner Auffassung richtig berücksichtige, dass dem Gleichheitssatz durch das Fremdenrecht völkerrechtliche Einschränkungen entgegenstünden: H.-P. Ipsen, Gleichheit, in: Die Grundrechte, S. 133 f., 158.

${ }^{358}$ Doehring, Fremdenrecht, S. 204, 205.

${ }^{359}$ BVerfGE 9, 124 (128).
} 
Völkerrecht berufen. Zwar sind nach Art. 25 GG die allgemeinen Regeln des Völkerrechts Bestandteil des Bundesrechts geworden. Aber es gibt keinen völkerrechtlichen Rechtssatz, wonach der Ausländer ohne weiteres dieselben Aufenthalts- und Niederlassungsrechte wie ein Inländer hat. ${ }^{360}$ Doehring kritisierte das Gericht dahingehend, dass die Pflicht zur Berücksichtigung der Fremdeneigenschaft durch Art. 25 GG explizit vorgeschrieben sei und nicht lediglich durch den Gleichheitssatz nach Art. 3 GG gewährt werde. Deshalb verstoße die Voraussetzung einer Gegenseitigkeit bei der Staats- und Amtshaftung für Fremde nicht gegen den Gleichheitssatz. ${ }^{361}$ Der BGH stellte ebenso fest, dass durch Art. 3 GG keine gänzliche Gleichbehandlungspflicht von Ausländern und Deutschen gefordert würde. ${ }^{362}$ Doehring merkte auch dazu an, dass nicht von ungleichen Tatbeständen gesprochen hätten werden sollen, sondern vom Maßstab zulässiger Ungleichbehandlungen im Fremdenrecht durch Art. 25 GG. ${ }^{363}$

\subsection{Zwischenergebnis}

Art. 25 GG wurde hinsichtlich des völkerrechtlichen Fremdenrechts überdeutlich am Wortlaut ausgelegt und allein daraus und mit Verweis auf die Entstehungsgeschichte wurden Individualansprüche hergeleitet. Somit ist die unmittelbare Geltung für alle Adressaten begründet. Art. 25 GG erkenne das Völkerrecht „,vorbehaltlos“ an und erzeuge Individualrechte, die den Staat in völkerrechtlich legitimierten Abwehrmaßnahmen behindern könnten. ${ }^{364}$ Art. 25 Satz 2 GG könne durch die einzelnen Individuen im Falle des Verstoßes gegen allgemeine Völkerrechtsregeln als Anspruchsgrundlage dienen. Dieser Anwendungsbefehl war für Doehring derart schlagkräftig, dass die spezifische innerstaatliche Sicht der Völkerrechtsnormen sogar über den Theorienstreit zwischen Dualismus und Monismus hinweg- und es auf diesen dabei nicht ankomme. Daran anknüpfend zog er die Verbindung zum deutschen Gleichheitsgrundsatz, dieser könne ähnliche Folgen haben bei einer Auslegung, die die Forderungen des Fremdenrechts überschneidet. Bei den beiden Vorschriften handele es sich um diejenigen, deren Auslegung für die Anwendung aller anderen Vorschriften des Fremdenrechts innerstaatlich von Bedeutung ist. Doehrings Auffassung

\footnotetext{
${ }^{360}$ BVerwGE 3, 235 (236).

${ }^{361}$ BGHZ 13, 241 (243).

${ }^{362}$ BGH, Urteil vom 01.10.1956, Az. III ZR 48/55, in: NJW 49/1956, S. 1836 f.

${ }^{363}$ Doehring, Fremdenrecht, S. 194.

${ }^{364}$ Doehring, Fremdenrecht, S. 118.
} 
hat allerdings nur dann Bestand, wenn man auf eine bis heute umstrittenen Mindermeinung besteht, die den allgemeinen Völkerrechtsregeln einen Gleichrang mit der deutschen Verfassung einräumt. Anderenfalls ist es nicht möglich, Art. 25 GG als lex specialis zu Art. 3 GG zu werten und den völkerrechtlichen Fremdenrechten einen Vorrang zukommen zu lassen. Bis heute hat sich jedoch der sogenannte Zwischenrang der allgemeinen Völkerrechtsregeln als überwiegend anerkannte Überzeugung gehalten. ${ }^{365}$ Die aufgezeigte Argumentation und Grundhaltung entspringt der nachwirkenden Ausgangslage zur Zeit der Schaffung des Grundgesetzes. Nach dem Zerfall des nationalsozialistischen Deutschlands wollten auch führende Rechtspersönlichkeiten der Bundesrepublik Deutschland ein uneingeschränktes Bekenntnis gegenüber der Völkerrechtstreue Deutschlands bekunden. Auch die Auffassung, ein Adressatenwechsel durch Art. 25 Satz 2 GG hinsichtlich staatengerichteter allgemeiner Völkerrechtsnormen sei zwingend notwendig, um ansonsten die Übernahme in den innerstaatlichen Rechtsraum nicht sinnlos werden zu lassen ${ }^{366}$, überzeugt nicht. Art. 25 GG entfaltet ein umfängliches Berücksichtigungsgebot, welches die deutsche Staatsgewalt dazu verpflichtet, ihre Handlungen und Rechtsakte konform mit Regeln des allgemeinen Völkerrechts auszuführen.

\section{Beispiel Migrationsrecht}

Am Beispiel der Zugehörigkeit und Teilhabe im Migrationsrecht gibt es Ansätze in der Literatur, völkerrechtlichen Rechtsprinzipien individuelle Geltung zu verschaffen und zur Einhaltung für die Staatsgewalt verbindlich zu machen. Untersucht wurden die progressive Inklusion und die statische Zuordnung von Personen zu Staaten als Rechtsprinzipien und deren Zuordnung zu völkerrechtlichen Rechtsquellen im Sinne des Art. 38 IGH-Statut. Farahat vertritt, dass sich Rechtsprinzipien häufig erst anhand einer Rekonstruktion verschiedener Materialien entwickeln ließen, zu denen Rechtsnormen ebenso gehörten wie die diese betreffende Rechtsprechung sowie Beschlüsse völkerrechtlicher Vertragsorgane, die keine Verpflichtungswirkung für die Staaten entfalten. ${ }^{367}$

\footnotetext{
365 Jüngst bestätigt in BVerfGE 141, 1 (17); 143, 101 (135).

${ }^{366}$ Doehring, Fremdenrecht, S. $153 \mathrm{f}$.

${ }^{367}$ Farahat, Progressive Inklusion, S. 266.
} 
Die Prinzipien der progressiven Inklusion und der statischen Zuordnung von Personen zu Staaten sollen Migranten in die soziale, wirtschaftliche und politische Ordnung ihres Aufenthaltslandes einbeziehen, indem sie von vornherein mit eigenen Rechten ausgestattet werden. ${ }^{368}$ Der Rechtsstatus der Staatsangehörigen soll bestenfalls auch für Migranten unverzüglich erreicht werden zwecks nachhaltiger Verfestigung in den dauerhaften Aufenthaltsstaaten. Es widerspräche dem Inklusionsprinzip, bekämen Migranten nur den minimalen grundrechtlichen Schutz gewährt, der jedem Menschen im Aufenthaltsstaat zukommt. Es sollten vielmehr darüberhinausgehende Teilhaberechte gewährt werden, um die Inklusion zu fördern. Dafür soll auch die europäische Rechtsauffassung sprechen. ${ }^{369}$ Die Inklusion erfolge dabei schrittweise, die Teilhaberechte müssen nicht unverzüglich identisch mit den Rechten der Staatsangehörigen sein. Es sei jedoch eine anschließende, kontinuierliche Erweiterung der Rechte vorgesehen. Auch soll die rechtliche Inklusion in mehreren Staaten gleichzeitig möglich sein, also kein Kriterium für Ausschlüsse rechtlicher Möglichkeiten im Aufnahmeland darstellen. ${ }^{370}$

\subsection{Bisherige Praxis in Deutschland anhand fiktiver Beispiele}

Anhand mehrerer fiktiver Beispiele kann die aktuelle Rechtsanwendung hinsichtlich der Berücksichtigung beider Prinzipien präsentiert werden. So etwa bei der Entscheidungspflicht von Migranten zweiter Generation mit 23 Lebensjahren bezüglich ihrer Staatsangehörigkeit oder auch der Ausweisung dieser. Die Optionspflicht begrenzt den Staatsangehörigkeitserwerb bei Geburt. Die statische Zuordnung steht beim Staatsangehörigkeitserwerb daher der Inklusion vor. Darin sollen aber unvereinbare Nichtbeachtung des Prinzips der progressiven Inklusion und bei der Optionspflicht ein Verstoß gegen Art. 3 Abs. 1 und Abs. 3 GG vorliegen. ${ }^{371}$ Zur Verbesserung der Situation von Migranten im deutschen Recht fordert Farahat eine Beteiligung von Migranten unter anderem am Wahlrecht in Deutschland, um dieses nicht lediglich den Deutschen vorzubehalten. ${ }^{372}$

\footnotetext{
${ }^{368}$ Dabei verfolgen Prinzipien die Aufgaben der „Ordnung“ bestehenden Rechts, eines „Werkzeugs“ der rechtlichen Konfliktevaluation und der „Übersetzung“ außerrechtlicher normativer Diskurse in die Rechtssprache, in: v. Bogdandy, in: v. Bogdandy/Bast, Europäisches Verfassungsrecht, S. 17 f., 20, 21.

${ }^{369}$ Farahat, Progressive Inklusion, S. 76, 77, 341.

${ }^{370}$ Farahat, Progressive Inklusion, S. 78, 79.

${ }^{371}$ Farahat, Progressive Inklusion, S. 347, 348, 350, 358.

${ }^{372}$ Farahat, Progressive Inklusion, S. 247 f., 362.
} 
Es ist nachvollziehbar, dass es der Integration dienlich wäre, könnten Migranten in Deutschland an der öffentlichen Willensbildung teilnehmen und ihrer Meinung auch politisch Ausdruck verleihen, allerdings erschließt sich nicht unbedingt die zwingende Pflicht aus einem bloßen Rechtsprinzip, dass eine Inklusion fordert und innerstaatliche Praxen folglich ungenügend seien. Immerhin ist es in Deutschland auch Ausländern möglich, die sogenannten Deutschen-Grundrechte über eine europäische Auslegung in Verbindung mit Art. 2 Abs. 1 GG vor dem höchsten Verfassungsgericht geltend machen zu können. ${ }^{373}$ Die Autorin macht selbst darauf aufmerksam, dass diese in eingeschränktem Umfang auch für Ausländer gelten. ${ }^{374}$

Es ist jedoch nicht ersichtlich, warum die Rechtsangleichung für Ausländer und Nichtdeutsche innerhalb Deutschlands nicht bereits genug Rechtsschutz und ausreichend Inklusion sein sollten. Es ergibt sich nicht, weshalb deutsche Staatsbürger und Nichtstaatsbürger rechtlich auf dieselbe Rechtsstufe gestellt werden, vor allem aber ihnen Teilhaberechte gewährt werden sollten. Außerdem ist zweifelhaft, ob die Verfasser des Art. 25 GG tatsächlich beabsichtigten, auch wenn das Recht bewusst nicht auf Deutsche begrenzt wurde, dass bloße Rechtsprinzipien über den deutschen Gesetzen stehen sollen und nahezu Verfassungsrang einnehmen.

\subsection{Rechtsprinzipien als allgemeine Rechtsgrundsätze im Sinne des Art. 38 IGH-Statut}

Die Stabilisierung des Rechts durch Staatenpraxis ist nicht mehr notwendig, konzipiert man die allgemeinen Rechtsgrundsätze nicht überwiegend als Ge- und Verbote, sondern als Rechtsprinzipien, denn diese schreiben keine bestimmte Lösung vor. Danach soll auch die Notwendigkeit der Stabilisierung der Grundsätze durch eine entsprechende Staatenpraxis wegfallen. Außerdem könnten ansonsten wenige Staaten einen Konsens erzeugen, ohne dass jeder einzelne Staat vorher dazu befragt werden müsste. Sie begründen mehr Kriterien für die Bewertung staatlichen Handelns. ${ }^{375}$

\footnotetext{
${ }^{373}$ BVerfGE 78, 179 (196) zugunsten des Ausländerschutzes trotz Nichtanwendbarkeit eines Deutschenrechts; am Bsp. Von Art. 12 GG siehe OVG Münster, Beschluss vom 23.08.1994, Az. 13 C 129/94, in: DVB1. 23/1994, S. 1374 (Leitsatz); zugunsten nichteuropäischer Ausländer bzgl. Prozessgrundrechte auch BVerfGE 12, 6 (8); 21, 362 (363);

${ }^{374}$ Farahat, Progressive Inklusion, S. 166, 363.

${ }^{375}$ Farahat, Progressive Inklusion, S. 272, 274.
} 
Farahats Herangehensweise ist kritisch zu betrachten. Sie führt aus, das Völkerrecht habe sich gewandelt und eine Beschränkung auf übereinstimmende nationale Rechtsordnungen zum Vorliegen einer Staatspraxis sei nicht mehr erforderlich. ${ }^{376}$ Vielfach würden Staaten ihre Auffassungen mittels internationaler Organisationen ausdrücken, so dass auch Beschlüsse entsprechender Vertragsorgane einen Konsens implizieren. Die auf das Recht bezogenen Erklärungen seien mitnichten als Lippenbekenntnisse zu verstehen und deshalb rechtlich relevant. Gerade Resolutionen der UN-Generalversammlung ließen menschenrechtliche Mindeststandards erkennen, welche als allgemeine Rechtsgrundsätze zu qualifizieren seien. Sie sieht damit das Problem gelöst, eine Normativität ohne die staatliche Praxis herstellen zu können. Diese sei bei den Menschenrechten ohne reziproken Charakter nicht erforderlich, beträfen sie doch nur das Innenverhältnis der Staaten statt die Beziehung dieser untereinander. ${ }^{377}$ Andere vertreten, dass die geforderte Staatenpraxis keine Begründung einer Normativität sei, sondern lediglich den Einklang zwischen Normen und wirklicher staatlicher Rechtsauffassung darstelle. ${ }^{378}$ Farahat stellt selbst heraus, dass von ihr die Erwartungen an die allgemeinen Rechtsgrundsätze, anders als dies Simma und Alston in ihrem Vorschlag tun, bewusst gesenkt werden, um so auch auf eine Zustimmung durch die Staaten verzichten zu können. Rechtsprinzipien determinierten selbst in der Regel keine konkreten Lösungen. ${ }^{379}$ Die Gegenläufigkeit der Prinzipien Inklusion und statische Zuordnung stellen Gegengewichte dar, die jedoch das innerstaatliche Recht aufnehmen, ausgleichen und berücksichtigen soll. ${ }^{380}$

Die in anderen Kapiteln bereits vielfach erwähnte Entstehungsgeschichte muss hier ebenso mahnend angeführt und nachgefragt werden, ob die Verfasser des Grundgesetzes völkergewohnheitsrechtliche Regeln und allgemeine Rechtsgrundsätze derart weitreichend implementieren wollten, auch an demokratischen Grundpfeilern wie dem Wahlrecht und der Verleihung der Staatsangehörigkeit rütteln zu können, ohne deutscher Staatsbürger zu sein.

Die Autorin sieht die progressive Inklusion als allgemeinen Rechtsgrundsatz im Sinne des Art. 38 Abs. 1 c) IGH-Statut mit der Folge, dass diese auch durch deutsche Behörden und

\footnotetext{
${ }^{376}$ Die Autoren wollen allerdings nicht alle Rechtsprinzipien als allgemeine Rechtsgrundsätze des Völkerrechts interpretieren, sondern nur jene besonders wichtigen Menschenrechtsnormen, S. 103; so auch $\mathrm{Ka}$ delbach/Kleinlein, auch bzgl. besonders allgemeine Probleme betreffende Rechtsgrundsätze, in: GYIL 2007, S. 303 (342).

${ }^{377}$ Farahat, Progressive Inklusion, S. 271, 272; Simma/Alston, in: AYIL 1988/1989 S. 88 (102, 105); so wohl auch Petersen, Demokratie als teleologisches Prinzip, S. 81; Kadelbach/Kleinlein, in: GYIL 2007, S. 303 (340 f.).

${ }^{378}$ Petersen, Demokratie als teleologisches Prinzip, S. 63, $67 \mathrm{f}$.

${ }^{379}$ Farahat, Progressive Inklusion, S. 274, 278; Kadelbach/Kleinlein, in: GYIL 2007, S. 303 (339).

${ }^{380}$ Farahat, Progressive Inklusion, S. 280.
} 
Gesetzgeber berücksichtigt werden müssten. Sie begründet dies unter anderem damit, dass nach dem Zweiten Weltkrieg die massiven Fluchtbewegungen und die politischen Konflikte sowie eine zunehmende Arbeitskräftewanderung der wesentliche Motor für die Entwicklung des Inklusionsprinzips gewesen seien, das dem Prinzip einer statischen Zuordnung entgegenzuhalten war. Auch in Rechtsprinzipien spiegelten sich daher regelmäßig auch rechtspolitische Aspekte wider. Mögliche Kollisionen der Rechtsprinzipien seien daher hinzunehmen, diese könnten koexistieren. Rechtsprinzipien sollen aber vor allem als Argumentationsressource bei Auslegung und Anwendung innerstaatlich geltender Normen und deren vorrangiger Nutzung relevant werden. ${ }^{381}$ Es fällt jedoch besonders in den letzten Jahren auf, dass die Politik sehr valide in ihren internationalen Stellungnahmen und Kursen bezüglich auf die Einhaltung internationaler Abkommen ist, und konkrete internationale Vereinbarungen aus politischen Gründen nicht mehr befolgt oder gar - wenn auch nicht durch Deutschland selbst - einseitig aufgekündigt werden. ${ }^{382}$

Die Rechtsprechung hingegen ist stärker manifestiert, sie drückt eine tatsächliche, zumindest mehr als nur temporäre verlässliche Rechtsauffassung aus. Politische Sonderfälle und ihre im Zweifel sehr weit ausgelegten Rechtsverständnisse sollten keinesfalls bereits als eine Art mündlich kodifiziertes Völkerrecht wahrgenommen werden. Allgemeine Rechtsgrundsätze könnten zwar möglicherweise auch weniger konkrete Prinzipien einschließen, allerdings handelt es sich dabei immer noch um universelles Völkerrecht, welchem über die wechselnde Politik hinaus eine bedeutende Rolle zukommt. Dass Art. 25 GG für Deutschland dieses Recht in das innerstaatliche Recht einpflanzt, zeigt den zu bewahrenden Stellenwert, der nicht mittels Politik verwaschen werden können sollte. Dies lässt sich freilich nicht vollumfänglich gewährleisten, dennoch zeigt es die Empfindlichkeit des Völkerrechts gegenüber politischen Agenden auf. Auch die UN-Versammlungen und Beschlüsse zeigten sich am Beispiel des seit 2011 in Syrien anhaltenden Bürgerkriegs als nahezu wirkungslos $^{383}$. Wenn die UN-Versammlungen, gerade im Bereich menschenrechtlicher Aspekte und Völkerrechtswidrigkeiten seitens Regierungen gegenüber dem eigenen Volk,

\footnotetext{
${ }^{381}$ Farahat, Progressive Inklusion, S. 275, 278, 340.

${ }^{382}$ Beispielsweise das Klimaübereinkommen von Paris vom 12.12.2015 (BGB1. III Nr. 197/2016), aus welchem die USA zum Jahr 2020 austreten (https://www.spiegel.de/politik/ausland/trump-regierung-usa-erklaeren-austritt-aus-pariser-klimavertrag-a-1161486.html), oder das Atomabkommen mit Iran vom 14.07.2015, aus welchem sich US-Präsident Donald J. Trump mit der Ankündigung vom 08.05.2018 zurückzog (https://www.spiegel.de/politik/ausland/donald-trump-verkuendet-ausstieg-aus-iran-atomabkommen-und-sanktionen-a-1206893.html).

${ }^{383} \mathrm{https} / / / \mathrm{www} . d e m o c r a c y w i t h o u t b o r d e r s . o r g / d e / 5141 /$ der-un-sicherheitsrat-hat-syrien-im-stich-gelassen-esist-an-der-zeit-seine-autoritaet-in-frage-zu-stellen/;
} 
derart ohnmächtig wirken, sollte man vor dem Hintergrund eventuell erwägen, die Staatspraxis als solche, nämlich die tatsächliche praktische Anwendung und Festigung eines Grundsatzes, als Erfordernis konsequent bei allen Rechtsgebieten aufrechtzuerhalten.

Mangels völkerrechtlicher Normen, die die beiden benannten Prinzipien konkret formulieren, sollen diese im dogmatischen Kontext bereits bestätigt sein, wenn völkerrechtliche Dokumente $^{384}$ mit konvergierenden Regelungsanliegen hinsichtlich der beiden Prinzipien vorliegen. Nicht jedes internationale Rechtsproblem sei zwar von den Prinzipien statischer Zuordnung von Personen und progressiver Inklusion erfasst. Man könne daher von sektoralen Rechtsgrundsätzen sprechen, was wiederum nicht gegen die Qualifikation als allgemeine Rechtsgrundsätze nach Art. 38 Abs. 1 c) IGH-Statut spräche. Die für herkömmliches Völkergewohnheitsrecht auch anerkannte Regionalität, welche nur in begrenzten Gebieten nachweisbar sei, könnte aber auch ohne Bedenken auf allgemeine Rechtsgrundsätze übertragen und diese als Rechtsprinzipien konzipiert werden. ${ }^{385}$ Jedoch ist hierzu anzumerken, dass bereits die sektorale Geltung als ausreichendes Erfordernis für die Entstehung von Völkergewohnheitsrecht stark umstritten ist. ${ }^{386}$

Verstehe man die allgemeinen Rechtsgrundsätze nun als Rechtsprinzipien, schließe dies die Gegenläufigkeit und Konflikthaftigkeit dieser Rechtsprinzipien mit ein. Auch sei das Erfordernis der Allgemeinheit nicht mehr in Abgrenzung zu sektorale Fragen betreffenden Regelungen aufzufassen, sondern in Abgrenzung zu Regelungen, die lediglich Einzelfragen isoliert zum Gegenstand haben. ${ }^{387}$ Die allgemeinen Rechtsgrundsätze sollen nicht mehr darauf beschränkt sein, nur die Rechtsnormen zu umfassen, die sich aus einer vergleichenden Analyse nationaler Rechtsordnungen ergeben. ${ }^{388}$ Hinsichtlich der Geltung regional und

https://www.sueddeutsche.de/politik/krieg-in-syrien-das-brutale-versagen-der-vereinten-nationen1.3877937 .

${ }^{384}$ Sog. ,practice papers“ als Staatenpraxis im weiteren Sinne: Guzman, in: MJIL 1/2005, S. 115 (124 f).

${ }^{385}$ Farahat, Progressive Inklusion, S. 266, 277.

${ }^{386}$ Die Einbeziehung regionalen Völkerrechts befürwortend, vgl. Bleckmann, Grundgesetz und Völkerrecht, S. 291; Tomuschat, in: HdStR Bd. 7, § 172 Rn 13, 14, der die Entstehungsgeschichte nicht als Ausschluss regionalen Gewohnheitsrechts ansieht, da dieses immer steigende Bedeutung zukomme, jedoch bilaterales Völkergewohnheitsrecht wegen seiner Vertragsähnlichkeit ausschließt; Streinz, in: Sachs, Art. 25 GG, Rn 27; Koenig, in: v. Mangoldt/Klein/Starck, Art. 25 GG, Rn 7, 27 f.; Wollenschläger, in: Dreier, Art. 25 GG, Rn 24; siehe auch Calliess, Staatsrecht III (2014), S. 104 Rn 30 f., unverändert in der Folgeauflage 2018, S. 106 Rn 30 f.; Zuleeg, in: Denninger, Art. 24 Abs. 3/Art. 25 GG (2001), Rn 16., 27, der eine Analogie deshalb ablehnt (anders noch in der Vorauflage, Rn 27), weil regionales Völkerrecht bereits unter Art. 25 Satz 1 GG zu fassen sei. Siehe auch Papadimitriu, Stellung der allgemeinen Regeln im innerstaatlichen Recht, S. 73;

Anderer Meinung Rojahn, in: v. Münch/Kunig, Art. 25 GG, Rn 10, 15 f.; Schorkopf, Staatsrecht der internationalen Beziehungen, $\S 3$ Rn 11, 12.

${ }^{387}$ Farahat, Progressive Inklusion, S. 277.

${ }^{388}$ Simma/Alston, in: AYIL 1988/1989, S. 88 (102); anders: Pellet, in: Zimmermann/Tomuschat/OellersFrahm/Pellet, in: Statute of the ICJ, Rn 249 f. 
sektoral begrenzter allgemeiner Rechtsgrundsätze im deutschen Recht sei die Anwendbarkeit über Art. 25 GG weit zu verstehen. Der Völkerrechtsfreundlichkeit der deutschen Verfassung könne nur dadurch Rechnung getragen werden, wenn auch Regeln zum Inhalt des Art. 25 GG zählen, die regional überwiegend anerkannt sind, obwohl nicht der Großteil der völkerrechtlichen Mehrheit diese anerkennt. ${ }^{389}$

Selbst ohne in ihrer Untersuchung eine entsprechende Staatenpraxis hinsichtlich der streitigen Rechtsüberzeugungen bestätigen zu können - Beschlüssen von Vertragsorganen und richterlichen Entscheidungen fehlt die Qualifikation zur staatlichen Übung und damit den Prinzipien zum Völkergewohnheitsrecht - sollen Rechtsprinzipien als allgemeine Rechtsgrundsätze im Sinne des Art. 38 Abs. 1 c) IGH-Statut über Art. 25 GG Einzug in die deutsche Rechtsordnung erlangen. Es liegt außerhalb des Gegenstandes dieser Arbeit, die internationale oder auch deutsche Staatspraxis zu untersuchen, um die Legitimität dieser Aussage zu verifizieren, weshalb lediglich die Auswirkungen ihrer Schlussfolgerungen auf Art. 25 GG beurteilt werden.

Diese stehen als völkerrechtliche Rechtsprinzipien im Rang dann zwar unterhalb des Grundgesetzes, jedoch oberhalb des einfachen Gesetzesrechts und müssten gemäß des Grundsatzes der Völkerrechtsfreundlichkeit beachtet werden. ${ }^{390}$ Farahat verzichtet dann doch darauf, vereinzelten Literaturstimmen zu folgen und das Erfordernis einer staatlichen Praxis zur Entstehung von Gewohnheitsrecht fallenzulassen, da dies zwar strategisch hilfreich wäre, jedoch dessen Funktionalität gefährden könnte. Auch seien die allgemeinen Rechtsgrundsätze heutzutage nicht mehr auf das Umfassen von Normen beschränkt, die einem Vergleich nationaler Rechtsordnungen entspringen. ${ }^{391}$ Mit Verweis auf die Entstehungsgeschichte der allgemeinen Rechtsgrundsätze wurden diese lange so verstanden, dass sie nur übereinstimmende Normen der nationalen Rechtsordnungen und für den Rechtsverkehr unerlässliche Normen aufnehmen. ${ }^{392}$

\footnotetext{
${ }^{389}$ Wollenschläger, in: Dreier, Art. 25 GG, Rn 24; Koenig/König, in: v. Mangoldt/Klein/Starck, Art. 25 GG, Rn 30, 31; Farahat, Progressive Inklusion, S. 279; Cremer, in: HdStR Bd. 11, § 235 Rn 17; zu den evtl. unklaren Konsequenzen einer solchen Eingliederung allerdings Rudolf, in: FS für Alfred Verdross, S. 435 (443 f.); ablehnend vor allem auch Herdegen, in: Maunz/Dürig, Art. 25 GG, Rn 41, der selbst eine analoge Anwendung des Art. 25 Satz 1 GG unterstützt, welche nicht zum Geltungsvorrang führt.

${ }^{390}$ Farahat, Progressive Inklusion, S. 347; Rojahn, in: Münch/Kunig, Art. 25 GG, Rn 36 f.; Bernhardt, in: Bundesverfassungsgericht und Grundgesetz, S. 154 (159 f.).

${ }^{391}$ Farahat, Progressive Inklusion, S. 269, 270; Simma/Alston, in: AYIL 1988/89, S. 88 (102).

${ }^{392}$ Vitanyi, in: Revue Générale du Droit International Public 86/1982, S. 96f.
} 
Der Gedanke einer unverzüglichen Ermächtigung und kontinuierlichen Annäherung der Rechte Fremder an die Rechte eigener Staatsangehöriger reicht für Farahat, diese als regionale Rechtsprinzipien und damit als regionale Rechtsgrundsätze anzuerkennen. Jedoch erweckt ihre Bearbeitung den nachhaltigen Eindruck, es werde mit dem Verzicht auf die Staatspraxis zur Qualifikation als Völkergewohnheitsrecht ein Mittel allein zu dem Zweck ${ }^{393}$ geschaffen, die Rechtsprinzipien der progressiven Inklusion und der statischen Zuordnung von Personen zu Staaten ohne dauerhafte mehrstaatliche Verifizierung über Art. 25 GG verpflichtend ins deutsche Recht aufzunehmen und praktisch durchsetzbar machen zu können.

\subsection{Die Rechtsprinzipien im Rahmen des Art. 25 GG}

Für völkergewohnheitsrechtliche Normen gilt für deren Zuordnung zu Art. 25 GG, dass diese im Fall einer sektoralen oder regionalen Begrenzung an der entsprechenden Staatspraxis beteiligt sein müssen. Erst dann fallen sie unter Art. 25 GG. ${ }^{394}$ Dies ist bei den Rechtsprinzipien der progressiven Inklusion und der statischen Zuordnung von Personen zu Staaten als völkerrechtliche und begrenzte Rechtsgrundsätze jedoch fraglich.

Allerdings sollen bezüglich Art. 25 GG vor allem zugunsten der zu verdeutlichenden Völkerrechtsfreundlichkeit auch solche Regeln einbezogen werden, die lediglich mehrheitlich anerkannt sind und nicht von der Mehrheit der Völkerrechtsgemeinschaft anerkannt werden. ${ }^{395}$ Es wird zwar erklärt, als Teil der allgemeinen Rechtsgrundsätze zählen die progressive Inklusion und die statische Zuordnung von Personen zu Staaten als Rechtsprinzipien zu den allgemeinen Völkerrechtsregeln des Art. 25 GG. Ein näherer Bezug zur tatsächlichen Durchsetzbarkeit bleibt jedoch aus. Nähme man Art. 25 GG als nahezu grundrechtsgleiches Recht und generelle Anspruchsgrundlage, mit der teils nicht-regelnde und nicht einmal übergreifend praktizierte Rechtsprinzipien geltend gemacht werden könnten, käme das Argument der drohenden Klageflut hier zur rechten Stelle.

\footnotetext{
${ }^{393} \mathrm{Vgl}$. dazu die Formulierung ,,...] wurde nach einer Möglichkeit gesucht, geteilte Rechtsüberzeugungen rechtsquellendogmatisch im Völkerrecht zu verorten, ohne dass es auf eine entsprechende Staatenpraxis ankommt.“, Farahat, Progressive Inklusion, S. 280.

${ }^{394}$ Kunig, in: Vitzthum/Proelß, S. 115 Rn 140 f.; Rojahn, in: Münch/Kunig, Art. 25 GG, Rn 9, 15.

${ }^{395}$ Wollenschläger, in: Dreier, Art. 25 GG, Rn 20; Koenig/König, in: v. Mangoldt/Klein/Starck, Art. 25 GG, Rn 30.
} 
Unterstützend wird auch die Rechtsprechung des EGMR angeführt. Über Art. 8 EMRK soll das Prinzip der progressiven Inklusion stärker ausgedrückt werden können. Die Richter des EGMR wollten zwar keinen vollumfänglichen Ausweisungsschutz von Migranten der zweiten Generation gewährleisten, jedoch hohe Schranken hinsichtlich der Abschiebung im Aufenthaltsstaat geborener oder dort jung eingereister Kinder erhalten. ${ }^{396}$ Dies ergebe eine Verbindung von Art. 8 EMRK mit dem Schutzgedanken der UN-Kinderrechts-Konvention und den Empfehlungen des Europarates. ${ }^{397}$

Vorangetrieben wurde die rechtliche Inklusion durch die Fortbildung der deutschen Gerichte. Dabei konnten die Rechte hinsichtlich des Arbeitsmarktzugangs, der Verfestigung des Aufenthaltsstatus und der Familienzusammenführung kontinuierlich verstärkt werden. ${ }^{398}$ Weniger durchgesetzt hat sich die Entwicklung in der Legislative. Diese wurde eher zaghaft vollzogen, beispielsweise mit der Einführung einer Anspruchseinbürgerung im Jahre 2000. Ebenso wurde für Migranten der zweiten Generation der Schutz vor Ausweisung untermauert. Allerdings fehlen nach der Autorin immer noch Anstrengungen, die Inklusion in Sachen Politik, Sozialleben und Wirtschaft durchzuführen. ${ }^{399}$

\subsection{Stellungnahme zur nationalen Rechtslage}

Im Folgenden wird aufgezeigt, ob das bestehende deutsche Recht die in Frage stehenden Prinzipien ausreichend beachtet und Einzelne dadurch ungerechtfertigte Rechtseinbußen erleiden. Die Autorin vertritt dahingehend, dass das Prinzip der progressiven Inklusion hinsichtlich des Prinzips der statischen Zuordnung von Personen zu Staaten übervorteilt werde. ${ }^{400}$

Bereits vor der Erläuterung möglicher Rügemöglichkeiten Einzelner bei etwaigen Verletzungen der Prinzipien fällt auf, dass Farahat, anders als die vorbenannten Autoren, eben

\footnotetext{
${ }^{396}$ Farahat, Progressive Inklusion, S. 357; vgl. u. a. auch EGMR (Große Kammer), Judgement of 18.10.2006, Üner vs Netherlands, Nr. $46410 / 99$ (2007) 45 E.H.R.R. 14, Rn 55 f.; EGMR, Kaya vs Germany, Nr. 31753/02, in: Informationsbrief Ausländerrecht 2007, S. 325.

${ }^{397}$ EGMR (Große Kammer), Judgement of 23.06.2008, Maslov vs Austria, Nr. 1638/03 (2008) 47 E.H.R.R. 20, Rn 36 f., 73.

${ }^{398}$ Bade, Europa in Bewegung, S. $337 \mathrm{f}$.

${ }^{399}$ Farahat, Progressive Inklusion, S. 365.

${ }^{400}$ Farahat, Progressive Inklusion, S. 170, 210, 262 f.
} 
nicht Art. 25 Satz 2 GG als Individualanspruchsgrundlage heranzieht und verteidigt, sondern lediglich Art. 25 GG als Grundlage der Berücksichtigungspflicht der Prinzipien im deutschen Recht betrachtet. ${ }^{401}$

Über Art. 59 Abs. 2 GG gelten auch die Vorschriften der EMRK in Deutschland, deren Schutzzweck für Ausländer in Deutschland als Rechtsgrundlagen vorgezogen werden.

Um etwaige Unverhältnismäßigkeiten der deutschen Ausweisungsnormen aufzuzeigen, bedient sich die Autorin am europäischen Schutz von Privat- und Familienleben gem. Art. 8 EMRK. Durch Art. 59 Abs. 2 GG erfährt die EMRK im deutschen Recht geltende Wirkung, da es sich bei dieser um einen völkerrechtlichen Vertrag handelt. Die innerstaatliche Wirksamkeit erhält der völkerrechtliche Vertrag durch ein zustimmendes Bundesgesetz. Mit dem Gesetz vom 7. August $1952^{402}$ und der Ratifizierung vom 5. Dezember 1952 hat der Bundestag der EMRK zugestimmt, so dass diese national anzuwenden ist und im Rang über den einfachen Bundesgesetzen steht. ${ }^{403}$ Der EGMR führt zu Art. 8 EMRK aus, dass das Prinzip der progressiven Inklusion stärker betont werden soll. Die Mehrzahl der Richter sieht darin zwar keinen absoluten Ausweisungsschutz von Migranten zweiter Generation, allerdings werden stärkere Anforderungen für die Abschiebung von im Aufenthaltsstaat geborenen oder dort früh eingereisten Kindern aufgestellt. Begründet wird die Ansicht damit, dass Art. 8 EMRK zusammen mit den Empfehlungen des Europarates sowie der UNKinderrechts-Konvention aufzufassen ist. Auch wenn Ausweisungsentscheidungen im Ermessen der Behörde liegen, sind dabei die vom EGMR entwickelten Maßstäbe zu berücksichtigen. Allerdings gibt es in Deutschland keinen absoluten Schutz für Migranten zweiter Generation vor Ausweisung, ebenso gibt es im deutschen Recht auch keine Regelvermutung gegen die Ausweisung entsprechend der EGMR-Rechtsprechung. 404

Die EMRK geht dem Aufenthaltsrecht nicht direkt vor, ist aber aufgrund der in Art. 20 Abs. 3 GG geregelten Gesetzesbindung deutscher Gerichte zu berücksichtigen. ${ }^{405}$ Das BVerfG

\footnotetext{
${ }^{401}$ Für das Beispiel der Aufenthaltsproblematiken verweist die Autorin auf die $\S \S 18$ a, 25 Abs. 5, 104 a und 104 b AufenthG.

${ }^{402}$ Gesetz über die Konvention zum Schutz der Menschenrechte und Grundfreiheiten vom 22.08.1952 (BGB1. II S. 685).

${ }^{403}$ Giegerich, in: Konkordanzkommentar zum europäischen und deutschen Grundrechtsschutz, S. 62; Grabenwarter, EMRK, § 3 Rn $8 \mathrm{f}$.

${ }^{404}$ Farahat, Progressive Inklusion, S. 357, 358.

${ }^{405}$ Papier, in: EuGRZ 1/2006, S. 1.
} 
hat ebenfalls die besondere einfache Gesetzeswirkung der EMRK über die Verpflichtung zur völkerrechtsfreundlichen Verfassungsauslegung ${ }^{406}$ ausgedrückt. ${ }^{407}$

Das Privat- und Familienleben wird durch Art. 8 EMRK umfassend geschützt. Der EGMR hat seine Auffassung hinsichtlich des Schutzumfangs erweitert: Art. 8 EMRK, ,protects the right to establish and develop relationships with other human beings and the outside world and can sometimes embrace aspects of an individual's social identity“. ${ }^{408}$ Von besonderer Bedeutung ist bei der erweiterten Auslegung des Schutzbereichs und Eingriffs in das Privatleben die Verhältnismäßigkeitsprüfung nach Art. 8 Abs. 2 EMRK hinsichtlich der Rechtmäßigkeit von Ausweisungen. Über Art. 8 EMRK soll hingegen kein Recht begründet werden, sich innerhalb eines bestimmten Staatsgebiets aufzuhalten oder dieses betreten zu dürfen. ${ }^{409}$ Die Auffassung der EGMR-Richter hat ihre Wirkung auf die deutsche Rechtsprechung und Literatur entfaltet und wird von den allgemeinen Verwaltungsvorschriften zum AufenthG konkret aufgegriffen. ${ }^{410}$

\subsection{Zwischenergebnis}

Untersucht wurde in diesem Abschnitt die Auffassung, dass regionale völkerrechtliche Grundsätze von Art. 25 Satz 1 GG erfasst und eingegliedert werden. Begründet wurde diese Ansicht mit der Rechtsangleichung zwischen Ausländern und Inländern und einer aus dem Völkerrecht entspringenden Pflicht zur Völkerrechtsfreundlichkeit und Inklusion sowie Integration. Die Ansichten der Literatur, die dies vertreten und eine völkerrechtliche Bindung der Staaten bewusst auf eine Bindung durch das Völkergewohnheitsrecht ausweiten wollen, verfolgen allerdings erkennbar politische Motive wie beispielsweise eine Erweiterung des Wahlrechts und Umgehung der geltenden normativen Beschränkungen auf deutsche Staatsbürger. Die Autorin konstruiert die Rechtsprinzipien als allgemeine völkerrechtliche Grundsätze im Sinne des Art. 38 IGH-Statut, um diesen sodann über Art. 25 GG verfas-

\footnotetext{
${ }^{406}$ Tomuschat, in: HdStR Bd. 7, § 172 Rn 27: Danach ist immer diejenige Auslegung vorzuziehen, die mit den entsprechenden völkerrechtlichen Verträgen konformgeht.

${ }^{407}$ BVerfGE 111, 307 (308 f.); Cremer, in: EuGRZ 22/2004, S. 683 (688).

${ }^{408}$ Siehe EGMR (Große Kammer), Judgement of 18.10.2006, Üner vs Niederlande, Nr. $46410 / 99$ (2007) 45 E.H.R.R. 14, Rn 59; EGMR (Große Kammer), Judgement of 23.06.2008, Maslov vs Österreich, Nr. 1638/03 (2008) 47 E.H.R.R. 20, Rn 63.

${ }^{409}$ Thym, in: ILCQ 57/2008, S. 87 (108).

${ }^{410}$ BMI, Allgemeine Verwaltungsvorschrift zum Aufenthaltsgesetz, vor Nr. 53.5.6.
} 
sungsrechtliche Wirkung verleihen zu können. Die Autorin offenbart ihre strukturelle Herangehensweise, die Prinzipien der progressiven Inklusion und der statischen Zuordnung von Personen zu Staaten als allgemeine Rechtsgrundsätze im Sinne des Art. 38 Abs. 1 lit. c) IGH-Statut konstruieren und somit über die völkerrechtliche Verankerung des Art. 25 GG ins deutsche Rechtssystem über die allgemeinen Gesetze platzieren zu wollen.

Die oftmals angeführten Argumente der Entstehungsgeschichte und des Wortlauts des Art. 25 GG scheitern allerdings auch hier am Sinn und Zweck der Norm. Die deutschen Verfassungs- und Gesetzesgeber haben bereits bewusst die Grundsätze eines effizienten Rechtsstaates, Sicherheit des Rechts und Gesetzesvorbehalt, durch Art. 25 GG gelockert ${ }^{411}$, um weltweit geltendes Völkerrecht in die deutsche Rechtsordnung aufnehmen zu können, so unkonkret diese auch sein könnten. Als Mitglied einer internationalen Gemeinschaft ist die Bundesregierung dazu bereit, allerdings nur in sehr klaren Fällen. Da Art. 25 GG die allgemeinen Völkerrechtsregeln in der deutschen Rechtsordnung über den einfachen Bundesrechten verortet, sind die damit einhergehenden Rechtsfolgen für eine zu universelle Geltung zu weitreichend, so dass eine Umfangsbegrenzung zwingend ist. Es soll vielmehr vermieden werden sich an sogenanntes partikulares Völkergewohnheitsrecht zu binden, dazu sind die völkerrechtlichen Verträge ausreichend. Die vielfach ausführlich angeführte Entstehungsgeschichte und der Wortlaut des Art. 25 GG als Argumente für eine Bejahung der Subjektivierung einzelner allgemeiner Völkerrechtsregeln durch Satz 2 des Art. 25 GG sprechen an dieser Stelle allerdings auch gegen die Geltung lediglich partikularen oder regionalen Gewohnheitsrechts (und auch Rechtsgrundsätze). Mit dem gegenüber Art. 4 WRV geänderten Wortlaut, dass nicht mehr nur die von Deutschland anerkannten allgemeinen Völkerrechtsregeln aufgenommen werden, sollte vielmehr erreicht werden, dass es für die Wirksamkeit der Völkerrechtsregeln nicht mehr auf die unabdingbare deutsche Anerkennung ankommt. Die ursprüngliche Intention beinhaltete nicht den Willen, auch regionales Völkergewohnheitsrecht damit eine breite Geltung zu verschaffen. ${ }^{412}$

Vermehrt lehnen Literaturstimmen daher die, sei es auch nur entsprechende, Anwendung des Art. $25 \mathrm{GG}^{413}$ auf regionales sowie bilaterales Völkergewohnheitsrecht ab. Die Rechtsprechung vertrat ursprünglich, dass es sich bei der Einbeziehung „vorwiegend um

\footnotetext{
${ }^{411}$ BVerfGE 23, 288 (317), so bspw. auch Schorkopf, Staatsrecht der internationalen Beziehungen, § 3 Rn 11.

${ }^{412}$ Vgl. Schorkopf, Staatsrecht der internationalen Beziehungen, § 3 Rn 11.

${ }^{413}$ So bspw. Zuleeg, in Denninger, Art. 24 Abs. 3/25 GG (2. Auflage, 1989), Rn 21, 27. Später vertrat er, dass lokales Völkergewohnheitsrecht direkt unter Art. 25 falle und eine entsprechende Anwendung deshalb überflüssig sei, in: AK-GG, Art. 24 Abs. 3/Art. 25 GG (3. Auflage 2001), Rn 16.
} 
universell geltendes Völkergewohnheitsrecht“" handeln soll. ${ }^{414}$ Später sprach das Gericht nur noch von „universell geltenden Völkerrechtssätzen“4415, und weiter davon, dass das Bestehen von Völkergewohnheitsrecht eine von zahlreichen, alle weltweit bestehenden Rechtskulturen repräsentierenden Staaten befolgte Praxis voraussetze. ${ }^{416}$

Das Aufzeigen der unterschiedlichen Meinungen veranschaulicht die Problematik innerhalb der Literatur, sich auf eine gemeinsame Auffassung über die Geltung und den inhaltlichen Umfang einigen zu können. Setzte man einmal die von Doehring vertretene Auffassung eines Verfassungsgleichrangs der allgemeinen Völkerrechtsregeln voraus, hätte dies bei Farahats Modell gravierende Folgen. So könnten lediglich sektoral geltende, unkonkrete und nicht allgemein durch eine Mehrzahl von Staaten geübte Rechtsprinzipien den Vorzug vor nationalem Bundes- und Landesrecht einnehmen und eventuell auch Auswirkungen auf die Grundrechte und Verfassungsgrundsätze Deutschlands ausüben, ohne dass diese durch eine explizite und eingrenzende Formulierung des Art. 25 GG ausgestaltet werden. Die Entstehung und Befolgung regionalen Völkergewohnheitsrechts hätte theoretisch auch innerhalb der jeweiligen Bundesländer, soweit diese im Völkerrechtsbereich partizipieren ${ }^{417}$, Problematiken zur Folge, wenn sich diese auch an der Entstehung von Gewohnheitsrecht beteiligten. ${ }^{418}$ Das von Farahat vorgestellte und befürwortete Modell birgt beim vorherrschend vertretenen Zwischenrang der allgemeinen Regeln die Gefahr, die deutsche Staatsordnung zu umgehen und, speziell am Beispiel des Wahlrechts, in der Praxis gegen geltendes Recht zu verstoßen.

Folgt man den Ansichten der Kritiker an einer übergreifenden Aufnahme des Völkergewohnheitsrechts, was gerade vor der Erheblichkeit der Bedeutung, die die Eingliederung über Art. 25 GG ins deutsche Rechtssystem zur Folge hätte, nachvollziehbar ist (siehe am Beispiel des Völkerstrafrechts in Kapitel § 4), ist vorliegend der Ansatz, wenigstens regional geltende allgemeine Rechtsgrundsätze über Art. 25 GG einzugliedern, abzulehnen. Dies

\footnotetext{
${ }^{414}$ BVerfGE 15, 25 (33); 23, 288 (317).

${ }^{415}$ BVerfGE 31, 145 (177).

${ }^{416}$ BVerfG, Kammerbeschluss vom 21.05.1987, Az. 2 BvR 1170/83, in: NJW 23/1988, S. 1462-1462 (Leitsatz und Gründe), Rn 11 f. nach juris.

${ }^{417}$ Beispielsweise bei eigens i. S. d. Art. 32 Abs. 3 GG abgeschlossenen Verträgen des Völkerrechts, Rojahn, in: v. Münch/Kunig, Art. 32 GG, Rn 56 f., 59; Streinz, in: Sachs, Art. 32 GG, Rn 12 f., 49,51 f.

${ }^{418}$ Cremer, in: HdStR Bd. 11, § 235 Rn 18, der dort das theoretische Beispiel anführt, zwischen dem Bundesland Schleswig-Holstein und Dänemark könnte sich ein grenzübergreifendes Gewohnheitsrecht bilden, prägten beide dieselbe Rechtsüberzeugung. Hierzu bedürfe es dann aber dennoch der Zustimmung der Bundesregierung, vgl. Rojahn, in: v. Münch/Kunig, Art. 32 GG, Rn 58; Streinz, in: Sachs, Art. 32 GG, Rn 52.
} 
hätte wiederum zur Folge, dass für partikulare Rechtssätze auf eventuell abgeschlossene Völkerrechtsverträge im Sinne des Art. 59 Abs. 2 GG verwiesen werden könnte und eine prozessuale Anwendung des Art. 25 GG damit überflüssig wäre. Der inhaltliche Umfang bliebe im Sinne der Verfasser begrenzt auf Gewohnheitsrecht und Rechtsgrundsätze gemäß dem Wortlaut und könnte nicht im Sinne einiger Autoren als Individualanspruch konzipiert oder konstruiert werden.

Wie bereits herausgestellt baut die präsentierte Argumentation nicht direkt auf der Grundlage einer Anerkennung und Förderung von Art. 25 (Satz 2) GG als individuelle Anspruchsgrundlage auf und bewertet diesen auch nicht als Rechtsquelle für die Durchsetzung der Rechtsprinzipien, sondern lediglich als Verpflichtung von Politik und Rechtsprechung diese zu beachten. Anhand ihrer konkreten Beispiele stellt sie vielmehr auf nationale Spezialgesetze ab wie das Aufenthaltsgesetz, das Staatsangehörigkeits-gesetz, das Sozialgesetzbuch IV und VI, das Bundeswahlgesetz, das Europawahlgesetz und andere. ${ }^{419}$

Die Einordnung und Konstruktion der Rechtsprinzipien der progressiven Inklusion und der statischen Zuordnung von Personen zu Staaten wurde kritisch beurteilt und wird sowohl aus definitionsbezogener, als auch politischer Sichtweise im Rahmen dieser Untersuchung nicht geteilt. Somit müssten diese auch nicht aufgrund von Art. 25 GG im deutschen Recht berücksichtigt und gewürdigt werden. Allerdings bewirkt ihre Argumentation dasselbe Ergebnis, denn Art. 25 Satz 2 GG soll für sie keine individuelle Anspruchsgrundlage sein. Die oben benannten einfachen Gesetze wären gemäß ihrer Natur vor den entsprechenden Fachgerichten geltend zu machen. Der darüberstehende Art. 25 GG bleibt daher eine Inkorporationsklausel.

Sie stellt überwiegend auf die europäische Rechtsprechung des EGMR zu Art. 8 Abs. 1 EMRK am Beispiel der Ausländerausweisungen ab, welche für Migranten einen entsprechenden individuellen Schutz gewährt und auch vor dem Gerichtshof durchgesetzt werden kann.

Es muss daher geschlussfolgert werden, dass Art. 25 Satz 2 GG, entgegen der vorher genannten Literaturstimmen, nicht als Individualanspruch anzusehen ist mit der Folge, dass keine individuellen unmittelbar geltenden Rechte und Pflichten bestehen, sondern nach Art. 25 Satz 1 und 2 GG die allgemeinen Rechtsgrundsätze (und unterstellt auch die Rechtsprinzipien) und das Völkergewohnheitsrecht zwingend bei der Gesetzesentstehung und -

\footnotetext{
${ }^{419}$ Vgl. Farahat, Progressive Inklusion; zum Staatsangehörigkeitsgesetz auf S. 141 f., zum Aufenthaltsgesetz auf S. 171 f., zum Sozialgesetzbuch auf S. 211 f., zum Bundeswahlgesetz und Europawahlgesetz auf S. $246 \mathrm{f} ., 330 \mathrm{f}$.
} 
anwendung zu berücksichtigen sind. Die Herangehensweise der vorgenannten Autoren, insbesondere die wörtliche und inhaltliche Auslegung des Art. 25 GG, wird im Folgenden bei der Betrachtung anderer literarischer Werke weiterhin einbezogen.

4. Individualentschädigungs- und Wiedergutmachungsansprüche des Völkerrechts und Kriegsvölkerrechts

Im Kreise nationaler und internationaler Autoren wird die Anerkennung individueller Ansprüche auf Entschädigungen von Verletzungen des humanitären Völkerrechts mittlerweile vereinzelt anerkannt. ${ }^{420}$

Gem. Art. 39, 42 der UN-Charta darf Gewalt gegenüber anderen Staaten nur ausüben, wer vorher die Zustimmung des UN-Sicherheitsrats eingeholt hat, oder wer nach Art. 51 UNCharta in die Lage einer nötigen Selbstverteidigung gebracht wird. Dieses Selbstverteidigungsrecht besteht nur solange „bis der Sicherheitsrat die zur Wahrung des Weltfriedens und der internationalen Sicherheit erforderlichen Maßnahmen getroffen hat.“

National wird die Bundesregierung immer wieder mit Forderungen auf individuelle Entschädigung aufgrund der Verbrechen im Zweiten Weltkriegs oder wegen Beteiligungen am Kosovo-Krieg konfrontiert. ${ }^{421}$ Mit der Zustimmung des Deutschen Bundestages hatten auch deutsche Luftkräfte an der Nato-Operation ${ }^{422}$ teilgenommen und im damaligen Jugoslawien das Ziel unterstützt, eine humanitäre Katastrophe zu verhindern. In den anschließenden Zivilprozessen haben die Instanzgerichte Klagen auf Staatshaftung noch abgewiesen. ${ }^{423}$ Nachdem der BGH zunächst noch an seine Rechtsprechung angeknüpft und Individualansprüche auf Schmerzensgeld aus dem Völkerrecht abgelehnt hatte - das Völkerrecht verstehe den Einzelnen nicht als Völkerrechtssubjekt und gewähre ihm lediglich mittelbaren Schutz - modifizierte er seine Ansicht und erkannte das Individuum zumindest als partielles Völkerrechtssubjekt an. ${ }^{424}$ Allerdings wurde auch festgehalten, dass trotz eines im-

\footnotetext{
${ }^{420}$ Zegveld, in: IRRC 849/2003, S. 497 f., Hofmann, in: Dupuy, Völkerrecht als Wertordnung, S. 341-359; Bank/Schwager, in: GYIL 2006, S. 367 (410 f.).

${ }^{421}$ Sigrid Boysen, Kriegsverbrechen im Diskurs nationaler Gerichte, in: AVR 3/2006, S. 363 ff.; ablehnend bspw. BVerfG, Beschluss vom 13.08.2013, Az. 2 BvR 2660/06, in: DÖV 2013, S. 946 ff.

${ }^{422}$ Friedrich, Die deutsche Außenpolitik im Kosovo-Konflikt, 2005, S. 55 f.

${ }^{423}$ LG Bonn, Urteil vom 10.12.2003, Az. 1 O 361/02, in: NJW 8/2004, S. 525 f.; OLG Köln, Urteil vom 28.07.2005, Az. 7 U 8/04, in: NJW 39/2005, S. 2860-2865 (Leitsatz und Gründe).

${ }^{424}$ BGHZ 169, S. 348 (351, 353); mit Bezug auf die Distomo-Entscheidung des BVerfG, K 7, 303 (308). Zu den Völkerrechtssubjekten siehe auch unter Kapitel $\S 3$.
} 
mer dichter werdenden Netzes menschenrechtlicher Verpflichtungen nicht zu schlussfolgern sei, dass jede vertragliche Regelung zum Schutz der Menschenrechte tatsächlich auch Individualrechte erzeuge und zuweise. Dies sei immer noch durch Auslegung zu ermitteln. Nach wie vor gelte auch, dass Schadensersatzansprüche aufgrund völkerrechtswidriger Staatshandlungen nur durch die entsprechenden Heimatstaaten geltend gemacht werden können. ${ }^{425}$

In Frage steht im Folgenden, ob solche Sekundärrechte unter Art. 25 Satz 2 GG gefasst werden können, und ob dieser sogar als direkte Anspruchsgrundlage herangezogen werden könnten.

\subsection{Anwendbarkeit des Staatshaftungsrechts auf bewaffnete Konflikte}

Auch wenn sich der BGH noch hinsichtlich der Feststellung einer individuellen Anspruchsinhaberschaft zurückgehalten hat, so blieb die Staatshaftung für völkerrechtswidrige Militäreinsätze nach Art. 839 BGB in Verbindung mit Art. 34 GG mitnichten ausgeschlossen. Danach muss ein Beamter drittgerichtete Amtspflichten in Ausübung seines öffentlichen Amtes kausal und schuldhaft verletzt haben. Dabei existieren auch Haftungsausschlüsse oder -beschränkungen. ${ }^{426}$ Im haftungsrechtlichen Sinne wird der Beamtenbegriff weiter verstanden und umfasst auch Beliehene und Militärangehörige. ${ }^{427}$ Verletzt werden müssen sodann drittgerichtete Amtspflichten, die über die Regelung der Dienstausführung durch Beamte auch dem Schutz von Individualinteressen dienen ${ }^{428}$, beispielsweise das Verbot zur Tötung von Nicht-Kombattanten und des Angriffs von Zivilobjekten. ${ }^{429}$ Die Rechtsfolge bestimmt Art. 34 Satz 1 GG mit der Einstandspflicht des Staates. Der einzelne Beamte bleibt in der Haftung in Beziehung zum Dienstherren, soweit dieser vorsätzlich oder grob fahrlässig gehandelt hat. ${ }^{430}$

Verglichen zu Art. 25 Satz 2 GG ist auf den ersten Blick bereits auffällig, dass die innerstaatlich anerkannten und bewährten Amtshaftungsansprüche konkrete Voraussetzungen benennen, inhaltlich ausgestaltet und auch begrenzt wurden. Art. 25 Satz 2 GG kommt an

\footnotetext{
${ }^{425}$ Bisherige Entscheidungen zu Art. 3 HLKO: BVerfGE 112, 1 (32 f.); BVerfK 3, 277 (284).

${ }^{426}$ Detterbeck, Allgemeines Verwaltungsrecht, Rn 1055 f., 1086 f.

${ }^{427}$ Vgl. Moewes, in: Frau, Drohnen und das Recht, S. 207.

${ }^{428}$ Detterbeck, Allgemeines Verwaltungsrecht, Rn $1066 \mathrm{f}$.

${ }^{429}$ Moewes, in: Frau, Drohnen und das Recht, S. 207.

${ }^{430}$ Siehe Art. 34 Satz 2 GG; Näheres in Detterbeck, Allgemeines Verwaltungsrecht, Rn 1086 f.
} 
diese Voraussetzungen, die ebenso auch Anspruchs- und Rechtssicherheit gewähren sollen, nicht heran.

Die herrschenden Auffassungen in Literatur und Rechtsprechung begrenzen bisher die Haftung Deutschlands bei bewaffneten Konflikten auf den Amtshaftungsanspruch aus Art. 839 BGB in Verbindung mit Art. 34 GG. ${ }^{431}$ In der Rechtssache Varvarin haben der BGH ${ }^{432}$ und das BVerfG ${ }^{433}$ ihre Auffassungen bestätigt.

4.2. Art. 25 Satz 2 GG als Anspruchsgrundlage auf Unterlassung und auf Entschädigung

Viele Autoren haben sich in ihren Werken mit subjektiven Ersatzansprüchen Einzelner und der Staatenverantwortlichkeit Deutschlands hinsichtlich völkerrechtswidriger Staatshandlungen befasst, deren Ausführungen im Folgenden exemplarisch für die zu beobachtende Strömung der Literatur dargestellt werden. Diese vertreten überwiegend, dass die allgemeinen Regeln des staatengerichteten Völkerrechts durch Art. 25 Satz 2 GG so weit individualisiert werden und subjektive Einzelrechte erzeugen, dass diese aus ihnen auch einen Anspruch auf Unterlassen geltend machen können. Die wissenschaftliche Diskussion wird auf der Ebene des nationalen Rechts stattfinden, denn einige Befürworter stützen einen Unterlassungsanspruch aus dem völkerrechtlichen Gewaltverbot auf Art. 25 Satz 2 GG.

\subsection{Ein völkerrechtlicher Unterlassungsanspruch in Deutschland}

Bei der Befürwortung völkerrechtlicher Unterlassungsansprüche, unter anderem aus dem Gewaltverbot in Verbindung mit Art. 25 Satz 2 GG, wird ebenfalls prominent auf den Wortlaut und die Entstehungsgeschichte des Art. 25 Satz 2 GG verwiesen. Danach sollen sich Bürger auf das Gewaltverbot berufen und Unterlassung verlangen können. Die Auffassung, Art. 25 Satz 2 GG und Art. 26 GG seien Anspruchsgrundlagen bei völkerrechtswidrigen

\footnotetext{
${ }^{431}$ Ossenbühl/Cornils, Staatshaftungsrecht, S. 127; v. Woedtke, Verantwortlichkeit Deutschlands, S. 364 f.

${ }^{432}$ BGHZ 169, 348 (358).

${ }^{433}$ BVerfG, Beschluss vom 13.08.2013, Az. 2 BvR 2660/06, 2 BvR 487/07, in: EuGRZ 6-9/2013, S. 563-570 (Leitsatz und Gründe), Rn 22 f., 40 f. nach juris.
} 
Angriffskriegen, wird teils als herrschende Auffassung der deutschen Verfassungsrechtslehre bezeichnet, obwohl diese überwiegend vereinzelt und einzig von starken Befürwortern humanitärvölkerrechtlicher Individualansprüche vertreten wird. ${ }^{434}$ Becker räumt allerdings selbst ein, dass es bisher jedoch noch kein deutsches Urteil gebe, dass einem persönlichen Unterlassungsanspruch aus Art. 25 Satz 2 GG zur Geltung verholfen hätte. Er verweist auf das Urteil des VG Köln vom 14. März 2013, welches der Möglichkeit eines subjektiven Unterlassungsanspruchs zwar zugestimmt, eine Klagebefugnis letztlich aber abgelehnt hatte und vom BVerwG in der Entscheidung bestätigt wurde. ${ }^{435}$ Das VG Köln hatte nicht nur eine Klagebefugnis des Klägers gefordert, sondern auch die denkbare Subjektivierung allgemeiner Völkerrechtsregeln auf solche Regeln beschränkt, die eine individualschützende oder individualverpflichtende Finalität aufweisen. ${ }^{436}$ Dennoch vertritt er, über Art. 25 Satz 1 GG gewähre das Gewaltverbot der UN-Charta individuellen Rechtsschutz und verweist auf ein Gutachten Fischer-Lescanos. ${ }^{437}$ Auch Becker reiht sich in die Autoren, die Art. 25 Satz 2 GG direkt als Rechtsgrundlage individueller Klagen akzeptieren. ${ }^{438}$ Der Autor bringt zutreffend ein, dass es sich bei Art. 25 GG nicht um ein Grundrecht handle, und knüpft Satz 2 der Norm an Art. 2 Abs. 1 GG, um ein Abwehrrecht aus Verstößen gegen die allgemeine Handlungsfreiheit vermitteln zu können. ${ }^{439}$ Diese Option der Geltendmachung wird noch an späterer Stelle näher betrachtet, inwiefern die Praxis der Rechtsprechung dies auch anerkennt. ${ }^{440}$

\footnotetext{
${ }^{434}$ Nicht zuletzt durch Becker, in: DÖV 13/2013, S. 493 (501) mit Verweis auf Rojahn, in: v. Münch/Kunig, Art. 25 GG, Rn 29; Hillgruber, in: Schmidt-Bleibtreu/Hofmann/Henneke, Art. 25 GG, Rn 18; a. A. Herdegen, in: Maunz/Dürig, Art. 25 GG, Rn 90.

${ }^{435} \mathrm{Vgl}$. BVerwGE 154, 328 (339 f.).

${ }^{436}$ VG Köln, Urteil vom 14.03.2013, Az. 1 K 2822/12, Rn 59 nach juris, mit Verweis auf Herdegen, in: Maunz/Dürig, Art. 25 GG, Rn 49 f., unverändert in der Aktualisierungslieferung 2019, Rn 89 f.; Hillgruber, in: Schmidt-Bleibtreu/Hofmann/Henneke, Art. 25 GG, Rn 19 (2008), unverändert in der aktuellen Auflage 2018, Rn 30 f.; Rojahn, in: v. Münch/Kunig, Art. 25 GG, Rn 31, 33 (2001), unverändert in der aktuellen Auflage 2012, Rn $50 \mathrm{f}$.

${ }^{437}$ Becker, in: Becker/Braun/Deiseroth, Frieden durch Recht?, S. 224, 231; Fischer-Lescano, Militärbasen und militärisch genutzte Flughäfen in Deutschland, S. 16 f., ebenso in Fischer-Lescano, in: AVR 3/2007, S. 299 (302 f.)

${ }^{438}$ Becker, in: Becker/Braun/Deiseroth, Frieden durch Recht?, S. 244.

${ }^{439}$ Becker, in: Becker/Braun/Deiseroth, Frieden durch Recht?, S. 146, ähnlich auch Hillgruber, in: SchmidtBleibtreu/Hofmann/Henneke, Art. 25 GG, Rn 23 f.; Geiger, Grundgesetz und Völkerrecht (4. Auflage 2009), S. 151, unverändert in der aktuellen 7. Auflage 2018 unter dem Titel „Staatsrecht III: Bezüge des Grundgesetzes zum Völker- und Europarecht, S. 155.

${ }^{440}$ Die Theorie der Geltendmachung i. V. m. Art, 2 Abs. 1 GG steht im Einklang mit der Rechtsprechung des BVerfG vom 26.10.2004 (BVerfGE 112, 1), in der es ausführt: „Nach dem verfassungsrechtlichen Maßstab sind die Behörden und Gerichte [...] verpflichtet, alles zu unterlassen, was eine unter Verstoß gegen allgemeine Regeln des Völkerrechts vorgenommene Handlung [...] Wirksamkeit verschafft, und gehindert, an einer gegen die allgemeinen Regeln des Völkerrechts verstoßenden Handlungen [...] mitzuwirken.“: BVerfGE 75, 1 (18 f.); 109, 13 (26); 109, 38 (52).
} 
Fischer-Lescanos Beiträge erlangen eine zunehmende Bedeutung in jüngeren Schriften, die einen Individualanspruch aus dem völkerrechtlichen Gewaltverbot sowie dem Verbot des Angriffskriegs über Art. 25 Satz 2 GG befürworten, obwohl die völkerrechtlichen Regeln zunächst nur an die Staaten gerichtet sind und keine subjektiven Rechte beinhalten und gewähren. Er ist ein starker Befürworter der individuellen Rechtsstellung im humanitären Völkerrecht. Festzustellen ist jedoch, dass Fischer-Lescano wiederum verstärkt auf die Ausführungen Doehrings verweist, die bereits an anderer Stelle präsentiert wurden. Doehrings Werk über die allgemeinen Regeln des völkerrechtlichen Fremdenrechts wird als Paradezitat dafür angeführt, dass staatengerichtete Völkerrechtsregeln, die zumindest einen Individualbezug möglich erscheinen lassen, durch Art. 25 Satz 2 GG subjektiviert würden, obwohl sie zuvor auf völkerrechtlicher Ebene nicht individualisiert existent waren, und Art. 25 Satz 2 GG auch als Rechtsgrundlage anwendbar sei, sich staatlichen Maßnahmen zu erwehren, wenn deren Vollzug das Verbot des Angriffskriegs verletzt. ${ }^{441}$

Bei den von Doehring befürworteten subjektivierten fremdenrechtlichen Regeln handelt es sich jedoch um bereits auf völkerrechtlicher Ebene (auch) individualgerichtete Regeln. Das Gewaltverbot für Staaten beinhaltet jedoch keinen individuellen Bezug und ist nicht individualgerichtet, so dass Einzelne weder berechtigt noch verpflichtet werden. ${ }^{442}$ Auch die Erkenntnisse aus Kapitel $§ 3$, dass Individuen mittlerweile als Völkerrechtssubjekte angesehen werden könnten und der Normzweck des Gewaltverbots es ist, den Gewaltanwendungen der Völkerrechtssubjekte untereinander vorzubeugen, berechtigt Individuen nicht direkt, sondern schützt allein sie und ihre Rechtsgüter. ${ }^{443}$

Fischer-Lescano schränkt die Individualisierung jedoch insoweit ein wie die staatengerichteten, zumindest nicht von vornherein auf Individuen zielenden, Normen des Völkergewohnheitsrechts Einzelne auch verpflichten können. Dabei soll es so sein, dass diese mangels exakten Wortlauts mit den nationalen Grundsätzen des Gesetzesvorbehalts und der Bestimmtheit einer Eingriffsgrundlage kollidieren. ${ }^{444}$ Es wird darauf verwiesen, dass in der Lehre deshalb bereits die abstrakte Eignung einer allgemeinen Völkerrechtsregel ausreiche, um durch Art. 25 Satz 2 GG subjektiviert zu werden. ${ }^{445}$

\footnotetext{
${ }^{441}$ Vgl. Doehring, Fremdenrecht, S. 125 f., 165 f.; Fischer-Lescano/Hanschmann, in: Becker/Braun/Deiseroth, Frieden durch Recht?, S. 188, 196.

${ }^{442}$ Repräsentativ hierzu Kessler/Salomon, in: DÖV 7/2014, S. 283 (284 f.)

${ }^{443}$ Dahm/Delbrück/Wolfrum, Völkerrecht Bd. I/3, S. 822 f.

${ }^{444}$ Dazu bereits in Kapitel $§ 5$ Punkt 5.

${ }^{445}$ So Kunig, in: Vitzthum/Proelß, Völkerrecht, S. 119 Rn 154.
} 
Die in vorherigen Kapiteln bereits aufgezeigten Probleme der teils unzureichenden Bestimmtheit einer Eingriffsgrundlage völkerrechtlichen Ursprungs in Deutschland werden offenbar vorbehaltlos dadurch relativiert, dass diese überwiegend bei der unmittelbaren Erzeugung von Individualpflichten aufkämen, insoweit also die Rechtserzeugung davon nicht betroffen sei. ${ }^{446}$ Ein Verweis ${ }^{447}$ auf das Normenverifikationsverfahren nach Art. 100 Abs. 2 GG schlägt ebenso fehl. Der Autor vertritt, dass das Verfahren nach Art. 100 Abs. 2 GG zur Ausräumung solcher Zweifel geschaffen worden sei. Das Entscheidungsmonopol hinsichtlich der Klärung einer Rechts- oder Pflichtenerzeugung durch eine allgemeine Regel obliege dem BVerfG. Das Verfahren sei sogar ein Argument für ein extensives Verständnis von Art. 25 Satz 2 GG, förderten doch beide Normen die Effektivität des Völkerrechts im deutschen Recht. ${ }^{448}$ Es wird jedoch verkannt, dass es sich beim Normenverifikationsverfahren nach Art. 100 Abs. 2 GG nicht um ein Verfahren zum Schutz Einzelner oder zur Durchsetzung individueller Ansprüche handelt. Es wird vom BVerfG geklärt, $o b$ allgemeine Völkerrechtsregeln überhaupt Rechte oder Pflichten erzeugen. Seitens der unterstützenden Lehre werden die allgemeinen Völkerrechtsregeln in individualgerichtet oder staatengerichtet zunächst theoretisch unterschieden und eine konstitutive Wirkung des Art. 25 Satz 2 GG befürwortet, praktisch sei dann jedoch durch das BVerfG nachträglich die Reichweite zu klären. Die von der Literatur hier angenommene Reihenfolge der Legitimation ist falsch und die Erarbeitung individueller Ansprüche auf dieser Grundlage dogmatisch fehlerhaft und deshalb abzulehnen.

Doehring sah ebenfalls das Gegenargument, Individuen seien ,,regelmäßig zur objektiven Beurteilung der Rechtslage des ius ad bellum nicht in der Lage““. ${ }^{449}$ Es ist nicht verständlich, warum Fischer-Lescano dies lediglich als Hintergrundannahme deklariert und bestreitet, dass eine verfassungsrechtlich gebotene Subjektivierung dadurch eingeschränkt würde. ${ }^{450}$ Er sieht die Anerkennung der (zumindest partiellen) Völkerrechtssubjektivität natürlicher Personen als Indiz für einen subjektivierten Rechtszustand. Die Resolution des UN-Sicherheitsrates habe lediglich bestätigt, nicht begründet, dass Einzelnen eine Kompensationsforderung zustehen könne. ${ }^{451}$ Insbesondere beinhalten die Verbote der Anwendung von Ge-

\footnotetext{
${ }^{446}$ Fischer-Lescano/Hanschmann, in: Becker/Braun/Deiseroth, Frieden durch Recht?, S. 195.

${ }^{447}$ Ders.

${ }^{448}$ Ders., S. 195, 196.

${ }^{449}$ Siehe Doehring, Fremdenrecht, S. $166 \mathrm{f}$.

${ }^{450}$ Fischer-Lescano/Hanschmann, in: Becker/Braun/Deiseroth, Frieden durch Recht?, S. 196.

${ }^{451}$ Fischer-Lescano, Militärbasen und militärisch genutzte Flughäfen, S. 9.
} 
walt und des Führens eines Angriffskriegs zwar subjektive Unterlassungspflichten des Einzelnen, jedoch nicht automatisch auch damit einhergehende Anspruchsrechte auf Unterlassen. ${ }^{452}$ Ebenso inkonsequent ist den Wortlaut des Art. 25 Satz 2 GG vorbehaltlos anzuwenden, somit als logische Folge auf alle allgemeinen Völkerrechtsregeln zu beziehen, dann jedoch in der Wirkung auf allgemeine Regeln zu beschränken, denen zumindest nicht offensichtlich ein Anwendungsbezug zu Einzelnen abgesprochen werden kann. ${ }^{453}$

\subsection{Der Entschädigungsanspruch bei Kriegsschäden}

Gegenwärtig ist offen, ob über die Staatspflicht zur Bereitstellung von Schadensersatz und Abhilfe hinaus bei massiven Verletzungen beispielsweise des humanitären Völkerrechts und Menschenrechten ein Anspruch aus Völkergewohnheitsrecht, also auch aus Art. 25 GG, auf Entschädigung besteht. National und international wurden bisher kaum Gerichtsurteile gefällt, die Kriegsopfern Schadensersatzansprüche auf Grundlage des Völkergewohnheitsrechts zuerkennen. Der IGH hat in neuerer Praxis im Jurisdictional Immunities das Vorliegen einer Ius-cogens-Norm der Individualentschädigung verneint. ${ }^{454}$ Es ist anzunehmen, dass der IGH die Existenz ebenfalls verneint, andere sehen eine völkergewohnheitsrechtliche Anspruchsgrundlage in der Rechtspraxis allerdings für möglich. ${ }^{455}$ Wenn es um die Sekundäransprüche gegen den Staat geht, beispielsweise um Entschädigungsansprüche von Kriegsopfern, kommt dieser an die Grenzen der Leistungsfähigkeit seines Rechts. Gegen eine Anerkennung von Individualansprüchen auf Schadensersatz wird oftmals angeführt, dies führe zu einer Klagewelle vor den Gerichten.

Am konkreten Beispiel des Einsatzes militärisch genutzter Drohnen gab es Ansätze, einen subjektiven Staatshaftungsanspruch über Art. 25 Satz 2 GG zu begründen. Von Woedtke meinte, dass Art. 25 Satz 2 GG für individualgerichtete Völkerrechtsregeln allenfalls deklaratorische Wirkung zukomme, da diese bereits auf völkerrechtlicher Ebene individuelle Rechte erzeugen. ${ }^{456}$ Er sieht die weiterentwickelte Völkerrechtssubjektivität Einzelner als Grund an, ihre Beteiligtenfähigkeit im Rahmen der völkerrechtlichen Verantwortlichkeit

\footnotetext{
${ }^{452}$ Soweit auch Kessler/Salomon, in DÖV 7/2014, S. 283 (285).

${ }^{453}$ So zumindest Fischer-Lescano, Militärbasen und militärisch genutzte Flughäfen, S. 21.

${ }^{454}$ IGH, Judgement of 03.02.2012, Case Concerning Jurisdictional Immunities (Federal Republic of Germany vs Italian Republic), ICJ Reports 2012, S. 37.

${ }^{455} D^{\prime}$ Argent, Les réparations de guerre en droit international public, S. 788.

${ }^{456}$ v. Woedtke, Die Verantwortlichkeit Deutschlands, S. $365 \mathrm{f}$.
} 
zu diskutieren. ${ }^{457}$ Sind Völkerrechtssubjekte in ihren verliehenen Rechten verletzt, sollen sie passiv beteiligtenfähig sein an der durch die Verantwortlichkeit des Staates entstehenden Rechtsbeziehung. Dabei komme es darauf an, dass Individuen bei Kriegsfällen auch völkerrechtliche Rechte zustehen. ${ }^{458}$ Gestützt wird diese Auffassung durch die bereits präsentierte Rechtsprechung des BGH im Fall $\operatorname{Varvarin}^{459}$ und des IGH im Fall LaGrand ${ }^{460}$, wonach Individuen mittlerweile, vor allem im menschenrechtlichen Regelungsbereich, als völkerrechtliche Rechts- und Pflichteninhaber auch partielle Völkerrechtssubjekte sind.

Von Woedtke zieht allerdings selbst die Kausalität infrage, die Völkerrechtssubjektivität Einzelner direkt auf die Rechtsbeziehung anwenden zu können, die im Rahmen der völkerrechtlichen Verantwortlichkeit zwischen verletztem (Primär-)Rechtsträger und verantwortlichem Staat entsteht. Es sei mitnichten so, dass ein Mechanismus automatisch begründeter Sekundärrechte in Gang gesetzt würde, die betroffene Individuen selbst geltend machen könnten. ${ }^{461}$

An anderer Stelle im Rahmen dieser Bearbeitung wurde die Anerkennung einer partiellen Völkerrechtssubjektivität vom Verfasser als Indiz gesehen, dass die einzelnen Personen im Völkerrecht eine bedeutendere Rolle einnehmen. ${ }^{462}$ Dies wurde dann abgelehnt und weiter ausgeführt, dass auf die Verletzung individualbezogener Primärrechte nicht die Herleitung individueller Wiedergutmachungsansprüche wegen Kriegsschäden folge. Eine automatische Begründung von Sekundärrechten für das betroffene Völkerrechtssubjekt komme nicht in Betracht. ${ }^{463}$

Versucht wurde ebenfalls, eine völkergewohnheitsrechtliche Grundlage für den Individualanspruch aufgrund von Kriegsschäden zu finden. Dabei stimmte von Woedtke der Argumentation Fischer-Lescanos zu. Die betreffenden Opfer sollen danach auf Grundlage allgemeiner Völkerrechtsregeln Schadensersatzansprüche gegen den verantwortlichen Staat geltend machen können. ${ }^{464}$

\footnotetext{
${ }^{457}$ v. Woedtke, Die Verantwortlichkeit Deutschlands, S: 70, 198; Dörr, in: Völkerrecht, § 29 Rn 4, § 31 Rn 7. ${ }^{458}$ v. Woedtke, Die Verantwortlichkeit Deutschlands, S. 198, 199; Crawford, in: AJIL 4/2002, Art. 36 Rn 4.

${ }^{459}$ BGHZ 169, 348 (351 f.).

${ }^{460} \mathrm{IGH}$, Judgement of 27.06.2001, LaGrand Case (Germany vs. USA), ICJ Report 2001, S. 466.

${ }^{461} v$. Woedtke, Die Verantwortlichkeit Deutschlands, S. 212, 214; vgl. auch Hagelberg, Die völkerrechtliche Verfügungsbefugnis des Staates über Rechtsansprüche von Privatpersonen, S. 183; Hofmann, in: Dupuy, Völkerrecht als Wertordnung, S. 341 (357).

${ }^{462}$ Siehe dazu unter Kapitel $§ 3$, Unterpunkt 1.1.4.

${ }^{463} v$. Woedtke, Die Verantwortlichkeit Deutschlands, S. 214.

${ }^{464}$ v. Woedtke, Die Verantwortlichkeit Deutschlands, S. 230; Fischer-Lescano, in: AVR 3/2007, S. 299 (326, $331)$.
} 
Mit Blick auf die internationale Praxis ${ }^{465}$ macht von Woedtke aus, dass zunehmend die Belange der Opfer von Verletzungen menschenrechtlicher und humanitärrechtlicher Normen Würdigung finden, den sogenannten ,victim-centered approach“. ${ }^{466}$ Dieser Ansatz beinhalte eine Forderung oder Anerkennung individueller Entschädigungsansprïche, aber dennoch zweifelt er die Qualifizierung der vereinzelten Rechtsprechung als Völkergewohnheitsrecht an. Erst seit der Jahrtausendwende gelangt dieses Thema zunehmend in den Fokus. Demnach seien auch die praktischen Fälle, über die entschieden werden mussten, überschaubar gewesen. Der Autor führt die mangelnde Staatenpraxis an, sofern sich diese überhaupt zu Wiedergutmachungsansprüchen wegen Kriegsschäden geäußert haben. Für die nationale Praxis bedeute das, dass die Gerichte keine Ansprüche für Kriegsopfer auf völkerrechtlicher Grundlage anerkannt haben, obwohl europäische Gerichte Ersatzansprüche dieser Art gegen Deutschland bestätigen. ${ }^{467}$ Durch den IGH hat die Bundesrepublik Deutschland bestätigen lassen, dass der Grundsatz der Staatenimmunität, der auch über Art. 25 GG innerstaatlich Anwendung findet, auch für vergangene Kriegshandlungen gilt. Es gehört zum Völkergewohnheitsrecht durch ausländische Rechtsprechung, dass die Staatenimmunität auch für solche Fälle gelten soll. Ausnahmen waren die streitgegenständlichen italienischen und auch griechische Entscheidungen, die regelmäßig Entschädigungsansprüche gegen Deutschland befürworten. ${ }^{468}$

Die nationalen Rechtsprechungen werden noch im folgenden Kapitel näher betrachtet. Überwiegend lehnen die Gerichte begehrte Entschädigungen deshalb ab, weil die Konzeption des Völkerrechts keine Ansprüche geschädigter Individuen gegen verantwortliche Staaten vorsähe. ${ }^{469}$

\footnotetext{
${ }^{465}$ Unter anderem: IGH, Advisory Opinion of 09.07.2004, Legal Consequences of the Construction of a Wall in the Occupied Palestinian Territory; IGH, Advisory Opinions of 08.07.1996, Legality of the Threat of the Use of Nuclear Weapons; EGMR, Judgement of 28.07.1998, Ergi vs. Turkey, Nr. 66/1997/850/1057; Judgement of 24.02.2005, Isayeva u. a. vs. Russia, Nr. 57950/00,; beispielsweise die Resolution der UNGeneralversammlung vom 21.03.2006 (UN-Doc. A/Res/60/147); Beschluss der UN-Menschenrechtskommission vom 13.04.2005 (UN Doc. E/CN.4/2005/L.48); Commission on Human Rights, Report of the 61 ${ }^{\text {st }}$ Session (UN Doc. E/2005/23 - E/CN.4/2005/135); Resolution der UN-Generalversammlung vom 15.12.2006 (UN Doc. A/ES-10/L.20/Rev.1); ILA, Committee on Compensation for Victims of War, Toronto Conference (2006).

${ }^{466} v$. Woedtke, Die Verantwortlichkeit Deutschlands, S. $271 \mathrm{f}$.

${ }^{467}$ v. Woedtke, Die Verantwortlichkeit Deutschlands, S. 288; vgl. auch Zegveld, in: IRRC 849/2003, S. 497 (512).

${ }^{468} \mathrm{IGH}$, Judgement of 03.02.2012, Case Concerning Jurisdictional Immunities of the State Italy vs. Germany, ICJ Report 2012, S. 37 f.

${ }^{469} v$. Woedtke, Die Verantwortlichkeit Deutschlands, S. 289.
} 
Als Alternative zum Amtshaftungsanspruch aus $\S 839$ BGB in Verbindung mit Art. 34 GG kommt auch die Option einer Subjektivierung des völkergewohnheitsrechtlichen Schadensersatzanspruchs für die zurechenbaren Völkerrechtsverletzungen über Art. 25 Satz 2 GG in Betracht. Von Woedtke beschränkt sich bei seiner Aufstellung auf die staatengerichteten Völkerrechtsregeln, die ihrem Gehalt nach auch individualschützende oder -verpflichtende Finalität entfalten können, und erkennt die konstitutive Wirkung des Art. 25 Satz 2 GG für solche Regeln an, beispielsweise für die dem Individualschutz dienenden Vorschriften des humanitären Völkerrechts wie Art. 48 f. ZP-I. ${ }^{470}$

Theoretisch ist es auch möglich, die primär staatengerichteten Völkerrechtsnormen, die (sekundäre) Schadensersatzansprüche regeln, über Art. 25 Satz 2 GG subjektivieren zu können. ${ }^{471}$ Allerdings stünden aktuell noch die völkerrechtliche Lage und insbesondere die Rechtsprechung des BVerfG dagegen, einer Subjektivierung der auch individualgerichteten Völkerrechtsregeln, und damit der Schadensersatzansprüche, stattzugeben. Diese dürften nach wie vor nur von den entsprechenden Heimatstaaten geltend gemacht werden. Ebenso vertritt der Autor die Auffassung, dass neben dem etablierten Amtshaftungsanspruch des $\S$ 839 BGB in Verbindung mit Art. 34 GG kein Raum für eine Subjektivierung durch Art. 25 Satz 2 GG sei. ${ }^{472}$ Auch der BGH hat 2006 die Möglichkeit der Subjektivierung völkergewohnheitsrechtlicher Schadensersatzansprüche für die Verletzungen individualberechtigender Völkerrechtsregeln durch Art. 25 Satz 2 GG offengelassen. ${ }^{473}$

Kritisiert wird an von Woedtkes Vorstoß, dass die seiner Meinung nach offensichtliche Verdrängung der dualistischen Trennung von Völkerrecht und innerstaatlichem Recht lediglich mit Kelsens Lehre des Monismus ${ }^{474}$ zu stützen und zu begründen wäre. Ein völkerrechtliches Verbürgen könne lediglich völkerrechtlich bindend wirken, und es bedürfe eines Transformationsaktes zur innerstaatlichen Geltung. ${ }^{475}$ Diese Möglichkeit wird jedoch be-

\footnotetext{
${ }^{470}$ v. Woedtke, Die Verantwortlichkeit Deutschlands, S. 364; auch in Herdegen, in: Maunz/Dürig, Art. 25, Rn 89; Koenig/König, in: v. Mangoldt/Klein/Starck, Art. 25 GG, Rn 61 f.; Streinz, in: Sachs, Art. 25 GG, Rn 47; Dörr, in: JZ 11/2004, S. 572 (576).

${ }^{471}$ v. Woedtke, Die Verantwortlichkeit Deutschlands, S. 364 mit Verweis auf Dutta, in: AÖR 2/2008, S. 191 (203).

${ }^{472}$ v. Woedtke, Die Verantwortlichkeit Deutschlands, S. 364, 365 mit Verweis auf BVerfGE 94, 315 (329); BVerfGK 7, 303 (307 f.); Hillgruber, in: Schmidt-Bleibtreu/Hofmann/Henneke, Art. 25 GG, Rn 29; Rojahn, in: v. Münch/Kunig, Art. 25 GG, Rn 53; Streinz, in: Sachs, Art. 25 GG, Rn 76, 97.

${ }^{473}$ BGHZ 169, 348 (356 f.).

${ }^{474}$ Hierzu Schweitzer/Dederer, Staatsrecht, S. 13 Rn 47 f.

${ }^{475}$ Moewes, in: Frau, Drohnen und das Recht, S. 212; zur monistischer Lehre vgl. Kapitel $\S 3$, Unterpunkt 1.3.1.
} 
reits aufgrund „mangelnden Realitätsbezugs“ abgelehnt, da diese heute nicht mehr vertreten werde. ${ }^{476}$ Der Autor vertritt ebenso die Meinung, das bereits bestehende nationale Staatshaftungsrecht reiche aus, auch die Gefahren der automatisierten Kriegsführung hinreichend zu umfassen und im Streitfall bewältigen zu können. ${ }^{477}$

Diese Kritik der allenfalls herausfordernden Situation des bestehenden Staatshaftungsrechts spricht ebenfalls für eine Ablehnung des Art. 25 Satz 2 GG als eigenständige Anspruchsgrundlage für internationale Entschädigungsansprüche Einzelner.

\subsection{Die ,faktische Betroffenheit“ als zusätzliche Anspruchsvoraussetzung}

Es gibt Ansätze, eine zu weite Anwendbarkeit des Art. 25 Satz 2 GG einzudämmen und einen derart extensiven Adressatenwechsel zu korrigieren. Dazu wird eine sogenannte „faktische Betroffenheit ${ }^{\text {“478 }}$ als Voraussetzung installiert, um eine Verletzung allgemeiner Völkerrechtsregeln rügen zu können. Auf diese Weise sollen Popularklagen vermieden werden, indem auf eine andere Norm des Völkerrechts zurückgegriffen wird. Bereits an dieser Stelle ist anzumerken, dass es höchst inkonsequent erscheint, Art. 25 Satz 2 GG als Rechtsgrundlage anzuerkennen und zu unterstützen, die eigenen berechtigten Zweifel ${ }^{479}$ an der durch den Wortlaut des Art. 25 Satz 2 GG eröffneten Popularklagemöglichkeit dann aber mit einer zusätzlichen Voraussetzung eindämmen zu wollen. Bezug genommen wird dazu auf eine Entscheidung des IGH, in der dieser eigens die Konzeption einer wenigstens „faktischen Betroffenheit“ benannte, um subjektive Rechte begründen zu können. ${ }^{480}$ Zum Ausdruck kommt diese Konzeption im ILC-Kodifikationsentwurf zur Staatenverantwortlichkeit, der das Völkergewohnheitsrecht systematisiert. Art. 42 des Entwurfs besagt, dass ein „State is entitled as an injured State to invoke the responsibility of another State if the obligation breached is owed to: (a) that State individually; or (b) a group of States including that State, or the international community as a whole, and the reach of the obligation: (i) socially affects that State; or (ii) is of such a character as radically to change the

\footnotetext{
${ }^{476}$ S. Moewes, in: Frau, Drohnen und das Recht, S. 212; Schweitzer/Dederer, Staatsrecht, S. 13 Rn 47 f.

${ }^{477}$ Ders., S. 213.

${ }^{478}$ Fischer-Lescano/Hanschmann, in: Becker/Braun/Deiseroth, Frieden durch Recht?, S. 197.

${ }^{479}$ Diese Bedenken hat auch Fischer-Lescano, Militärbasen und militärisch genutzte Flughäfen, S. 22; vergleichbar auch Doehring, Völkerrecht, Rn 731.

${ }^{480} \mathrm{IGH}$, Judgement of 30.06.1995, East Timor (Portugal vs. Australia), ICJ Reports 1995, S. 90, 102 ; vgl. auch IGH, Advisory Opinion of 08.07.1996, Legality of the Threat or Use of Nuclear Weapons, ICJ Reports 1996, S. 226, 258.
} 
position of all the other States to which the obligation is owed with respect to the further performance of the obligation.“. Die Norm adressiert ausschließlich Staaten als Rechtssubjekte, zu subjektiven Ansprüchen oder Rechten und Pflichten einzelner gibt es keine Regelungen. Die Berechtigungen von Individuen, die das Völkerrecht bereits kennt, bleibt davon unberührt. Die ILC erkennt insbesondere an, dass es individuelle völkerrechtliche Kompensationsansprüche gegen Staaten gibt. ${ }^{481}$

Vereinzelte Stimmen sehen jedoch keinen Grund, diese Norm nicht zur Beschränkung des individuellen Anspruchs aus Art. 25 Satz 2 GG anwenden zu können, um zur Vermeidung von Popularklagen ein ,special interest“ zu verlangen. Die Kommentierung zu Art. 42 des ILC-Entwurfs führt weiter aus, dass die gebrochene völkerrechtliche Norm das jeweilige Rechtssubjekt „betreffen“ muss, so dass dieses von der Allgemeinheit unterschieden wird. Dabei reicht statt einer rechtlichen Betroffenheit eine rein faktische Betroffenheit. Diese soll bereits bestehen, wenn eine unmittelbare Betroffenheit von Interessen das Rechtssubjekt, verglichen zur Allgemeinheit, besonders auszeichnet. ${ }^{482}$ Die in Art. 48 ILC-Entwurf genannten Rechte sollen auch von Individuen geltend gemacht werden können. Art. 25 GG als Eingliederungsnorm bewirke, dass die Befugnis eines Staates zur Anspruchsdurchsetzung auch den Bürgerinnen und Bürgern des Bundesgebietes aus dem Völkergewohnheitsrecht zukomme. Dies könnten auch faktisch betroffene Nachbarn militärisch genutzter Flughäfen sein. Die in Art. 42 ILC-Entwurf geforderte spezielle Betroffenheit gehe auch nicht durch den Adressatenwechsel des Art. 25 GG verloren. ${ }^{483}$

Bei der Heranziehung und Bearbeitung des Art. 42 ILC-Entwurf zur Eindämmung von Popularklagen wird allerdings übergangen, dass die Norm, so wie der gesamte ILC-Entwurf, lediglich Staaten oder die Staatengemeinschaft adressiert und die Rügemöglichkeiten untereinander bestimmt und ausgestaltet. Dies beinhaltet auch die Gefahr, würden Einzelne als „Staaten“ aufgefasst, um klagebefugt sein zu können, dass diese zu ihrem Unterlassungsanspruch auch Repressalien ausüben könnten. ${ }^{484}$ Zwar gibt es auch Stimmen der Literatur, die vertreten, dass durch die Erweiterung des Kreises der Völkerrechtssubjekte auch

\footnotetext{
${ }^{481}$ ILC-Kommentar, Art. 28, S. 214 f.

${ }^{482} \mathrm{Vgl}$. Fischer-Lescano/Hanschmann, in: Becker/Braun/Deiseroth, Frieden durch Recht?, S. 197 f.; FischerLescano, Militärbasen und militärisch genutzte Flughäfen, S. 24 f.; ,For a State to be considered injured, it must be affected by the breach in a way which distinguishes it from the generality of other States to which the obligation is owed."; ILC-Kommentar, Art. 42 des Entwurfs, S. 119.

${ }^{483}$ Fischer-Lescano/Hanschmann, in: Becker/Braun/Deiseroth, Frieden durch Recht?, S. 199; Fischer-Lescano, Militärbasen und militärisch genutzte Flughäfen, S. 25.

${ }^{484}$ Vgl. dazu Kunig, in: Vitzthum/Proelß, Völkerrecht, S. 120 Rn 154, der zwar Art. 25 Satz 2 GG ebenfalls konstitutiv versteht, jedoch die Staatenverantwortlichkeit von einer Subjektivierung ausnimmt, da das Recht zu Repressalien ausschließlich staatengerichtet ist.
} 
die Anwendbarkeit des Verantwortungsprinzips erweitert wurde ${ }^{485}$, allerdings war diese (zumindest partielle) Anerkennung der Völkerrechtssubjektivität Einzelner bereits in den Neunzigerjahren schrittweise zu beobachten. Auch das IGH-Urteil im Fall LaGrand, welches ein halbes Jahr vor Zustandekommen des ILC-Entwurfs gefällt, und in welchem diese partielle Völkerrechtssubjektivität durch die höchste internationale Instanz zuerkannt wurde, fand keinen Einfluss auf den ILC-Entwurf hinsichtlich möglicher Individualrechte der Staatsbürger in Fragen der Staatenverantwortung.

An vorheriger Stelle wurde angemerkt, dass Staaten erst mit der Zustimmung des UN-Sicherheitsrates Gewalt ausüben dürfen. Bei der Ausübung eines individuellen völkerrechtlichen Selbstverteidigungsrechts kämen die natürlichen Rechtssubjekte in eine vorteilhaftere rechtliche Lage als die ursprünglich adressierten Staaten auf völkerrechtlicher Ebene. Die einzelnen Bundesbürger müssen, so zumindest die nationale Rechtslage mangels inhaltlicher Ausgestaltung des Art. 25 GG, der diese ebenso berechtigt, nicht vorher an den UNSicherheitsrat wenden, um eine Zustimmung zu etwaigen Vorhaben einzuholen. Problematisch erscheint ebenso, wer die rechtlichen oder nicht-rechtlichen Schritte Einzelner überprüfen könnte oder müsste, nationale Gerichte oder der IGH oder der UN-Sicherheitsrat selbst.

Art 25 GG trat im Jahr 1949 in Kraft und beinhaltet die Formulierung der „unmittelbaren“" Erzeugung von Rechten und Pflichten. Im Jahr 1963 erkannte Doehring Satz 2 der Norm als Anspruchsgrundlage für die Bürgerinnen und Bürger Deutschlands an, ohne auf einen Ausschluss von Popularklagen einzugehen und eine Klageflut infolge der unmittelbaren Erzeugung von Rechten und Pflichten zu beschränken. Es scheint so, als diene die Schaffung dieser Voraussetzung als Fremdkörper des Art. 25 GG lediglich der Korrektur unliebsamer Folgen einer unbeschränkten Anwendbarkeit.

Es erscheint dogmatisch herausfordernd und ist höchst inkonsequent, dass die Befürworter der Literatur, die Art. 25 Satz 2 GG selbst als Anspruchsgrundlage anerkennen, prominent auf Doehring und dessen Wortlautargument abstellen, jedoch dabei scheinbar übersehen, dass diese Norm als Anspruchsgrundlage die Rechtspraxis vor gravierende Probleme stellen würde. Diese werden im folgenden Kapitel noch etwas näher betrachtet.

Erst im Jahr 2001 wurde der ILC-Entwurf vorgestellt. Insbesondere ist er für diese unverbindlich. Der Entwurf wurde zwar durch die Generalversammlung der Vereinten Nationen am 12. Dezember 2001 angenommen (Resolution 56/83), es kam bisher jedoch noch nicht

${ }^{485}$ So beispielsweise Dörr, in: Völkerrecht, § $29 \mathrm{Rn} 4, \S 31 \mathrm{Rn} 7$. 
zum Abschluss eines daran anknüpfenden Völkervertrags. Auch, wenn die staatliche Verantwortlichkeit in der Theorie ausformuliert und niedergeschrieben wurde, hinkt doch die praktische Verwendbarkeit. Auch in den Folgejahren wurde nichts Vergleichbares verabschiedet, was die allgemeine Scheu vor dem bedeutsamen Thema wieder verdeutlicht. Ein ungeschriebener Vorbehalt der Staatenverantwortlichkeit gegenüber Individuen, wie ihn einzelne Stimmen ausmachen ${ }^{486}$, erscheint spätestens praktisch wertlos. Nicht zuletzt ist es widersprüchlich, aus dem Konvent von Herrenchiemsee und den Ausführungen Schmids einen zukunftsorientierten Modellcharakter des Art. 25 Satz 2 GG ableiten zu wollen ${ }^{487}$, dann aber auf einen über fünfzig Jahre später geschaffenen, unverbindlichen Entwurf zurückzugreifen, der zudem gar nicht an Individuen gerichtet ist, um diese unterstellte zukunftsorientierte konstitutive Wirkung tatsächlich praktikabel gestalten zu können. Tatsächlich ist im Rahmen der Konventsitzungen von Herrenchiemsee eine konstitutive Wirkung des Art. 25 Satz 2 GG nicht thematisiert worden. Ein über die Herauslösung des Völkerrechts aus dem vorherigen Staatenrecht hinausgehendes Ziel der Verfasser kann jedenfalls nicht eindeutig ausgemacht werden.

Daraus auf eine „faktische Betroffenheit“ als Quasi-Voraussetzung des Art. 25 GG zu schließen, ist ein Trugschluss. Sind die staatlichen Organe an die allgemeinen Völkerrechtsregeln gebunden, die immer öfter von der höchsten Rechtsprechung auch als durch Art. 25 Satz 2 GG subjektiviert erachtet werden, muss die Norm nicht zusätzlich zur verfassungsrechtlichen Anspruchsgrundlage konstruiert werden. Eine Voraussetzung der faktischen Betroffenheit gibt es im Wortlaut des Art. 25 GG nicht. Auch die Entstehungsgeschichte spricht nicht dafür, Art. 25 GG als Tor für Popularklagen öffnen zu wollen. Dies trüge sicher nicht zur steigenden Effektivität des Völkerrechts in Deutschland bei. Gerade an dieser Stelle sprechen insbesondere der oft zitierte Wortlaut und auch die Entstehungsgeschichte des Art. 25 GG gegen die Eingrenzung von Popularklagen, die jedoch auf völkerrechtlicher und innerstaatlicher Ebene vermieden werden.

Die Voraussetzung einer „faktischen Betroffenheit“ gibt es zudem innerstaatlich beispielsweise im Baurecht. ${ }^{488}$ Dort ist diese jedoch nicht gedacht, einen subjektiven Anspruch erst

\footnotetext{
${ }^{486}$ Fischer-Lescano, in: AVR 3/2007, S. 299 (307).

${ }^{487}$ Fischer-Lescano, Militärbasen und militärisch genutzte Flughäfen, S. 17 mit Verweis auf Der Parlamentarische Rat: 1948-1949, Fünfte Sitzung des Hauptausschusses vom 18.11.1948 bzgl. Art. 29 des Herrenchiemsee Entwurfs (später Art. 25 GG) S. 160, 161, deutlich anderer Meinung vgl. Kessler/Salomon, in: DÖV 7/2014, S. 283 (288).

${ }^{488}$ Vgl. auch Kessler/Salomon, in: DÖV 7/2014, S. 283 (290).
} 
zu begründen, sondern um einen Eingriff in ein subjektives Recht zu ermöglichen. Nachbarn können sich so nach der Ansicht des BVerwG direkt auf Art. 14 GG für die Klagebefugnis berufen, wenn die „vorgegebene Grundstückssituation nachhaltig verändert und dadurch die Nachbarn schwer und unerträglich“ betroffen sind. ${ }^{489}$ Es widerspräche im Übrigen dem Normzweck des Art. 19 Abs. 4 GG, würde Art. 25 Satz 2 GG als Anspruchsgrundlage für Individualrechte und -pflichten anerkannt. Diese Hürde sollte nicht mit der Schaffung und Heranziehung künstlicher Voraussetzungen nachträglich genommen werden. In der deutschen Rechtspraxis hat die Konzeption einer „faktischen Betroffenheit“ keine nennenswerte Beachtung erfahren, und auch das Völkerrecht hat dies bisher noch nicht ändern können. Lediglich in zwei Verfahrensgängen zu Anwohnerklagen gegen die Drohnenflüge von der US-Airbase Ramstein beschäftigten sich die einzelnen Instanzen kurz mit dem vereinzelten Vorschlag in der Literatur, Art. 25 Satz 2 GG als Rechtsgrundlage eines völkerrechtlichen Unterlassungsanspruchs anzusehen. Jedoch konnte auch in diesen Ausnahmefällen praktischer Bezugnahme auf eine mögliche „faktische Betroffenheit“ eine solche nicht festgestellt werden. ${ }^{490}$

Dies zeigt deutlich, dass dieses Konstrukt nicht nur eine vereinzelte Ausnahme des Schrifttums zur Ausweitung von Ansprüchen aus Art. 25 GG ist, sondern auch, dass diese einer praktischen Anwendung nicht standhält und deshalb abzulehnen ist. Dies hätte somit zur Folge, dass Art. 25 Satz 2 GG aufgrund einer ausschweifenden Subjektivierung allgemeiner Völkerrechtsregeln offen als Gegenstand von Popularklagen wäre. Da ein solcher Zweck jedoch von den Verfassern des Grundgesetzes und auch der heute einhelligen Meinung abgelehnt wird, spricht dies an dieser Stelle gegen Art. 25 Satz 2 GG als individuelle Anspruchsgrundlage. Es gibt kritische Autoren, die den Zweck des Art 25 GG - die Hervorhebung völkerrechtlicher Regeln aus der Sphäre bloßen Staatenrechts - bereits dadurch erreicht sehen, dass bis heute die Menschenrechte sowie das Völkerstrafrecht dynamisch fortentwickelt und ins Staatenrecht eingegliedert wurden. ${ }^{491}$ Die Funktion des Art. 25 GG ist insbesondere auch nicht, etwaige Defizite der nationalen Rechtsordnung auszugleichen, sondern diese mit den ungeschriebenen Völkerrechtsnormen zu synchronisieren. ${ }^{492}$

\footnotetext{
${ }^{489}$ BVerwGE 32, 173 (178); 36, 248 (249 f.); 44, 244 (246 f.); 50, 282 (287); Papier/Shirvani, in: Maunz/Dürig, Art. 14 GG, Rn 187.

${ }^{490}$ VG Köln, Urteil vom 14.03.2013, Az. 1 K 2822/12, Rn 68 f. nach juris; OVG Münster, Urteil vom 04.11.2014, Az. 4 A 1058/13, in: DVB1. 8/2015, S. 514-520 (Leitsatz und Gründe, Rn 64 f. nach juris; ebenso hinsichtlich weiterer Ramstein-Anwohnerklagen OVG Münster, Beschluss vom 07.05.2013, Az. 4 A 1913/11, in: DVB1. 17/2013, S. 1129 (Leitsatz und Gründe), Rn 22 nach juris.

${ }^{491}$ So beispielsweise Kessler/Salomon, in DÖV 7/2014, S. 183 (288); ähnlich auch Steinberger, in: HdStR Bd. 7, § 173 Rn 69.

${ }^{492}$ Schorkopf, Staatsrecht internationaler Beziehungen, § 3 Rn 18.
} 


\subsection{Zwischenergebnis}

Sowohl nationale, als auch internationale Stimmen fordern zur Steigerung der Effektivität humanitärer Völkerrechtsbestände die Einräumung von Individualansprüchen, vor allem auch individuelle Schadensersatzansprüche. Insbesondere soll den Einzelnen eröffnet werden, selbst ihre Ansprüche gegenüber Staaten geltend machen zu können, statt wie bisher nur durch die jeweiligen Heimatstaaten. In ihrer Meinung bestärkt wurden die Vertreter durch die Entscheidung des IGH 2004, dass auch in bewaffneten Konflikten die Normen des völkerrechtlichen Minderheitsschutzes anwendbar seien. ${ }^{493}$ Daraus wurde teils geschlussfolgert, subjektive Entschädigungsansprüche Einzelner gegen Staaten seien zum Völkergewohnheitsrecht geworden. ${ }^{494}$ Die deutschen Gerichte haben aber stattdessen die bereits etablierte Staatshaftung nach $\S 839$ BGB in Verbindung mit Art. 34 GG fortgebildet, so dass beispielsweise auch deutschen Soldaten Amtspflichten gegenüber Opfern militärischer Auseinandersetzungen zukommen könnten. Konkrete individuelle Ersatzansprüche sind jedoch noch nicht zugesprochen worden und eine direkte Anwendbarkeit des $§ 839$ BGB in Verbindung mit Art. 34 GG offengeblieben. ${ }^{495}$

Es ist inkonsequent, sämtliche Bedenken der Unüberschaubarkeit, Undefinierbarkeit und praktischen Handhabung abzuweisen und Art. 25 Satz 2 GG als Rechtsgrundlage zu konstruieren, dann jedoch Definition und Schaffung von Praktikabilität an ein Verfahren zu knüpfen, das der Einzelne vor Gericht nicht einmal subjektiv anstrengen kann ${ }^{496}$, da es überhaupt nicht zum Individualschutz geschaffen wurde.

Die zumindest partielle Anerkennung des Einzelnen als Völkerrechtssubjekt ${ }^{497}$ sollte nicht missverstanden werden als gesteigertes Rechtsbewusstsein über eigene völkerrechtliche Rechte oder Pflichten und wie diese innerstaatlich durchgesetzt werden können. Darüber hinaus handelt es sich bei den international ausnahmsweise anerkannten Entschädigungsansprüchen Einzelner aufgrund gewaltverbotswidriger staatlicher Handlungen um Ausnahmen. Daraus eine generelle und umfängliche Individualausrichtung des Gewaltverbots und

\footnotetext{
${ }^{493} \mathrm{IGH}$, Advisory Opinion of 09.07.2004, Legal Consequences of the Construction of a Wall in the Occupied Palestinian Territory, ICJ Reports 2004, S. 55, 171; a. A. war der EGMR, Judgement of 24.02.2005, Isayeva u.a. vs. Russia, 57950/00 (2005), Rn 191.

${ }^{494}$ Vgl. Derleder, in: Becker/Braun/Deiseroth, Frieden durch Recht?, S. 343.

${ }^{495}$ Derleder, in: Becker/Braun/Deiseroth, Frieden durch Recht?, S. 339 f.; vgl. u. a. BGHZ 169, 348 (359 f.).

${ }^{496}$ Siehe in Art. 100 Abs. 2 GG: ,[...] so hat das Gericht die Entscheidung des BVerfG einzuholen.“

${ }^{497}$ Siehe dazu Kapitel $§ 4$.
} 
des Verbots des Angriffskriegs abzuleiten ist nicht naheliegend. Diese Ansprüche sind gerade nicht auf internationaler Ebene generell anerkannt, sondern wurden lediglich in Sonderfällen zugelassen. ${ }^{498}$

\section{Fazit}

Auf der Seite der Befürworter einer erweiterten Subjektivierung der allgemeinen Völkerrechtsregeln durch Art. 25 Satz 2 GG haben sich Teile der Literatur darauf fokussiert, die Entstehungsgeschichte des Art. 25 GG und das Grundgesetz im Ganzen als fortschrittliche Avantgarde einer völkerrechtsfreundlichen Behandlung Einzelner aufzugreifen. Schmid wird dabei überwiegend zitiert und sein Wirken im Konvent von Herrenchiemsee so wiedergegeben, dass völkerrechtliche Regeln auch dann individualberechtigend sein müssten, auch wenn sie grundsätzlich an Staaten gerichtet seien. Es ist jedoch darauf hinzuweisen, dass zur Zeit des Konvents von Herrenchiemsee das Völkerrecht mit seinen Regelungen fast ausschließlich staatengerichtet war. Sollte dieses als Staatenrecht eine Berechtigung Einzelner begründen, brauchte es noch eines nationalen Umwandlungsbefehls. ${ }^{499}$ Mit einer veränderten Dogmatik des Völkergewohnheitsrechts wäre es aber auch möglich, dass Art. 25 Satz 2 GG anders ausgelegt werden muss. Individualisierende Tendenzen gab es bereits mit der Allgemeinen Erklärung der Menschenrechte 1948 und den Nürnberger Prozessen von 1945 bis 1949.

Die zahlreichen Autoren, die den Konflikt mit den Grundsätzen der Bestimmtheit der Gesetze und des Gesetzesvorbehaltes zwar erkennen, aber für die Erzeugung von völkerrechtlichen Individualrechten aus den allgemeinen Völkerrechtsregeln verwerfen, verkennen, dass sie dies im Rahmen der immer noch schwelenden Diskussion um Individualrechte tun. Von der herrschenden Meinung der Lehre, die lediglich eine konstitutive Wirkung des Art. 25 Satz 2 GG für allgemeine Völkerrechtsregeln mit Individualbezug akzeptiert, sind bisher nur vereinzelte Normen als allgemeine Regeln mit konstitutiver Wirkung anerkannt: beispielsweise weite Teile des völkerrechtlichen Fremdenrechts, das erweiterte humanitäre

\footnotetext{
${ }^{498}$ Bspw. infolge der irakischen Invasion in Kuwait wurde nach der Sicherheitsratsresolution 687 von 1991 eine „United Nations Claims Commission“ eingerichtet, die für einzelne unmittelbar Verletzte einen Entschädigungsapparat aufstellte; befürwortend für eine umfängliche Individualausrichtung der Entschädigungsansprüche: Fischer-Lescano, Militärbasen und militärisch genutzte Flughäfen, S. 9 f.

${ }^{499}$ So erkennt es auch Fischer-Lescano an, vgl. Militärbasen und militärisch genutzte Flughäfen, S. 19 f.
} 
Völkerrecht, das Recht der Staatenimmunität beim gerichtlichen Erkenntnisverfahren sowie Sicherungs- und Zwangsvollstreckungsverfahren und das Auslieferungsrecht. ${ }^{500}$ Es gibt jedoch auch Stimmen, die diese Kausalität in Zweifel ziehen und nicht akzeptieren. Wie gezeigt vertritt von Woedtke, dass aus der Verletzung von Primärrechten nicht automatisch die Entstehung von Sekundärrechten zu folgern sei, deren Inhaber die verletzten Individuen wären.

Allerdings sollte dies nicht überinterpretiert werden als Vormarsch zur generellen Subjektivierung von Normen allgemeiner Völkerrechtsregeln durch Art. 25 Satz 2 GG, sondern als Besinnung darauf, dass auch siebzig Jahre nach Erlass des Art. 25 Satz 2 GG in seiner bis heute unveränderten Fassung eine konstitutive Wirkung nur für wenige allgemeine Völkerrechtsregeln anerkannt wurde. Eine grundlegende Befürwortung einer generellen Subjektivierung der allgemeinen Völkerrechtsregeln durch Art. 25 Satz 2 GG darf es deshalb nicht geben. Auch bei der Befürwortung einzelner Rechte und Pflichten sollte behutsam vorgegangen werden. Die bezweckte Ergründung individualrechtlichen Neulands sollte nicht auf Kosten der innerstaatlichen verfassungsrechtlichen Verfahrensgrundsätze gehen, deren Einhaltung das Fundament der deutschen Rechtsstaatlichkeit darstellt. Den deutschen Gesetzen geht bis zu ihrem Inkrafttreten, damit sie für alle Bürger tatsächlich auch einklagbar sein können, ein aufwendiger Gesetzgebungsprozess voraus. An diesen Voraussetzungen fehlt es den Normen allgemeiner Völkerrechtsregeln grundlegend, um sie als gleichrangige, wenn nicht sogar übergesetzesrangige, Individualrechte eingliedern zu können. So kurz und missverständlich die Norm des Art. 25 GG formuliert ist, so achtsam sollte mit der Auslegung und Anwendung umgegangen werden, wenn es um die Formulierung einer individualbezogenen Anspruchsgrundlage mit völkerrechtlichen Einschlägen geht. Dies zu beurteilen sollte einzig den deutschen Richtern zukommen, die inhaltliche Reichweite, aber auch die Grenze des Art. 25 Satz 2 GG betreffend aller allgemeinen Völkerrechtsregeln zuzusprechen. Dass dies nur für eine überschaubare Kategorie von Völkerrechtsregeln geschieht, zeigt die Komplexität der Thematik auf, die tunlichst nicht mit fortlaufenden Verweisen auf den Wortlaut einer siebzig Jahre alten Norm verworfen werden sollten. Obwohl auch jeder Staat durch Völkergewohnheitsrecht berechtigt wird Seeräuberei auf Hoher See

\footnotetext{
${ }^{500} \mathrm{Vgl}$. für diese und andere Beispiele in: Steinberger, in: HdStR Bd. 7, § 173 Rn 69; Rojahn, in: v. Münch/Kunig, Art. 25 GG, Rn 35; Fischer-Lescano/Hanschmann, in: Becker/Braun/Deiseroth, Frieden durch Recht?, S. 195, auch in Fischer-Lescano, Militärbasen und militärisch genutzte Flughäfen, S. 22.
} 
zu bekämpfen, verneinte die Bundesregierung, dass sich aus Art. 25 Satz 2 GG ein bundesrechtlicher Individualanspruch einzelner Schiffsbesitzer oder Reeder auf ein Tätigwerden der Deutschen Bundesmarine gegen Seeräuber ergebe. ${ }^{501}$

Das Argument, dass die Geltendmachung sekundärrechtlicher Ansprüche durch den Heimatstaat lediglich Zwecken der Praktikabilität diene und der Subjektivierung völkerrechtlicher Entschädigungsansprüchen keine Grenze sei, darf bezweifelt werden. Gerade in der teils auch automatisierten Kriegsführung des 21. Jahrhunderts ist die ausschließliche Begründung der „Sperre“ einer Geltendmachung durch Individuen jedoch zu oberflächlich und überholt. Bei der Tötung einzelner mutmaßlicher Terroristen oder Foltervorwürfen einzelner Kriegsgefangener wären keinesfalls Tausende Klagen abzusehen, so dass es dort möglich sein sollte, Entschädigungsansprüche als Einzelperson auch ohne Zwischenschaltung des Heimatstaates geltend machen zu können. Einzelne Völkerrechtsregeln als individualgerichtet anzuerkennen und eventuell auch über eine konstitutive Wirkung des Art. 25 Satz 2 GG subjektiviert anzuerkennen erweist sich in der Praxis als wirkungslos, sollte die Durchsetzung solcher Rechte nicht möglich sein, weil letztendlich dennoch ausschließlich der entsprechende (Heimat-)Staat prozesslegitimiert ist.

Um auch staatengerichtete allgemeine Völkerrechtsregeln subjektivieren und deren Durchsetzung darüber hinaus über Art. 25 Satz 2 GG als Anspruchsgrundlage stützen zu können, soll eine „faktische Betroffenheit“ im Sinne des Art. 42 ILC-Entwurf als zusätzliche, künstliche Voraussetzung installiert werden. Dadurch soll Popularklagen vorgebeugt und eine uferlose Anspruchsberechtigung verhindert werden. Jedoch ist einerseits in Art. 25 Satz 2 GG keine „faktische Betroffenheit“ formuliert, und eine solche liefe ebenso auch dem Normwortlaut zuwider, der doch eine „unmittelbare“ Erzeugung von Rechten und Pflichten anordnet. Die Übernahme der „faktischen Betroffenheit“ aus Art. 42 ILC-Entwurf hinkt im Übrigen daran, dass der Entwurf nicht nur ausschließlich Staaten adressiert und deren Verantwortlichkeit ausgestaltet, sondern im Übrigen unverbindlich ist, da die Staaten selbst bereits den Entwurf nicht ratifizieren wollten. Ebenso stünde den Einzelnen die Möglichkeit offen, über Art. 25 Satz 2 GG Repressalien gegen andere Staaten zu fordern. Ein unverbindlicher Entwurf aus dem Jahr 2001 vermag jedoch nicht den unpräzisen Wortlaut des Art. 25 Satz 1 und 2 GG von 1949 zu korrigieren. Doehring sprach bereits 1963 dem Art. 25 Satz 2 GG die Natur einer Rechtsgrundlage zu, beschränkte jedoch die Anwendbarkeit

\footnotetext{
${ }^{501} \mathrm{Vgl}$. Rechte und Pflichten der Deutschen Marine bei der Bekämpfung der Piraterie, Antwort der Bundesregierung, BT-Drs. 16/9286, 23.05.2008, S. 3, 4; Talmon, in: JZ 1/2013, S. 12 (13); Schorkopf, Das Staatsrecht der internationalen Beziehungen, $\S 3$ Rn 51 .
} 
auf solche, die inhaltlich nicht ausschließlich Staaten adressieren und einem individuellen Bezug wenigstens zugänglich sind. Von der Rechtsprechung ist, wie an anderer Stelle bereits ausgeführt, eine konstitutive Wirkung für einzelne allgemeine Völkerrechtsregeln bestätigt worden, die einen engen Individualbezug aufweisen und einer Subjektivierung nicht durch ihren Norminhalt entgegenstehen. Andere Meinungen, die eine generelle Subjektivierung fordern oder sogar aus Art. 25 GG herauslesen, halten einer kritischen Betrachtung anhand eines aktuellen völkerrechtlichen Verständnisses nicht stand.

Die Tendenz der Literatur ist nicht zu leugnen und auch vor der weltweiten Entwicklung der Völkerrechtslage bei vereinzelten Völkerrechtsregeln gut nachvollziehbar. Diese Tendenzen beruhen überwiegend auf der Entwicklung der Stellung des Individuums und dessen Völkerrechtssubjektivität auf der internationalen Ebene. Die Subjektivierung individualbezogener Regeln und solcher, die einem Individualbezug trotz Staatenadressierung zugänglich sind, durch Art. 25 Satz 2 GG ist daher zu befürworten und die Entscheidung des BVerwG folglich richtig.

Es sei hier auch angemerkt, dass die seitens der anspruchsbefürwortenden Literatur oft beschworene Völkerrechtsfreundlichkeit des deutschen Rechts mit zwingend einhergehender Anspruchsinhaberschaft Einzelner aus Art. 25 Satz 2 GG vor dem Hintergrund der beschriebenen internationalen politischen Friktionen missverstanden sein könnte. Vor den deutschen Gerichten erfolgreich aus Art. 25 Satz 2 GG auf Unterlassen oder Vornahmen von Handlungen, oder sogar Entschädigung klagen zu können, könnte die Sicherheit des völkerrechtlichen Friedens unter Umständen sogar gefährden. Wie sich in der Betrachtung mancher internationalen Gerichtsgänge gezeigt hat, wurden Klagen auf Grundlage allgemeiner Völkerrechtsregeln mehrheitlich abgewiesen. Begründet wurden diese mit außenpolitischen Argumenten zur Pflege von Beziehungen und der Bewahrung völkerrechtlicher Herausforderungen. ${ }^{502}$

Einseitige Durchsetzungen ursprünglich nicht unmittelbarer (,self-executing“) allgemeiner Völkerrechtsregeln von deutschen Bundesbewohnern würden auf der internationalen Völkerrechtsbühne mindestens als irritierend aufgenommen, stellen die internationalen Partner dieses Forum ihren Staatsbürgern und -bewohnern doch nicht zur Verfügung. Deshalb müsste bedacht wären, ob die Völkerrechtsfreundlichkeit der innerstaatlichen Rechtsordnungen nicht auch anders verstanden werden sollte. Das Bild des völkerrechtsfreundlichen Staates ist allerdings kein Selbstzweck, sondern es muss der „Frieden in der Welt“ im Sinne

\footnotetext{
${ }^{502}$ Hierauf wird auch im nächsten Kapitel näher eingegangen.
} 
der Präambel und Art. 1 Abs. 2 des Grundgesetzes gewahrt werden. ${ }^{503}$ Art. 25 Satz 2 GG darf nicht über anerkannte Restriktionen völkerrechtlicher Regeln (nicht „,self-executing“) hinaus helfen und Rechte oder Pflichten begründen, die von der internationalen völkerrechtlichen Gemeinschaft aus genannten Gründen nicht geteilt werden.

Im Folgenden wird die Sicht und die Entwicklung der deutschen Rechtsprechung auf die konstitutive Wirkung des Art. 25 Satz 2 GG noch einmal genauer betrachtet und auf eine fortschreitende Einheitlichkeit sowie die Sichtweise auf Art. 25 Satz 2 GG als Rechts- und Anspruchsgrundlage untersucht. Es wird auch ein Blick auf die vereinzelt angesprochene Alternative geworfen, allgemeine Regeln prozessual über eine etwaige Verletzung der allgemeinen Handlungsfreiheit im Sinne des Art. 2 Abs. 1 GG geltend zu machen, soweit sie als Teil der verfassungsmäßigen Ordnung gelten.

${ }^{503}$ So auch Schorkopf, Staatsrecht der internationalen Beziehungen, § 3 Rn 40. 
$\S 6$ Die Entwicklung und Rolle der allgemeinen Völkerrechtsregeln und Art. 25 GG in der Rechtsprechung

In den vorangegangenen Kapiteln wurden einzelne Literaturansichten dargelegt, die den Wortlaut sowie den inhaltlichen Umfang des Art. 25 Satz 1 und Satz 2 GG weit auslegen und teilweise eine unmittelbare Anspruchsgrundlage in Art. 25 Satz 2 GG für jeden Einzelnen befürworten. Vereinzelt ist auch die Umsetzung oder Ablehnung durch die deutschen Gerichte dargestellt worden, um die Praktikabilität der teils komplexen Auffassungen zu schildern. Im Folgenden wird ein über die vereinzelte Darstellung in Kapitel $§ 5$ hinausgehender Blick auf die Historie der deutschen Rechtsprechung zu Art. 25 GG geworfen mit dem Ziel, insbesondere das praktische Verständnis der allgemeinen Völkerrechtsregeln herauszustellen. Dabei werden Entscheidungen der obersten Bundesgerichte in historischer Abfolge auf das Vorliegen und den Umfang inhaltlicher Ausführungen zu den allgemeinen Völkerrechtsregeln im Sinne des Art. 25 GG, Entscheidungsausgang und Entwicklungen der Ansichten näher betrachtet.

In den letzten zwei Jahrzehnten gelangten als Praxisfälle allgemeiner Völkerrechtsregeln überwiegend Entschädigungsklagen von Opfern völkerrechtswidriger kriegerischer Handlungen vor nationale und internationale Gerichte. Im zunächst dargestellten nationalen Vergleich soll untersucht werden, ob vor den Gerichten anderer Nationalitäten bei der Geltendmachung allgemeiner Völkerrechtsregeln direkt auf diese zurückgegriffen wird, oder ob es mit Art. 25 GG vergleichbare Regelungen gibt, die in anderen Nationen als individuelle Rechtsgrundlage anerkannt und praktiziert werden.

\section{Internationaler Vergleich}

Es hat bereits Ansätze dazu gegeben, teils auch durch die bereits betrachteten Werke des Schrifttums, nationale Entscheidungen verschiedener Staaten hervorzuheben und zu vergleichen. Manche der angeführten Stimmen sehen in ausländischen Entscheidungen, die im Folgen aufgeführt werden, dass die Verleihung individueller Sekundäransprüche gegenüber den Staaten mehr Anerkennung erfahre. Dadurch seien die Ansprüche zu Völkergewohnheitsrecht erstarkt. Zwar ließen die Gerichte die Haftung, die im Einzelfall überwie- 
gend verneint wurde, an der Staatenimmunität oder an Verfahrensvoraussetzungen scheitern. Jedoch könne man daran erkennen, dass Individualkläger mittlerweile nicht mehr nur auf der internationalen Bühne ihre Ansprüche eingeräumt bekämen, sondern sich auch nationale Foren bieten. ${ }^{504}$ Wie ursprünglich gezeigt, hat das BVerwG hier auch die Unterlassungsklage der Anlieger der US-Airbase Ramstein aufgrund einer mangelnden Klagebefugnis abgelehnt, eine Anspruchsinhaberschaft aber für möglich gehalten. Beispielsweise in Großbritannien ließ die britische Rechtsprechung lange individuelle Schadensersatzklagen an der Staatenimmunität scheitern, allerdings die anspruchsbegründende oder -vernichtende Wirkung der fraglichen Völkerrechtsnormen offen. ${ }^{505} \mathrm{Im}$ Folgenden soll näher herausgestellt werden, ob es eine gemeinsame Linie, wenigstens aber einen gemeinsamen Trend der ausländischen Rechtsprechung gibt hinsichtlich völkerrechtlicher Individualansprüche vor nationalen Gerichten. Dabei wird Stellung dazu bezogen wie stichfest die Annahme ist, individuelle Ansprüche, insbesondere Entschädigungsansprüche, seien vor nationalen Gerichten auf Grundlage allgemeiner Regeln des Völkerrechts geltend zu machen.

\subsection{Italien und Griechenland}

Auch in Italien wurde bereits bei Entschädigungsklagen die Frage offengelassen, ob das humanitäre Völkerrechte individuelle Sekundärrechte begründe. ${ }^{506}$ Die Angehörigen der im Zweiten Weltkrieg im Deutschen Reich internierten italienischen Militärangehörigen begehrten von der Bundesrepublik Deutschland ebenso Entschädigungszahlungen, entsprechende Anträge wurden bisher jedoch abgelehnt. Da die Soldaten als Kriegsgefangene eingestuft wurden, wird ihnen nach dem Gesetz zur Errichtung einer Stiftung „Erinnerung, Verantwortung und Zukunft“ vom 2. August $2000^{507}$ keine Entschädigungen zugestanden.

\footnotetext{
${ }^{504}$ Fischer-Lescano, in: AVR 3/2007, S. 299 (372).

${ }^{505}$ Beispielsweise High Court of Justice QB, Judgement of 14.12.2004, Al Skeini vs. The Secretary of State for Defence, EWHC 2911, bestätigt durch den Court of Appeals for England and Wales, Judgement of 21.12.2005, The Queen (on the application of Al Skeini and Others) vs. The Secretary of State for Defence, BLD 221205584 (2005) EWCA Civ 1609; so auch Supreme Court of Judicature, Court of Appeal (Civil Division), Judgment of 21.01.1994, Al-Adsani vs. Government of Kuwait and Others (ex parte), FC3 93/6212/E, in: International Law Report 100 (1995), S. 465 f.; näheres in Fischer-Lescano, in: AVR 3/2007, S. 299 (338, 339).

506 Über den Fall von Dusko Markovic: M. Frulli, in: JICJ 2/2003, S. 406-427.

${ }^{507}$ BGB1. I, 1263.
} 
Das BVerfG hat eine Verfassungsbeschwerde dagegen im Jahr 2004 nicht zur Entscheidung angenommen. ${ }^{508}$

In jenem Fall zeigt sich die politische Brisanz internationaler Entschädigungsbegehren. Der italienische Oberste Gerichtshof hat 2008 italienischen Zwangsarbeitern und griechischen NS-Opfern Schadensersatz zugesprochen und die deutsche Berufung auf Staatenimmunität verworfen. Das Gericht argumentierte, es verstoße gegen die Grundprinzipien der italienischen Verfassung, dass die völkergewohnheitsrechtliche Staatenimmunität eine Behandlung deutscher Kriegsverbrechen verhindere. ${ }^{509}$ Die Bundesregierung wehrte sich allerdings gegen die drohende Zwangsenteignung deutschen Eigentums in Italien, indem sie den IGH anrief und sich erfolgreich auf den Grundsatz der Staatenimmunität berief. ${ }^{510}$ Das Urteil des IGH wurde durch das Gesetz Nr. 5/2013 des italienischen Gesetzgebers umgesetzt, allerdings 2014 durch das italienische Verfassungsgericht aufgehoben. Das Gericht argumentierte, die völkergewohnheitsrechtliche Regel der Staatenimmunität verstoße gegen die Grundprinzipien der italienischen Verfassung. ${ }^{511}$

In Griechenland werden zunehmend Ersatzansprüche gegen die Bundesrepublik Deutschland wegen Verbrechen des Zweiten Weltkriegs bestätigt. Die Distomo-Fälle erregten dabei besondere Aufmerksamkeit. Auch wenn die Schadensersatzklagen im Ergebnis, obwohl erstinstanzlich stattgegeben, abgewiesen wurden ${ }^{512}$, erkannte das entscheidende Urteil des Anotato Eidiko Dikastirio die subjektiven Schadensersatzansprüche nach Völkerrechtsverletzungen an. Unbeantwortet blieb allerdings die Frage nach der individuellen Anspruchsgrundlage. ${ }^{513} \mathrm{Im}$ Minderheitenvotum der Richter wurde jedoch darauf eingegangen, dass

\footnotetext{
${ }^{508}$ BVerfGK 3, $277 \mathrm{f}$.

${ }^{509}$ Corte Suprema di Cassazione (Sezioni Unite Civilli), Verfügung (ordinanza) vom 29.05.2008, Nr. 14201/08, Mantelli e.a. c. Republica federale di Germania.

${ }^{510} \mathrm{Nachzusehen} \mathrm{in} \mathrm{IGH,} \mathrm{Judgement} \mathrm{of} \mathrm{03.02.2012,} \mathrm{Case} \mathrm{Concerning} \mathrm{Jurisdictional} \mathrm{Immunities} \mathrm{(Federal} \mathrm{Re-}$ public of Germany vs Italy), ICJ Report 2012, S. 37 f.; näheres in Steger, Staatenimmunität und Kriegsverbrechen, 2012.

${ }^{511}$ Corte costituzionale, Urteil vom 22.10.2014, Az. 238/2014, concerning the constitutionality [...] of Law No. 5 of 14 January 2013 (Accession by the Italian Republic to the United Nations Convention on Jurisdictional Immunities of States and their Property [...], näheres unter www.verfassungsblog.de/italienim-dilemma-zwischen-verfassungs-und-voelkerrechtstreue-2/.

${ }^{512}$ Anotato Eidiko Dikastirio, Urteil vom 17.09.2002, Az. 6/2002, Federal Republic of Germany vs. Miltiadis Margellos.

${ }^{513}$ Vgl. Fischer-Lescano, in: AVR 3/2007, S. 299 (342 f.).

Die erstinstanzliche Entscheidung des LG Polymeles Protodikeio Leivadia gab der Entschädigungsklage wegen deutscher Kriegsverbrechen noch statt; Präfektur Voiotia als Vertreterin von Konstantinos Avoritis u.a. vs. Federal Republic of Germany, Urteil vom 30.10.1997, Az. 137/1997, in: RHDI 50 (1997), S. 595 f.

Deutschland unterlag im Folgenden vor dem Obersten Gerichtshof Areios Pagos, Urteil vom 04.05.2000, Nr. 11/2000), abgedruckt in: AJIL 1/2001, S. 198 f. Bereits begonnene Zwangsvollstreckungsmaßnahmen gegen deutsches Eigentum sah Deutschland im Widerspruch zu geltendem Völkerrecht und erreichte vor dem Landgericht Athen am 19.0.2000 die Aussetzung des Zwangsvollstreckungsverfahrens (Az.
} 
die Berechtigung der Individuen nicht aus dem IV. Haager Abkommen entnommen worden sei, sondern aus einem völkergewohnheitsrechtlichen Gedanken, dass Staaten gegenüber Individuen bei Kriegsverbrechen zu Schadensersatzleistungen verpflichtet seien. ${ }^{514}$

\subsection{Japan}

In Japan wurden Entschädigungsansprüche aufgrund von Verbrechen während des Zweiten Weltkriegs seit dessen Ende regelmäßig vor Gericht gebracht. Hinsichtlich der Opfer der Atombombenangriffe auf die Städte Hiroshima und Nagasaki hat das Bezirksgericht in Tokio 1963 in seinem Urteil die Angriffe als schwere Kriegsvölkerrechtsverletzungen deklariert, jedoch eine Individualisierung von völkerrechtlichen Regelungen, gestützt auf die Anlage zum IV. Haager Abkommen ${ }^{515}$, abgelehnt. ${ }^{516}$ Geltend gemacht wurde seitens der Kläger, dass die japanische Regierung mit der Unterzeichnung des Friedensvertrags von San Francisco (1951) auf Rechte der Kläger verzichtet hätte, von den USA Schadensersatz wegen Einsatzes der Atombombe verlangen zu können, und somit selbst entschädigungspflichtig würde. ${ }^{517}$ Das Gericht räumte zwar die Kriegsrechtswidrigkeit des Atombombeneinsatzes ein, stellte jedoch fest, dass infolge völkerrechtswidriger Kampfhandlungen kein Weg für die geschädigten Opfer offenstehe, auf völkerrechtlicher Grundlage Schadensersatz verlangen zu können. ${ }^{518}$

Zeichen der Änderung zeigten sich allerdings in jüngeren Entscheidungen aus 1998 beispielsweise zu Entschädigungsforderungen der in Japan zwangsweise gehaltenen holländischen Kriegsgefangenen und philippinischen „Comfort Women““519. Während des Zweiten Weltkriegs wurden durch die japanische Arme etwa 300.000 niederländische Staatsangehörige Opfer massiver Menschenrechtsverletzungen. Gestützte wurden die jeweiligen Anspruchsforderungen auf Art. 3 des IV. Haager Abkommens und Völkergewohnheitsrecht.

8206/2000) unter Berufung auf Vollstreckungsimmunität gem. Art. 923 der griechischen Zivilprozessordnung, bestätigt durch den Präsidenten des Landgerichts Athen am 18.07.2001; näheres in Kempen, in: Cremer, Tradition und Weltoffenheit des Rechts, S. $179 \mathrm{f}$.

${ }^{514}$ Anotato Eidiko Dikastirio, Dissenting Opinion, Federal Republic of Germany vs. Miltiadis Margellos, Judgement of 17.09.2002, in: RHDI 56 (2003), S. 299 (207).

${ }^{515}$ Abkommen betreffend die Gesetze und Gebräuche des Landkriegs vom 18.10.1097, RGB1. 1910, S. $107 \mathrm{f}$.

${ }^{516}$ Tokyo District Court, Judgement of 07.12.1963, Shimoda et al. vs. Japan, in: JYIL 1964, S. 212 f.; näheres in: Falk, in: AJIL 59 4/1965, S. 759 f.

${ }^{517}$ Tokyo District Court, Judgement of 07.12.1963, Shimoda et al. vs. Japan, in: JYIL 1964, S. 212 (220).

${ }^{518}$ Tokyo District Court, Judgement of 07.12.1963, Shimoda et al. vs. Japan, in: JYIL 1964, S. 212 (227).

${ }^{519}$ Über die sog. „Trostfrauen“ umfassend: Igarashi, in: JYIL 2000, S. 45 f. 
Das Gericht stellte zunächst fest, dass das Völkerrecht nur in Ausnahmefällen für Individuen ausdrücklich bestimmte Rechte einräume. Für die Auslegung des Art. 3 des IV. Haager Abkommens führte das Gericht aus, dass dieser lediglich die Staaten für völkerrechtswidrige Handlungen zu Schadensersatzzahlungen verpflichte. Individuelle Berechtigungen zu Schadensersatzansprüchen seien der Norm allerdings nicht zu entnehmen. ${ }^{520}$

Auch hinsichtlich der Schadensersatzforderungen der philippinischen „Comfort Women“" entschied das Gericht, dass den geschädigten Individuen durch Art. 3 des IV. Haager Abkommens kein Recht zur Geltendmachung von Schadensersatzansprüchen eingeräumt werde. ${ }^{521}$ Ebenso sei auch der Rechtsprechung nach Inkrafttreten der Haager Abkommen nicht zu entnehmen, dass ein solches Individualrecht bestehe. ${ }^{522}$

Der in beiden Fällen angerufene Tokyo High Court bestätigte die Urteile und die Ausführungen der Richter, dass sowohl das Völkergewohnheitsrecht, als auch Art. 3 des IV. Haager Abkommens den durch Kriegshandlungen Geschädigten keinen Schadensersatzanspruch direkt gegen den verantwortlichen Staat verleihen. ${ }^{523}$ Mit derselben Begründung wurde erst 2005 eine Klage eines chinesischen Staatsangehörigen abgewiesen, der entstandene Schäden aus der durch Japan angeordneten Zwangsarbeit während des Zweiten Weltkriegs geltend machen wollte. ${ }^{524}$

Ein zunächst erfolgreiches Entschädigungsurteil aus 1998 wegen der verübten Verbrechen und schwerwiegenden Menschenrechtsverletzungen japanischer Soldaten während des Zweiten Weltkriegs wurde allerdings 2001 aufgehoben. ${ }^{525}$ Der Lower Court erachtete die gegenständlichen Handlungen japanischer Soldaten als schwere Verletzungen der Menschenwürde und erkannte daraus die Pflicht der japanischen Regierung an, die Opfer zu entschädigen. ${ }^{526}$ Die Berechtigung zur Schadensersatzforderung folge aus dem Umstand,

\footnotetext{
${ }^{520}$ Tokyo District Court, Judgement of 30.11.1998, Dutch Nationals vs. Japan, in: JYIL 1999, S. 143 (145, 146).

${ }^{521}$ Tokyo District Court, Judgement of 09.10.1998, Filipina Comfort Women vs. Japan, in JYIL 1999, S. 170 (173).

${ }^{522}$ Tokyo District Court, Judgement of 09.10.1998, Filipina Comfort Women vs. Japan, in: JYIL 1999, S. 170 (177).

${ }^{523}$ Tokyo High Court, Judgement of 08.02.2001, Dutch Nationals vs. Japan, in: JYIL 2002, S. 142 (144); Tokyo High Court, Judgement of 06.12.2000, Filipina Comfort Women vs. Japan, in: JYIL 44 2001, S. $174 \mathrm{f}$.

${ }^{524}$ Tokyo High Court, Judgement of 23.06.2005, Japan vs. Y, in: JYIL 2007, S. 194 (198 f.).

${ }^{525}$ Hiroshima High Court, Judgement of 29.03.2001, Ha Sun-nyo et. al. vs. Japan; 1759 La Cases Reports Vol. 1081 (2002), S. 91-154.

${ }^{526}$ Yamaguchi Lower Court, Judgement of 27.04.1998, Ha Sun-nyo et al. vs. Japan, in: PRLPJ 8 (1999), S. 63 (101).
} 
dass die japanische Regierung bis dahin noch keiner Entschädigungspflicht nachgekommen sei ${ }^{527}$ Der Hiroshima High Court hat die Aufhebung damit begründet, dass die Beurteilung der Zuerkennung von Entschädigungsansprüchen eine politische Entscheidung sei und dem Ermessensspielraum der Legislative zufalle. ${ }^{528}$

Im Jahr 2005 hat der Tokyo High Court ebenfalls die Klagen chinesischer Frauen abgewiesen, die während des Zweiten Weltkrieges von japanischen Soldaten gefangen genommen und vergewaltigt wurden. Begründet wurde die Ablehnung mit dem zwischen Japan und China geschlossenen Friedensvertrag, in welchem auf die Geltendmachung von Forderung wegen Schäden aus Völkerrechtsverletzungen durch chinesische Staatsangehörige verzichtet wurde. ${ }^{529} \mathrm{Im}$ vorherigen Jahr hatte ein Bezirksgericht den Klägern eine Entschädigungszahlung in Höhe von 800.000 \$ zugesprochen und entgegen der bisherigen Abweisungen aufgrund von Staatenimmunität oder Verjährung geurteilt. Die Beklagten legten unmittelbar Berufung ein. ${ }^{530}$ Auch gibt es seit den 90er Jahren das Women's International Tribunal on Japanese Military Sexual Slavery, welches zahlreiche Fälle verhandelt und Entschädigungsansprüchen stattgegeben hat. ${ }^{531}$

Auch wenn die japanische Rechtsprechung immer wieder aufgrund der Staatenimmunität und Verjährung entsprechende Klagen abgelehnt hat ${ }^{532}$, wurden die Ansätze der Richter vereinzelt als zwingende Indizien für eine allgemeine Übung hinsichtlich der Individualrechte auf Schadensersatz seitens der verantwortlichen Staaten gesehen. ${ }^{533}$ Auch andere Urteile der japanischen Rechtsprechung gäben zumindest Raum zur Frage, ob sich die völkerrechtliche Rechtslage im Wandel befindet. Zwar wurden Klagen gegen die japanische Regierung im Jahr 1996 abgewiesen ${ }^{534}$, allerdings wurde die Ablehnung mit der Rechtslage während des Zweiten Weltkriegs begründet, ohne dann jedoch auszuführen, ob sich diese gegenwärtig geändert oder gehalten haben. ${ }^{535}$

\footnotetext{
${ }^{527}$ Yamaguchi Lower Court, Judgement of 27.04.1998, Ha Sun-nyo et al. vs. Japan, in: PRLPJ 8 (1999), S.63 (103).

${ }^{528}$ Hiroshima High Court, Judgement of 29.03.2001, Ha Sun-nyo et. al. vs. Japan; 1759 La Cases Reports Vol. 1081 (2002), S. 91-154.

${ }^{529}$ Tokyo High Court, Judgement of 18.03.2005, X et al. vs. Japan, in: JYIL 2006, S. 149 (150-152).

${ }^{530}$ Bong, in: JICJ 1/2005, S. 187 (197).

${ }^{531}$ Chinkin, Women's International Tribunal on Japanese Military Sexual Slavery, in: AJIL 2/2001, S. 335 f.

${ }^{532}$ Repräsentativ Japanese Supreme Court, Judgment of 27.04.2007, $2^{\text {nd }}$ Petty Bench, Nishimatsu Construction Co vs. Song Jixiao, 61 Minshu 1188, 1969 Hanrei Jiho 31, 2004 No. 1658 (Judgement concerning paragraph 5 of the Joint Communique of the government of Japan and the government of the People's Republic of China).

${ }^{533}$ So jedenfalls Fischer-Lescano, in: AVR 3/2007, S. 299 (351).

${ }^{534}$ Ders.; Tokyo High Court, Judgement of 07.08.1996, X et al. vs. Japan, in: JYIL 1997, S. 116 f.

${ }^{535}$ Tokyo High Court, Judgement of 07.08.1996, X et al. vs. Japan, in: JYIL 1997, S. 116 (117).
} 
Mit einer Vereinbarung aus dem Jahr 2015 haben Japan und Südkorea den Disput über die sogenannten „Comfort Women“ endgültig gelöst. Dabei hat sich Japan für die verursachten Verbrechen offiziell entschuldigt und seine Schuld anerkannt, sowie eine einmalige Zahlung in Höhe von umgerechnet über 8 Millionen Dollar in einen Fond in Aussicht gestellt. 536

\subsection{Die Vereinigten Staaten von Amerika}

Besonders in den USA ist auffallend, dass die Durchsetzung von Rechten der Opfer schwerer Völkerrechtsverletzungen oft durch die Legislative unterstützt wird, allerdings letztendlich an Interventionen der staatlichen Exekutive scheitert. So werden beispielsweise „Letters of Interest" dokumentiert, die einer erfolgreichen Geltendmachung in konkreten Prozessen außen- und wirtschaftspolitische Gründe gegenüberstellen, um Schäden durch Ziviloder Strafprozesse zu vermeiden. Die Rechtsprechung entscheidet sich häufig zugunsten der Respektierung politischer Interessen der Regierung, allerdings ohne die Geltung individueller Schadensersatzansprüche generell in Abrede zu stellen. ${ }^{537}$ Ist deshalb denkbar, die Rechtspraxis der US-amerikanischen Gerichte als derart gefestigt anzusehen, dass mit der vorausgehenden Schaffung zivilrechtlicher Verfolgungsmöglichkeiten von Völkerrechtsverletzungen eine allgemeine Rechtsüberzeugung ausgedrückt wird, die die individuellen Entschädigungsansprüche Einzelner als Völkergewohnheitsrecht qualifizieren können $?^{538}$

Die amerikanischen Berufungsrichter verneinten gegenüber den Klägern den ,,self-executing“-Charakter des Art. 3 des IV. Haager Abkommens und die Einräumung völkerrechtlicher Individualansprüche auf Schadensersatz. Das Haager Abkommen stelle kein privates Klagerecht für Individuen zur Verfügung. ${ }^{539}$ Vielzählige Klagen vor US-Gerichten, unter

${ }^{536} \mathrm{Vgl}$. https://www.bbc.com/news/world-asia-35188135 (abgerufen am 29.11.2018).

${ }^{537}$ Vgl. Fischer-Lescano, in: AVR 3/2007, S. 299 (354 f.); vgl. hierzu auch US District Court (Southern District of New York), Judgement of 14.02.2001,: Tachiona and others vs. Robert Mugabe in his individual and personal capacity, 186 F Supp 2d 383 2001, Rn 41.

${ }^{538}$ So jedenfalls Fischer-Lescano, in: AVR 3/2007, S. 299 (368).

${ }^{539}$ US Court of Appeals (4 ${ }^{\text {th }}$ Circuit 1992), Judgement of 16.06.1992, Goldstar Panama S.A. vs. USA, 967 F.2d 965 (966, 968 f.); vorher bereits zum mangelnden „self-executing“-Charakter des Haager Abkommens und der Genfer Kriegsgefangenenkonvention repräsentativ US Court of Appeals (Court District California 1985), Judgement of 31.01.1985, Leo Handel v. Andrija Artukovic, 601 F. Supp. 1421 (1425); 
anderem auch gegen die Bundesrepublik Deutschland, werden mit Verweis auf die bestehende Staatenimmunität abgewiesen. ${ }^{540}$ Der enorme Einfluss der Politik auf dieses Streitthema zeigte sich insbesondere auch dadurch, dass aufgrund der Anhängigkeit weiterer Verfahren gegen die BRD vor US-Gerichten und des politischen Drucks die Stiftung „Erinnerung, Verantwortung und Zukunft“" zur Bereitstellung von Finanzmitteln an ehemalige Zwangsarbeiter in Deutschland während des Zweiten Weltkriegs errichtet wurde, vgl. auch $\S 2$ Abs. 1 StiftungsG. ${ }^{541}$ Im Gegenzug verpflichtete sich die US-Regierung mittels eines „Statement of Interest“ die US-Gerichte zur Beendigung der anhängigen Verfahren zu beeinflussen. ${ }^{542}$

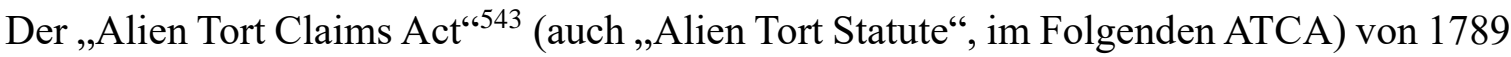
regelt die sachliche Gerichtszuständigkeit für Nicht-US-Bürger, die wegen Völkerrechtsverletzungen Entschädigungsklagen vor US-Gerichten auf das amerikanische Zivilrecht stützen wollen, ohne dass die Parteien oder die Tat im Zusammenhang mit den USA stehen müssen. ${ }^{544}$ In der Rechtsprechung zum ATCA ist nicht einheitlich definiert worden, ob dieser bei der Verletzung völkerrechtlicher Vorschriften die Zuständigkeit amerikanischer Gerichte vorschreibt oder hierzu zusätzlich eine Klagebefugnis der Kläger voraussetzt. Interessant ist die Betrachtung dieser Gesetze zur Zivilgerichtsbarkeit aus dem Grund, dass die Diskussion der Auslegung und der Rechtsbezug mit Art. 25 Satz 2 GG als eventuell Rechtsgrundlage verglichen werden können. Im Rahmen dieser Betrachtung wird der These nachgegangen, dass es sich bei Art. 25 Satz 2 GG um eine Art deutschen ATCA handele und subjektive Rechte an Einzelne vermittele.

\footnotetext{
${ }^{540}$ So beispielsweise zunächst zugunsten des Klägers US District Court (District of Columbia 1992), Judgement of 23.12.1992, Hugo Princz vs. Federal Republic of Germany, 813 F.Supp.22 f., dann aber für die Bundesrepublik Deutschland und die Berufung auf das Recht der Staatenimmunität US Court of Appeals (District of Columbia Circuit 1994), Judgement of 01.07.1994, Hugo Princz vs. Federal Republic of Germany, 26 F.3d 1166; US District Court (District of Columbia 2001), Judgement of 04.10.2001, Hwang Geum Joo et al. vs. Japan, 172 F.Supp.2d 52 (58 f.).

${ }^{541}$ Zum Gesetz zur Errichtung einer Stiftung „Erinnerung, Verantwortung und Zukunft“ (BGBl. I S. 1263) und dessen Hintergrund siehe Hahn, in: NJW 48/2000, S. 3521 f.; v. Woedtke, Die Verantwortlichkeit Deutschlands, S. 279.

Im Zusammenhang mit den wegen Zwangsarbeit gegen deutsche Unternehmen erhobenen Klagen vor US-Gerichten repräsentativ: US District Court (District New Jersey 1999), Judgement of 13.09.1999, Burger-Fischer et al. vs. Degussa AG and Lichtman et al. vs. Siemens AG, F.Supp.2d $248 \mathrm{f}$.

${ }^{542} \mathrm{Vgl}$. Heß, in: v. Heinegg/Kadelbach/Hilf/Benedek, Entschädigung nach bewaffneten Konflikten, S. 107 (201).

${ }^{543}$ Näheres zum ATS in: Meyer, Der Alien Tort Claims Act: zwischen Völkerrecht und amerikanischer AuBenpolitik.

${ }^{544}$ Wortlaut des $\S 1350$ „Alien Tort Claims Act“ (28 U.S.C.): „The district courts shall have original jurisdiction of any civil action by an alien for a tort only, committed in violation of the law of nations or a treaty of the United States."; vgl. auch zur Historie des ATCA in Meyer, Der Alien Tort Claims Act, S. $14 \mathrm{f}$.
} 
Das US-Berufungsgericht („Court of Appeal“) vertrat 1980 im Fall Filartiga vs. Pena Irala die Überzeugung, dass der ATCA die US-Bundesgerichte lediglich für zuständig erkläre über Verletzungen völkerrechtlicher Regeln zu urteilen, wenn diese „,well established, universally recognized norms of international law" sind. ${ }^{545}$ Auch wenn es Gegenstimmen gab, die den Rechtsweg vor den US-Gerichten nur bei Vorliegen einer entsprechenden Klagebefugnis der Kläger nach Völkerrecht als eröffnet ansehen ${ }^{546}$, bauten folgend weitere Gerichte auf der erstgenannten Auffassung auf und entschieden über Völkerrechtsverletzungen, bei denen allgemein anerkannte Normen des Völkerrechts betroffen waren. Darunter fielen bisher das Piraterieverbot, das Verbot des Völkermordes, der Sklaverei und auch die Kernbereiche des humanitären Völkerrechts. ${ }^{547}$ Das Gericht betonte hierbei, dass es den ATCA weniger als Gesetz verstand, das neue Ansprüche einräumen sollte, sondern als Mittel zur Geltendmachung bereits bestehender Völkerrechtsansprüche. ${ }^{548}$ Wie in vorherigen Kapiteln bereits beschrieben, gelten diese Verbote und Regelungen in Deutschland als Völkergewohnheitsrecht und über Art. 25 Satz 1 GG in der deutschen Rechtsordnung.

So hat ein US-Bezirksgericht im Jahr 1996 nicht nur die Zuständigkeit nach dem ATCA aufgenommen, sondern im Urteil erklärt, dass das Völkerrecht keine allgemeinen Anspruchsgrundlagen für Entschädigungszahlungen beinhalte. Diese seien vielmehr durch die jeweiligen Staaten selbst zu installieren, und ein Rechtsmittel für Entschädigungsforderungen bei Völkerrechtsverletzungen stelle der ATCA dar. ${ }^{549}$ Das Gericht sah in dem Gesetz somit eine Anspruchsgrundlage für Individuen, aufgrund von Verletzungen des Völkergewohnheitsrechts auf zivilem Klageweg Entschädigungen ohne zusätzliche Klagebefugnis verlangen zu können ${ }^{550}$, so wie vereinzelte Literaturstimmen auch für das deutsche Recht in Art. 25 Satz 2 GG eine individuelle Anspruchsgrundlage sehen.

Der Oberste Gerichtshof der USA (,US Supreme Court“) hat allerdings bereits 2004 zur Geltendmachung von Entschädigungsansprüchen wegen Völkerrechtsverletzungen auf Grundlage des ATCA entschieden, dass dieser zum einen lediglich als Zuständigkeitsvorschrift gesehen werden sollte und eben keine gesetzliche Anspruchsgrundlage für Einzelne

\footnotetext{
${ }^{545}$ US Court of Appeals (2 ${ }^{\text {nd }}$ Circuit 1980), Judgement of 30.06.1980, Filartiga vs. Pena-Irala, 630 F.2d 876 (887 f.).

${ }^{546}$ Richter Bork, in: US Court of Appeals (District of Columbia Circuit 1984), Judgement of 03.02.1984, Tel Oren et al. vs. Libyan Arab Republic, 726 F.2d 774 (817); im selben Urteil dagegen Richter Edwards, ders., 726 F.2d 774 (777 f.).

${ }^{547} \mathrm{He}$, in: v. Heinegg/Kadelbach/Hilf/Benedek, Entschädigung nach bewaffneten Konflikten. S. 107 (177 f.).

${ }^{548}$ Meyer, Der Alien Tort Claims Act, S. 89.

${ }^{549}$ US Court of Appeals ( ${ }^{\text {nd }}$ Circuit 1996), Judgement of 06.01.1996, Kadic vs. Karadzic, 70 F.3d 232 (246).

${ }^{550}$ Hofmann/Riemann, Compensation for victims of war, Background Report für ILA vom 17.03.2004, Committee on Compensation for Victims of War, S. 34.
} 
darstelle. ${ }^{551}$ Andererseits sei jedoch zum Erlasszeitpunkt der ATCA so verfasst worden, dass er die Gerichte zur Verhandlung begrenzter Fallkategorien ermächtige, in denen die Völkerrechtsvorschriften inhaltlich genau gefasst und von der zivilisierten Welt anerkannt worden sein müssen. Dazu gehörten das Verbot der Piraterie, Verletzungen der Rechte von Botschaftern und Verletzungen sicherer Verhaltensweisen. ${ }^{552}$ Dennoch begründe das Gesetz keine Individualrechte und das Oberste Gericht hat den Umfang des Anwendungsbereichs erheblich eingeschränkt. In der Folge der Sosa-Entscheidung entschieden die meisten Berufungsgerichte jedoch überwiegend anders als der Oberste Gerichtshof. Die Klagen gegen US-Unternehmen wegen Verletzungen von Menschenrechten im Ausland stiegen indes noch an, und die Berufungsgerichte der einzelnen Bundesstaaten entschieden geradezu überwiegend zugunsten der Kläger. ${ }^{553}$

Im Jahr 2013 entschied der Oberste Gerichtshof erneut über eine ATCA-Streitigkeit. Dabei wurde die Reichweite der Anspruchsverfahren weiter eingegrenzt auf eine inländische Anwendung, außer der Kongress bestimmt ausdrücklich etwas anderes. Das Gericht wies im Übrigen auch auf die politische Relevanz hin, indem es ausführte, dass es zu diplomatischen Spannungen mit den entsprechenden Staaten kommen könnte, wenn aus diesen Ländern stammende Ansprüche aus unerlaubten Handlungen vor US-Gerichten unbegrenzt verhandelt würden. ${ }^{554}$ Dieses Ziel entspreche nicht der ursprünglichen Zwecken des ATCA. Beschränkt sei der Gerichtsstand also nur auf Ansprüche, die auf Ereignisse in den USA zurückgeführt werden können. ${ }^{555}$

Die dritte wichtige ATCA-Entscheidung des Obersten Gerichtshofs erging erst im April 2018 und schränkt die prozessuale Überprüfbarkeit des Auslandsverhaltens privater Unternehmen weiter ein. Insbesondere erklärte der Gerichtshof, dass die Bundesgerichte in den USA weitere Rechtsmittelgründe in Erwägung ziehen könnten. ${ }^{556}$ Sie sollten allerdings große Vorsicht walten lassen hinsichtlich der Anerkennung weiterer Rechtsmittelgründe

\footnotetext{
${ }^{551}$ Meyer, Der Alien Tort Claims Act, S. $189 \mathrm{f}$.

${ }^{552}$ Meyer, Der Alien Tort Claims Act, S. 189 f., 195 f.; US Supreme Court, Judgment of 29.06.2004, Sosa vs. Alvarez-Machain, 214 S. Ct 2739 (2743, 2754, 2765); diese Auffassung vertraten die Richter des Obersten Gerichtshofs einstimmig auch in der Entscheidung vom 24.04.2018, Jesner et al. vs. Arab Bank, PLC, 138 S. Ct. 1386 (1420, 1421).

553 https://www.forbes.com/sites/wlf/2018/04/25/u-s-supreme-court-continues-to-nibble-away-at-alien-tortstatutes-sweep/\#1e929653d9fe (aufgerufen am 10.01.2019).

${ }^{554}$ US Supreme Court, Judgment of 29.06.2013, Kiobel et al. vs. Royal Dutch Petroleum Co., 133 S. Ct. 1659 (1672).

${ }^{555}$ US Supreme Court, Judgment of 17.04.2013, Kiobel et al. vs. Royal Dutch Petroleum Co., 133 S. Ct. 1659 (1666).

${ }^{556}$ US Supreme Court, Judgment of 24.04.2018, Jesner et al. vs. Arab Bank, PLC, 138 S. Ct. 1386 (1388, 1389).
} 
neben dem Verbot der Piraterie, der Verletzung der Rechte von Botschaftern und der Verletzung sicherer Verhaltensweisen. Der Grund dieser Erklärung liegt darin, dass es in der Regel dem US-Kongress zustehe, solche Anerkennungen zu bestätigen, und nicht den betreffenden Gerichten. ${ }^{557}$ Dennoch ist nicht auszuschließen, dass Haftungsfragen inländischer Unternehmen wieder vor dem Obersten Gerichtshof verhandelt werden könnten, da mehrere Berufungsgerichte bereits dem Leiturteil des Obersten Gerichtshofs in ATCA-Anwendungsfragen widersprechen. ${ }^{558}$ Bereits in der Sosa-Entscheidung aus 2004 mahnte der Oberste Gerichtshof an, dass Gerichte keine Völkerrechtsnormen als allgemein anerkannt heranziehen sollen, deren missbräuchliche Ausübung ein gerichtlicher Ermessensfehler wäre und politische Spannungen zur Konsequenz hätte. ${ }^{559}$

Mit dem ATCA wurde Einzelnen ein zivilrechtliches Mittel zugesprochen, vor den nationalen Gerichten der USA eigene völkerrechtliche Ansprüche geltend zu machen. Erheblich für den Vergleich zu Art. 25 GG ist, dass es sich dabei nicht um einen Rechtsweg auf internationaler Ebene handelt, sondern materiell-rechtliche Ansprüche der völkerrechtlichen Ebene über eine nationale Norm auf nationalem Rechtsweg dem Einzelnen zustehen. Es gibt Stimmen, die den ATCA somit als Instrument verstehen, über das die USA völkerrechtlich begründete Ansprüche ins nationale Recht transformieren, und auch die Weiterentwicklung Einzelner als Völkerrechtssubjekte sehen. ${ }^{560}$

\subsection{Zwischenergebnis}

Der kurze Überblick ${ }^{561}$ über ausländische nationale Rechtsprechungen hat deutlich gezeigt, dass die Entschädigungsklagen auf der Grundlage des Art. 3 des IV. Haager Abkommens und Art. 91 ZP-I ablehnend entschieden wurden. Dabei wurde zwar nicht zusammenhängend, aber im länderübergreifenden Konsens eine unmittelbare Berechtigung Einzelner

\footnotetext{
${ }^{557}$ US Supreme Court, Judgment of 24.04.2018, Jesner et al. vs. Arab Bank, PLC, 138 S. Ct. 1386 (1389, 1394); diese Mahnung zur Vorsicht mit Verweis auf die politische Tragweite voreiliger Entscheidungen der US-Bundesgerichte vertraten die Richter des Obersten Gerichtshofs bereits in der Entscheidung vom 29.06.2004, Sosa vs. Alvarez-Machain, 214 S. Ct 2739 (2756).

558 https://www.forbes.com/sites/wlf/2018/04/25/u-s-supreme-court-continues-to-nibble-away-at-alien-tortstatutes-sweep/\#3dflc4ded9fe (aufgerufen am 10.01.2019).

${ }^{559}$ US Supreme Court, Judgment of 29.06.2004, Sosa vs. Alvarez-Machain, 214 S. Ct 2739 (2742, 2747, 2756).

${ }^{560}$ So Cassidy, in: Deakin Law Review 2/2004, S. 533 (558 f., 563); Abel, Der Alien Tort Statute nach der Entscheidung des US Supreme Court in der Sache Sosa vs. Alvarez-Machain, S.63 f., 168 f.; Meyer, Der Alien Tort Claims Act, S. 354 f.

${ }^{561}$ Vgl. die ausführlichere Darstellung der gezeigten ausländischen Gerichtsentscheidungen auch in FischerLescano, in: AVR 3/2007, S. 299 (337-355).
} 
(,self-executing ") abgelehnt. Die Normen stünden nicht als individuelle Anspruchsgrundlagen dem Einzelnen zur Verfügung und Rechtsverletzungen Einzelner in ihren Völkerrechten seien durch die Heimatstaaten zu rügen und durchzusetzen. Die einzelnen Individuen könnten sich nicht auf individuell-berechtigende allgemeine Völkerrechtsregeln berufen, da diesen der ,self-executing“-Charakter fehlt.

Die Auffassung vereinzelter Autoren des Schrifttums, die wenigen positiven Urteile einzelner Nationen vermitteln gemeinsam eine erkennbare allgemeine völkergewohnheitsrechtliche Übung anerkannter Individualansprüche auf Schadensersatz, kann nicht geteilt werden. ${ }^{562}$ Es hat sich bereits bei der Betrachtung ausländischer nationaler Verfahren gezeigt, dass die Berufungsgerichte oder obersten Gerichte die Urteile mit politischen Argumenten oder nach Intervention der jeweiligen Regierungen geändert haben. Sie vertraten, die Entscheidung über Entschädigungen an Opfer völkerrechtswidriger bewaffneter Auseinandersetzungen stünde der Politik zu und nicht den Gerichten. Für das Vorliegen einer allgemeinen rechtlichen Übung kommt es allerdings nicht auf politische Positionen an. ${ }^{563}$ Die Vermengung von Politik und Recht ist mit Vorsicht zu betrachten. Bei der bisher erfolgten Aufarbeitung völkerrechtswidriger Verbrechen und anschließenden Entschädigungen handelt es sich um Sonderfälle, um politische Friktionen beizulegen. Besonders deutlich wurde dies bei der Beilegung des Streits um die sogenannten „Comfort Women“ und den griechischen Entschädigungsforderungen gegen die Bundesrepublik Deutschland aufgrund der begangenen SS-Verbrechen. Auch das Vorliegen der Voraussetzung der längere Zeit andauernden Übung muss bezweifelt werden. Gerichtliche Entscheidungen der Kosovo-Geschehnisse gab es erst ab Ende der 1990er-Jahre, und die Entschädigungsurteile wegen völkerrechtswidriger Militärhandlungen im Zweiten Weltkrieg erlangten erst in den 2000er-Jahren eine bemerkbare Häufigkeit. Das BVerwG hielt fest, dass eine längere Zeit andauernde Übung und auch die Überzeugung nötig sei, dass es sich um die Befolgung ungeschriebenen Rechts handle. ${ }^{564}$ Die rechtliche Überzeugung der Staaten von ungeschriebenem Recht kann, auch wenn einzelne positive Gerichtsentscheidungen den Eindruck erwecken, nicht ernsthaft vertreten werden. Aufgrund lange unbeantworteter Entschädigungsforderungen der Opfer und deshalb ungelöster staatlicher Friktionen, beziehungsweise um diesen vorzubeugen, intervenieren die Regierungen. Solche in erster Linie

\footnotetext{
${ }^{562}$ Ablehnend auch erst BVerfG, Nichtannahmebeschluss vom 13.08.2013, Az. 1 BvR 2660/06, 2 BvR 487/07, in: EuGRZ 6-9/2013, S. 563 f.

${ }^{563}$ Schweitzer/Weber, Handbuch der Völkerrechtspraxis der BRD, Rn 249.

${ }^{564}$ BVerwGE 37, 116 (123 f.).
} 
politischen Sondersituationen dürfen auch dann nicht als fortdauernde allgemeine Übung verstanden werden, wenn zahlreiche Fälle über eine gewisse Dauer, beispielsweise betreffend den Zweiten Weltkrieg, verhandelt und abgeurteilt werden.

Die vorhergehende Betrachtung zeigte andererseits auch, dass es im nationalen Recht der jeweiligen Länder keine einfach-gesetzlichen Gesetzesnormen gibt und auch keine durch Politik und Gesetzgebung geschaffen wurden, um individuelle Rechte aus den allgemeinen Völkerrechtsregeln dem Einzelnen per Anspruchsgrundlage zugänglich zu machen. Einen individuellen einfachgesetzlichen Anspruch zur Geltendmachung der allgemeinen Völkerrechtsregeln gibt es in den verglichenen nationalen Rechtsordnungen nicht, und eine anderweitige Durchsetzung wird von den Gerichten, spätestens aber von der Politik blockiert. In den USA gibt es mit dem ATCA ein bundesrechtliches Gesetz, über das Verletzungen völkergewohnheitsrechtlicher Rechtssätze gerügt und auch entschädigt werden könnten. Auch wenn die Rechtslage nicht gänzlich der problematischen Anwendungsfrage des Art. 25 Satz 2 GG gleichgestellt werden kann, drängt sich doch der vorgenommene Vergleich auf. Der Oberste Gerichtshof der USA sah den ATCA nicht als ursprünglich von den Verfassern bezweckte Individualberechtigung zur Klageerhebung an.

Hinsichtlich der untersuchten These, bei Art. 25 Satz 2 GG handle es sich - eventuell auch unerkannt - um eine Art deutschen ATCA, ist die praktisch hohe Hürde der Wahrung auBenpolitischer Aspekte bei der Durchsetzung individueller Völkerrechtsverletzungen ein deutlich nachteiliger Impuls, da neben den rechtlichen Faktoren politische wenigstens gleichgestellt berücksichtigt werden müssen.

Aus der Entstehungsgeschichte des Art. 25 GG konnte bis heute nicht abschließend oder unbestritten entnommen werden, ob Satz 2 eine individuelle Anspruchsgrundlage hinsichtlich berechtigender oder verpflichtender allgemeiner Völkerrechtsregeln gewährt. Als Ergebnis der ausländischen nationalen Rechtsprechungen muss anhand der gewonnenen Indizien geschlussfolgert werden, dass es zum einen keine einfach-gesetzlichen Anspruchsgrundlagen zur Durchsetzung allgemeiner Völkerrechtsregeln gibt und zum anderen die innerstaatlichen Gesetze keine unmittelbare Berechtigung Einzelner bezwecken sollen. Im deutschen Rechtssystem ist die Zuständigkeit für Menschenrechtsklagen gegen Unternehmen vor nationalen Gerichten nach § 17 ZPO und Art. 4 EuGVO geregelt. Allerdings wird nicht etwa Art. 25 GG als Rechtsgrundlage herangezogen oder eine vergleichbare Rechtsgrundlage des öffentlichen Rechts, sondern aufgrund der privaten Rechtsformen der Unter- 
nehmen $\S \S 823$ Abs. 1 wegen unerlaubter Handlungen und 823 Abs. 2 BGB wegen Verstößen gegen Schutznormen. ${ }^{565}$ Eine Verweisung auf oder eine Verbindung zu Art. 25 GG ist nicht gegeben. Ohne in die Inhalte und Voraussetzungen der Ansprüche des BGB tiefer einzusteigen kann hier bereits zurückgeblickt werden auf die Ansicht von Woedtkes, der für einen Anspruch aus Art. 25 Satz 2 GG neben dem Entschädigungsanspruch aus § 839 BGB in Verbindung mit Art. 34 GG keinen Raum sah ${ }^{566}$. Auch mit den Ansprüchen aus $§ 823$ Abs. 1 und 2 BGB liegen demnach praktikable Anspruchsgrundlagen vor, die die Menschenrechtsverletzungen von Unternehmen berücksichtigen, ohne auf Art. 25 GG zurückgreifen zu müssen.

\section{Auffassung der deutschen Rechtsprechung}

Nachdem die Zweifel an der Anerkennung einer ausländischen Rechtspraxis zugunsten individueller völkerrechtlicher Ansprüche dargelegt wurden, wird im Folgenden die deutsche Rechtspraxis vergleichend hierzu untersucht, ob sich entsprechende Tendenzen zeigen und die vorgenannte Auffassung ergänzen, oder ob sich das Gegenteil aufweist. Insbesondere steht hierbei die Frage der Rechts- und Anspruchsgrundlagen im Raum.

Die höchstrichterliche Rechtsprechung Deutschlands verweist auf Entscheidungen des IGH, um den Norminhalten völkerrechtlicher Verträge und der allgemeinen Völkerrechtsregeln Geltung zu verschaffen. ${ }^{567}$ So haben häufig die IGH-Entscheidungen zu den Tatbestandsvoraussetzungen einer Völkergewohnheitsrechtsregel Einfluss in die Rechtsprechung gefunden. ${ }^{568}$ Weitere nennenswerte Verweise der höchsten deutschen Gerichte auf die Entscheidungen des IGH gibt es kaum. Eine ausführliche Auseinandersetzung findet nicht statt, die Entscheidungen des Gerichtshofs werden überwiegend zur Bestätigung deutscher Ge-

\footnotetext{
${ }^{565} \mathrm{Felz}$, Der Alien Tort Statute, S. 554 f. mit Verweis auf Brief of amicus curiae The Federal Republic of Germany, Kiobel v. Royal Durch Petroleum Co., 133 Ct. 1659 No. 10-1491 (2013), p. 11; Seibert-Fohr, in ZaöRV 2003, S. 195 (204).

${ }^{566} \mathrm{Vgl}$. Kapitel $\S 6$ Unterpunkt 4.4.

${ }^{567}$ Schweitzer/Weber, Handbuch der Völkerrechtspraxis der BRD, Rn 374.

${ }^{568}$ Bspw. die Frage nach einer allgemeinen Regel des Völkerrechts über Unzulässigkeit der Zwangsvollstreckung Botschaftskontos BVerfGE 46, 342 (367), ähnlich auch E 66, 39 (64 f.); bzgl. der Bestätigung materieller Gerichtsergebnisse BVerfGE 63, 343 (361); bzgl. des Einbezugs eines IGH-Gutachtens BVerfGE 59, 63 (92); 77, 137 (162 f.), 112, 1 (36); im Rahmen des Staatsangehörigkeitsrechts BVerwGE 1, 206 (208) oder auch durch den BGH bzgl. der Allgemeinen Erklärung der Menschenrechte in Strafsachen, vgl. BGHSt 40, 241 (244) oder zum Weltrechtsprinzip, BGHSt 45, 64 (67).
} 
richtsauffassungen herangezogen. Hinsichtlich der vorher besprochenen Individualansprüche auf Kriegsentschädigungen hat der IGH ebenso offengelassen, ob es mittlerweile eine allgemeine völkergewohnheitsrechtliche Regel des humanitären Völkerrechts gibt, nach der Einzelne Schadensersatz nach Völkerrechtsverletzungen vom verantwortlichen Staat verlangen könnten. Mit dem Wiener Konsularrechtsabkommen und der Entscheidung des IGH im Fall LaGrand und auch Avena ${ }^{569}$ befassten sich das BVerfG und der BGH jedoch intensiver. ${ }^{570}$ Die Rechtsprechung der international höchsten Instanzen können am Beispiel des IGH für die vorliegenden Untersuchung als Indizien wirken, regeln die nationalen Gerichte die auch völkerrechtlich relevanten Geschehnisse doch überwiegend selbst. Auch die IGH-Entscheidung im Fall LaGrand über eine (wenigstens partielle) Völkerrechtssubjektivität des Einzelnen findet in der deutschen Rechtsprechung keine Berücksichtigung. Die deutschen Gerichte verweisen stets auf die traditionelle Konzeption der Staaten als Völkerrechtssubjekte mit Ausnahme der Fortentwicklung des Status Einzelner im Bereich der Menschenrechte. ${ }^{571}$ Um deshalb handfeste Rückschlüsse auf das deutsche Rechtsverständnis der allgemeinen Völkerrechtsregeln und eine etwaigen Subjektivierung ziehen zu können, wird im Folgenden auf die rein nationalen Entscheidungen geblickt.

Bei der näheren Betrachtung der deutschen Rechtsprechung ist nicht bezweckt aufzuzählen, welche völkerrechtlichen Praktiken mittlerweile als Völkergewohnheitsrecht oder allgemeine Rechtsgrundsätze und damit als allgemeine Völkerrechtsregeln im Sinne des Art. 25 GG anerkannt sind. Das Ziel der Betrachtung ist es, die Wertung der Gerichte zur Problematik der etwaigen konstitutiven Wirkung des Art. 25 Satz 2 GG herauszufinden, und ob diese für einzeln Rechte in jüngerer Zeit anerkannt wurde. Dabei wird vor allem auch der Frage nachgegangen, ob die breite Rechtsprechung direkt auf Art. 25 Satz 2 GG gestützte Klagen zulässt und die Norm damit als individuelle Anspruchsgrundlage anerkennt.

\footnotetext{
${ }^{569} \mathrm{IGH}$, Judgement of 31.03.2004, Case Concerning Avena and other Mexikaner Nationals (Mexico vs. USA), ICJ Reports 2004, S. 12.

${ }^{570}$ BVerfK 9, 174 f.; 17, 390 f.; BVerfG, Nichtannahmebeschluss vom 05.11.2013, Az. 2 BvR 1579/11, in: NJW 8/2014, S. 532-535 (Leitsatz und Gründe); BGHSt 52, 110 (119); BGHR StPO § 344 Abs. 2 S. 2: Rügevoraussetzungen 1 (Gründe).

${ }^{571}$ Repräsentativ BVerfG, Nichtannahmebeschluss vom 13.08.2013, Az. 2 BvR 2660/06, 2 BvR 487/07, in: EuGRZ 6-9/ 2013, S. 563-570 (Leitsatz und Gründe), Rn 46 nach juris.
} 


\subsection{Allgemeine Völkerrechtsregeln als direkte Anspruchsgrundlage?}

Auch in Deutschland ist bis auf wenige Ausnahmen weitläufig anerkannt, dass die allgemeinen Regeln des Völkerrechts auf völkerrechtlicher Ebene nicht „self-executing“ sind, um von Einzelnen innerstaatlich direkt geltend gemacht werden zu können. Das OVG Münster musste 1952 über einen Fall verhandeln, in dem ein deutscher Staatsbürger bei einem Verkehrsunfall mit alliierten Militärangehörigen zu Schaden gekommen war. Das OVG war von der Anspruchsnatur öffentlich-rechtlichen, aber auch völkerrechtlichen Ursprungs überzeugt und leitete damals die Haftung der Besatzungsmacht auch aus der Erfolgshaftung des Art. 3 des IV. Haager Abkommens von 1907 ab. ${ }^{572}$

Im Distomo-Fall ${ }^{573}$ hat der BGH in Deutschland entschieden, dass die Kompensationsansprüche der Opfer völkerrechtswidriger Verbrechen des Zweiten Weltkriegs abzulehnen seien. ${ }^{574}$ Art. 3 des IV. Haager Abkommens lehnte der BGH als unmittelbare Individualanspruchsgrundlage jedoch ab, da die Rechtslage zum Tatzeitpunkt und die traditionelle Völkerrechtskonzeption zum Schluss führten, dass die Ansprüche fremder Staatsangehöriger lediglich den betreffenden Heimatstaaten zustünden. ${ }^{575}$ Das BVerfG entschied gleich in mehreren Fällen ebenso wie im Distomo-Fall ${ }^{576}$ über italienische Militärinternierte ${ }^{577}$ und Alteigentümer ${ }^{578}$ und verneinte den individuellen Anspruchscharakter für die Normen der Haager Abkommen.

Im Rahmen der Verfassungsbeschwerde im Anschluss des Distomo-Urteils erklärte auch das BVerfG, Art. 3 des IV. Haager Abkommens sei nicht „self-executing“ und begründe zumindest keinen unmittelbaren Individualentschädigungsanspruch bei Kriegsvölker-

${ }^{572}$ OVG Münster, Urteil vom 09.04.1952, Az. III A 1279/51, in: NJW 26/1952, S. 1030 f.

${ }^{573}$ Infolge der Vergeltungsaktion durch SS-Truppen im griechischen Dorf Distomo 1944 klagten viele Nachfahren der ermordeten Dorfbewohner aufgrund völkerrechtswidriger Handlungen auf Entschädigungen durch die Bundesrepublik Deutschland; vgl. zu Klageverfahren bspw. Sigrid Boysen, Kriegsverbrechen im Diskurs nationaler Gerichte, in: AVR 3/2006, S. 363 ff.

${ }^{574}$ BGHZ 155, 279 (281).

${ }^{575}$ BGHZ 155, 279 (283 f.).

${ }^{576}$ BVerfGK 7, $303 \mathrm{f}$.

${ }^{577}$ BVerfGK 3, 277 (280 f.); Die deutsche Bundesregierung hatte gutachterlich überprüfen lassen, ob ehemals italienische internierte Militärangehörige während des Zweiten Weltkriegs in den Zivilstatus überführt worden waren. Dies wurde verneint mit der Folge, dass diese vom Anwendungsbereich und Entschädigungsanspruch des Gesetzes zur Errichtung einer Stiftung „Erinnerung, Verantwortung und Zukunft" (BGB1. I 2000, S. 1263) ausgeschlossen wurde.

${ }^{578}$ BVerfGE 112, 1 f. Nach der Kapitulation der deutschen Wehrmacht im Mai 1945 erfolgten in der sowjetischen Besatzungszone zwischen 1945 und 1949 diverse entschädigungslose Enteignungen. Entschädigungsbegehren der Hinterbliebenen auf Entschädigungen aufgrund völkerrechts- und verfassungswidriger Handlungen wurden zurückgewiesen. 
rechtsverstößen. Aus der Entstehungsgeschichte folge nicht, dass die Vorschrift als Grundlage unmittelbarer, völkerrechtlicher Ersatzansprüche Einzelner gegen den Staat denkbar wären. Ungeachtet der Entwicklungen der Menschenrechte stünden die Rechtsansprüche immer noch lediglich den Heimatstaaten der Geschädigten zu. ${ }^{579}$ Das griechische Landgericht Leivadia hatte 1997 bereits über den Fall entschieden und die Berufung Deutschlands auf die Staatenimmunität überwunden, da die Handlungen der SS-Truppen Normen des zwingenden Völkerrechts verletzt hatten. ${ }^{580}$ Das Gericht sprach den Opfern daher teilweise Entschädigungen zu, ohne dass der Heimatstaat dazwischengeschaltet werden musste. ${ }^{581}$ Obwohl der griechische Oberste Gerichtshof dem LG Leivadia recht gab und die Staatenimmunität ebenfalls nicht als Durchsetzungshindernis $\operatorname{sah}^{582}$, wurde dieses Urteil aufgrund politischer Intervention nicht vollstreckt, denn der damalige griechische Justizminister verweigerte die notwendige Zustimmung zur Urteilsvollstreckung. ${ }^{583}$

Im Fall Varvarin ${ }^{584}$ ist der BGH davon ausgegangen, dass sich das Völkerrecht nicht derart weiterentwickelt habe, so dass individuelle Entschädigungsansprüche gegenüber Staaten nicht berücksichtigt werden müssten. Auch in diesem Fall zog der BGH neben den innerstaatlichen Amtshaftungsansprüchen auch die völkerrechtlichen Bestimmungen des Art. 91 ZP-I und Art. 3 des IV. Haager Abkommens in Betracht. Ein individueller unmittelbarer Entschädigungsanspruch wurde jedoch auch wie im Distomo-Fall abgelehnt. Abgelehnt wurde die individualberechtigende Wirkung auch für Art. 91 ZP-I. ${ }^{585}$ Gegenteilige Stimmen wurden sogar als „Idealvorstellungen“ und „zukunftsgerichtete Bestrebungen“ bezeichnet. ${ }^{586}$ Der BGH führte ferner aus, dass sich lediglich möglicherweise (Primär-)Rechte der einzelnen Betroffenen auf Einhaltung der in Art. 51 und 91 ZP-I enthaltenen Verbote entnehmen ließen ${ }^{587}$, und begründete dies mit der Entstehung und dem Wortlaut des Art. 91 ZP-I. Art. 91 ZP-I entspricht wörtlich fast Art. 3 des IV. Haager Abkommens, so dass eine entsprechende Auslegung naheliege, und auch den Konferenzen über

\footnotetext{
${ }^{579}$ BVerfGK 7, 303 (308); BGHZ 155, 279 (283 f.)

${ }^{580}$ LG Polymeles Protodikeio Leivadia, Urteil vom 30.10.1997, Präfektur Voiotia als Vertreterin von Konstantinos Avoritis u.a. vs. Federal Republic of Germany, Nr. 1377/1997, in: RHDI 50 (1997), S. 595 f.

${ }^{581}$ LG Polymeles Protodikeio Leivadia, Urteil vom 30.10.1997, Präfektur Voiotia als Vertreterin von Konstantinos Avoritis u.a. vs. Federal Republic of Germany, Nr. 1377/1997, in: RHDI 50 (1997), S. 595.

${ }^{582}$ Oberster Gerichtshof Areios Pagos, Urteil vom 04.05.2000, Nr. 11/2000, Präfektur Voiotia gegen Federal Republic of Germany, in: AJIL 1/2001, S. 198 (200).

${ }^{583}$ http://lernen-aus-der-geschichte.de/Lernen-und-Lehren/content/12739.

${ }^{584}$ Im Rahmen des Kosovo-Kriegs 1999 hat die deutsche Bundeswehr zur Aufklärung eines NATO-Luftangriffs beigetragen, in dessen Folge bei einem Brückenbeschuss zahlreiche Zivilpersonen getötet und verletzt wurden.

${ }^{585}$ BGHZ 169, $348(353,354)$.

${ }^{586}$ BGHZ 169, 348 (356).

${ }^{587}$ BGHZ 169, 348 (353, 354).
} 
die Protokolle ließen sich keine Indizien entnehmen, die eine über Art. 3 des IV. Haager Abkommens hinausgehende Bedeutung rechtfertigten. ${ }^{588}$

Auch für die deutsche Rechtspraxis könnten nach Fischer-Lescano, einem im gegenwärtigen deutschen Rechtsgefüge prominenten Befürworter völkerrechtlicher Individualansprüche, die Auffassungen der Gerichte als entstandenes Völkergewohnheitsrecht anzusehen sein, obwohl die Endurteile überwiegend gegenläufig entschieden wurden. Die Ansprüche könnten anerkannt worden sein, und die kritischen Reaktionen auf ablehnende Urteile zeigten demnach nur eine Relativierung auf, die der Qualifikation als Völkergewohnheitsrecht nicht entgegenstünden. Unmittelbar gegen die schädigenden Staaten gerichtete Entschädigungsansprüche stünden den Individuen damit zu und trügen zur Effektivität des Völkerrechts bei. ${ }^{589}$

Die individuellen Rechte jedoch nicht abzulehnen oder die Individualanspruchsinhaberschaft offenzulassen kann jedoch nicht im Umkehrschluss bedeuten, dass sie generell oder partiell bestehen. Es ist zu bezweifeln, ob dies als allgemeine Übung im Sinne der Entstehung von Völkergewohnheitsrecht angesehen werden kann.

Auch in jüngeren Entscheidungen der höchsten Gerichte wurde stets von den Richtern betont, dass die allgemeinen Völkerrechtsregeln keinen unmittelbaren Rechtsanspruch für Einzelne gewähren. ${ }^{590} \mathrm{Am}$ Beispiel völkergewohnheitsrechtlicher Sekundäransprüche erklärte das BVerfG erneut erst 2013, dass es keine allgemeine Regel des Völkerrechts gebe, auch nicht Art. 3 des IV. Haager Abkommens und Art. 91 ZP-I, denen der Charakter als unmittelbare individuelle Rechtsgrundlage zukomme und der Einzelne daraus keinen Schadensersatz verlangen könne. Ungeachtet der Entwicklungen des humanitären Völkerrechts stünden Sekundärrechte auf Entschädigungen immer noch allein den Heimatstaaten zu. ${ }^{591}$ Trotz der Hinweise auf die entwickelte Stellung Einzelner im Netz menschenrechtlicher Beziehungen bestätigte der BGH noch einmal seine Auffassung zu Art. 3 des IV. Haager Abkommens und Art. 91 des ZP-I. Sekundärrechtliche Schadensersatzansprüche stünden nach wie vor lediglich den entsprechenden Heimatstaaten zu. ${ }^{592}$ Ein individueller Wiedergutmachungsanspruch ergebe sich allerdings für Verletzungen humanitärer Völkerrechte

\footnotetext{
${ }^{588}$ BGHZ 169, 348 (354).

${ }^{589}$ Fischer-Lescano, in: AVR 3/2007, S. 299 (380).

${ }^{590} \mathrm{Zu}$ den Individualpflichten aus allgemeinen Regeln des Völkerrechts näheres in Kapitel $\S 5$.

${ }^{591}$ BVerfG, Nichtannahmebeschluss vom 13.08.2013, Az. 2 BvR 2660/06, 2 BvR 487/07, in: EuGRZ 69/2013, S. 563-570, Rn 13, 41 f. nach juris.

${ }^{592}$ Dabei bezog sich der BGH auch auf bisherige Entscheidungen betreffend Art. 3 des IV. Haager Abkommens, darunter auch die prominente Alteigentümer-Entscheidung aus 2004, BVerfGE 112, 1 f., sowie BVerfGK 3, 277 f.; 7, 303 f.
} 
weder aus dem Wortlaut noch aus der Entstehungsgeschichte oder Anwendungspraxis. Hätte man eine Bedeutung dieser Art bei der Erarbeitung des Zusatzprotokolls zum Genfer Abkommen gewollt, hätte man auch Art. 5 Abs. 5 EMRK als Anspruch ausweisen können. ${ }^{593}$

Es darf bezweifelt werden, dass der Vergleich nationaler Rechtspraktiken eine einheitliche, dauerhafte und auch verbreitete Praxis individueller Ersatzansprüche des Völkerrechts präsentiert, um eine staatliche Übung zur Entstehung völkergewohnheitsrechtlicher Sekundäransprüche zu rechtfertigen. Schutzsysteme wie die EMRK stellen Möglichkeiten individueller Klagen für Verletzungen des Völkervertragsrechts und der darin verfestigten Menschenrechtsgarantien zur Verfügung, nicht jedoch für Verletzungen der humanitärvöl-

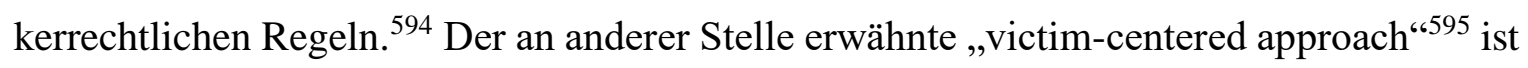
zwar deutlich erkennbar ${ }^{596}$, dennoch ist dies noch kein Nachweis einer allgemeinen völkergewohnheitsrechtlichen Regel. Auch Art. 75 IStGH-Statut hilft hinsichtlich der Wiedergutmachungsleistungen an Opfer nicht weiter, da dieser den verurteilten Kriegsverbrecher anspricht und nicht den verantwortlichen Staat.

Auf nationaler Ebene ließen sich aus der kurzen Betrachtung keinerlei Urteile präsentieren, die einen Individualanspruch auf Entschädigung wegen verletzter humanitärer Völkerrechtsregeln zugesprochen hätten. Auf völkerrechtlicher Grundlage erfolgte ein solcher $\mathrm{Zu}-$ spruch bisher nicht, und die vereinzelten Fälle begründen noch keine ausreichende Staatenpraxis. $^{597}$

\subsection{Art. 25 (Satz 2) GG als individuelles Recht?}

Am Beispiel der Entschädigungsklagen infolge kriegsvölkerrechtlicher Vergehen hat sich gezeigt, dass - bis auf das humanitäre Völkerrecht ${ }^{598}$ - keine allgemeinen Völkerrechtsregeln vorliegen, welche als „self-executing“ unmittelbar von Individuen vor Gericht bean-

\footnotetext{
${ }^{593}$ Derleder, in: Becker/Braun/Deiseroth, Frieden durch Recht?, S. 440.

${ }^{594}$ So auch v. Woedtke, Die Verantwortlichkeit Deutschlands, S. 291.

${ }^{595}$ Kapitel $\S 6$ Punkt 4.1.2.

${ }^{596}$ So zumindest $v$. Woedtke, Die Verantwortlichkeit Deutschlands, S. 291.

${ }^{597}$ Vgl. vor allem in diese Richtung auch v. Woedtke, Die Verantwortlichkeit Deutschlands, S. 192; Bothe/Fleck (Hrsg.), in: The Handbook of International Humanitarian Law, Rn 1417, 1418; Hagelberg, Die völkerrechtliche Verfügungsbefugnis des Staates über Rechtsansprüche von Privatpersonen, S. 195.

${ }^{598}$ Für die Genfer Flüchtlingskonvention repräsentativ in BVerwGE 4, 309 f.; 49, 202 f.; 88,254 f.
} 
sprucht werden könnten. Die Forderungen nach Entschädigungen sind jedoch nicht der einzig denkbare Anwendungsfall individueller Klagebegehren vor deutschen Gerichten. Es wird im Folgenden die praktische Legitimität der Überlegung geprüft, ob Art. 25 Satz 2 GG eine Anspruchsgrundlage darstellt, indem bisherige Verfahren, die direkt eine mutmaßliche Verletzung des Art. 25 GG behandelt haben, näher beleuchtet und die Auffassung und Kritik der Rechtsprechung herausgestellt werden. Näheren Aufschluss soll auch die Handhabung der Richter mit den allgemeinen Völkerrechtsregeln im innerstaatlichen Recht geben und welche Rolle diesen zukommt.

Bisher blickte die Untersuchung besonders auf die Subjektivierung der allgemeinen Völkerrechtsregeln durch Art. 25 Satz 2 GG, dessen etwaige konstitutive Wirkung für alle oder nur bestimmte allgemeine Regeln sowie die mögliche Rechtsgrundlage in Art. 25 Satz 2 GG. Aus diesem Grunde wird die Betrachtung der Rechtsprechung auf Satz 2 des Art. 25 GG fokussiert, um den im Raum stehenden Fragen gründlicher nachgehen zu können.

\subsection{Ursprünglich generell keine Subjektivierung der allgemeinen Völkerrechtsregeln}

Ob Vorschriften in Deutschland lediglich deklaratorischen Charakter haben, oder ob diese

eine konstitutive Wirkung entfalten, entscheiden grundsätzlich die Gerichte. ${ }^{599}$ Auch wenn der Gesetzgeber den Norminhalt vorgibt und ändern oder präzisieren kann, stehen ihm anders als im Völkerrecht authentische Interpretationen nicht zu. ${ }^{600}$ In der frühen Staatspraxis Deutschlands erfüllte sich der durch die Entstehungsgeschichte des GG erwartete Avantgarde-Charakter des Art. 25 GG zunächst nicht. Nach Inkrafttreten des Art. 25 GG erfolgten die ersten einschlägigen Gerichtsentscheidungen des BVerfG überwiegend hinsichtlich Detailfragen der Staatenimmunität. ${ }^{601}$

Bekannt ist, dass in den ersten Entscheidungen des BVerfG zu Art. 25 GG deutlich die lediglich deklaratorische Wirkung des Art. 25 Satz 2 GG vertreten wurde, und Satz 2 der Norm keine eigene Regelungswirkung als Grundrecht zukomme, um dessen Verletzung mittels Verfassungsbeschwerde rügen zu können. Die allgemeinen Regeln seien bereits über Art. 25 Satz 1 GG unmittelbar anwendbar, und die unmittelbare Berechtigung oder

\footnotetext{
${ }^{599} \mathrm{BVerfGE}$ 126, 369 (392); 135, 1 (16).

${ }^{600}$ BVerfGE 131, 20 (37).

${ }^{601}$ Repräsentativ in BVerfGE 15, 25; 16, 27; 23, 288. 
Verpflichtung ergebe sich deshalb aus dem entsprechenden Regelinhalt oder aus deren Aufnahme ins Bundesrecht. ${ }^{602}$ Art. 25 Satz 2 GG besagt daher lediglich dieselbe Rechtswirkung für die allgemeinen Völkerrechtsregeln für und gegen den Einzelnen wie das restliche innerstaatliche Recht und, sofern es inhaltlich zulässig ist, auch subjektive Rechte und Pflichten für den Einzelnen. ${ }^{603}$ Auch hinsichtlich des Verständnis des Normenverifikationsverfahrens hatte das Urteil des BVerfG von 1962 eine Bedeutung. So erklärten die Richter, dass, sofern die Formulierung ,[...] erzeugen Rechte und Pflichten unmittelbar für die Bewohner des Bundesgebietes“ in Art. 25 Satz 2 GG nur die durch Satz 1 geregelte Eingliederung der allgemeinen Völkerrechtsregeln in das Bundesrecht bedeute, auch die Formulierung ,[...] und ob sie unmittelbar Rechte und Pflichten für den Einzelnen erzeugt (Art. 25 GG)“ in Art. 100 Abs. 2 GG entsprechend verstanden werden müsste. Das Verfahren vor dem BVerfG sei dann lediglich zur Umschreibung der Qualität einer allgemeinen Völkerrechtsregel gedacht und mit dem Wortlaut des Art. 100 Abs. 2 GG vereinbar. ${ }^{604}$

\subsection{Jüngere Tendenzen und Entspannung der Sicht der Gerichte}

Das BVerfG erweiterte seine Rechtsprechung hinsichtlich der Auslegung des Art. 25 GG Ende der 1970er-Jahre mit der sogenannten Botschaftskonto-Entscheidung ${ }^{605}$. Dabei argumentierten die Richter auch mit materiellen Rechtsinhalten ergänzend zur bisherigen Orientierung an der Existenz allgemeiner Völkerrechtsregeln. Der häufigste Anwendungsfall des Art. 25 GG ist auch bis heute die normative Verknüpfung für den völkerrechtlichen Mindeststandard, der das zwingende Völkerrecht eingliedert. Der Mindeststandard wird als Maßstab von den Fachgerichten in Einzelfällen angewendet und wurde erstmals als menschenrechtlicher Mindeststandard 1977 im Botschaftskonto-Fall erwähnt ${ }^{606}$, ohne an diesen besondere Rechtsfolgen zu binden oder weiter zu konkretisieren. ${ }^{607}$ Im BotschaftskontoFall wich das BVerfG von seiner stringenten Ablehnung einer möglichen konstitutiven Wirkung des Art. 25 Satz 2 GG ab. Das Gericht ließ die Frage offen, ob dem Satz 2 der Norm

\footnotetext{
${ }^{602}$ BVerfGE 15, 25 (33 f.); 18, 441 (448); 27, 253 (273 f.); 41, 126 (160); 46, 342 (362 f., 403 f.); 63, 343 (373).

${ }^{603}$ BVerfGE 15, 25 (33).

${ }^{604}$ BVerfGE 15, 25 (33).

${ }^{605} \mathrm{BVerfGE} 46,342 \mathrm{f}$.

${ }^{606}$ BVerfGE 46, 342 (362).

${ }^{607}$ Vgl. Schorkopf. Das Staatsrecht der internationalen Beziehungen, § 3 Rn 20.
} 
eine subjektivierende Wirkung zukomme ${ }^{608}$, wurde dieser historisch doch als rein deklaratorisch betrachtet. Die Richter hatten hinsichtlich staatengerichteter Normen die Drittwirkung zunächst nicht geklärt, „ob und in welchen Fällen Art. 25 Satz 2 GG den Adressatenkreis solcher allgemeiner Regeln, die auf der Geltungsebene des Völkerrechts ausschließlich an Staaten [...] gerichtet sind, innerstaatlich erweitert, in dem er zusätzlich subjektive Rechte oder Pflichten des Einzelnen begründet oder verändert. “609 Im selben Urteil hat es die Drittwirkung der fraglichen allgemeinen Völkerrechtsregel ${ }^{610}$ allerdings versagt. „Sie begründet ausschließlich Rechte und Pflichten im völkerrechtlichen Verhältnis der Staaten zueinander, nicht hingegen begründet oder verändert sie subjektive Rechte oder Pflichten des privaten Einzelnen im Hoheitsbereich Deutschlands [...].“ Danach sind die staatengerichteten Normen in ihrer Tragweite als Bestandteil des Bundesrechts von allen rechtsetzenden und -anwendenden Organen Deutschlands als objektives Recht zu beachten und anzuwenden. ${ }^{611}$

Vorher entschieden die Richter nicht über eine mögliche Subjektivierung einzelner allgemeiner Völkerrechtsregeln durch Art. 25 Satz 2 GG, jedenfalls stellten sie sich einer zumindest teilweisen konstitutiven Wirkung nicht entgegen. Allerdings lehnten sie ab, dass durch Satz 2 der Norm ein Adressatenwechsel vorgenommen würde zugunsten einzelner Individuen. ${ }^{612}$ Später hat sich das BVerfG noch differenzierter mit Art. 25 GG und dessen Bedeutung für das innerstaatliche Recht auseinandergesetzt. Danach seien kraft Art. 25 GG deutsche Behörden und Gerichte ,grundsätzlich daran gehindert [...], innerstaatliches Recht in einer Weise auszulegen und anzuwenden, welche die allgemeinen Regeln des Völkerrechts verletzt. Sie sind auch verpflichtet, alles zu unterlassen, was einer unter Verstoß gegen allgemeine Regeln des Völkerrechts vorgenommenen Handlung nichtdeutscher Hoheitsträger im Geltungsbereich des Grundgesetzes Wirksamkeit verschafft, und gehindert, an einer gegen die allgemeinen Regeln des Völkerrechts verstoßenden Handlung nichtdeutscher Hoheitsträger bestimmend mitzuwirken. “613

\footnotetext{
${ }^{608}$ BVerfGE 46, $342(363,403)$.

${ }^{609}$ BVerfGE 46, 342, (363).

${ }^{610}$ Unzulässig ist die Zwangsvollstreckung durch den Gerichtsstaat in sich in dessen Hoheitsbereich befindende Gegenstände eines fremden Staates ohne dessen Zustimmung, welche im Zeitpunkt des Beginns der Vollstreckungsmaßnahme noch hoheitlichen Zwecken des fremden Staates dient; BVerfGE 46, 342 $(364,403)$.

${ }^{611}$ BVerfGE 46, 342 (363); vgl. auch E 15, 25 (33); 41, 126 (160); 46, 288 (362 f.); 63, 343 (363, 373 f.). Deiseroth, in: Das Recht in guter Verfassung?, S. 35.

${ }^{612}$ Repräsentativ BVerfGE 18, 441 (448); 27, 253 (273 f.); 41, 126 (160).

${ }^{613}$ BVerfGE 75, 1 (18 f.); s. später u. a. auch BVerfGE 109, 13 (26); 109, 38 (52); 112, 1 (27); BVerwGE 131, 316 (340); 154, 328 (340 f.); BVerfG, Nichtannahmebeschluss vom 26.02.2018, Az. 2 BvR 107/18, Rn 25 nach juris.
} 
Bisher sind nur wenige positive Entscheidungen höchster Gerichte über die Subjektivierung allgemeiner Regeln zugunsten Einzelner ergangen. Im Folgenden werden einige der jüngsten aussagekräftigen Beispiele näher betrachtet.

Der auszumachende Trend des BVerfG, Individuen zunehmend zu begünstigen, setzte sich fort. So erweiterte es zunehmend den praktischen Anwendungsbereich des Art. 25 Satz 2 GG und tendierte zu einer möglichen Subjektivierung allgemeiner Völkerrechtsregeln. So sollen Einzelne sich mithilfe der Verfassungsbeschwerde auf das Recht zur freien Entfaltung der Persönlichkeit gem. Art. 2 Abs. $1 \mathrm{GG}^{614}$ berufen können, wenn sie sich durch gerichtliche Entscheidungen belastet fühlen, und diese auf Vorschriften des innerstaatlichen Rechts beruhen, welche mit den allgemeinen Völkerrechtsregeln unvereinbar sind. Die Richter begründen diese Sichtweise, wenngleich die Verfassungsbeschwerde im Ganzen abgewiesen wurde, mit der effektiven Durchsetzung des allgemeinen Völkerrechts: „Dieser Grundsatz gilt jedenfalls für Konstellationen, in denen völkerrechtliche Regelungen einen engen Bezug zu individuellen hochrangigen Rechtsgütern aufweisen, [...]. Die Institution des Eigentums trägt die private Zuordnung von Vermögenswerten Gegenständen in sich, so dass der völkerrechtliche Schutz von Eigentumspositionen, zum Beispiel durch ein Enteignungsverbot, zumindest in der Schutzwirkung subjektiv gerichtet ist, auch wenn sich der ursprüngliche Wille eher auf die objektive Einhaltung von gegenseitig anerkannten zi-

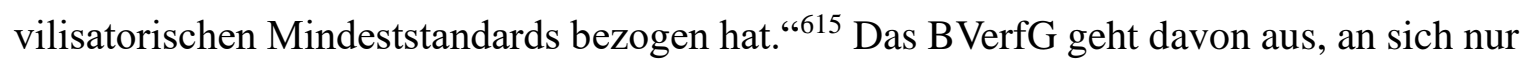
staatenverpflichtende Normen über Art. 25 Satz 2 GG auch zu subjektiven Rechten und Pflichten für Einzelne umwandeln zu können. Die entsprechenden Normen erstarken dann im Wege eines Adressatenwechsels innerstaatlich zu subjektiven Rechten und Pflichten.

Ob dieser Praxisentwicklung auch die mögliche Subjektivierung staatengerichteter allgemeiner Völkerrechtsregeln entnommen werden kann ${ }^{616}$, wird in der Literatur teils infrage gestellt. Die Erklärung des Gerichts, dass es unabhängig der Anspruchsinhaberschaft Einzelner kraft Völkerrechts ,geboten sein [könne], Völkerrechtsverstöße als subjektive Rechtsverletzungen geltend machen zu können“617, folgte gleich auf die Feststellung: „Eine den Einzelnen belastende gerichtliche Entscheidung, die auf einer den allgemeinen Regeln des Völkerrechts widersprechende Vorschrift des innerstaatlichen Rechts [...] beruht, kann gegen das durch Art. 2 Abs. 1 GG geschützte Recht der freien Entfaltung der Persönlichkeit

\footnotetext{
${ }^{614}$ Die Bedeutung des Art. 2 Abs. 1 GG als Anspruchsgrundlage individueller Klagen und Beschwerden zur Rüge von Verstößen gegen Art. 25 GG wird im folgenden Kapitel § 9 genauer beleuchtet.

${ }^{615}$ BVerfGE 112, 1 (22), ohne weitere Ausführung offengelassen in BVerfGE 96, 68 (96).

${ }^{616}$ Rojahn, in: v. Münch/Kunig, Art. 25 GG, Rn 47.

${ }^{617}$ BVerfGE 112, 1 (22).
} 
verstoßen“"618. Es wird bei der Kritik ${ }^{619}$ an der Versagung einer Geltendmachung über Art. 25 Satz 2 GG direkt durch das BVerfG versäumt, die durch BVerfG und BVerwG anerkannte Möglichkeit einer Subjektivierung wenigstens individualbezogener allgemeiner Völkerrechtsregeln durch Art. 25 Satz 2 GG und eine, sowohl theoretisch als auch praktisch gut umsetzbare, Rügemöglichkeit über Art. 2 Abs. 1 GG zu preisen.

Im Jahr 2008 hat sich das BVerwG bezüglich einer konstitutive Wirkung des Art. 25 Satz 2 GG hinsichtlich staatengerichteter allgemeiner Völkerrechtsregeln noch nicht festgelegt und diese offengelassen. Für das völkergewohnheitsrechtliche Gewaltverbot schloss es allerdings auch nicht aus, dass Art. 25 Satz 2 GG für die Bewohner des Bundesgebietes unmittelbar Rechte erzeugen könnte. ${ }^{620}$ Nähere Ausführungen oder etwaige Voraussetzungen für die entsprechenden Völkerrechtsregeln zur Subjektivierung blieb das Gericht schuldig. Erst 2011 hatte wurde über einen Fall bezüglich in Deutschland gelagerter US-Atomwaffen entschieden und die Klage mangels Klagebefugnis als unzulässig abgewiesen. ${ }^{621}$ Eine in der Nähe des Fliegerhorsts Büchel wohnende Bürgerin fürchtete, möglichen terroristischen Angriffen gegen die auf dem NATO-Gelände stationierte US Air Force ausgesetzt zu sein, da dort auch zahlreiche Atombomben gelagert würden. ${ }^{622}$ Es verstoße gegen das Gewaltverbot der Satzung der UN, demzufolge Staaten nur in Ausnahmefällen militärische Gewalt anwenden dürften. Mit den „Konzeptionellen Leitlinien zur Weiterentwicklung der Bundeswehr" vom 12. Juli 1994 hat sich die Bundesregierung jedoch festgelegt, dass die Bundeswehr die Beladung der Jets, den Transport und Abwurf nuklearer Bomben in deutscher Hand durch Piloten des Jagdbombergeschwaders 33 in Büchel ausüben lässt. ${ }^{623}$ Das Gericht versagte einklagbare subjektive Reche aus Art. 25 GG. Die Klägerin könne sich nicht auf die allgemeinen Völkerrechtsregeln des völkergewohnheitsrechtlichen Gewaltverbots im Sinne des Art. 2 Ziff. 4 UN-Charta oder des Verbots eines Angriffskrieges im Sinne des Art. 26 Abs. 1 GG berufen, da diese nicht, wie etwa das Folterverbot oder das Verbot rassistischer Diskriminierung, individualgerichtet seien und deshalb keine einklagbaren

\footnotetext{
${ }^{618}$ Ders.

${ }^{619}$ Cremer, in: HdStR Bd. 11, § 235 Rn 33; BVerfGE 66, 39 (64); Giegerich, in: Grabenwarter, Allgemeinheit der Grundrechte und Vielfalt der Gesellschaft, S. 108 f.; Herdegen, in: Maunz/Dürig, Art. 25 GG, Rn 97, welcher die Anwendbarkeit des Art. 2 Abs. 1 i. V. m. Art. 25 GG nur auf die Verletzung solcher Völkerrechtsregeln beschränkt, die unmittelbar subjektive Rechte Einzelner begründet oder wenigstens starken individualschützenden Gehalt hat.

${ }^{620}$ BVerwGE 131, 316 (343).

${ }^{621}$ VG Köln, Urteil vom 14.07.2011, Az. 26 K 3869/10.

${ }^{622}$ VG Köln, Urteil vom 14.07.2011, Az. 26 K 3869/10, Rn 1 f. nach juris.

${ }^{623}$ Ders., Rn 3, 5 nach juris.
} 
Rechte über Art. 25 Satz 2 GG erzeugen. Einem Adressatenwechsel entzögen sich die allgemeinen Regeln, die Staaten als Inhaber der Hoheitsgewalt verpflichteten. ${ }^{624}$ Im Übrigen scheiterte die Klage am Fehlen einer Klagebefugnis der Klägerin. ${ }^{625}$ Ohne nähere Ausführungen lehnte es die Subjektivierung ausschließlich staatengerichteter allgemeiner Völkerrechtsregeln ab. ${ }^{626}$

In der Berufungsinstanz vor dem OVG Münster scheiterte die Klägerin 2013 ebenfalls. ${ }^{627}$ Das OVG entzog sich der Beurteilung, ob das VG die Möglichkeit einer subjektiven Rechtsverletzung aus Art. 25 Satz 2 GG zurecht deutlich verneint hat, da ein Verstoß gegen allgemeine Völkerrechtsregeln jedenfalls nicht vorliege. ${ }^{628}$ Die Literaturauffassung $\mathrm{Fi}$ scher-Lescanos und die eine Klagebefugnis begründende „faktische Betroffenheit“ erwähnt das Berufungsgericht, verwarf sie jedoch als nicht weiterführend. ${ }^{629}$

Das VG Karlsruhe verzichtete 2012 beispielsweise gänzlich auf eine Differenzierung der allgemeinen Völkerrechtsregeln oder die Möglichkeit deren Subjektivierung und lehnte eine Rechtserzeugung zugunsten Einzelner hinsichtlich des Erfordernisses der Zustimmung eines Staates ab, auf dessen Staatsgebiet Hoheitsakte vorgenommen werden sollen. Die Regel diene dem Schutz der Souveränität und sei zu einer Erzeugung subjektiver Rechte gänzlich ungeeignet. ${ }^{630}$

Das VG Köln hat auch die in der Bearbeitung eingangs vorgestellten Sache im Jahr 2013 erstinstanzlich entschieden, in dem es um die etwaige Subjektivierung des staatengerichteten völkergewohnheitsrechtlichen Gewaltverbots ging. Die Richter erachteten eine individuelle Geltung staatengerichteter allgemeiner Völkerrechtsregeln durch einen konstitutiven Effekt des Art. 25 Satz 2 GG nun jedoch für möglich, der eine subjektiv-rechtliche Umformung im Sinne eines Adressatenwechsels vornähme. Diese Wirkung entfalte der Satz 2 des Art. 25 GG allerdings, wie 2004 das BVerfG ${ }^{631}$ ausführte, nur bei einer individualschützen-

\footnotetext{
${ }^{624}$ Ders., Rn 84,85 nach juris.

${ }^{625}$ Ders., Rn 53 nach juris.

${ }^{626}$ VG Köln, Urteil vom 14.07.2011, Az. 26 K 3869/10, Rn 85 nach juris.

${ }^{627}$ OVG Münster, Beschluss vom 07.05.2013, Az. 4 A 1913/11, in: DVB1. 17/2013, S. 1129 (Leitsatz und Gründe).

${ }^{628}$ OVG Münster, Beschluss vom 07.05.2013, Az. 4 A 1913/11, in: DVBl. 17/2013, S. 1129 (Leitsatz und Gründe), Rn 22 nach juris.

${ }^{629}$ OVG Münster, Beschluss vom 07.05.2013, Az. 4 A 1913/11, in: DVB1. 17/2013, S. 1129 (Leitsatz und Gründe), Rn 22 nach juris.

${ }^{630}$ VG Karlsruhe, Urteil vom 26.04.2012, Az. 3 K 330/10, in: ZfWG 2012, S. 377.

${ }^{631}$ BVerfGE 112, 1 (22).
} 
den oder -verpflichtenden Finalität der Regel, beispielsweise bei den Normen des humanitären Völkerrechts. ${ }^{632}$ Das VG setzte sich ausführlich mit den unterschiedlichen Auffassungen der kommentierenden Literatur auseinander bezüglich der Erzeugung individueller Rechte aus dem völkergewohnheitsrechtlichen Gewaltverbot. Dabei zog es für den konkreten Einzelfall einige Theorien der Literatur zur praktischen Anwendung in Betracht: „Aus Rechten des Staates können Rechte des Einzelnen werden, aus Staatspflichten können Rechtspflichten, aber auch subjektive Rechte des Einzelnen erwachsen. Ein über Art. 25 Satz 2 GG erzeugtes subjektives Recht benötigt unter Umständen zu seiner Verwirklichung erst eine Festlegung durch Gesetz." ${ }^{\text {633 }}$ Das VG Köln bezog auch die extreme Ansicht $F i$ scher-Lescanos ein, sämtliche allgemeine Völkerrechtsregeln subjektivieren und auch aus den staatengerichteten Regeln wie dem Gewaltverbot Unterlassungsansprüche Einzelner gegen den vornehmenden Staat ableiten zu können. ${ }^{634}$ Allerdings versagten die Richter die Klagebefugnis des Klägers, da auch das Korrektiv der „faktischen Betroffenheit “635 neben einer eklatanten Verletzung zum Ausschluss von Popularklagen nicht zur Begründung subjektiver Rechte beitragen konnte. Das Rechtssubjekt müsste in einer besonderen Form betroffen sein, so dass es von der Allgemeinheit unterschieden und im Vergleich mit dieser besonders identifiziert werden kann. ${ }^{636}$

Die Entscheidung des VG Köln zeichnet aus, dass die Richter nicht nur eine Subjektivierung spezieller allgemeiner Völkerrechtsregeln für möglich erachteten, sondern erstmals umfassend auch die praktische Vermittelbarkeit literarischer Auffassungen in Betracht zogen, die erkennbar liberaler hinsichtlich einer konstitutiven Wirkung des Art. 25 Satz 2 GG argumentieren. Auch wenn die Verwaltungsrichter keine abschließende Präferenz oder Abwägung der einzelnen Literaturstimmen äußerten, sondern lediglich festhielten, dass durch keine der Ansichten eine konkrete Klagebefugnis bestimmt werden konnte ${ }^{637}$, weicht die konkrete Rechtsprechung samt Urteilsbegründung doch entschieden von vergangenen Ablehnungen einer konstitutiven Wirkung des Art. 25 Satz 2 GG ab. Nicht nur wurde eine

\footnotetext{
${ }^{632}$ VG Köln, Urteil vom 14.03.2013, Az. 1 K 2822/12, Rn 59 nach juris, mit Verweis auf Herdegen, in: Maunz/Dürig, Art. 25 GG, Rn 49 f., unverändert in der Aktualisierungslieferung 2019, Rn 89 f.; Hillgruber, in: Schmidt-Bleibtreu/Hofmann/Henneke, Art. 25 GG, Rn 19 (2008), unverändert in der aktuellen Auflage 2018; Rojahn, in: v. Münch/Kunig, Art. 25 GG, Rn 50 31, 33 (2001), unverändert in der aktuellen Auflage 2012, Rn $50 \mathrm{f}$.

${ }^{633}$ Siehe VG Köln, Urteil vom 14.03.2013, Az. 1 K 2822/12, Rn 64 nach juris.

${ }^{634}$ VG Köln, Urteil vom 14.03.2013, Az. 1 K 2822/12, Rn 66 f. nach juris; Fischer-Lescano/Hanschmann, in: Becker/Braun/Deiseroth, Frieden durch Recht?, S. 197 f.

${ }^{635}$ Näheres dazu in Kapitel $§ 7$ Punkt 4.5.

${ }^{636}$ VG Köln, Urteil vom 14.03.2013, Az. 1 K 2822/12, Rn 68 nach juris.

${ }^{637}$ VG Köln, Urteil vom 14.03.2013, Az. 1 K 2822/12, Rn 70 nach juris.
} 
Subjektivierung allgemein staatengerichteter Völkerrechtsregeln, die auch individualschützend oder individualverpflichtend sind, als möglich angesehen, auch wenn im konkreten Fall die Klage als unzulässig abgewiesen wurde. Die Rechtsprechung nahm sogar großzügige Rücksicht auf die Literaturmeinungen hinsichtlich einer etwaigen Subjektivierung allgemein lediglich staatengerichteter Völkerrechtsregeln wie dem völkergewohnheitsrechtlichen Gewaltverbot durch Art. 25 Satz 2 GG.

Die Berufungsinstanz befasste sich 2014 ausführlicher mit der Rechtsnatur des Art. 25 Satz 1 und Satz 2 GG. Die Berufungsklage wurde als unbegründet abgewiesen. Die Unterlassung der vom Kläger begehrten Auskünfte verletzte ihn nicht in seinen Rechten aus Art. 25 Satz 2 GG in Verbindung mit dem völkergewohnheitsrechtlichen Gewaltverbot und dem Verbot des Angriffskrieges. ${ }^{638}$ Im Übrigen fehlte es dem Kläger bereist an der Klagebefugnis, die sich nicht aus Art. 25 Satz 2 GG begründen ließ. ${ }^{639}$

Die Berufungsrichter beziehen sich im Weiteren auf die bereits vorgestellte AlteigentümerEntscheidung des BVerfG aus 2004, die mittlerweile von Teilen des Schrifttums befürwortet wird, in dem eine begrenzte Subjektivierung nur staatengerichteter allgemeiner Völkerrechtsregeln als möglich eingestuft wurde, wenn ein enger Bezug zu individuellen hochrangigen Rechtsgütern besteht und die verletzte völkerrechtliche Regel individualschützend ist. ${ }^{640}$ „Gemeint sind damit in erster Linie jene Normen des völkerrechtlichen Fremdenrechts und des humanitären Völkerrechts, die nach derzeitigem allgemeinen Völkerrecht nicht schon selbst als subjektive Rechte oder Pflichten des Einzelnen anerkannt sind. Sie erstarken im Wege eines sogenannten Adressatenwechsels durch Art. 25 Satz 2 GG innerstaatlich zu subjektiven Rechten und Pflichten für den Betroffenen."641 Die Rechtsprechung des BVerfG aus 2004, Deutschland habe jegliches Mitwirken an völkerrechtswidrigen Handlungen oder deren Förderung zu unterlassen, bedeutet, dass ein bloßes Unterlassen der BRD auf Bündnispartner einzuwirken, die eventuell gegen Art. 25 GG verstoßen, nicht ausreicht, um eigens nicht gegen Art. 25 GG zu verstoßen. Die Richter des

\footnotetext{
${ }^{638}$ OVG Münster, Urteil vom 04.11.2014, Az. 4 A 1058/13, in: DVB1. 8/2015, S. 514-520 (Leitsatz und Gründe), Rn 43 nach juris.

${ }^{639}$ OVG Münster, Urteil vom 04.11.2014, Az. 4 A 1058/13, in: DVB1. 8/2015, S. 514-520 (Leitsatz und Gründe), Rn 46 f. nach juris.

${ }^{640}$ BVerfGE 112, 1 (22); OVG Münster, Urteil vom 04.11.2014, Az. 4 A 1058/13, in: DVB1. 8/2015, S. 514520 (Leitsatz und Gründe), Rn 56 nach juris.

${ }^{641}$ Siehe OVG Münster, Urteil vom 04.11.2014, Az. 4 A 1058/13, in: DVB1. 8/2015, S. 514-520 (Leitsatz und Gründe), Rn 58 nach juris.
} 
OVG bringen es auf den Punkt, dass durch Art. 25 GG der BRD nicht die Rolle als ,eine Art allgemeine Weltstaatsanwaltschaft" zukommen solle. $^{642}$

Die Berufungsrichter blickten wie die Ausgangsinstanz ebenfalls auf die differenzierten Meinungen des Schrifttums, kritisierten allerdings die bereits umfassend diskutierte Voraussetzung einer „faktischen Betroffenheit“ zur Anspruchsbegrenzung als zu ,unscharf" ${ }^{643}$ Im Übrigen orientiert sich das OVG Münster an der Argumentation des VG Köln und versagt weiter die Zustimmung dazu, dass das Völkerrecht eine Subjektivierung selbst fordere und sie für einen Geltungsanspruch im Bundesgebiet notwendig sei. ${ }^{644}$ Die Richter gehen indes so weit, aus praktischen Überlegungen anzunehmen, die Klägerauffassung sei zutreffend. Dies hätte dann jedoch bei einer generellen Subjektivierung ausschließlich staatengerichteter allgemeiner Völkerrechtsregeln zur Folge, dass auch die völkerrechtlich garantierten Menschenrechte ohne eine individuelle Betroffenheit geltend gemacht werden könnten unter Berufung auf Art. 25 Satz 2 GG. Diese Option ließe sich jedoch nicht damit vereinbaren, dass die Verfasser des Grundgesetzes für die innerstaatlichen Grundrechte eine individuelle Betroffenheit voraussetzen, um eine Befugnis zur Verfassungsbeschwerde vorweisen zu können. ${ }^{645}$ Darüber hinaus ist eine Verfassungsbeschwerde nach ständiger Rechtsprechung des BVerfG nicht allein auf Art. 25 Satz 2 GG zu stützen. ${ }^{646}$ Des Weiteren sei nicht nachzuvollziehen, warum die Fachgerichte unabhängig einer individuellen Betroffenheit des Einzelnen die Vereinbarkeit staatlichen Handelns mit allgemeinen Völkerrechtsregeln prüfen müssten, während das BVerfG selbst deren Befolgung nur bei einer zusätzlichen, konkreten Grundrechtsverletzung garantieren könnte. ${ }^{647}$ Das OVG bekräftigt die Auffassung, dass sich aus Art. 25 Satz 2 GG nicht ableiten lasse, dass jede allgemeine Völkerrechtsregel unabhängig ihres mittelbaren oder unmittelbaren Adressatenkreises subjektive Rechte für jedes Individuum innerhalb des Bundesgebietes begründe.

\footnotetext{
${ }^{642}$ OVG Münster, Urteil vom 04.11.2014, Az. 4 A 1058/13, in: DVB1. 8/2015, S. 514-520 (Leitsatz und Gründe), Rn 75 nach juris.

${ }^{643}$ OVG Münster, Urteil vom 04.11.2014, Az. 4 A 1058/13, in: DVB1. 8/2015, S. 514-520 (Leitsatz und Gründe), Rn 47 f., 62 f., 66 nach juris.

${ }^{644}$ OVG Münster, Urteil vom 04.11.2014, Az. 4 A 1058/13, in: DVB1. 8/2015, S. 514-520 (Leitsatz und Gründe), Rn 84 nach juris.

${ }^{645}$ OVG Münster, Urteil vom 04.11.2014, Az. 4 A 1058/13, in: DVB1. 8/2015, S. 514-520 (Leitsatz und Gründe), Rn 95 nach juris, mit Verweis auf BVerfGE 59, 280 (286); 63, 332 (338), zusammenfassend Cremer, in: HdStR Bd. 11, § 235, Rn 40.

${ }^{646}$ BVerfGE 6, 389 (440); 18, 441 (451); 112, 1 (21); so auch Cremer, in: HdStR Bd. 11, § 235 Rn 33; Burghart, in: Leibholz/Rinck, Grundgesetz für die Bundesrepublik Deutschland, Art. 25 GG, Rn 91

${ }^{647}$ OVG Münster, Urteil vom 04.11.2014, Az. 4 A 1058/13, in: 8/DVB1. 2015, S. 514-520 (Leitsatz und Gründe), Rn 101 nach juris.
} 
Denn auch ein reiner Adressatenwechsel berge die Gefahr, bei einer weitergehenden subjektivierenden Auslegung den Zweck des Art. 25 GG zu konterkarieren, eine Balance zwischen nationalem Recht und allgemeinen Völkerrechtsregeln zu schaffen. ${ }^{648}$

Im Anschluss an die Entscheidung des OVG legte der Kläger Revision vor dem BVerwG ein. Dieses sah die zulässige Revision als unbegründet an, das OVG habe die Klage zutreffend als unzulässig abgewiesen. ${ }^{649}$ Art. 25 Satz 2 GG vermöge zwar eine Rechtsstellung zu vermitteln, die zur Klagebefugnis führe, allerdings sei nicht von Verfassungswegen auf die Klagebefugnis als Voraussetzung verzichtet worden. An dieser fehlte es jedoch. ${ }^{650}$ Die Richter des BVerwG gingen in ihrer Urteilsbegründung ins Detail und untersuchten den Wortlaut und die Entstehungsgeschichte des Art. 25 Satz 1 und Satz 2 GG hinsichtlich der Rechtserzeugung für Individuen. Der Wortlaut der Norm schränke ihren Inhalt zwar nicht ein, dass nur solche allgemeinen Völkerrechtsregeln individuelle Rechte und Pflichten begründen können, die einer Subjektivierung zugänglich sind. ${ }^{651}$ In dieser Hinsicht stimmt die höchstrichterliche Verwaltungsrechtsprechung überein mit bereits genannten Literaturstimmen. An vorheriger Stelle ließ das BVerwG noch offen, ob das völkergewohnheitsrechtliche Gewaltverbot nach Art. 25 Satz 2 GG subjektiviert wird: „Sollte das völkergewohnheitsrechtliche Gewaltverbot als allgemeine Regel des Völkerrechts gem. Art. 25 Satz 2 GG Rechte unmittelbar für die Bewohner des Bundesgebiets erzeugen, könnten diese Rechte im Verfahren zur Erteilung der Einflugerlaubnisse geltend gemacht werden.“652 Ohne jedwede Einschränkungen eröffnete der VGH Mannheim ebenfalls 2008 die Durchsetzbarkeit aller allgemeinen Völkerrechtsregeln durch Einzelne vor innerstaatlichen Gerichten, da Art. 25 Satz 2 GG ihnen den Charakter eines subjektiven Rechts verleihe. ${ }^{653}$

\footnotetext{
${ }^{648}$ OVG Münster, Urteil vom 04.11.2014, Az. 4 A 1058/13, in: DVB1. 8/2015, S. 514-520 (Leitsatz und Gründe), Rn 87 f., 99, 103, 105 nach juris.

${ }^{649}$ BVerwGE 154, 328 (332 f.).

${ }^{650}$ Ders.

${ }^{651}$ BVerwGE 154, 328 (341).

${ }^{652}$ Siehe BVerwGE 131, 316 (343).

${ }^{653}$ OVG Mannheim, Urteil vom 08.05.2008, Az. 2 S 2163/06, in: DÖV 19/2008, S. 829 (Leitsatz), Rn 34 nach juris; anders das FG Stuttgart, Urteil vom 23.06.2010, Az. 1 K 4176/09, in: EFG 2010, S. 1668-1670 (Leitsatz und Gründe), Rn 18 f. nach juris, welches eine subjektive Rechtsstellung aus dem Prinzips der territorialen Souveränität als staatengerichtete allgemeine Völkerrechtsregel verneint. Der Einzelne könne sich nicht auf einen Verstoß gegen das Völkerrecht berufen, da durch den Territorialitätsgrundsatz keine Individualrechte begründet werden und nur die betroffenen Staaten im Verhältnis untereinander einschlägige Völkerrechtsverstöße rügen können, vgl. auch VG Düsseldorf, Beschluss vom 18.05.2009, Az. 27 L 1607/08, in: ZfWG 2009, S. 211-227 (Leitsatz und Gründe), Rn 14 nach juris.
} 
Allerdings widersprachen die Richter 2016 deutlich dem Gedanken, dass die Entstehungsgeschichte des Art. 25 GG Anhaltspunkte gäbe, aus dieser eine gewollte generelle Subjektivierung allgemeiner Völkerrechtsregeln ableiten zu können. ${ }^{654} \mathrm{Im}$ Rahmen einer sehr umfassenden Darstellung und Auslegung der Entstehungsgeschichte des Art. 25 GG aus Art. 4 WRV heraus untersuchten die Bundesverwaltungsrichter den Verfassungskonvent von Herrenchiemsee. Dabei legten sie offen, was die Verfasser der Norm ursprünglich intendierten, und führten aus: „Aus den Entstehungsmaterialien ergibt sich der Wille des Verfassungsgesetzgebers, den allgemeinen Grundsätzen des Völkerrechts eine weitergehende innerstaatliche Bedeutung beizumessen als dass nach der lediglich staatengerichteten Regelung in Art. 4 WRV der Fall war. [...] Das bedeutet allerdings nicht, dass die Väter und Mütter des Grundgesetzes damit auf das Erfordernis einer individuellen Betroffenheit verzichten und über die allgemeine Regel des Art. 19 Abs. 4 GG herausgehen wollten [...]. Aus den Gesetzesmaterialien ergeben sich keine Anhaltspunkte dafür, dass Art. 25 GG einen umfassenden subjektiv-rechtlichen Anspruch auf die Wahrung objektiven Völkerrechts begründen oder ein Recht zur Popularklage normieren wollte, um allgemeine Grundsätze des Völkerrechts über die Regelung des Art. 19 Abs. 4 GG hinaus durchzusetzen.“655

Die Richter verwiesen insbesondere auf die Rechtsprechung des BVerwG in Fällen, in denen die Durchsetzbarkeit allgemeiner Völkerrechtsregeln positiv entschieden wurde. So berechtigt Art. 25 GG Soldaten zur Nichtbefolgung von Befehlen, die bei ihrer Ausführung gegen allgemeine Völkerrechtsregeln verstießen. ${ }^{656}$ Die Bundesrichter verweisen auf die eigene Rechtsprechung aus 2008, laut der Anwohner von Flughäfen bestimmte Militärflüge rügen könnten, die gegen das völkergewohnheitsrechtliche Gewaltverbot verstoßen, sofern dieses unmittelbare Rechte für die Bewohner des Bundesgebietes erzeugen. ${ }^{657}$ Im Urteil aus 2016 konkretisierten sie dazu, dass die Kläger in jedem Fall auch unmittelbar betroffen sein müssen. ${ }^{658}$

Wie bereits Doehring 1962 nimmt das BVerwG im Anschluss an die Alteigentümer-Entscheidung des BVerfG aus 2004 eine ausführliche Trennung der allgemeinen Völkerrechtsregeln vor: ausschließlich staatengerichtete Regeln, die bei Anwendung auf Individuen inhaltlichen und zweckbezogenen Sinn verlören, dann bereits auf völkerrechtlicher Ebene individualbezogene Regeln und schließlich solche, die sich auf völkerrechtlicher Ebene

\footnotetext{
${ }^{654}$ BVerwGE 154, 328 (341 f.).

${ }^{655}$ BVerwGE 154, 328 (343 f.).

${ }^{656}$ BVerwGE 127, 302 (316 f.); vgl. auch Deiseroth, in: Das Recht in guter Verfassung?, S. 25 (38 f.).

${ }^{657}$ BVerwGE 131, 316 (343).

${ }^{658}$ BVerwG, 154, 328 (343 f.).
} 
ausschließlich an Staaten richten, ihrem Sinn und Inhalt nach jedoch einem Individualbezug zugänglich sind. ${ }^{659}$

Die jüngste ausführliche Bearbeitung des Art. 25 Satz 2 GG nahm das BVerfG im Jahr 2018 im Anschluss an oben bearbeiteten Verfahren vor, in welchen die damalige Klägerin versuchte, die BRD dahingehend verpflichten zu lassen, gegenüber den USA auf einen Abzug von auf dem Fliegerhorst Büchel stationierten US-Atomwaffen hinzuwirken. Mit der Verfassungsbeschwerde vor dem BVerfG verfolgte die Beschwerdeführerin denselben Zweck, jedoch wurde diese nicht zur Entscheidung angenommen. ${ }^{660}$ Die Verfassungsrichter berücksichtigen die ursprüngliche Rechtsprechung des BVerfG, dass Art. 25 Satz 2 GG lediglich deklaratorische Wirkung habe und allgemeine Regeln lediglich über Art. 25 Satz 1 GG ins innerstaatliche Recht aufgenommen würden. ${ }^{661}$ Es verweist jedoch auf die jüngere höchstrichterliche Rechtsprechung der Anerkennung einer konstitutiven Wirkung des Satz 2 der Norm, und dass subjektive Ansprüche auf innerstaatlicher Ebene unabhängig der Anspruchsnatur der allgemeinen Völkerrechtsregeln auf völkerrechtlicher Ebene geboten sein könnte. ${ }^{662}$

Das BVerfG knüpft an die in der Alteigentümer-Entscheidung festgelegten Voraussetzungen eines engen Bezugs zu individuellen hochrangigen Rechtsgütern an und verweist auf den Sinn und Zweck des Art. 25 GG, der einen weitgehenden Gleichklang zwischen freiheitlicher Verfassungsordnung und Völkerrecht verfolge. Die Verfassung erzwinge somit die Gestaltung des Bundesrechts entsprechend der allgemeinen Regeln des Völkerrechts. ${ }^{663}$ Die Verfassungsrichter fuhren konsequent fort, dass diese Zielsetzung unterlaufen würde, könnten staatengerichtete allgemeine Völkerrechtsnormen wie das Gewaltverbot, das nach ihrer Auffassung keinen engen individuellen Bezug zu individuellen Rechtsgütern hat, über Art. 25 Satz 2 GG inhaltlich zu einem subjektiven Individualrecht verändert werden. Dies ginge über die Intention des Völkerrechts hinaus. ${ }^{664}$ Damit beurteilt das BVerfG im Abstand von zwei Jahren die strittige Frage der konstitutiven Wirkung des Art. 25 Satz 2 GG

\footnotetext{
${ }^{659}$ BVerwGE 154, 328 (345 f.).

${ }^{660}$ BVerfG, Nichtannahmebeschluss vom 15.03.2018, Az. 2 BvR 1371/13, in: NJW 32/2018, S. $2312-2316$ (Leitsatz und Gründe).

${ }^{661}$ BVerfGE 15, 25 (33 f.) 27, 253 (274); 41, 126 (160); 46, 342 (372 f.); 63, 343 (373 f.).

${ }^{662}$ BVerfG, Nichtannahmebeschluss vom 15.03.2018, Az. 2 BvR 1371/13, in: NJW 32/2018, S. 2312-2316 (Leitsatz und Gründe), Rn 35 f., mit Verweis auf BVerfGE 112, 1 (22) und insbesondere BVerwGE 154, 328 (346).

${ }^{663}$ Vgl. BVerfGE 23, 288 (316); 112, 1 (25); Streinz, in: Sachs, Art. 25 GG, Rn 9; Rojahn, in: v. Münch/Kunig, Art. 25 GG, Rn 1.

${ }^{664}$ BVerfG, Nichtannahmebeschluss vom 15.03.2018, Az. 2 BvR 1371/13, in: NJW 32/2018, S. 2312-2316 (Leitsatz und Gründe), Rn 37 f. nach juris, mit umfassendem Verweis auf zustimmende Literatur: Kunig, in: Vitzthum/Proelß, Völkerrecht, S. 118 f. Rn 150 f.; Hofmann, in: Umbach/Clemens, Art. 25 GG, Rn 25;
} 
für nur staatengerichtete allgemeine Völkerrechtsregeln deutlich konsequenter als das BVerwG. Dieses hatte die Frage offengelassen und die Geltendmachung über Art. 25 Satz 2 GG ermöglicht, sofern das völkergewohnheitsrechtliche Gewaltverbot subjektive Rechte erzeuge. Es nahm weiter eine befürwortende Stellung zu den vom BVerfG 2004 aufgestellten Voraussetzungen hinsichtlich eines Adressatenwechsels durch Art. 25 Satz 2 GG bei individualschützenden und -verpflichtenden Völkerrechtsnormen ein. ${ }^{665}$ In der Auslegung der Entstehungsgeschichte des Art. 25 GG stimmt das BVerfG mit dem BVerwG überein, dass Satz 2 GG der Norm nicht als Ausnahme zum Erfordernis einer Klagebefugnis zur Verhinderung von Popularklagen zwecks einer umfassenden individuellen Rechtsstellung verstanden werden könnte. ${ }^{666}$

Auch in Verbindung mit Art. 2 Abs. 1 GG konnte für die Berufung auf Art. 25 GG keine Klagebefugnis bejaht werden. Das BVerfG bestätigte jedoch die Ansicht der Ausgangsinstanz, dass sich auch in Verbindung mit Art. 2 Abs. 1 GG durch die Übernahme ins innerstaatliche Recht gem. Art. 25 Satz 2 GG aus den allgemeinen Völkerrechtsregeln keine subjektive Rechtsposition ableiten lasse. ${ }^{667}$ Das völkergewohnheitsrechtliche Gewaltverbot gewährleiste für den Einzelnen, und hier widerspricht das BVerfG deutlich den weitgehendsten Ansichten der Literatur, keinen Unterlassungsanspruch. Dies setze eine Subjektivierung der Regeln zur Staatenverantwortlichkeit voraus, jedoch beinhalte das Gewaltverbot nur eine Unterlassungspflicht der Staaten. Ein Anspruch auf Unterlassung entspringe lediglich völkerrechtlichen Normen zur Staatenverantwortlichkeit, vgl. Art. 43 Abs. 2 lit. a) und Art. 48 Abs. 2 lit. a) des ILC-Entwurfs, die beispielsweise verletzten Staaten den Anspruch einräumen, rechtswidriges Handeln zu unterlassen. ${ }^{668}$ Wie sich in der Bearbeitung zeigte, adressiert der ILC-Entwurf jedoch nur die internationale Staatengemeinschaft und nicht individuelle Einzelne. Dies betonten auch die Verfassungsrichter: „Die insoweit anspruchsvermittelnden Normen des Völkerrechts, die Reaktionsmöglichkeiten auf ein

Rojahn, in: v. Münch/Kunig, Art. 25 GG, Rn 41, 49 f.; Cremer, in: HdStR Bd. 11, § 235 Rn 32; Kessler/Salomon, in: DÖV 7/2014, S. 283 (288 f.); Wollenschläger, in: Dreier, Art. 25 GG, Rn 36; Herdegen, in: Maunz/Dürig, Art. 25 GG, Rn 90; abweichend auch das Gewaltverbot über subjektivierend vgl. Fischer-Lescano/Hanschmann, in: Becker/Braun/Deiseroth, Frieden durch Recht?, S. 181, 189 f.

${ }^{665}$ BVerwGE 154, 328 (345 f.).

${ }^{666}$ BVerfG, Nichtannahmebeschluss vom 15.03.2018, Az. 2 BvR 1371/13, in: NJW 2018, S. 2312-2316 (Leitsatz und Gründe), Rn 54 f. nach juris, mit Verweis auf BVerwGE 154, 328 (347 f.); BVerfGE 6, 309 (362 f.); 23, 288 (300); 31, 145 (177); 112, 1 (21 f.); 141, 1 (17); BVerfG, Beschluss vom 17.05.2017, Az. 2 BvR 893/17, in: NStZ-RR 7/2017, S. 226 f.

${ }^{667}$ BVerfG, Nichtannahmebeschluss vom 15.03.2018, Az. 2 BvR 1371/13, in: NJW 32/2018, S. 2312-2316 (Leitsatz und Gründe), Rn 55 nach juris.

${ }^{668}$ BVerfG, Nichtannahmebeschluss vom 15.03.2018, Az. 2 BvR 1371/13, in: NJW 32/2018, S. 2312-2316 (Leitsatz und Gründe), Rn 56 nach juris. 
rechtswidriges Verhalten innerhalb eines Rechtssystems gleichberechtigter Staaten ohne zentrale Durchsetzungsgewalt schaffen, sind indes lediglich staatengerichtet und daher nicht geeignet, nach Art. 25 Satz 2 GG Rechte und Pflichten für den Einzelnen zu begründen. “669

Jüngst hat das OVG Münster erneut als Berufungsinstanz über einen Fall entschieden, in dem die Völkerrechtmäßigkeit der über die US-Airbase Ramstein gesteuerten Drohnenflüge angezweifelt wurde. ${ }^{670}$ Das BVerwG hatte 2016 eine Anwohnerklage mangels individueller Klagebefugnis abgelehnt, da diese nicht durch Drohneneinsätze der USA im Ausland betroffen seien, die BRD an diesen nicht aktiv partizipiere und terroristische Racheakte an der US-Airbase Ramstein nicht absehbar seien, welche die Anwohner betreffen könnten. ${ }^{671}$ Anders als bei den Anwohnern konnten die Kläger, die nahe Angehörige durch Drohnenangriffe im Jemen verloren haben und dort ein Gebiet bewohnen, in dem es häufiger auch zu zivilen Opfern kommt, eine Klagebefugnis geltend machen. Sie sind tatsächlich der Gefahr ausgesetzt, Opfer solcher militärischen Drohneneinsätze zu werden. ${ }^{672}$ Während das VG Köln die Klage noch als unbegründet abgewiesen hat, da die BRD ihren extra-territorialen Schutzpflichten nachkomme und deshalb keine Handlungspflicht für die deutsche Regierung bestehe, entschieden die Richter des OVG zugunsten der Kläger. Sie bezogen sich auf die Alteigentümer-Entscheidung des BVerfG, und dass es geboten sein könnte, Völkerrechtsverletzungen als subjektive Rechtsverletzungen durch Individuen geltend machen zu können. Dies gelte auch unabhängig davon, ob diesen bereits kraft Völkerrechts subjektive Ansprüche zukämen oder nicht. ${ }^{673}$ Die Völkerrechtsfreundlichkeit des Grundgesetzes verpflichte die deutschen Staatsorgane das Völkerrecht zu respektieren und im eigenen Verantwortungsbereich durchzusetzen, wenn es durch andere Staaten verletzt wird. ${ }^{674}$

Das OVG Münster bezieht auch die Voraussetzungen in die Argumentation der Urteilsbegründung ein, unter denen ein subjektiver Rechtsanspruch möglich sei. Allerdings stellt die Entscheidung des OVG Münster erneut eine Ausnahmeentscheidung dar. Das BVerwG hat

\footnotetext{
${ }^{669}$ BVerfG, Nichtannahmebeschluss vom 15.03.2018, Az. 2 BvR 1371/13, in: NJW 32/2018, S. 2312-2316 (Leitsatz und Gründe, Rn 36 nach juris.

${ }^{670}$ OVG Münster, Urteil vom 19.03.2019, Az. 4 A 1361/15, in: NJW 26/2019, S. 1898 (Leitsatz).

${ }^{671} \mathrm{Vgl}$. dazu bereits in Kapitel $\S 1$.

${ }^{672}$ OVG Münster, Urteil vom 19.03.2019, Az. 4 A 1361/15, in: NJW 26/2019, S. 1898 (Leitsatz), Rn 89, 97, 117 nach juris.

${ }^{673}$ OVG Münster, Urteil vom 19.03.2019, Az. 4 A 1361/15, in: NJW 26/2019, S. 1898 (Leitsatz), Rn 198 nach juris.

${ }^{674}$ OVG Münster, Urteil vom 19.03.2019, Az. 4 A 1361/15, in: NJW 26/2019, S. 1898 (Leitsatz), Rn 204 nach juris; BVerfGE 112, 1 (26).
} 
in der Revisionsinstanz die Entscheidung der ersten Instanz wiederhergestellt und die Klage abgewiesen. ${ }^{675}$ Zwar bestehe dem Grunde nach ein individueller Anspruch auf Schutzmaßnahmen Deutschlands für ausländische Staatsbürger im Ausland, wenn Drohneneinsätze dort von der Air Base Ramstein aus gesteuert werden. ${ }^{676}$ Für den nicht im Jemen wohnenden Kläger ist bereits eine Klagebefugnis abgelehnt worden. ${ }^{677}$ Nach Ansicht des BVerwG reiche der Schutzzweck des Art. 2 Abs. 1 und Abs. 2 GG räumlich grundsätzlich auch ins Ausland. Im konkreten Fall sind Individualansprüche abgelehnt worden, da die Geltendmachung von Verstößen gegen die allgemeinen Regeln des Völkerrechts lediglich möglich erscheinen. Für einen Schutzanspruch bedürfte es vorherige Verletzungen, die für die Zukunft vergleichbare Verstöße konkrete erwarten lassen. ${ }^{678}$ Weiter folgt das Erfordernis eines hinreichend engen Bezugs zum deutschen Staat für die Entstehung einer grundrechtlichen Schutzpflicht aus dem Verfassungsrecht. Denn Art. 1 Abs. 3 GG enthält zwar keine Beschränkung auf das Staatsgebiet ${ }^{679}$, erfordert jedoch auch eine politische Entscheidungverantwortung. Eine unbegrenzte legislative oder exekutive Verantwortung der deutschen Staatsgewalt sei dem Grundgesetz fremd. ${ }^{680}$

\subsection{Zwischenergebnis}

Die Untersuchung hat gezeigt, dass die Rechtsprechung auch nach Jahrzehnten der praktischen Anwendung uneins ist über den Umfang der rechtlichen Begünstigung einzelner Personen im Rahmen des innerstaatlichen Rechts. Die direkte individuelle Anwendbarkeit von Art. 3 des IV. Haager Abkommens sowie Art. 91 ZP-I wurde vom BGH und BVerfG einstimmig in der Distomo-Entscheidung abgelehnt. In seiner Varvarin-Entscheidung wurde der BGH noch deutlicher als er eine Weiterentwicklung des Völkerrechts hinsichtlich individueller Entschädigungsansprüche klar ablehnte. Der Rahmen, in welchem sich die höchsten Gerichte bewegen, ist jedoch erkennbar schmaler geworden.

\footnotetext{
${ }^{675}$ BVerwG, Urteil vom 25.11.2020, Az. 6 C 7/19, Rn 28 f. nach juris.

${ }^{676}$ Ders., Rn 57 f. nach juris.

${ }^{677}$ Ders., Rn 23 nach juris.

${ }^{678}$ Ders., Rn 51 f. nach juris.

${ }^{679}$ BVerfG, Urteil vom 19.05.2020, Az. 1 BvR 2835/17, in: NJW 2020, S. 2235 Rn 89.

${ }^{680}$ BVerwG, Urteil vom 25.11.2020, Az. 6 C 7/19, Rn 46, 56 f. nach juris.
} 
Bezogen auf die aufgeworfene These, dass es sich bei Art. 25 Satz 2 GG um eine Art deutschen ATCA verglichen zu den USA handele, kann diese nicht bestätigt werden. Die Richter der höchsten deutschen Gerichte sind zwar von ihrer Einstellung zur lediglich deklaratorischen Wirkung von Satz 2 des Art. 25 GG nicht nur erkennbar abgerückt. Sowohl das BVerwG als auch das BVerfG eröffnen die konstitutive Wirkung für allgemeine Völkerrechtsregeln für einzelne Bewohner des Bundesgebietes. Während das BVerfG in seiner Botschaftskonto-Entscheidung zunächst lediglich offenließ, ob Art. 25 Satz 2 GG für spezielle allgemeine Völkerrechtsregeln eine konstitutive Wirkung entfalte, gingen die Richter 2004 in ihrer Alteigentümer-Entscheidung so weit, dass durch Art. 25 Satz 2 GG über einen Adressatenwechsel manche allgemeinen Völkerrechtsregeln zu subjektiven Rechten und Pflichten für Einzelne umgewandelt werden können. Damit stimmt die Rechtsprechung überein mit Stimmen der Literatur wie Doehring, welche vorher bereits einer Subjektivierung durch Art. 25 Satz 2 GG deutlich liberaler gegenüberstanden, jedoch ohne diese in der Urteilsbegründung zu erwähnen. Dieser Adressatenwechsel findet nach den Verfassungsrichtern jedoch nur bei allgemeinen Völkerrechtsregeln statt, die eine individualschützende oder -verpflichtende Finalität besitzen.

Während das BVerfG erst 2018 eine Subjektivierung des völkerrechtlichen Gewaltverbots durch Art. 25 Satz 2 GG deutlich aufgrund eines mangelnden Individualbezugs verneinte, ließ das BVerwG wenige Jahre vorher dieselbe Frage immer noch offen.

Die Divergenz rechtlicher Einschätzung und Anwendung zeigt sich allerdings hier deutlich und auch die anfängliche Uneinigkeit der höchsten Bundesrichter. Diese stellten sich bisher konsequent gegen die Literaturmeinungen, aus der Entstehungsgeschichte des Art. 25 GG lasse sich eine generelle Subjektivierung allgemeiner Regeln des Völkerrechts ableiten.

Da die Rechtsprechung in der Differenzierung einzelner Arten von allgemeinen Völkerrechtsregeln mit den Ausführungen der Literatur übereinstimmt, kann diese als anerkannte Trennung festgehalten werden. Es gibt demnach ausschließlich auf völkerrechtlicher Ebene staatengerichtete allgemeine Regeln des Völkerrechts, die nach Inhalt und Zweck ihren Sinn verlören, wären sie auf oder durch Individuen anwendbar. Weiter gibt es die bereits auf völkerrechtlicher Ebene lediglich individualgerichteten Regeln und letztlich die staatengerichteten allgemeinen Völkerrechtsregeln, welche ihren inhaltlichen und intendierten Sinn nicht verlieren, wendet man sie auch auf Individuen an. Sie sind somit einem Individualbezug zugänglich.

Dieser finale Individualbezug bleibt jedoch zurecht als entscheidende Bedingung vorauszusetzen, um eine konstitutive Wirkung des Art. 25 Satz 2 GG auch praktikabel entfalten 
zu können. Andere Alternativen und Konstruktionen des Schrifttums halten, wie gezeigt, einer praktischen Probe nicht stand und werden als solche auch zurecht entschieden abgelehnt. Das BVerwG nahm 2016 ausführlich Bezug auf die Alteigentümer-Entscheidung des BVerfG betreffend den Adressatenwechsel durch Art. 25 Satz 2 GG sowie die Differenzierung zwischen drei unterschiedlichen Arten völkerrechtlicher Regeln.

Die höchstrichterliche Rechtsprechung sowohl der obersten Verfassungs- als auch Verwaltungsrichter hat sich in der Folge auch in den niedrigeren Instanzen verfestigt, dass Art. 25 Satz 2 GG eine konstitutive Wirkung für eine bestimmte Gruppe staatengerichtete allgemeine Völkerrechtsregeln entfaltet. Die bisherige Begrenzung der Subjektivierung durch Art. 25 Satz 2 GG und die zögerliche Anerkennung einzelner allgemeiner Regeln als tatsächlich durch Art. 25 Satz 2 GG erzeugte Rechte und Pflichten mindert den Fortschritt der Völkerrechtslage seit Inkrafttreten des Grundgesetzes 1949 jedoch keinesfalls. Die deut-

sche Rechtsprechung befasst sich bis heute in wenigen Fällen mit den allgemeinen Regeln des Völkerrechts. Nach der Jahrtausendwende hat sich die beschriebene Entwicklung allerdings als aktueller Rechtsstandard etabliert. Inwiefern dieser durch weitere Entscheidungen vertieft und vor allem weiter konkretisiert wird, ist in Zukunft abzuwarten. Ebenso ist ungewiss, ob das BVerfG in Zukunft für weitere allgemeine Regeln des Völkerrechts eine individualschützende oder -verpflichtende Finalität anerkennen und auch anwenden wird. Besonders relevant wird dafür der Faktor sein, ob die Gerichte lediglich eine rechtliche oder auch politische Beurteilung vornehmen.

\section{Fazit}

Die Anerkennung einer restriktiveren Subjektivierung allgemeiner Völkerrechtsnormen ist mit Hinblick auf die aktuelle und über die letzten Jahrzehnte erkennbar modernisierte Völkerrechtslage bezüglich einzelner Personen gut vertretbar. Danach ist der, verglichen zum nationalen und internationalen Schrifttum, vorsichtigen Herangehensweise der Rechtsprechung zuzustimmen. Eine umfassende, nahezu bedingungslose, Befürwortung einer generellen konstitutiven Wirkung des Art. 25 Satz 2 GG hinsichtlich ausschließlich staatengerichteter allgemeiner Völkerrechtsregeln ist besonders aus dem Grund abzulehnen, dass ansonsten die völkerrechtlich garantierten Menschenrechte mit schwächeren Verfahrensvoraussetzungen geltend gemacht werden könnten als die nationalen Grundrechte. Es hat sich gezeigt, dass der Verfassungsgesetzgeber dies nicht beabsichtigt hatten. 
Auffällig in der Betrachtung diverser nationaler Rechtsprechungen ist der Umfang politischer Einflussnahme auf die völkerrechtliche Rechtslage. Die positiven Entscheidungen italienischer und griechischer Gerichte bezüglich individueller Entschädigungsklagen wegen deutscher SS-Verbrechen des Zweiten Weltkriegs wurden durch die höchsten Gerichte zurückgenommen, oft nicht ohne die vorherige Intervention in- oder ausländischer Politiker. In einer übergreifenden Gesamtschau muss im Ergebnis festgestellt werden, dass international und auch national eine unmittelbare individuelle Berechtigung durch allgemeine Völkerrechtsregeln strikt abgelehnt wird. Die Übereinkünfte zur Entschädigung einzelner Opfer völkerrechtswidriger Verbrechen, beispielsweise Koreas zur Entschädigung der „Comfort-Women“, sind als politische Ausnahmefälle zu verzeichnen. Daraus sind keinesfalls greifbare Rückschlüsse auf eine entsprechende Rechtspraxis zu schließen, zumal bisher in keiner nationalen Rechtsprechung eine vergleichbare Differenzierung der allgemeinen Völkerrechtsregeln in unterschiedliche Adressatengruppen vorgenommen wurde.

Mit der Erklärung des OVG Münster Anfang 2019, dass die Beurteilung der Völkerrechtmäßigkeit ausländischer Militäraktionen doch keine politische, sondern eine rechtliche Prüfung erfordere ${ }^{681}$, stellte sich zwar erstmals ein deutsches Gericht gegen den aufgezeigten Eindruck der internationalen Länderrechtsprechungen, einen politischen Beurteilungsspielraum einfließen zu lassen, wenn ausländische Militäraktionen betroffen sind. Damit knüpfen die Richter an die Rechtsprechung des BVerfG an, dass der Bundesregierung keine Einschätzungsprägorative zukommt, wenn es um das Gebot effektiven Rechtsschutzes nach Art. 19 Abs. 4 GG geht. ${ }^{682}$ Dennoch wurde die Entscheidung durch die Revisionsinstanz wieder aufgehoben und eine Völkerrechtsverletzung abgelehnt. Das BVerwG hat allerdings offen gelassen, ob eine grundrechtliche Schutzpflicht der Bundesregierung gegenüber Einzelnen entstanden ist. ${ }^{683}$

Hinsichtlich einer Subjektivierung der allgemeinen Regeln des Völkerrechts hat sich durchgesetzt und in der fortlaufenden Rechtsprechung etabliert, einen Bezug zu hochrangigen Individualgütern vorauszusetzen, um diese individuell geltend machen zu können. Liegt eine individualschützende oder -verpflichtende Finalität einer allgemeinen Regel vor, nimmt Art. 25 Satz 2 GG einen Adressatenwechsel vor. Deutschland hat neben den USA

\footnotetext{
${ }^{681}$ OVG Münster, Urteil vom 19.03.2019, Az. 4 A 1361/15, in: NJW 26/2019, S. 1898 (Leitsatz), Rn 215 nach juris, deutlicher in: Mündliche Urteilsverkündung, S. 6, abrufbar unter: http://www.ovg.nrw.de/behoerde/presse/pressemitteilungen/11_190319/Muendliche_Urteilsbegruendung.pdf (zuletzt aufgerufen am 09.07.2019).

${ }^{682}$ Siehe OVG Münster, Urteil vom 19.03.2019, Az. 4 A 1361/15, in: NJW 26/2019, S. 1898 (Leitsatz), Rn 293 nach juris.

${ }^{683}$ BVerwG, Urteil vom 25.11.2020, Az. 6 C 7/19, Rn 18 f. nach juris.
} 
als einziges der in diesem Kapitel genannten Länder mit Art. 25 GG eine Norm in seiner Verfassung, welche die allgemeinen Regeln des Völkerrechts ins nationale Recht eingliedert. Die USA haben zwar mit dem ATCA eine Rechtsgrundlage für etwaige individuelle Entschädigungsansprüche geschaffen, aber auch diese ist in ihrem Geltungsbereich nicht unstrittig, und die Anspruchsinhaberschaft Einzelner ist beschränkt. 
$\S 7$ Sichtweise der Rechtsprechung zu Art. 25 Satz 2 GG als unmittelbare Rechtsgrundlage

In diesem Kapitel wird näher beleuchtet, inwiefern ein subjektives Recht über einen Rechtsanspruch mittels Art. 25 Satz 2 GG als Anspruchsgrundlage geltend gemacht werden könnte. Es wird im Rahmen der Untersuchung auch ein gezielter Seitenblick auf die Beachtung und Eingliederung der in $\S 5$ benannten Literaturmeinungen geworfen und ob sich die Judikative von den Vorstößen des Schrifttums beeinflussen lässt. Dass Individuen subjektive völkerrechtliche Rechte über Art. 25 GG zukommen sollen, wird im folgenden Kapitel praktisch hinterfragt. Insbesondere ist fraglich, ob auch positive Entscheidungen infolge von Verletzungen allgemeiner Völkerrechtsregeln ergangen sind, und auf welcher Rechtsgrundlage erfolgreiche Rechtsmittel vor deutschen Gerichten gestützt werden konnten. Vereinzelte Autoren vertreten, dass Art. 25 Satz 2 GG als individuelle Rechts- und Anspruchsgrundlage, wie am Beispiel von Sekundäransprüchen in Kapitel § 5 aufgezeigt, herangezogen werden kann.

Besondere Relevanz kommt der Frage zu, ob auch die Rechtsprechung Art. 25 Satz 2 GG als Anspruchsgrundlage heranzieht oder Klagen, die allein auf Art. 25 Satz 2 GG gestützt werden, überhaupt zulässt.

\section{Politische Aspekte zu den allgemeinen Völkerrechtsregeln als Individualrechte}

Eine Gegenseitigkeit von politischem Interesse und völkerrechtlicher Wahrung bildet den Grundbaustein der Effektivität des Völkerrechts. Die völkerrechtlichen Normen entstehen aufgrund von politischen Intentionen, welche in der Zeit nach der Entstehung dem Norminhalt zuwiderlaufen könnten. Allerdings könnte es der Politik, die möglicherweise eine völkerrechtliche Norm missachten möchte, widerfahren, dass sie sich in der Zukunft selbst einmal auf eben diese völkerrechtliche Norm berufen möchte. ${ }^{684}$ Auch die internationale Rechtsprechung des IGH wird nicht konsequent durch die internationale Staatengemeinschaft beachtet. Die USA haben nach dem LaGrand-Urteil das Fakultativprotokoll zum Wiener Konsularrechtsübereinkommen gekündigt, um sich einer Gerichtsbarkeit des IGH

${ }^{684}$ Vitzthum, in: Vitzthum/Proelß, Völkerrecht, S. 6 f. Rn 5 f.; Ipsen, in: Ipsen, Völkerrecht, § 3 Rn 1 f. 
dauerhaft zu entziehen. ${ }^{685}$ Trinidad und Tobago hat sich ebenfalls von der Gerichtsbarkeit des IGH entzogen, weil der UN-Menschenrechtsausschuss Kritik aufgrund der Ausübung der Todesstrafe geübt hatte. ${ }^{686}$

Internationale politische Beziehungen können zu Rechtsbeziehungen erwachsen, wenn der Umschlag von politischer Intention zum verbindlichen Rechtssatz erfolgt. Ein Völkerrechtssatz ist dabei das Ergebnis der Verrechtlichung politischer Tatbestände und bleibt auch nach seiner Entstehung mit der Politik verbunden. ${ }^{687}$ Diese Regelung ist von einem späteren politischen oder sozialen Wandel unberührt und damit rechtsverbindlich. Dennoch sind völkerrechtliche Regelungen in ihrem Geltungsbereich politisch zugänglich, so dass die Effektivität völkerrechtlich verbindlicher Rechtsnormen auf Dauer angezweifelt werden könnte. ${ }^{688}$ Inwieweit also die Entscheidung des OVG Münster aus 2019, die Völkerrechtmäßigkeit ausländischer Drohnenflüge sei rechtlich und nicht politisch zu entscheiden, eine signifikante Reichweite entfalten wird, muss deshalb zurückhaltend betrachtet werden. Eine Revision wurde vom OVG aufgrund der hohen sachlichen Bedeutung zugelassen. ${ }^{689}$ Das BVerwG hat 2020 dann hingegen gegensätzlich entschieden und einen weiteren Individualanspruch auf weitergehendes Tätigwerden der Bundesregierung zur Verhinderung von Drohneneinsätzen der USA im Jemen unter Nutzung der Air Base Ramstein verneint. ${ }^{690}$ Für den nicht im Jemen lebenden Kläger bestand bereits keine Klagebefugnis. ${ }^{691}$ Die übrigen Kläger können sich entgegen der Ansicht des OVG Münster nicht bereits auf die Möglichkeit einer völkerrechtswidrigen Beeinträchtigung ihrer Grundrechte berufen. Die Schutzpflicht des Staates aus Art. 2 Abs. 1 GG reicht nicht so weit, mehr als diplomatische und politische Konsultationen für im Jemen lebende jemenitische Staatsangehörige vorzunehmen, denn die Schutzpflicht entsteht erst mit der konkreten Erwartung zukünftiger Völkerrechtsverstöße infolge bereits eingetretener Völkerrechts-verletzungen. ${ }^{692}$ Offenkundig ist, dass das OVG Münster 2014 noch ausdrücklich vertreten hat, dass über Art.

\footnotetext{
${ }^{685}$ Kündigungsschreiben der US-Außenministerin an den UN-Generalsekretär vom 07.03.2005.

${ }^{686} \mathrm{Am}$ selben Tag wieder beigetreten unter der Prämisse, dass alle Beschwerden an Todesstrafen an Häftlingen ausgeschlossen werden, siehe UNHRC, Kennedy vs. Trinidad and Tobago, Individualmitteilung Nr. 845/1998 (UN-Doc. CCPR/C/67/D/845/1999), Zulässigkeitsentscheidung vom 31.12.1999, S. 483, 615.

${ }^{687}$ Vitzthum, in: Vitzthum/Proelß, Völkerrecht, S. 6 f. Rn 5 f.

${ }^{688}$ Ipsen, in: Ipsen, Völkerrecht, § 3 Rn $1 \mathrm{f}$.

${ }^{689}$ OVG Münster, Urteil vom 19.03.2019, Az. 4 A 1361/15, in: NJW 26/2019, S. 1898 (Leitsatz), Rn 584 nach juris.

${ }^{690}$ BVerfG, Urteil vom 25.11.2020, Az. 6 C 7/19, Rn 28 nach juris.

${ }^{691}$ BVerfG, Urteil vom 25.11.2020, Az. 6 C 7/19, Rn 23 f. nach juris.

${ }^{692}$ BVerfG, Urteil vom 25.11.2020, Az. 6 C 7/19, Rn 51 f., 75 f. nach juris.
} 
25 GG nicht von Deutschland verlangt werden könne, international als Weltstaatsanwaltschaft aufzutreten, und 2019 die Frage der Völkerrechtmäßigkeit ausländischer Drohneneinsätze fremder Staaten einer rein rechtlichen Überprüfung allerdings eröffnet. Hier zeigt sich auch eine vielsagende Parallele zwischen Art. 25 Satz 2 GG und dem ATCA. So sind beide Normen obergerichtlich in Deutschland und in den USA als individuelle Grundlagen anerkannt und Ansprüche bestätigt worden, höchstrichterlich scheitert die Durchsetzung bisher hingegen an außenpolitischen Gründen.

\section{Eine Frage der bisherigen Durchsetzbarkeit?}

Dem Völkerrecht, insbesondere den näher betrachteten allgemeinen Völkerrechtsregeln im Sinne des Art. 25 GG, fehlt es an Sanktionen mit präventiver Wirkung zugunsten der Effektivität gegenüber möglichen Rechtsverletzungen. Kann dieser also als Anspruchsgrundlage durch Einzelne herangezogen werden?

Das BVerfG und der BGH vertraten vor einigen Jahren noch die Auffassung bezüglich Ansprüchen des humanitären Völkerrechts, dass die Träger von Sekundärpflichten lediglich die Heimatstaaten der Opfer seien. Fremdenrechtliche Individualansprüche gab es demnach lediglich aufgrund innerstaatlicher Normen. ${ }^{693}$ Auch die Wirkung des völkerrechtlichen Mindeststandards wurde dadurch eingeschränkt, dass nur der entsprechende Staat auf völkerrechtlicher Ebene Individualrechte durchsetzen konnte. ${ }^{694}$ Das BVerfG führte 2004 aus: „Dieser sekundärrechtliche Schadensersatzanspruch besteht jedoch nur in dem Völkerrechtsverhältnis zwischen den betroffenen Personen auf Einhaltung der Verbote des humanitären Völkerrechts, der in dem Völkerrechtsverhältnis zwischen dem ein Territorium besetzenden Staat und der in diesem Gebiet lebenden Bevölkerung besteht. “695 Eine ebensolche vergleichbare Durchsetzbarkeit der allgemeinen Völkerrechtsregeln über Art. 25 GG mit einer stetigen Rechtspraxis oder überhaupt einer judikativen Ausgestaltung oder Definition gibt es nicht. Art. 25 GG konnte bisher nicht als prozessual durchsetzbare Anspruchsgrundlage zugunsten Einzelner überzeugen. Die Effektivität der allgemeinen Völkerrechts-

\footnotetext{
${ }^{693}$ Anzilotti, Lehrbuch des Völkerrechts, S. 98; De Vattel, Le droit des gens ou principes de la loi naturelle, 1959, § 71; Lillich, The Human Rights of Aliens, S. 8f.; Lauterpacht, International Law and Human Rights, S. 27.

${ }^{694}$ Farahat, Progressive Inklusion, S. 104.

${ }^{695}$ BVerfG 112, 1 (32 f.).
} 
regeln konnte innerstaatlich mit Art. 25 GG ebenso nicht vorangetrieben werden, da inhaltliche Ausgestaltungen durch die Rechtsprechung nur zögerlich vorgenommen wurden und in den meisten verhandelten Fällen auch keine inhaltliche Befassung mit der Materie nötig war, da eine individuelle Klage- oder Beschwerdebefugnis abgelehnt wurde.

Bei der Betrachtung der Stimmen des Schrifttums, welche Art. 25 Satz 2 GG als unmittelbare individuelle Anspruchsgrundlage befürworten und praktisch ohne dogmatische oder prozessuale Bedenken anwendbar sehen, sind jedoch starke Bedenken aufgekommen. Diese bezogen sich zum einen auf die künstliche Voraussetzung einer ,faktischen Betroffenheit“, zum anderen auf den Mangel an Präzision der allgemeinen Völkerrechtsregeln selbst, welche der Art. 25 GG in seiner Kürze lediglich eingliedert, ohne einen eigenen Anwendungsrahmen aufzustellen.

Für die Effektivität des Völkerrechts im innerstaatlichen Recht ist es besonders vor dem Hintergrund der oft unkonkret formulierten allgemeinen Völkerrechtsregeln unabdingbar, dass eine Anspruchsgrundlage zur praktischen Durchsetzung dem deutschen Bestimmtheitsgebot gem. Art. 103 Abs. 2 GG entspricht. Bereits am Beispiel des Völkerstrafrechts hinsichtlich völkerrechtlicher Individualpflichten (vgl. Kapitel § 4) hat sich gezeigt, dass Art. 25 GG hierzu nicht als Rechtsgrundlage oder Verbotsnorm herangezogen wird und werden kann. Die Voraussetzung für den Erfolg von Individualklagen ist, dass staatliche Instanzen die Anspruchsinhaberschaft von Einzelnen zunächst auf der Primärrechtsund zusätzlich auf der Sekundärrechtsebene anerkennen.

In der Rechtsprechung ist bereits früh festgehalten worden, dass das Rechtsmittel der Verfassungsbeschwerde nicht allein auf Art. 25 Satz 2 GG als Rechtsgrundlage gestützt werden kann. ${ }^{696}$ Vereinzelt wurde vorgetragen, dass die allgemeinen Regeln des Völkerrechts im Rahmen einer Verfassungsbeschwerde über Art. 2 Abs. 1 GG geltend gemacht werden können, da diese Teil der verfassungsmäßigen Ordnung seien.

Im Folgenden wird dieser Ansatz näher betrachtet und beurteilt, ob dieser Weg der Geltendmachung praktikabler ist als eine unmittelbare Berufung auf Art. 25 (Satz 2) GG. Sofern diese hinsichtlich des Schutzcharakters zugunsten Einzelner überzeugender und rechtssicherer ist, könnte und müsste zusammen mit den bisher gewonnenen Argumenten der Schluss gezogen werden, dass Art. 25 Satz 2 GG nicht nur grundlegend nicht unmittel-

${ }^{696}$ BVerfGE 4, 110 (111 f.); so auch Cremer, in: HdStR Bd. 11, § 235 Rn 33. 
bar als Individualrechtsgrundlage herangezogen wird, sondern bereits eine andere Anspruchsgrundlage besteht, auf die sich die Bewohner des Bundesgebietes bei Verstößen gegen völkerrechtliche Regeln berufen können.

\section{Keine eigenständige Rechtsgrundlage mit Art. 25 Satz 2 GG}

Dass allgemeine Regeln des Völkerrechts nicht die Grundlage einer Verfassungsbeschwerde sein können, ist sowohl von Schrifttum als auch Rechtsprechung anerkannt. ${ }^{697}$ Das bedeutet, dass Art. 25 GG nicht der unmittelbare Prüfungsmaßstab rechtlicher Überprüfungen sein kann. Erreicht wird dieser dadurch, dass durch die Wiedergabe materieller Rechtsgehalte der allgemeinen Völkerrechtsregeln in Grundrechten und grundrechtsgleichen Rechten die Subjektivierung über Art. 25 Satz 2 GG vorgenommen wird. ${ }^{698}$

Bislang wurde vertreten, dass die Vorschrift des Art. 25 GG weder eine mögliche unmittelbare Anwendbarkeit speziell hinsichtlich der Abrufbarkeit der Norm sei, noch die Frage des materiell-rechtlichen Inhalts als subjektives Recht regele. ${ }^{699}$ Lediglich die deutschen Gerichte seien gem. Art. 25 GG daran gehindert, innerstaatliches Recht nicht so auszulegen und anzuwenden, dass das durch die Norm eingegliederte Völkergewohnheitsrecht dadurch verletzt würde. ${ }^{700}$ Wenn also innerstaatliches Recht verletzt erscheint, weil Art. 25 GG nicht entsprechend beachtet und die innerstaatliche Norm nicht entsprechend ausgelegt und angewendet wurde, dann können Gerichte und Behörden dazu angehalten werden, sich entsprechend des Regelungsgehalts des Art. 25 GG zu verhalten. Dass Art. 25 GG selbst als Rechtsgrundlage dazu herangezogen werden könnte, ist damit wohl somit nicht gemeint. Die bereits vorgestellte Entscheidung des BVerwG aus 2016 beinhaltete eine sehr ausführliche und gründliche Bearbeitung der Entstehung des Art. 25 GG im Rahmen des Verfassungskonvents von Herrenchiemsee. Die Richter führten aus, dass die Entstehungsmaterialien des Grundgesetzes keinen Hinweis darauf geben, dass den allgemeinen Grundsätzen des Völkerrechts eine weitergehende Bedeutung im innerstaatlichen Recht beigemessen

\footnotetext{
${ }^{697}$ Bspw. BVerfGE 6, 389 (440); Schorkopf, Staatsrecht der internationalen Beziehungen, § 3 Rn 56; Ruppert/Schorkopf/Henke, in: Burkiczak/Dollinger/Schorkopf, $\S 90$ BVerfGG, Rn 94; Bethge, in: Maunz/Schmidt-Bleibtreu/Klein/Bethge, § 90 BVerfGG, Rn 225.

${ }^{698}$ Schorkopf, Staatsrecht der internationalen Beziehungen, § 3 Rn 57.

${ }^{699}$ Geiger, Grundgesetz und Völkerrecht (4. Auflage 2009), S. 151, unverändert in der aktuellen 7. Auflage 2018 unter dem Titel ,Staatsrecht III: Bezüge des Grundgesetzes zum Völker- und Europarecht, S. $151 \mathrm{f}$.

${ }^{700}$ BVerfG, Nichtannahmebeschluss vom 08.06.2010, Az. 2 BvR 432/07, 2 BvR 507/08, in: NJW 2011, S. 591-594 (Leitsatz nach Gründe), Rn 27 nach juris; Peters, Jenseits der Menschenrechte, S. 465; Ruppert/Schorkopf/Henke, in: Burkiczak/Dollinger/Schorkopf, § 90 BVerfGG, Rn 66.
} 
werden sollte als durch Art. 4 WRV. Insbesondere sei keinesfalls auf die Notwendigkeit einer individuellen Betroffenheit gem. Art. 19 Abs. 4 GG verzichtet worden. ${ }^{701}$

Hierbei handelt es sich jedoch anscheinend nicht um eine Verfahrensvoraussetzung im Rahmen eines Rechtsmittels auf Grundlage des Art. 25 (Satz 2) GG, sondern um die Beschränkung des Stützens individueller Rechtsmittel auf Art. 25 GG wegen Verstößen staatlichen Handelns gegen das allgemeine Völkerrecht. Das BVerwG führt selbst Entscheidungen der eigenen Rechtsprechung an, in denen sich Kläger zwar auf eine Verletzung der allgemeinen Völkerrechtsregeln im Sinne des Art. 25 GG berufen könnten. In diesen kommt Art. 25 Satz 2 GG jedoch nicht der Charakter einer Anspruchsgrundlage zu. Art. 25 GG berechtigt Soldaten zur Nichtbefolgung von Befehlen, deren Ausführung gegen die allgemeinen Völkerrechtsregeln verstößt. ${ }^{702}$ Die Gehorsamsverpflichtung eines Soldaten der Deutschen Bundeswehr ergibt sich aus $\S 11$ Abs. 1 Satz 1 und 2 Soldatengesetz. Der Soldat hat dabei diesen Befehlen Folge zu leisten und diese vollständig, gewissenhaft und unverzüglich auszuführen. Die Verwaltungsrichter erklärten: „Entsprechend der Vorrangwirkung des Art. 25 Satz 2 GG kann [...] ein Befehl eines Vorgesetzten, der den 'allgemeinen Regeln des Völkerrechts' widerspricht, von Untergebenen keinen Gehorsam nach $§ 11$ Abs. 1 Satz 1 und 2 SG beanspruchen. Der Untergebene hat also [...] diese Regeln anstelle des ihm erteilten Befehls zu befolgen. Denn Art. 25 GG verdrängt insoweit die Rechtswirkungen des $§ 11$ Abs. 1 Satz 1 und 2 GG und verpflichtet den Untergebenen unmittelbar"“. ${ }^{703}$ Nach $\S 10$ Abs. 4 SG dürfen militärische Befehle nur unter Beachtung der Regeln des Völkerrechts, einschließlich des Völkervertragsrechts, erteilt werden. ${ }^{704}$ Der Anspruch auf eine freie Gewissensentscheidung ergibt sich hierbei nicht aus Art. 25 GG, gegen den bei Befolgung der Befehle verstoßen würde, sondern aus Art. 4 Abs. 1 GG. ${ }^{705}$

Auch sollen sich Anwohner von militärisch genutzten Flughäfen wegen Verstößen gegen das völkerrechtliche Gewaltverbot auf Art. 25 GG berufen können, sofern dieses unmittelbar Rechte für die Bewohner erzeugt, wenn sie individuelle Rechte im Verfahren zur Erteilung von Einflugerlaubnissen geltend machen wollen. Diese richtet sich nach §§ 1c Nr. 6 , 2 Abs. 7 Luftverkehrsgesetz oder über die Beschränkung der Erlaubnisfreiheit nach § 96a

\footnotetext{
${ }^{701}$ BVerwGE 154, 328 (343 f.).

${ }^{702}$ BVerwGE 127, 302 (316 f.); ebenso auch Deiseroth, in: Das Recht in guter Verfassung?, S. 25 (38 f.).

${ }^{703}$ BVerwGE 127, 302 (316); vgl. dazu auch Jescheck/Weigend, Lehrbuch des Strafrechts, § 35 II. 2b), S. 393.

${ }^{704}$ BVerwGE 127, 302 (316).

${ }^{705}$ Vertieft zur Gewissensfreiheit im Rahmen militärischer Rangverhältnisse, vgl. Morlok, in: Dreier, Art. 4 GG, Rn 174 f.
} 
Abs. 1 Satz 1 Luftverkehrszusatzordnung ${ }^{706}$. Die Richter machten deutlich, dass Art. 25 GG kein Prüfungsrecht für Genehmigungs- und Planfeststellungsbehörden hinsichtlich der Vereinbarkeit der Luftraumnutzung mit allgemeinen Völkerrechtsregeln gebiete. Allgemein regele Art. 25 GG nicht, welche Behörden in welchen Verfahren zu prüfen hat, ob Handlungen nichtdeutscher Stellen, an denen verschiedene deutsche Stellen mitwirken, allgemeine Völkerrechtsregeln verletzen oder nicht. ${ }^{707}$ Stattdessen müssten Zuständigkeitsund Verfahrensvorschriften eine Mitwirkung deutscher Behörden an völkerrechtswidrigen Handlungen verhindern können. Die luftverkehrsrechtlichen Vorschriften erfüllen dieses Finalitätserfordernis. ${ }^{708}$ Diese sind hier also die entsprechenden Rechtsgrundlagen. 2016 bekräftigte das BVerwG weiter, dass das Schrifttum berechtigterweise auf die geringe Regelungsdichte und die inhaltliche Unschärfe des Art. 25 Satz 2 GG hinweist. Diese genügen nicht den praktischen Anforderungen der innerstaatlichen Anwendbarkeit einer präzisen Rechtsgrundlage. ${ }^{709}$ Sollten Einzelne auch unabhängig einer erforderlichen unmittelbaren Betroffenheit über Art. 25 Satz 2 GG erzeugte Rechte verwirklichen können, wäre dies durch den Gesetzgeber erst durch Gesetz festzulegen. ${ }^{710}$

Auch der BFH lehnte einen möglichen Rechtsanspruch aus Art. 25 GG vor den deutschen Steuergerichten bereits früh ab. Die Richter stellten klar, dass der Grundsatz ,pacta sunt servanda“ als allgemeine Völkerrechtsregel höchstens durch Einzelne über die verwaltungsrechtliche Leistungsklage geltend gemacht werden könnte. Diese Verfahren könnten jedoch nur zum Inhalt haben, die BRD zur Einhaltung ihrer vertraglichen Verpflichtungen einzuhalten. ${ }^{711}$

\footnotetext{
${ }^{706}$ In seiner Neubekanntmachung vom 10.05.2007 (BGB1. I S. 698), zuletzt geändert durch Art. 2 des Gesetzes vom 20.07.2017 (BGB1. I S. 2808, 2833).

${ }^{707}$ BVerwGE 131, 316 (340 f.).

${ }^{708}$ BVerwGE 131, 316 (341).

${ }^{709}$ BVerwGE 154, 328 (348); mit Verweis auf Rojahn, in: v. Münch/Kunig, Art. 25 GG, Rn 51.

${ }^{710}$ BVerwGE 154, 328 (348).

${ }^{711}$ BFHE 73, 399 (411 f.).

Der Grundsatz Pacta Sunt Servanda steht für die Pflicht, öffentliche und private Verträge einzuhalten, und stellt den wichtigsten Grundsatz des Vertragsrechts dar. Näheres dazu in Weller, Die Vertragstreue: Vertragsbindung - Naturalerfüllungsgrundsatz - Leistungstreue.
} 


\section{Art. 25 Satz 2 GG als mittelbare Anspruchsgrundlage?}

Im Jahr 2013 hatte das BVerfG abschließend über den Varvarin-Fall zu entscheiden. Die Beschwerdeführer begehrten über Art. 2 Abs. 1 in Verbindung mit 25 GG einen Schadensersatz- und Entschädigungsanspruch geltend zu machen. Die Richter stellten jedoch fest, dass mittels des Rechtsbehelfs der Verfassungsbeschwerde nur gerügt werden könne, dass zivilgerichtliche Urteile nicht zur verfassungsmäßigen Ordnung im Sinne des Art. 2 Abs. 1 GG gehörten, sofern sie sich nach Art. 25 GG als innerstaatliches Recht geltende völkergewohnheitsrechtliche Regeln hinwegsetzen. ${ }^{712}$ Allerdings gebe es noch keine allgemeine Völkerrechtsregel, nach der Einzelne einen Anspruch auf Schadensersatz aufgrund humanitärer Völkerrechtsverletzungen ausüben können. Diese stünden nach wie vor nur den entsprechenden Heimatstaaten zu. ${ }^{713}$

Die Schadensersatz- und Entschädigungsbegehren einzelner Personen sind im Allgemeinen überwiegend mit dem Verweis auf die Anspruchsinhaberschaft des Heimatstaates abgewiesen worden. Die Konsequenz daraus erscheint logisch, dass es überhaupt keine innerstaatliche Rechtsgrundlage zur Geltendmachung allgemeiner Völkerrechtsregeln gibt.

Dennoch hat es, wenngleich deren Zahl bis heute gering bleibt, auch erfolgreiche Klagen gegen Verstöße gegen allgemeine Regeln des Völkerrechts im Sinne des Art. 25 GG gegeben. Im Folgenden wird ein Überblick über vereinzelte Entscheidungen deutscher Gerichte gegeben, vor denen Verstöße gegen das allgemeine Völkerrecht erfolgreich durch einzelne Personen geltend gemacht werden konnten.

\subsection{Art. 2 Abs. 1 und Abs. 2 GG in Verbindung mit Art. 25 (Satz. 2) GG}

Den größten praktischen Anwendungsbereich erfährt Art. 2 Abs. 1 GG, der als unmittelbare Anspruchsgrundlage durch Individuen herangezogen wird, da die durch Art. 25 GG implementierten allgemeinen Völkerrechtsregeln zur verfassungsgemäßen Ordnung gehören. ${ }^{714}$

\footnotetext{
${ }^{712}$ BVerfG, Nichtannahmebeschluss vom 13.08.2013, Az. 2 BvR 2660/06, 2 BvR 487/07, in: EuGRZ 69/2013, S. 563-570 (Leitsatz und Gründe), Rn 22 f., 40 f. nach juris; mit Verweis auf BVerfGE 31, 145 (177); 66, 39 (64); BVerfGK 13, 246 (252).

${ }^{713}$ BVerfG, Nichtannahmebeschluss vom 13.08.2013, Az. 2 BvR 2660/06, 2 BvR 487/07, in: EuGRZ 69/2013, S. 563-570 (Leitsatz und Gründe), Rn 13, 41 nach juris.

${ }^{714}$ So etwa BVerfGE 141, 1 (17 f.);143, 101 (135), mit Verweis auf BVerwGE 6, 309 (363); 23, 288 (300); 31, 145 (177); 112, 1 (21 f.).
} 
Literarische Kommentierungen unterstützen die Stützung individueller Verfassungsbeschwerden auf Art. 2 Abs. 1 GG in Verbindung mit Art. 25 GG und berufen sich auf die Rechtsprechung des BVerfG im Alteigentümer-Fall. Das Urteil kann durch die häufig erfolgte Bezugnahme auf die Subjektivierung allgemeiner Völkerrechtsregeln in Literatur und Praxis als eine Art Leitentscheidung angesehen werden.

Als Begründung dieser Auffassung wird auf den Wortlaut der Norm verwiesen, und dass Satz 2 des Art. 25 GG die Wertung der Verfassung verdeutlichen soll, die Beachtung der allgemeinen Völkerrechtsregeln vor dem BVerfG einfordern zu können. ${ }^{715}$ Die Formulierung „Beachtung“ ist auf die vorgenannte Beachtungspflicht deutscher Behörden und Gerichte bezogen. Sie beinhaltet und bezweckt keinen Rechtsanspruch Einzelner auf Grundlage des Art. 25 GG. Die Anspruchsgrundlage des Art. 2 Abs. 1 GG wird, wenn auch ohne weitere inhaltliche Konkretisierungen, allerdings auch ohne Beschränkungen übergreifend für den Art. 25 GG angeführt. Dies hätte zur Folge, dass jede individualbezogene allgemeine Völkerrechtsregel auf Grundlage der deutschen Grundrechte in Verbindung mit Art. 25 GG geltend gemacht werden könnte.

Verstöße gegen den völkerrechtlichen Mindeststandard sind dann über Art. 2 Abs. 1 GG oder ein spezielleres Grundrecht zu rügen. Dies gilt auch für Verstöße der deutschen öffentlichen Gewalt gegen ausschließlich staatengerichtete allgemeine Völkerrechtsregeln. ${ }^{716}$ Getragen wird diese Auffassung durch die praktische Bestätigung der Rechtsprechung. ${ }^{717}$ Die praktischen Folgen sind durch die Rechtsprechung bereits dargelegt worden. Die gegen eine allgemeine Regel des Völkerrechts verstoßenden Gesetze sind so nicht grundsätzlich nichtig, wohl aber nicht im Stande, das entsprechende Grundrecht einzuschränken. ${ }^{718}$ Sie gehören also beispielsweise nicht zur verfassungsmäßigen Ordnung im Sinne des Art. 2 Abs. 1 GG. ${ }^{719}$ Die kommentierende Literatur nimmt ohne Festsetzung eines Rahmens für Anwendungsfälle an, dass über Art. 100 Abs. 2 GG hinaus Art. 2 Abs. 1 GG als umfassende

\footnotetext{
${ }^{715}$ Cremer, in: HdStR Bd. 11, §. 235 Rn 33; Hillgruber, in: Schmidt-Bleibtreu/Hofmann/Henneke, Art. 25 GG, Rn 23 f.; Koenig/König, in: v. Mangoldt/Klein/Starck, Art. 25 GG, Rn 76; Rojahn, in: v. Münch/Kunig, Art. 25 GG, Rn 37, 55; Herdegen, in: Maunz/Dürig, Art. 25 GG, Rn 97; Streinz, in: Sachs, Art. 25 GG, Rn 94 f., 96; Tomuschat, in: Kahl/Waldhoff/Walter, Bonner Kommentar zum Grundgesetz, Art. 25 GG, Rn 133.

${ }^{716}$ Steinberger, in: HdStR Bd. 7, § 173 Rn $72 \mathrm{f}$.

${ }^{717}$ Hinsichtlich der Beachtung des völkerrechtlichen Mindeststandards bei Auslieferungsverfahren vgl. BVerfGE 59, 280 (283); 63, 332 (337 f.); 71, 1 (16, 18); hinsichtlich Einlieferungsersuchen vgl. BVerfGE 57, 9 (23 f.).

${ }^{718}$ BVerfGE 23, 288 (300); 31, 145 (177).

${ }^{719}$ BVerfGE 56, 254 (265); BGHSt 7, 394 (402); hinsichtlich anderer Einzelakte, die auf völkerrechtskonforme Gesetze gestützt werden und gegen allgemeine Regeln verstoßen, so dass sie nicht durch die gesetzliche Eingriffsgrundlage gedeckt werden vgl. BVerfG, Beschluss vom 11.10.1985, Az. 2 BvR 336/85, in: NJW 22/1986, S. 1425-1427 (Leitsatz 1 und Gründe), Rn 1 f., 5 nach juris.
} 
Rechtsgrundlage heranzuziehen sei, wenn eine den Einzelnen belastenden Entscheidung auf einer den allgemeinen Regeln des Völkerrechts zuwiderlaufende Norm staatlichen Rechts oder der mit den allgemeinen Regeln unvereinbaren Auslegung und Anwendung dieser Norm beruht. ${ }^{720}$ Die Betonung der Theorie, dass Art. 25 GG praktisch korrekt ausgelegt und innerstaatliches Recht entsprechend angewendet werden müssten, fand ihre tatsächliche praktische Bestätigung bisher überwiegend hinsichtlich des völkerrechtlichen Mindeststandards und Fremdenrechts. Auch hinsichtlich der verfassungsimmanenten Schranken von Grundrechten, die nicht gesetzlich einschränkbar sind, ist eine Pflicht zur Berücksichtigung des Art. 25 GG nicht ausgeschlossen. Nach wie vor sind die allgemeinen Regeln im Rahmen der Abwägung von überragenden Gemeinschaftsgütern mit einzubeziehen. ${ }^{721}$ Das deutsche Grundgesetz nimmt somit eine besondere Stellung unter den Staatsverfassungen ein, indem es durch Art. 25 GG dem anerkannten normativen Grundund Menschenrechtsstandard ein besonderes Maß der Beachtung allgemeinen Völkerrechts gewährleistet, einschließlich des fremden- und menschenrechtlichen Mindeststandards. Besonders hinsichtlich der letztgenannten Standards hat die Rechtsprechung früh bestätigend entschieden. ${ }^{722}$

Es wird als besonderer Ausfluss der Völkerrechtsfreundlichkeit gesehen, dass Verstöße gegen die allgemeinen Regeln des Völkerrechts über die auf Art. 2 Abs. 1 GG in Verbindung mit Art. 25 GG gestützte Verfassungsbeschwerde gerügt werden können. Eine Verfassungsbeschwerde gegen Verletzungen der Handlungsfreiheit gem. Art. 2 Abs. 1 GG diene der Durchsetzung des Völkerrechts im innerstaatlichen Rechtssystem. ${ }^{723}$ An dieser Stelle ist besonders darauf hinzuweisen, dass die von vielen Stimmen des Schrifttums abgeleitete

${ }^{720}$ Vgl. Koenig/König, in: v. Mangoldt/Klein/Starck, Art. 25 GG, Rn 75, 76; so auch Hillgruber, in: SchmidtBleibtreu/Hofmann/Henneke, Art. 25 GG, Rn 23 f.; Rojahn, in: v. Münch/Kunig; Art. 25 GG, Rn 37, 55; Cremer, in: HdStR Bd. 11, § 235, Rn 33; Streinz, in: Sachs, Art. 25 GG, Rn 95; Tomuschat, in: Kahl/Waldhoff/Walter, Bonner Kommentar zum Grundgesetz, Art. 25 GG, Rn 133; nur bzgl. Art. 100 Abs. 2 GG Wollenschläger, in: Dreier, Art. 25 GG, Rn 53, 54.

${ }^{721}$ BVerfGE 71, 1 (78); 80, 81 (92 f.); 80, 315 (338 f.); Ein fremder Staatsangehöriger, der mit einer deutschen Staatsangehörigen verheiratet ist, wegen geheimdienstlicher Agententätigkeiten gegen die Bundesrepublik Deutschland oder unbefugten Vertriebs von Betäubungsmitteln rechtskräftig verurteilt wird und in sein Heimatland abgeschoben werden soll, führt dies im Einzelfall nicht zur Verfassungswidrigkeit der Abschiebungsanordnung. Wird zufolge der Rassengesetzgebung des Heimatlandes weder seine Ehe anerkannt noch ein eheliches Zusammenleben gestattet, sind die überragenden Gemeinschaftsgüter mit dem deutschen Grundrecht aus Art. 6 Abs. 1 GG abzuwägen.

${ }^{722}$ Bzgl. des menschenrechtlichen Standards vgl. bspw. BVerfGE 31, 58 (69); 57, 9 (25), 59, 280 (283 f.); 60 , 253 (303 f.); 63, 332 (337 f.); 75, 1 (19 f.).; bzgl. des Fremdenrechts, vgl. u.a. BVerfGE 9, 174 (181); 23, 288 (304); 30, 409 (413); 60, 253 (303 f.); BVerwGE 22, 66 (69); 56, 254 (258);

${ }^{723}$ Vgl. Tomuschat: in: HdStR Bd. 7, § 172, Rn 18; auch Calliess, Staatsrecht III (2014), S. 109 Rn 42, unverändert in der Folgeauflage 2018, S. 111 Rn 42. 
Verpflichtung Deutschlands, aufgrund der aus Art. 25 GG hervorgehenden Völkerrechtsfreundlichkeit des Grundgesetzes einen Individualanspruch mit Art. 25 Satz 2 GG als Rechtsgrundlage begründen zu müssen, vom BVerfG nicht geteilt wird. In seinem Konkordats-Urteil äußerte das Gericht, dass weder zugunsten von Landesverträgen noch zugunsten von Bundesverträgen eine Bindung des Gesetzgebers an völkerrechtliche Verpflichtungen konstruiert werden könne. Die Völkerrechtsfreundlichkeit habe lediglich die Funktion eines obiter dictum, dessen Erwähnung kein Einfluss auf die Beurteilung der verfassungsrechtlichen Lage zukomme. ${ }^{724}$ Hinsichtlich der völkerrechtsfreundlichen Interpretation einfachen Gesetzesrechts bestimmte das Gericht auch, dass der Vorrangbefehl des Art. 25 GG eine Harmonisierung zwischen innerstaatlichem und Völkerrecht erreiche, um denkbare Haftungen der BRD zu vermeiden. ${ }^{725}$ Das BVerfG schränkte den Schutzbereich des Art. 2 Abs. 1 und Abs. 2 GG hinsichtlich der Anwendbarkeit der Norm als Anspruchsgrundlage für die Rüge von Verstößen gegen die allgemeinen Völkerrechtsregeln im Sinne des Art. 25 GG bisher nicht ein.

Nicht positiv entschieden, jedoch inhaltlich diskutiert wurden unter anderem auch eine Ablehnung der Aufenthaltserlaubnis als Verletzung der allgemeinen Handlungsfreiheit nach Art. 2 Abs. $1 \mathrm{GG}^{726}$, ebenso die Freiheit vor gesetzlosem und gesetzwidrigem Zwang ${ }^{727}$, und der Geltendmachung von Verstößen gegen den über Art. 25 GG innerstaatlich geltenden Grundsatz „pacta sunt servanda“728. Die Klagen und Beschwerden scheiterten bisher jedoch weniger am unzureichenden Schutzbereich der geltend gemachten Grundrechte, sondern an der fehlenden Existenz angeblicher verletzter allgemeiner Völkerrechtsregeln. $^{729}$

\footnotetext{
${ }^{724}$ BVerfGE 6, 309 (362 f.).

${ }^{725}$ BVerfGE 58, 1 (34), so dass Gerichte darauf Acht nehmen müssen, „dass Verletzungen des Völkerrechts, die in der fehlerhaften Anwendung oder Nichtbeachtung völkerrechtlicher Normen durch deutsche Gerichte liegen und eine völkerrechtliche Verantwortlichkeit der Bundesrepublik Deutschland begründen könnten, nach Möglichkeit verhindert oder beseitigt werden“".

${ }^{726}$ So etwa BVerfGE 97, 49 (53, 58); BVerfG, Dreierausschussbeschluss vom 22.08.1983, Az. 2 BvR 1193/83, in: NVwZ 3/1984, S. 165-166 (Leitsatz und Gründe), Rn 9 f. nach juris; BVerfG, Nichtannahmebeschluss vom 26.09.2006, Az. 2 BvR 2048/04, Rn 6 f. nach juris.

${ }^{727}$ So etwa BVerfG, Nichtannahmebeschluss vom 08.03.2017, Az. 2 BvR 483/17, in: NJW 16/2017, S. 1166 (Leitsatz und Gründe), Rn 4 nach juris, mit Verweis auf BVerwGE 28, 268 (271); 54, 211 (221); vgl. auch BVerfGE 112, 1 (21 f.).

${ }^{728}$ So etwa BVerfG, Nichtannahmebeschluss vom 15.03.2018, Az. 2 BvR 1371/13, in: NJW 32/2018, S. 2312 2316 (Leitsatz und Gründe), Rn 38 nach juris; BVerfG, Nichtannahmebeschluss vom 24.10.2000, Az. 1 BvR 1643/95 = RdL 1/2001, S. 19-20 (Leitsatz und Gründe), Rn 9 nach juris.

${ }^{729}$ So etwa Vgl. BVerfGE 73, 339 (375); 111, 307 (322); 123, 267 (398); 126, 286 (302); 134, 366 (384); 141, 1 (25); dazu, dass keine allgemeinen Völkerrechtsregeln zur innerstaatlichen Erfüllung von Vertragspflichten existieren; BVerfGE 92, 277 f.; 109, 38 (58); BGHZ 212, 173 (178 f.).
} 
Urteile betreffend Verstöße gegen den völkerrechtlichen Mindeststandard im Sinne des Art. 25 GG bleiben bisher die einzigen positiven Entscheidungen. Anspruchsgrundlage ist dazu die allgemeine Handlungsfreiheit gem. Art. 2 Abs. 1 GG oder die Schutzpflicht gem. Art. 2 Abs. 2 GG. ${ }^{730}$ So wurde beispielsweise eine Verfassungsbeschwerde 2016 zur Entscheidung angenommen und als begründet angesehen. Die Nichtbeachtung des völkerrechtlichen Mindeststandards im Rahmen der Beurteilung der Zulässigkeit seiner Auslieferung an die USA verletzte den Beschwerdeführer in seinen Grundrechten aus Art. 2 Abs. 2 Satz 2 GG, jedenfalls aber aus Art. 2 Abs. 1 in Verbindung mit Art. 25 GG. ${ }^{731}$

Der Schutzzweck des Art. 2 Abs. 2 GG umfasst nicht alle völkerrechtlichen Waffeneinsätze, so dass neben Art. 2 Abs. 1 GG die Reichweite der verfassungsrechtlichen Schutzpflicht begrenzt ist. So schützt Art. 2 Abs. 2 Satz 1 GG nicht davor, wenn der völkerrechtmäßige Waffeneinsatz zur Verteidigung gegen den militärischen Gegen Rückwirkungen auf die zivile Bevölkerung bedeutet. ${ }^{732}$ Mit seinem Berufungsurteil Anfang 2019 hat das OVG Münster eine Klage gegen Verstöße gegen Art. 2 Abs. 2 in Verbindung mit Art. 25 GG als teilweise begründet gesehen. Auch wenn ein Abwehr- und Unterlassungsanspruch der Kläger aus Art. 2 Abs. 2 GG abgelehnt wird, so können diese aus dem Grundrecht auf Leben und körperliche Unversehrtheit einen Anspruch geltend machen. Die BRD habe sich mit geeigneten Maßnahmen zu vergewissern, dass die US-Airbase Ramstein durch die USA nicht für völkerrechtswidrige bewaffnete Drohneneinsätze im Jemen genutzt werde, und dass die BRD gegenüber den USA auf die Einhaltung des Völkerrechts aktiv hinwirken müsse. ${ }^{733}$ Der Schutzbereich des Art. 2 Abs. 2 GG umfasse auch den Schutz des Lebens und der körperlichen Unversehrtheit Einzelner gegen Verstöße gegen völkerrechtliche Regeln, sofern diese völkerrechtlichen Vorgaben einen engen Bezug zu den Schutzgütern des Art. 2 Abs. 2 GG Satz 1 GG haben. ${ }^{734}$

\footnotetext{
${ }^{730}$ Der menschenrechtliche Mindeststandard wird zusätzlich i. V. m. Art. 1 Abs. 1 und 2 GG unter Art. 2 Abs. 1 und Abs. 2 GG gefasst, vgl. dazu BVerfG, Einstweilige Anordnung vom 24.08.2000, Az. 2 BvR 1430/00, in: NJW 42/2001, S. 3110 (Leitsatz und Gründe), Rn 10 f.; auch BVerfGE 112, 1 (21 f.); 23, 288 (300, 305, 307); BVerfG, Dreierausschlussbeschluss vom 22.08.1983, Az. 2 BvR 1193/83, in: NVwZ 3/1984, S. 165-166 (Leitsatz und Gründe), Rn 9 f. nach juris.

${ }^{731}$ BVerfG, Kammerbeschluss vom 24.03.2016, Az. 2 BvR 175/16, in: StV 4/2017, S. 230 f.; vgl. positiv entschieden auch BVerfGK 3, $159 \mathrm{f}$.

${ }^{732}$ BVerfGE 77, 170 (221); vgl. dazu auch Cremer, in: HdStR Bd. 11, § 235 Rn 52.

${ }^{733}$ OVG Münster, Urteil vom 19.03.2019, Az. 4 A 1361/15, in: NJW 26/2019, S. 1998 (Leitsatz), Rn 133, 134 nach juris; das Verschulden Deutschlands und damit einen Anspruch aus Art. 2 Abs. 2 GG noch ablehnend, BVerfG, Nichtannahmebeschluss vom 15.03.2018, Az. 2 BvR 1371/13, in: NJW 32/2018, S. 2312-2316 (Leitsatz und Gründe), Rn $28 \mathrm{f}$. nach juris.

${ }^{734}$ OVG Münster, Urteil vom 19.03.2019, Az. 4 A 1361/15, in: NJW 26/2019, S. 1998 (Leitsatz), Rn 183 nach juris.
} 
Danach ergebe sich die Schutzpflicht der deutschen Staatsgewalt auch gegenüber Ausländern, sollten deren grundrechtliche Schutzgüter durch andere Staaten als durch Deutschland völkerrechtswidrig beeinträchtigt werden. Die hinreichende Wahrscheinlichkeit dieser Beeinträchtigung reicht bereits aus. Im konkreten Fall verstießen die Drohneneinsätze in der jemenitischen Provinz Hadramaut über die US-Airbase Ramstein gegen das humanitäre Völkerrecht zum Schutz von Zivilpersonen in bewaffneten Konflikten und gegen das Menschenrecht auf Leben. ${ }^{735}$ Das Gericht stellte fest, dass die räumliche und sachliche Reichweite der Grundrechtsbindung der deutschen Staatsgewalt die Regelungen des Grundgesetzes hinsichtlich des Völkerrechts und die Rolle Deutschlands in der internationalen Staatengemeinschaft berücksichtigt werden müssen. Auch zeigte sich bei beim Schutzanspruch des Einzelnen aus Art. 2 Abs. 2 GG die Bedeutung der allgemeinen Völkerrechtsregeln und die Rechtsprechung des BVerfG hinsichtlich subjektiver Rechtsansprüche. Unabhängig davon, ob bereits kraft Völkerrechts subjektive Rechtsansprüche wegen VölkerrechtsverstöBen bestehen, sollen Einzelansprüche auf nationaler Ebene geboten sein können. ${ }^{736}$

Das BVerwG hat in der Revision 2020 jedoch anders entschieden und eine solche Schutzpflicht gerade verneint sowie von einer Zurückweisung an das OVG Münster abgesehen. ${ }^{737}$ So erstrecke sich der Geltungsbereich staatlicher Schutzpflichten zwar auch auf den Schutz ausländischer Staatsangehöriger im Ausland. Allerdings ist dieser nach Ansicht des BVerwG abzulehnen, wenn eine Völkerrechtsverletzung lediglich möglich ist und keine zukünftigen Verletzungen konkret zu erwarten sind. ${ }^{738}$ So sei - hier hatte das OVG Münster gerade anders entschieden - doch eine politische Entscheidung erforderlich, wenn es um den engen Bezug der Ausübung der deutschen Hoheitsgewalt zur staatlichen Schutzpflicht gehe. ${ }^{739}$ Von diesen Maßstäben ausgehend hat das Bundesverwaltungsgericht im Ergebnis jedoch offengelassen, ob eine grundrechtliche Schutzpflicht der Beklagten gegenüber den Klägern überhaupt entstanden ist. Insoweit bestätigt sich die eingangs aufgeworfene These, dass die Erfolgsaussichten der Geltendmachung eines Anspruchs aus Art. 25 Satz 2 GG aufgrund hoher Voraussetzungen geringe Aussichten auf Erfolg haben.

Später erklärte das BVerfG, die grundrechtliche Schutzpflicht bezwecke die Bewahrung des Grundrechtsinhabers vor verletzenden staatlichen Einwirkungen nicht grundrechtlich

\footnotetext{
${ }^{735}$ OVG Münster, Urteil vom 19.03.2019, Az. 4 A 1361/15, in: NJW 26/2019, S. 1998 (Leitsatz), Rn 183 nach juris.

${ }^{736}$ OVG Münster, Urteil vom 19.03.2019, Az. 4 A 1361/15, in: NJW 26/2019, S. 1998 (Leitsatz), Rn 198 nach juris; BVerfGE 112, 1 (22).

${ }^{737}$ BVerfG, Urteil vom 25.11.2020, Az. 6 C 7/19, Rn 28 f. nach juris.

${ }^{738}$ BVerfG, Urteil vom 25.11.2020, Az. 6 C 7/19, Rn 51 f. nach juris.

${ }^{739}$ BVerfG, Urteil vom 25.11.2020, Az. 6 C 7/19, Rn 46 nach juris.
} 
gebundener Dritter. Diese Schutzpflicht bestehe daher, wenn die Rechtspositionen deutscher Staatsbürger, die sich im Ausland aufhalten, beeinträchtigt wurden oder durch Akte fremder Hoheitsgewalt gegenüber Deutschland oder seinen Staatsbürgern betroffen sind. Diese Fallgruppen sollen jedoch nicht abschließend sein. Vielmehr komme es für die Anwendbarkeit der Grundrechte auf ausländische Sachverhalte darauf an, dass ein enger Bezug zum deutschen Staat besteht. Dieser kann insbesondere dadurch entstehen, dass es sich um deutsche Staatsangehörige handelt oder sich diese im Inland aufhalten, aber auch, wenn die Maßnahmen hoheitlicher Gewalt Ausländer im Ausland betreffen. ${ }^{740}$

Die bereits vorgestellte Verfassungsrechtsprechung zur Völkerrechtsfreundlichkeit des Grundgesetzes und der konstitutiven Wirkung des Art. 25 Satz 2 GG hat einen hohen Einfluss auf das Urteil der Berufungsrichter und unterstreicht den abgeleiteten etablierten Rechtsstandard $^{741}$. Weiter schreibt das Gericht in seiner Urteilsbegründung wörtlich, dass „aufbauend“ auf der Rechtsprechung des BVerfG - für eine Subjektivierung allgemeiner Völkerrechtsregeln nach Art. 25 GG benötige es eines engen Bezugs zu individuellen hochrangigen Rechtsgütern - der deutsche Staat nach Art. 2 Abs. 2 GG verpflichtet sei, im Ausland lebende Ausländer vor Schäden an ihrem Leben oder ihrer körperlichen Unversehrtheit zu schützen. ${ }^{742}$ Im Lichte der praktischen Anwendung des Art. 2 Abs. 2 GG müsse die Schutzpflicht Deutschlands umso ernster genommen werden, je höher die fraglichen Rechtsgüter des Grundgesetzes anzusetzen sind. Über eine Verletzung des völkergewohnheitsrechtlichen Gewaltverbots hatte das OVG Münster nicht zu entscheiden, da die USDrohneneinsätze im Jemen mit der Zustimmung der jemenitischen Regierung stattfinden. Es erwähnte aber dennoch die Lage der diversen höchstrichterlichen Rechtsprechungen. ${ }^{743}$ Im konkreten Fall bejahten die Richter diesen Bezug für das Verbot willkürlicher Tötungen, das gem. Art. 6 Abs. 1 Satz 3 des Internationalen Pakts über bürgerliche und politische Rechte $^{744}$ vom 19. Dezember 1966 als Völkervertragsrecht für die BRD, die USA und im Jemen gilt. Auch fallen darunter das Verbot des gezielten und unterschiedslosen Angriffs

\footnotetext{
${ }^{740}$ BVerfGK 14, 192 (200); Jarass, in Jarass/Pieroth, Art. 1 GG, Rn 44, Ruffert, in: HdStR Bd. 10, § 206 Rn 34; Kahl, in: Kahl/Waldhoff/Walter, Bonner Kommentar zum Grundgesetz, Art. 1 Abs. 3, Rn 200, 210, $229 \mathrm{f}$.

${ }^{741}$ Siehe dazu in Kapitel $\S 7$.

${ }^{742}$ OVG Münster, Urteil vom 19.03.2019, Az. 4 A 1361/15, in: NJW 2019, S. 1998 (Leitsatz), Rn 210 nach juris.

${ }^{743}$ OVG Münster, Urteil vom 19.03.2019, Az. 4 A 1361/15, in: NJW 2019, S. 1998 (Leitsatz), Rn 216 f. nach juris, mit Verweis hinsichtlich Art. 25 Satz 2 GG und einem abgelehnten Individualbezug: BVerfG, Kammerbeschluss vom 15.03.2018, Az. 2 BvR 1371/13, in: NJW 32/2018, S. 2312-2316 (Leitsatz und Gründe), Rn 36 f. nach juris: offengelassen: BVerwGE 154, 328 (346 f.).

${ }^{744}$ IPBPR - BGB1. 1973 II S. 1553.
} 
auf Zivilpersonen und das Unterscheidungsgebot in bewaffneten Konflikten nach humanitärem Völkerrecht. ${ }^{745}$

Die Subjektivierung einer allgemeinen Regel des Völkerrechts im Sinne des Art. 25 GG fand im konkreten Fall somit statt und führte zu einer erfolgreichen Klage der unmittelbar Betroffenen. Einen Anspruch aus Art. 25 GG selbst stand dem Kläger jedoch nicht zu. Abgelehnt wurden diese jedoch nur aufgrund des ausländischen Aufenthalts, so dass er kein „Bewohner des Bundesgebietes“ ist. Hierzu zählen nur sich im Bundesgebiet aufhaltende natürliche Personen. ${ }^{746}$ Einen Anspruch über Art. 2 Abs. 2 Satz 1 GG hinaus konnten die Kläger jedoch auch nicht geltend machen, soweit zu den allgemeinen Völkerrechtsregeln im Sinne des Art. 25 Satz 1 GG, anders als zum humanitären Völkerrecht, insbesondere der völkergewohnheitsrechtliche Bestand der Menschenrechte gehörte. ${ }^{747}$ Rechtsschutzintensiver für die Kläger ist somit Art. 2 Abs. 2 GG, welcher in Verbindung mit Art. 25 GG auch vor der Verletzung völkerrechtlicher Regeln schützt, sofern diese in engem Bezug zum Schutzbereich des Art. 2 Abs. 2 GG stehen.

Auch ein Blick ins Schrifttum zu Art. 2 GG als Rechts- oder Anspruchsgrundlage hilft hierzu nicht weiter. Die Ausführungen der kommentierenden Lehre sind hinsichtlich Art. 2 Abs. 1 und 2 GG (in Verbindung mit Art. 25 GG) sehr oberflächlich. Es wird überwiegend darauf hingewiesen, dass die allgemeinen Regeln des Völkerrechts zur verfassungsmäßigen Ordnung gem. Art. 2 Abs. 1 GG gehören, und dass bei der Gestaltung und Anwendung des Bundesrechts den allgemeinen Völkerrechtsregeln Rechnung getragen werde. Danach können Bundesgesetze oder Gerichtsentscheidungen die durch Art. 2 Abs. 1 GG gewährten Rechts nicht wirksam beschränken, sollten diese mit allgemeinen Völkerrechtsregeln kollidieren. ${ }^{78}$ Verwiesen wird hinsichtlich der Rechtsgrundlage einer Verfassungsbeschwerde auf die Rechtsprechung des BVerfG, welches Art. 2 Abs. 1 in Verbindung mit Art. 25 GG nur für Verletzungen individualschützender Regeln anerkannt hat. ${ }^{749}$ Dabei ist es jedoch nicht die allgemeine Regel selbst, gegen die verstoßen würde, sondern die durch Art. 25

\footnotetext{
${ }^{745}$ OVG Münster, Urteil vom 19.03.2019, Az. 4 A 1361/15, in: NJW 26/2019, S. 1998 (Leitsatz), Rn 216 nach juris, hinsichtlich Art. 25 Satz 2 GG vgl. auch BVerwGE 154, 328 (346 f.); Herdegen, in: Maunz/Dürig, Art. 25 GG, Rn 91.

${ }^{746}$ BGHZ 169, 348 (356 f.); Jarass, in: Jarass/Pieroth, Art. 25 GG, Rn 16; Tomuschat, in: Kahl/Waldhoff/Walter, Bonner Kommentar zum Grundgesetz, Art. 25 GG, Rn 97 f.; Streinz, in: Sachs, Art. 25 GG, Rn 50; offengelassen jedoch von BVerfG, Nichtannahmebeschluss vom 13.08.2013, Az. 2 BvR 2660/06, 2 BvR 487/07, in: EuGRZ 6-9/2013, S. 563-570 (Leitsatz und Gründe), Rn 44 nach juris.

${ }^{747}$ OVG Münster, Urteil vom 19.03.2019, Az. 4 A 1361/15, in: NJW 26/2019, S. 1998 (Leitsatz), Rn 576 nach juris; BVerwGE 154, 328 (346 f.).

${ }^{748}$ Hillgruber, in: Clemens/Umbach, Art. 2 Abs. 1 GG, Rn 203; Dreier, in: Dreier, Art. 2 Abs. 1 GG, Rn 54.

${ }^{749}$ Bspw. BVerfGE 23, 288 (300); 31, 145 (177); 66, 39 (64); 92, 277 (317); 109, 38 (58).
} 
GG angeordnete verfassungsunmittelbare Transformations- und Vorrangregel des Art. 25 GG, dessen Missachtung einen Verstoß gegen Art. 2 Abs. 2 GG darstellt. ${ }^{750}$ Inhaltliche Besonderheiten oder umfängliche Ausführungen bezüglich Art. 2 Abs. 1 und Abs. 2 GG als Rechts- und Anspruchsgrundlage bleibt jedoch auch die Kommentierung schuldig.

4.2. Beispiele weiterer spezieller Verfassungsrechte und spezialgesetzliche Rechtsgrundlagen

Die deutschen Behörden und Gerichte sind gem. Art. 20 Abs. 3 in Verbindung mit Art. 25 GG dazu verpflichtet, deutsches Recht konform mit den allgemeinen Völkerrechtsregeln auszulegen. Diese zeigen somit auch dem Gesetzgeber Grenzen auf, die durch die Gerechte zu kontrollieren sind..$^{751}$

Art. 25 GG beeinflusst auch den Schutzgehalt anderer deutscher Grundrechte. Der bereits untersuchte Art. 2 Abs. 1 GG fungiert zur Geltendmachung von Verletzungen gegen allgemeine Völkerrechtsregeln als Auffangrechtsgrundlage. Sind speziellere Freiheitsrechte einschlägig, sind diese als Rechtsgrundlagen heranzuziehen. ${ }^{752}$

Schutzpflichten aus Art. 1 Abs. 1 und 2 GG werden beispielsweise bei der Missachtung allgemein anerkannter Menschenrechte im Rahmen strafrechtlicher Verurteilungen ausgelöst. ${ }^{753}$ Auch das Grundrecht des Fernmeldegeheimnisses nach Art. 10 Abs. 1 GG muss in Anwendung des sachlichen Schutzgehalts und der territorialen Reichweite mit einschlägigem Völkerrecht übereinstimmen. ${ }^{754}$

In Kapitel $\S 5$ wurden bereits Ansätze betreffend das völkerrechtliche Fremdenrecht bearbeitet, welches Art. 25 GG als lex specialis zu Art. 3 GG sah. Auch wenn diese Auffassung hier nicht geteilt wird, so entschied das BVerfG, dass staatliches Handeln gegen Art. 3 Abs.

\footnotetext{
${ }^{750}$ Hillgruber, in: Clemens/Umbach, Art. 2 Abs. 1 GG, Rn 204; vgl. auch die Kollision von Landes- mit Bundesrecht, welche aufgrund der verfassungsrechtlichen Vorrangregel des Art. 31 GG einen Verstoß des Landesrechts gegen objektives Verfassungsrecht begründet, vgl. ders., Art. 2 Abs. 1 GG, Rn 165.

${ }^{751}$ BVerfGE 23, 288 (300, 316); 75, 1 (18 f.); 109, 13 (26); 109, 38 (52); OVG Münster, Urteil vom 19.03.2019, Az. 4 A 1361/15, in: NJW 26/2019, S. 1998 (Leitsatz), Rn 202 nach juris.

${ }^{752} \mathrm{Vgl}$. Giegerich, in: Grabenwarter, Allgemeinheit der Grundrechte und Vielfalt der Gesellschaft, S. 109 f.; Hillgruber, in: Schmidt-Bleibtreu/Hofmann/Henneke, Art. 25 GG, Rn 23.

${ }^{753}$ BVerfGE 74, 358 (370); 101, 275 (289 f., 287 f., 290); 111, 308 (324, 317).

${ }^{754}$ BVerfGE 100, 313 (362 f.); Die Reichweite der Grundrechte ist aus dem Grundgesetz selbst zu ermitteln, dabei muss Art. 25 GG berücksichtigt werden. Art. 10 GG wurde aufgrund des hinreichenden Gebietskontakts als für die Aufzeichnungserfassung des Telekommunikationsverkehrs im Ausland mithilfe in Deutschland stehender Empfangsanlagen des BND einschlägig gehalten, vgl. Cremer, in: HdStR Bd. 11, $\S 235 \mathrm{Rn} 52$.
} 
1 GG verstoßen kann, wenn es nicht mit den allgemeinen Völkerrechtsregeln korreliert. ${ }^{755}$ Dabei kann das allgemeine Völkerrecht einen Differenzierungsgrund in Form des Gegenseitigkeitsprinzips ${ }^{756}$ darstellen oder mit dem Grundsatz der fremden Staatensouveränität den Bezug liefern für Rechtfertigungen des Staatsangehörigkeitsprinzips im deutschen Internationalen Privatrecht ${ }^{757}$.

Normiert ist auch die Grenze der Anwendung allgemeiner Völkerrechtsregeln in Art. 16 Abs. 2 Satz 1 GG. Kein Deutscher darf demnach ans Ausland ausgeliefert werden. Abweichend kann nur durch Gesetz eine Regelung für Auslieferungen an den IGH getroffen werden. Eine Grundlage für den IStGH besteht mit $\S 2$ IStGH-Gesetz. ${ }^{758}$ Die Formulierung „Internationaler Gerichtshof“ in Art. 16 Abs. 2 Satz 2 GG ist nicht auf den IStGH beschränkt und setzt ebenso wenig dessen Errichtung durch Vertrag mit deutscher Beteiligung voraus. ${ }^{759}$ Das Verbot der Auslieferung deutscher Staatsbürger an das Ausland gem. Art. 16 Abs. 2 Satz 1 GG begrenzt auch eine völkergewohnheitsrechtliche Verpflichtung zur Strafverfolgung. ${ }^{760}$ Art. 16 Abs. 2 Satz 1 GG bezweckt die Vermeidung der Staatenlosigkeit durch Verlust der deutschen Staatsbürgerschaft, und die Norm wird im Sinne der an völkerrechtlichen Bestrebungen gegen die Staatenlosigkeit anknüpfenden Zielsetzung der Verfasser des Grundgesetzes ausgelegt. ${ }^{761}$ Das BVerfG entwickelte deshalb aus Art. 16 Abs. 2 GG, unter Heranziehung der völkerrechtlichen Grundsätze, bezüglich der Rechtshilfe in Strafsachen die Verpflichtung für die das Gesetz ausführenden Stellen zu einer konkreten Abwägung der entgegenstehenden Rechtspositionen im Auslieferungsfall. ${ }^{762}$

Ebenso lässt sich am Beispiel der Bekämpfung der Piraterie feststellen, dass Art. 25 Satz 2 GG auch an dieser Stelle nicht unmittelbar als Rechtsgrundlage herangezogen werden kann, auch wenn es Stimmen gibt, die Art. 25 GG als Ermächtigungsgrundlage befürworten. ${ }^{763}$ Im Schrifttum wurde vereinzelt die Frage untersucht, ob die von Art. 87a Abs. 2 GG gefor-

\footnotetext{
${ }^{755}$ BVerfGE 112, 1 (22 f.).

${ }^{756}$ BVerfGE 30, 409 (413); 81, 208 (223 f.); 116, 96 (130).

${ }^{757}$ BVerfGE 116, 243 (265 f.), in welcher das Gericht die Staatsangehörigkeit als Differenzierungsgrund als verfassungswidrig beurteilt hat.

${ }^{758}$ Gesetz über die Zusammenarbeit mit dem Internationalen Strafgerichtshof vom 21.06.2002 (BGBl. 2002 I, S. 2144).

${ }^{759}$ Kokott, in: Sachs, Art. 16 GG, Rn 48; Talmon, in: JZ 1/2013, S. 12 (19); anders allerdings Kämmerer, in: Bonner Kommentar zum Grundgesetz, Art. 16 GG, Rn 138 f.

${ }^{760}$ Talmon, in: JZ 1/2013, S. 12 (19); anders aber beispielsweise Enache-Brown/Fried, in: McGill Law Journal 2/1998, S. 613 (631 f.).

${ }^{761}$ BVerfGE 116, 24 (47 f.), auch Cremer, in: HdStR Bd. 11, § 235, Rn 52.

${ }^{762}$ BVerfGE 113, 273 (303).

${ }^{763}$ Beispielsweise Wiefelspütz, in NZWehrR 2/2009, S. 133 (142); Kokott, in: Zypries (Hrsg.), Verfassung der Zukunft, 2009, S. 96 (106 f.).
} 
derte ,ausdrückliche Zulassung“ in Art. 25 GG gefunden wird. Der Vorteil der Eingliederung völkergewohnheitsrechtlicher Ermächtigungen deutscher Streitkräfte zur Pirateriebekämpfung gem. Art. 25 GG wäre die Verdrängung einfachen Bundesrechts wie $§ 6$ Satz 1 $\mathrm{BPolG}^{764}$. Danach hat die Bundespolizei ,auf See außerhalb des deutschen Küstenmeeres die Maßnahmen zu treffen, zu denen die BRD nach Völkerrecht befugt ist". § 6 BPolG nimmt jedoch keine Zuständigkeitszuweisung vor, sondern setzt die Zuständigkeit anderer Behörden oder der Streitkräfte voraus. Diese stehen dann jedoch auf anderen Rechtsgrundlagen. ${ }^{765}$ In $\S 1$ Abs. 3 Seeaufgabengesetz in Verbindung mit $\S 1$ Abs. 2 a der ZuständigkeitsbezeichnungsVO-See ist die Bekämpfung der Piraterie der Bundespolizei zugewiesen. ${ }^{766}$ Nach $\S 6$ Satz 2 BPolG ist die Bundespolizei nur dann nicht zuständig für Maßnahmen jenseits des Küstenmeeres, wenn diese ,ausschließlich“ durch Kriegsschiffe durchzuführen sind. Nach Art. 107 SRÜ ${ }^{767}$ sind auch andere im Staatsdienst stehende Schiffe, einschließlich Polizeischiffen, zur Bekämpfung der Seeräuberei heranzuziehen. Rechtlich zuständig ist also die Bundespolizei. ${ }^{768}$ Praktische Behandlung hat diese Problematik bereits erfahren als das BVerfG die Evakuierungsaktion der Bundeswehr aus Nafurah/Libyen ohne vorherige Zustimmung des Bundestages vorgenommen hat. ${ }^{769}$ Art. 87a Abs. 2 GG verlangt eine ausdrückliche, verfassungsrechtliche Ermächtigung. Da diese, wie bereits angemerkt, nicht existiert, wäre eine Beachtung des Art. 25 GG ähnlich der dogmatischen Funktion des Art. 24 Abs. 2 GG und die Einbeziehung einer völkergewohnheitsrechtlichen Erlaubnis denkbar gewesen. ${ }^{770}$ Art. 24 Abs. 2 GG begründet eine Ausnahme zu Art. 87a Abs. 2 GG. Die Problematik der fehlenden Rechtsgrundlage und ihre mögliche Ersetzung wurde jedoch vom BVerfG nicht entscheidend thematisiert. ${ }^{771}$

\footnotetext{
${ }^{764}$ Bundespolizeigesetz (BGB1. I S. 2978 f.), zuletzt geändert durch Art. 1 G vom 05.05.2017 (BGB1. I S. 1066).

${ }^{765}$ Vgl. Wagner, in: HFR 3/2010, S. 1 (15); Talmon, in: JZ 1/2013, S. 12 (17).

${ }^{766}$ Seeaufgabengesetz, in der Fassung der Bekanntmachung vom 17.06.2016 (BGB1. I S. 1489); zuletzt geändert durch Art. 3 des Gesetzes vom 30.06.2017 (BGBl. I S. 2190) und ZuständigkeitsbezeichnungsVOSee vom 04.03.1994 (BGBl. I S. 442); zuletzt geändert durch Art. 54 der VO vom 02.06.2016 (BGBl. I S. 1257).

${ }^{767}$ Seerechtsübereinkommen der Vereinten Nationen vom 10.12.1982, in Kraft getreten am 16.11.1994.

${ }^{768}$ Talmon, JZ 1/2013, S. 12 (17).

${ }^{769}$ Insgesamt 232 Mitarbeiter des deutschen Unternehmens Winterschall wurden 2011 durch die deutsche Bundeswehr unter Schutz bewaffneter Soldaten aus Libyen im Rahmen der Mission „Pegasus“ ausgeflogen. Auf diplomatischen Wege blieb ein vorheriger Antrag unbearbeitet, so dass aufgrund der Eilbedürftigkeit die damalige Bundesregierung die Einholung einer Zustimmung des Bundesrates zu der Militäroperation unterließ.

${ }^{770}$ So Schorkopf, Staatsrecht der internationalen Beziehungen, § 3 Rn 43.

${ }^{771}$ BVerfGE 140, 160 (188 f., 207).
} 
Das BVerfG hat bestimmt, dass sich die Exekutive nicht unter Berufung auf das Völkergewohnheitsrecht von der verfassungsrechtlichen Kompetenzordnung lösen darf. ${ }^{772}$ Deshalb kann auch nicht über Art. 25 GG eine völkergewohnheitsrechtliche Rechtsgrundlage zur Ermächtigung deutscher Streitkräfte zu Einsätzen nichtverteidigungsmäßiger Art herangezogen werden. ${ }^{773}$ Vermehrte Stimmen des Schrifttums erachten Art. 105 SRÜ hinsichtlich der kodifizierten Regel des Völkergewohnheitsrechts zur Festnahme von Piraten als inhaltlich unscharf. ${ }^{774}$ In solchen Fällen ist jedoch ebenso wenig Art. 25 Satz 2 GG selbst ans Rechtsgrundlage heranzuziehen, sondern die Norm verpflichtet den deutschen Gesetzgeber dazu, die durch Art. 25 Satz 2 GG erzeugten subjektiven Rechte und Pflichten durch eventuell noch zu schaffende Gesetze für die Gerichte und Exekutive inhaltlich anwendbar zu machen und anzupassen. ${ }^{775}$

\subsection{Zwischenergebnis}

Die Untersuchung hat gezeigt, dass es im deutschen Recht zahlreiche spezielle Rechtsgrundlagen gibt, mithilfe derer Einzelne ihre Rechte aus allgemeinen Völkerrechtsregeln im Sinne des Art. 25 GG geltend machen können. Art. 2 Abs. 1 GG kommt eine Art Auffangcharakter zu und bezweckt, ebenso Abs. 2 der Norm, die eigene Handlungsfreiheit und Unversehrtheit gegen beschränkende Hoheitsakte zu schützen. Praktische Bestätigung hat allein die Anwendung des Art. 2 Abs. 1 und Abs. 2 GG bisher gefunden. Der völkerrechtliche und menschenrechtliche Mindeststandard bildet jedoch nicht den exklusiven Anwendungsbereich des Art. 2 Abs. 1 GG. Andere Vorträge scheiterten an der Existenz der behaupteten allgemeinen Völkerrechtsregel und nicht am abschließenden Schutzbereich des Art. 2 Abs. 1 GG. Die Folge des Verstoßes eines Gesetzes gegen Art. 2 Abs. 1 oder Abs. 2 GG ist, dass dies nicht zur verfassungsmäßigen Ordnung gehört und demnach die Grund-

\footnotetext{
${ }^{772}$ BVerfGE 111, 307 (323).

${ }^{773}$ Vgl. die Rechte und Pflichten der Deutschen Marine bei der Bekämpfung der Piraterie, Antwort der Bundesregierung, BT-Drs. 16/9286, 23.05.2008, S. 4; vgl. auch Schmahl, in: AöR 1/2011, S. 44 (83); Schiedermair, in: AöR 2/2010, S. 185 (215).

${ }^{774}$ Talmon, in: JZ 1/2013, S. 12 (20); Schaller, in: Mair, Piraterie und maritime Sicherheit, S. 95; v. Arnauld, in: AVR 4/2009, S. 454 (473 f.).

${ }^{775}$ Vgl. Koenig/König, in: v. Mangoldt/Klein/Starck, Art. 25 GG, Rn 63; Talmon, in: JZ 1/2013, S. 12 (20); zu Art. 105 SRÜ als Rechtsgrundlage repräsentativ VG Köln, Urteil vom 11.11.2011, Az. 25 K 4280/09, in: JZ 7/2012, S. 366 f.
} 
rechte nicht einschränken kann. Sind jedoch speziellere Freiheitsrechte einschlägig, verdrängen diese den Art. 2 Abs. 1 GG. ${ }^{776}$ Positive Entscheidungen zugunsten Einzelner betreffend Verstöße gegen den völkerrechtlichen und menschenrechtlichen Mindeststandard bleiben bis heute die Ausnahme und der bisher überwiegende praktisch erfolgreiche Anwendungsfall der Art. 2 Abs. 1 und Abs. 2 GG. Die Rechtsgrundlagen sind dazu die allgemeine Handlungsfreiheit gem. Art. 2 Abs. 1 GG und die Schutzpflicht gem. Art. 2 Abs. 2 GG. Der Schutzbereich des Art. 2 GG umfasst demnach auch den Schutz der Handlungsfreiheit und des Lebens und der körperlichen Unversehrtheit Einzelner gegen Verstöße gegen völkerrechtliche Regeln, sofern diese einen engen Bezug zu den Schutzgütern des Art. 2 GG haben. Ein Abwehr- oder Unterlassungsanspruch aus Art. 2 Abs. 2 GG ist nicht anerkannt, jedoch können Einzelne aus dem Grundrecht auf Leben und körperliche Unversehrtheit einen Anspruch geltend machen, dass die BRD die nötigen Maßnahmen vornehmen muss, um Verstößen - auch von Drittstaaten ausgehend von deutschem Hoheitsgebiet - gegen Art. 2 Abs. 1 und Abs. 2 GG vorzubeugen. Bei einem Schutzanspruch Einzelner aus Art. 2 Abs. 1 und Abs. 2 GG wird der Bedeutung der allgemeinen Völkerrechtsregeln und der überwiegend übereinstimmenden Auffassung von Lehre und Rechtsprechung hinsichtlich subjektiver Rechtsansprüche Rechnung getragen.

\section{Das Normenverifikationsverfahren nach Art. 100 Abs. 2 GG}

Neben Art. 2 Abs. 1 GG wird immer wieder auf das Normenverifikationsverfahren nach Art. 100 Abs. 2 GG i. V. m. §§ 13 Nr. 12, 83, 84 BVerfGG als Rechtsbehelfsmöglichkeit für Einzelne verwiesen. ${ }^{777}$ Dieser Punkt der Bearbeitung zielt nicht auf eine modifizierte Sichtweise des Verifikationsverfahrens ab, welches in seinen verfahrensrechtlichen Voraussetzungen klar formuliert und nach seinem inhaltlichen Gehalt hinreichend abschließend ist. Ebenso sollen auch nicht die einzelnen Verfahrensvoraussetzungen analysiert werden. Allerdings ist deutlich zu unterstreichen, dass Art. 100 Abs. 2 GG auch zur heutigen Zeit immer noch die einzige direkt für die Klärung und Überprüfung der allgemeinen Völkerrechtsregeln vorgesehene Verfahrensart ist. Inwiefern das Verfahren dem Schutz Einzelner dienen kann, wird im Folgenden näher betrachtet.

\footnotetext{
${ }^{776} \mathrm{Vgl}$. auch BVerfGE 66, 39 (64); hierzu auch Giegerich, in: Grabenwarter, Allgemeinheit der Grundrechte und Vielfalt der Gesellschaft, 1994, S. 109 f.

${ }^{777}$ Matz-Lück, in: Burkiczak/Dollinger/Schorkopf, § 84 BVerfGG, Rn $1 \mathrm{f}$.
} 
Durch Art. 100 Abs. 2 GG wird den allgemeinen Völkerrechtsregeln eine Sonderrolle eingeräumt, obliegt es doch nur dem BVerfG, über deren Tragweite zu entscheiden. Die einzelnen Gerichte könnten unterschiedlich entscheiden, allerdings soll Art. 100 Abs. 2 GG dies gerade verhindern und eine Gewährleistungsfunktion zugunsten der allgemeinen Regeln bewirken. ${ }^{778}$ Die Sonderstellung der allgemeinen Völkerrechtsregeln kommt weiter zum Ausdruck, indem die Vorlage nach Art. 100 Abs. 2 GG auch dann zulässig sein soll, wenn das vorlegende Gericht lediglich Zweifel an der Tragweite der Völkerrechtsregel hat. Art. 25 GG fordert eine einheitliche Rechtsprechung auch über die Tragweite der allgemeinen Völkerrechtsregeln. ${ }^{779}$

Das BVerfG hat im Rahmen des Verifikationsverfahrens immer wieder zur Existenz von allgemeinen Völkerrechtsnormen Stellung bezogen und damit gezeigt, dass das Völkerrecht in der nationalen Rechtspraxis von Bedeutung ist. ${ }^{780}$ Praktisch bedeutsam sind bisher vor allem die Fälle betreffend die Staatenimmunität und den völkerrechtlichen Mindeststandard $^{781}$ gewesen, welche der deutschen Gerichtsbarkeit auch Grenzen ihrer Ausübung setzten, wie sich in Kapiteln $\S 6$ und $\S 7$ gezeigt hat. ${ }^{782}$

Der Wortlaut bestimmt lediglich, dass „,die Gerichte ${ }^{783}$ verpflichtet “ werden die Entscheidung des BVerfG einzuholen, sollten im Rahmen eines Rechtsstreits vor den Fachgerichten Zweifel an der Erzeugung von Rechten und Pflichten einer Regel des Völkerrechts für den Einzelnen aufkommen. Das Verfahren dient lediglich der Normenverifikation und der Normenqualifikation ${ }^{784}$ und übernimmt eine „Gewährleistungsfunktion“ angesichts der „dynamischen Entwicklung und seltenen Evidenz ${ }^{6785}$ der allgemeinen Völkerrechtsregeln. ${ }^{786}$ Fischer-Lescano beispielsweise argumentiert auch über Art. 100 Abs. 2 GG zugunsten eines extensiven Verständnisses des Art. 25 Satz 2 GG, solle doch besonders die innerstaatliche

\footnotetext{
${ }^{778}$ So die Entscheidungen des BVerfG, E 15, 25 (33); 23, 288; 46, 342 (363); 64, 14; 75, 11; ebenso Burghart, in: Leibholz/Rinck, Art. 100 GG, Rn. 337, 343; Matz-Lück, in: Burkiczak/Dollinger/Schorkopf, § 84 BVerfGG, Rn 7, 8; Müller-Terpitz, in: Maunz/Schmidt-Bleibtreu/Klein/Bethge, § 83 BVerfGG, Rn 5, 11 f.

${ }^{779}$ So die Entscheidungen des BVerfG, E 15, 25 (33); 16, 6; 23, 318; 64, 13; ebenso Burghart, in: Leibholz/Rinck, Art.100 GG, Rn. 335.

${ }^{780}$ So beispielsweise in BVerfGE 1, 208 (240); 23, 288 (300 f.); 30, 409 (413); Cremer, in: HdStR Bd. 11, § 235 Rn 34 f.; Müller-Terpitz, in: Maunz/Schmidt-Bleibtreu/Klein/Bethge, § 83 BVerfGG, Rn 19.

${ }^{781},[\ldots .$.$] von Verfassungs wegen gehalten zu prüfen, ob die Auslieferung [...] mit dem nach Art. 25$ GG [...] verbindlichen völkerrechtlichen Mindeststandard [...] vereinbar [ist]“, siehe BVerfGE 59, 280 (282 f.); 63, 332 (337); 75, 1 (19); 108, 129 (136); 113, 154 (162).

${ }^{782} \S \S 18$ bis 20 GVG erfassen die Staatenimmunität nicht vollständig. Von den Gerichten sind daher die allgemeinen Völkerrechtsregeln anzuwenden, die nach Art. 25 GG bereits vorrangig sind.

${ }^{783}$ Zum Begriff „Gericht“ siehe Stern, in: Bonner Kommentar zum Grundgesetz, Art. 100 GG, Rn 42 f., 230.

${ }^{784}$ BVerfGE 15, 25 (33); 23, 288 (318); Cremer, in: HdStR Bd. 11, § 235 Rn 41.

${ }^{785}$ Siehe BVerfGE 23, 288 (316 f.).

${ }^{786}$ Siehe BVerfGE 46, 342 (363).
} 
Wirksamkeit des Völkerrechts mit dem Vorlagerverfahren zu gesteigerter Effektivität verholfen werden. Aus diesem Grunde würde das „und“ in Art. 100 Abs. 2 GG als „oder“ gelesen. Es reichen zur Vorlage daher bereits lediglich Zweifel, ob eine allgemeine Völkerrechtsregel Rechte und Pflichten unmittelbar erzeugt. ${ }^{787}$

Jedoch dient es damit nicht ausdrücklich dem Individualschutz oder der unmittelbaren Durchsetzung völkerrechtlicher Individualrechte aus den allgemeinen Völkerrechtsregeln. Dazu kommt, dass die höchstrichterliche Rechtsprechung zum Verfahren des Art. 100 Abs. 2 GG ausgeführt hat, dass nicht jedes „einfache“ Gericht ermächtigt sein soll, innerstaatliches Recht nicht korrekt angewendet lassen zu dürfen, weil angeblich eine Kollision mit allgemeinen Völkerrechtsregeln vorliegt und diese das nationale Recht verdrängen. Der Vorrang vor den Gesetzen berge Gefahr für die gesetzgeberische Autorität, so dass nicht die Fachgerichte, sondern allenfalls das BVerfG über das Nichtbestehen oder Bestehen sowie die Tragweite einer allgemeinen Völkerrechtsregel entscheiden können soll. ${ }^{788}$ Die Fachgerichte verfügen in der Regel nicht über die Kapazitäten für den notwendigen wissenschaftlichen Aufwand, die Existenz und Reichweite allgemeiner Völkerrechtsregeln festzustellen. ${ }^{789}$ Auch sieht sich das BVerfG selbst als eine Art Garant des Völkerrechts, der „mittelbar im Dienst der Durchsetzung des Völkerrechts [...] im Rahmen seiner Zuständigkeit auch dazu berufen [ist], Verletzungen des Völkerrechts [...] zu verhindern und zu beseitigen“. ${ }^{790}$ Eine etwaige politische Brisanz als Auslegungs- oder Anwendungsfaktor allgemeiner Völkerrechtsregeln ${ }^{791}$ wurde vom OVG Münster als nicht erheblich eingestuft. $\mathrm{Ob}$ andere Instanzgerichte diesem Vorstoß folgen werden und so möglicherweise die Garantenstellung des BVerfG aufgeweicht wird, muss abgewartet werden.

Dass die Befugnis zur Überprüfung ausschließlich dem höchsten deutschen Verfassungsgericht obliegen soll, zeigt erneut die Bedeutung der Eingliederung allgemeiner völkerrechtlicher Regeln ins innerstaatliche Recht auf und die möglichen schwerwiegenden Konsequenzen. Im Umkehrschluss kann diese Restriktion auf eine Überprüfung durch das BVerfG, jedoch keine geregelte Beschwerdemöglichkeit vor dem BVerfG, nur als Indiz dafür gewertet werden, dass wohl auch nicht jeder einzelne Bewohner des Bundesgebietes

\footnotetext{
${ }^{787}$ Fischer-Lescano, Militärbasen und militärisch genutzte Flughäfen, S. 23; repräsentativ BVerfGE 15,25 (31 f.).

${ }^{788}$ BVerfGE 23, 288 (317 f., 318); 64, 1 (14 f.), 96, 68 (77 f.); 109, 13 (23); 109, 38 (49);

${ }^{789}$ Calliess, Staatsrecht III, S. 107 Rn 32, vgl. auch Matz-Lück, in: Burkiczak/Dollinger/Schorkopf, § 84 BVerfGG, Rn 10 f.; Müller-Terpitz, in: Maunz/Schmidt-Bleibtreu/Klein/Bethge, § 83 BVerfGG, Rn 25.

${ }^{790}$ Siehe BVerfGE 58, 1 (34); 59, 63 (89); 109, 13 (23 f.); 111, 307 (328).

${ }^{791}$ Calliess, Staatsrecht III, S. 107 Rn 32.
} 
ermächtigt sein soll, wegen ,,angeblicher“ Regelverletzungen vor Fach- oder Verfassungsgerichten unmittelbar klagen zu können. Seit Inkrafttreten des Grundgesetzes wurde keine explizite Beschwerde- oder Klageform geregelt, um diese Problematik zu begrenzen.

Auch wenn es das Fachgericht versäumen sollte, trotz objektiver Zweifel über Existenz oder Tragweite einer allgemeinen Völkerrechtsregel das BVerfG anzurufen, können die Parteien des Rechtsstreits nicht aufgrund einer Regelverletzung das Vorgehen des Gerichts rügen, sondern eine Entziehung des gesetzlichen Richters über Art. 101 Abs. 1 Satz 2 GG geltend machen. ${ }^{792}$

Das allgemeine Völkerrecht soll vom jedem beachtet werden. Dass das BVerfG die Funktion der inhaltlichen Feststellung der Geltungsweite zukommt, sei mehr als eine passive Rezeption laut Cremer. Das Gericht entscheidet darüber, ob Gewohnheitsrecht entstanden ist oder ob es nicht entstanden ist und welche Wirkung es entfaltet. Dadurch werde auch vertreten welche Haltung Deutschland zu Existenz und Inhalt gewisser völkerrechtlicher Regeln einnehme. ${ }^{793}$

Gerade dies lässt erkennen, welch hohe Bedeutung die Auslegung seitens der Verfassungsrichter innehat. Folgte man den Stimmen der Literatur, die eine Subjektivierung der staatengerichteten allgemeinen Völkerrechtsregeln befürworten, welche nach ihrem Inhalt auch einer Geltendmachung durch Individuen zugänglich wären, zeigt die Intention hinter der Installation des Art. 100 Abs. 2 GG und die exklusive Zuständigkeit des BVerfG, dass Art. 25 Satz 2 GG nicht als individuelle Anspruchsgrundlage gesehen werden darf.

Nur dem höchsten Verfassungsgericht, und keiner geringeren Instanz und keinem geringeren natürlichen Organ der Justiz, kommt das Privileg zu die Auslegung und Anwendung der allgemeinen Völkerrechtsregeln zu überschauen. Einzelne Personen sollten dies nicht willkürlich zu Gericht tragen können, wann immer sie, selbst betroffen oder nicht, eine Verletzung dieser Regeln erblicken. Dem Normenverifikationsverfahren kommt deshalb keine „Auffangfunktion“ chen Literaturstimmen bejahten Individualanspruch auszugestalten und zu konkretisieren.

\footnotetext{
${ }^{792}$ BVerfGE 18, 441 (447); 23, 288 (320); 109, 13 (23 f.); Cremer, in: HdStR Bd. 11, § 235 Rn 48 f.; so auch Fischer-Lescano, Militärbasen und militärisch genutzte Flughäfen, S. 13, der eine Subjektivierung völkerrechtlicher individueller Entschädigungsansprüche über Art. 25 Satz 2 GG befürwortet; Matz-Lück, in: Burkiczak/Dollinger/Schorkopf, § 84 BVerfGG, Rn 53 f.; Müller-Terpitz, in: Maunz/Schmidt-Bleibtreu/Klein/Bethge, $\S 83$ BVerfGG, Rn $25 \mathrm{f}$.

${ }^{793}$ So auch Cremer, in: HdStR Bd. 11, § 235 Rn 61, der jedoch auch eine Subjektivierung bestimmter allgemeiner Völkerrechtsregeln zugunsten Einzelner befürwortet.
} 


\section{Fazit}

Positive obergerichtliche Entscheidungen betreffend die Auslegung und Anwendung des Art. 25 GG bezogen auf andere Verfassungs- und Bundesrechte sind immer noch eine Ausnahme. Eine national verbreitete obergerichtliche Rechtspraxis konnte sich deshalb noch nicht entwickeln oder abzeichnen. Eine zukünftige Konstanz der Rechtsprechung des OVG Münsters bleibt indes abzuwarten, gerade weil das BVerwG in der Revision das erstinstanzliche Urteil wiederhergestellt und im konkreten Fall einen Individualanspruch auf Rechtsschutz durch den Staat Deutschland im Ausland verneint hat. Eine Durchsetzbarkeit der allgemeinen Völkerrechtsregeln im Sinne des Art. 25 GG auf Grundlage einer stetigen Rechtspraxis gibt es also nur vereinzelt. Art. 25 GG konnte bisher nicht als eigenständige Anspruchsgrundlage zugunsten Einzelner überzeugen. In der deutschen Rechtsprechung wurden dogmatische Ausgestaltungen oder Beschränkungen nur zögerlich vorgenommen oder am Beispiel der BVerwG-Entscheidung aus $2020^{794}$ die Hürde einer konkreten Gefahr für Rechtsgüter für die Anerkennung einer individuellen Rechtsverletzung hoch angesetzt. Auch die vom BVerfG 2004 ausgedrückte „Gebotenheit“, allgemeine Regeln des Völkerrechts über Art. 25 Satz 2 GG subjektivieren zu können, hat bisher keine überzeugende Umsetzung erfahren. In der überwiegenden Mehrzahl der Fälle scheuten die Gerichte eine inhaltliche Auseinandersetzung, da die Klagen und Beschwerden an der Zulässigkeitsvoraussetzung der Befugnis scheiterten.

Art. 25 Satz 2 GG stellt keine eigenständige Anspruchsgrundlage dar. Nur vereinzelte Stimmen des Schrifttums befürworten dies, welche sowohl von großen Teilen der Lehre als auch der Rechtsprechung nicht geteilt und abgelehnt wird. Art. 25 (Satz 2) GG wirkt praktisch lediglich als Verbindung nationaler und internationaler Normen, die die allgemeinen Völkerrechtsregeln im Rahmen der Auslegung und Anwendung anderer speziellerer (Verfassungs-)Rechte zur Geltung bringt und die deutschen Gerichte und Behörden zur Beachtung verpflichtet.

Zusammenfassend muss festgehalten werden, dass besonders aufgrund der Unbestimmtheit allgemeiner Völkerrechtsregeln und der inhaltlichen Unschärfe - ohne Sanktions- oder genauere Regelungsanordnung des Art. 25 GG - andere individuelle Anspruchsgrundlagen praktikabler und anerkannt sowie angewendet sind. Der Umfang der Anwendbarkeit des Art. 2 Abs. 1 und 2 GG wird in Schrifttum und Praxis nur vage skizziert und in der Regel

${ }^{794}$ BVerwG, Urteil vom 25.11.2020, Az. 6 C 7/19. 
erschöpft sich die inhaltliche Darstellung schlicht in der generellen Ermöglichung einer Verfassungsbeschwerde auf Grundlage des Art. 2 Abs. 1 GG. Jedoch bestätigen die, wenn auch wenigen, positiven Gerichtsentscheidungen zugunsten Einzelner auf Grundlage des Art. 2 GG die Norm als, nach aktuellem Stand der innerstaatlichen Rechtslage, universelle Anspruchsgrundlage für Individualrechte und -pflichten aus allgemeinen Regeln des Völkerrechts.

Es zeigt sich, dass das durch Art. 25 GG eingegliederte Völkergewohnheitsrecht sowie die allgemeinen Rechtsgrundsätze nicht als unmittelbare oder mittelbare Rechtsgrundlagen herangezogen werden. Die Untersuchung und die aufgezeigten Beispiele haben veranschaulicht, dass nationale (Verfassungs-)Rechte in ihrer Auslegung und Anwendung am Maßstab des Art. 25 GG gemessen werden und praktische Anerkennung finden. Besonders durch die inhaltliche Schärfe der bereits bestehenden Normen entsteht die nötige Rechtsanwendungssicherheit, welche sich im Geltungsbereich der allgemeinen Völkerrechtsregeln immer noch als problematisch zeigt. Sollte eine, direkt auf völkerrechtliche Regeln Bezug nehmende, Rechts- und Anspruchsgrundlage in den Augen des Gesetzgebers nötig sein, müsste diese erst noch erlassen werden. Die Komplexität der Materie zeigt jedoch, dass entweder der Schutzbereich des Art. 2 GG ausgeweitet und definiert werden oder eine solche Norm auf verfassungsrechtlicher Ebene erlassen werden muss. 


\section{$\S 8$ Abschließende Bewertung}

In der vorliegenden Arbeit wurden unterschiedliche Ansätze des Schrifttums und der ausländischen sowie nationalen Rechtsprechung vorgestellt, die Subjektivierung allgemeiner Regeln des Völkerrechts zugunsten Einzelner zu erarbeiten und zu interpretieren. Die These, dass auch die Entwicklungen des Völkerrechts seit Inkrafttreten des Grundgesetzes über Art. 25 Satz 2 GG ins deutsche Recht einfließen, kann nicht ohne Einschränkungen bestätigt werden. Zwar haben Einzelne eine partielle Völkerrechtssubjektivität, und auch ein Adressatenwechsel durch Art. 25 Satz 2 GG wird teilweise anerkannt. Es ist jedoch weiterhin umstritten, $o b$ die allgemeinen Völkerrechtsregeln auch Individualrechte verleihen, wenn sie vornehmlich nur die Staaten ansprechen. Auch, wenn Art. 25 GG spätestens seit den 1970er Jahren etwas seinen ursprünglichen Zweck von 1949 verloren hat, ist die Norm heutzutage immer noch bedeutend. Es ist immer noch hoch umstritten, $o b$ und welche allgemeine Völkerrechtsregeln dem Einzelnen auch Rechte oder Pflichten verleihen könnten, und $o b$ Art. 25 Satz 2 GG überhaupt über eine deklaratorische Wirkung hinauswächst zugunsten solcher Individualrechte. Ungenau formulierte Wortlaute und teils für exakte Schutzrichtungen unergiebige Entstehungsgeschichten können nicht zweifellos die Reichweite der Individualrechte bestimmen, selbst wenn eine Rechtsexistenz einmal vorausgesetzt würde. Vor dem Hintergrund einer durch die nationale Rechtsprechung ermöglichten Subjektivierung wurden insbesondere Individualansprüche befürwortende Literaturstimmen genauer betrachtet. Die praktische Anwendung gewohnheitsrechtlicher Normen ist jedoch aufgrund des deutschen Gesetzlichkeits- und Bestimmtheitsgrundsatzes gem. Art. 103 Abs. 2 GG nicht ohne Schwierigkeiten möglich. Mit Erlass des VStGB schuf der Gesetzgeber für das Völkerstrafrecht als Sonderfall individueller völkerrechtlicher Pflichten eine anerkannte und angewendete Alternative zur direkten Heranziehung allgemeiner Völkerrechtsnormen. Die $\S \S 8$ Abs. 1 Nr. 1 oder auch 11 Abs. 1 Nr. 1 VStGB stellen im Gegensatz zu Art. 25 GG tatsächliche Verbots- und Sanktionsnormen dar und drohen für völkerrechtswidriges Verhalten strafrechtliche Konsequenzen an. Am Beispiel des Völkerstrafrechts und der Anzahl an Verfahren und positiven Strafurteilen hat sich gezeigt, dass es für die Rechtspraxis praktikabler geworden ist. Es wurde auch der These nachgegangen, dass vereinzelte theoretische Vorstöße des Schrifttums den Anforderungen einer praktischen Umsetzung kaum standhalten können und daher nur geringe Erfolgschancen haben. Diese These konnte durch die Untersuchung bestätigt werden. Es zeigt sich, dass den allgemeinen 
Völkerrechtsregeln im Sinne des Art. 25 GG trotz ihrer Eingliederung ins deutsche Recht eine derart hohe Bedeutung betreffend Auslegung und Anwendbarkeit zukommt, dass nach den vorgebrachten Überlegungen nicht alle Bürger gleichermaßen individuell klagen und sich auf völkerrechtliche Regeln berufen können sollten.

Die Betrachtung unterschiedlicher Auffassungen des Schrifttums verdeutlichte die Problematik innerhalb der Literatur, wie divers sowohl der inhaltliche Umfang als auch die Geltung der allgemeinen Völkerrechtsregeln beurteilt werden. Die ober- und höchstrichterliche Rechtsprechung stimmt mittlerweile in Teilen mit den Ausführungen der Literatur überein, so dass als allgemein anerkannte Meinung feststeht, dass auf völkerrechtlicher Ebene hinsichtlich einer Subjektivierung drei Kategorien allgemeiner Völkerrechtsregeln differenziert werden können. Die vereinzelten Individualansprüche stark befürwortenden Literaturstimmen konnten hingegen nicht überzeugen. Diese hätten zum Teil unabsehbare Folgen für das deutsche Rechtssystem und könnten Grundpfeiler unseres gesellschaftlichen und politischen Rechtssystems wie das Wahlrecht umgehen, indem allgemeine Völkerrechtsregeln direkt als Rechtsgrundlage herangezogen werden.

Es gibt auf völkerrechtlicher Ebene ausschließlich staatengerichtete allgemeine Regeln des Völkerrechts, die ihren Sinn verlieren, werden sie auf oder durch Individuen anwendbar. Weiter gibt es die allgemeinen Regeln, die bereits auf völkerrechtlicher Ebene lediglich individualgerichtet sind. Schließlich gibt es staatengerichtete Völkerrechtsregeln, welche inhaltlich nicht ihren intendierten Zweck verlieren, wendet man sie auch auf Individuen an. Die partielle Anerkennung der Völkerrechtssubjektivität Einzelner sowie die Lockerung der Rechtsprechung bezüglich der konstitutiven Wirkung des Art. 25 Satz 2 GG sind große Schritte auf internationaler und nationaler Ebene hinsichtlich der Entwicklung der eigenständigen Rechtsstellung natürlicher Personen im Völkerrecht. Sie dürfen jedoch keinesfalls interpretiert werden als Einzelnen nun umfassend zustehende völkerrechtliche Ansprüche auf innerstaatlicher Rechtsebene. International sind Entschädigungen aufgrund völkerrechtswidriger Verletzungshandlungen bisher überwiegend politisch geförderte Ausnahmen gewesen.

Der vom BVerfG vorausgesetzte, und nach Teilen der Literatur bereits deutlich früher vertretene, enge Bezug allgemeiner Regeln zu hochrangigen Individualgütern, so dass diese von Einzelnen geltend gemacht werden können, hat sich einhellig als maßgebliche Voraussetzung etabliert. Art. 25 Satz 2 GG nimmt daher einen Adressatenwechsel vor, sofern allgemeine Regeln eine individualschützende und -verpflichtende Finalität aufweisen. Liegt 
diese Voraussetzung vor, besteht mit Art. 25 Satz 2 GG jedoch keine eigenständige Anspruchsgrundlage.

Vereinzelte Ansichten haben sich weder in der Gesamtheit des Schrifttums, noch in der Rechtsprechung durchsetzen können und sind insbesondere auf dogmatischen Widerstand gestoßen. Art. 25 Satz 2 GG wirkt lediglich als Schutzbereichserweiterung zugunsten spezieller Anspruchsgrundlagen, so dass allgemeine Völkerrechtsregeln in die Auslegung und Anwendung dieser Rechts- und Anspruchsgrundlagen einfließen. Den liberaleren Auffassungen des Schrifttums hat das BVerfG damit einen dogmatisch logischen und jedenfalls verfahrenstechnisch praktikablen Rahmen verliehen.

Es überzeugt, lediglich staatengerichtete Regeln, die einem Individualbezug nicht zugänglich sind, und rein individualgerichtete Regeln, welche bereits auf völkerrechtlicher Ebene Rechte und Pflichten für Einzelne erzeugen, von einer konstitutiven Wirkung des Art. 25 Satz 2 GG auszunehmen. Das Erfordernis eines engen Bezugs zu hochrangigen Individualgütern eröffnet eine dogmatisch logische Möglichkeit der Adressatenerweiterung oder des Adressatenwechsels, ohne künstliche Voraussetzungen zu schaffen, welche nicht durch die Verfassungsgeber installiert wurden und heute kaum auf historische Argumente gestützt werden können. Dennoch gab es bis auf das Fremdenrecht und das humanitäre Völkerrecht bisher keine weiteren Entscheidungen, in denen ein solch enger Bezug anderer allgemeiner Völkerrechtsregeln zu hochrangigen Individualrechtsgütern bestätigt wurde. Die konstitutive Wirkung des Art. 25 Satz 2 GG hat sich bisher nicht weiter entfaltet. Auch an einer universellen Anspruchsgrundlage fehlt es immer noch. Über Art. 2 Abs. 1 und Abs. 2 GG können positiv Verletzungen allgemeiner Regeln wie des völkerrechtlichen Mindeststandards geltend gemacht werden. Diese gehören dann nicht zur verfassungsgemäßen Ordnung. Dies gilt sowohl für die Verfassungsbeschwerde vor dem BVerfG als auch für das verwaltungsrechtliche Verfahren, so lange eine unmittelbare Betroffenheit i. S. d. § 42 Abs. 2 VwGO vorliegt. Dass das Völkerrecht nicht mehr bloß staatengerichtet ist und die Individuen nicht als Rechtssubjekte erfasst, ist unstreitig. Es ist jedoch ohne überzeugende Begründung nicht erkennbar, weshalb der Geschichte des Art. 25 GG eine Deutung zu entnehmen sein sollte, die konstitutiv auch staatengerichtete völkerrechtliche Normen subjektiviert.

Um der historischen Dynamik völkerrechtlicher Rechtsprechung, der befürwortenden Literatur und auch der entwickelten Rolle des Einzelnen als Völkerrechtssubjekt ausgiebig Rechnung tragen zu können, liegt es nahe, die Gruppe völkerrechtlicher Regeln als durch 
Art. 25 Satz 2 GG subjektiviert anzusehen, die bereits auf völkerrechtlicher Ebene einen Individualbezug deutlich vorgeben, wie beispielsweise das Fremdenrecht.

Es hat sich gezeigt, wenn auch nicht kritiklos, dass einige Autoren Art. 25 Satz 2 GG als Rechtsgrundlage für völkerrechtliche Entschädigungsansprüche gegen verantwortliche Staaten befürworten. Dazu nehmen diese unter anderem die mittlerweile anerkannte Völkerrechtssubjektivität Einzelner als positives Indiz.

Prozessual gibt es für Einzelne dennoch bereits bestehende Verfahrensmöglichkeiten, mit Hilfe derer hoheitliche Handlungen und Gesetze überprüft werden können. Im Rahmen des Instanzenzugs müssen die Fachgerichte über Art. 100 Abs. 2 GG an das BVerfG vorlegen, sofern sie Zweifel daran hegen, ob die Regel Bestandteil des Bundesrechts ist und ob sie unmittelbar Rechte und Pflichten für Einzelne erzeugt. Dabei entfaltet Art. 100 Abs. 2 GG keine individualschützende Wirkung. Auch wenn das BVerfG heute eine kognitive Wirkung des Art. 25 Satz 2 GG ebenfalls anerkennt und praktisch bestätigt, muss die Bedeutung des Art. 100 Abs. 2 GG nicht angepasst werden. Das Normenverifikationsverfahren bestätigt lediglich die Qualität einer Regel und übernimmt eine Gewährleistungsfunktion, bestimmt jedoch nicht den subjektiven Charakter. Zusammen mit Art. 2 GG als Grundlage einer Verfassungsbeschwerde wird auch dem Wortlaut und Zweck des Art. 25 GG Rechnung getragen, dass die allgemeinen Völkerrechtsregeln lediglich über den Gesetzen, jedoch nicht über der Verfassung stehen. Auch würde man der oft zitierten Aussage Schmids aus dem Verfassungskonvent von Herrenchiemsee gerecht, dass Gesetzesverstöße mit der Verfassungsbeschwerde gerügt werden können sollen.

Dass sich die konstitutive Wirkung des Art. 25 Satz 2 GG auch praktisch erfolgreich entfaltet, und sich die Rechtsprechung bereits obergerichtlich einer rein rechtlichen Überprüfung völkerrechtlicher Individualstreitigkeiten öffnet, statt auf politische Einflüsse maßgebend Rücksicht zu nehmen, könnte zukünftig dem Einzelnen nachhaltig den Rechtsweg und somit die Teilnahme am internationalen Völkerrechtsschutz ermöglichen. Eine weitere Fortentwicklung könnte dafür sorgen, dass das Völkerrecht nicht nur eine Sphäre über den Bürgern ist, sondern zu ihnen durchschlägt und Rechte und Pflichten tatsächlich geltend gemacht werden können. Nach jetzigem Stand der nationalen Rechtslage und der Stellung Einzelner im völkerrechtlichen Gefüge kann und darf Art. 25 Satz 2 GG jedoch nicht als Anspruchsgrundlage herangezogen werden.

Aufgrund der Brisanz der geführten Diskussion über die konstitutive Wirkung des Art. 25 Satz 2 GG, und vor allem der aufgezeigten systematischen Mängel der Norm und ihrer 
praktischen Untauglichkeit, ist jedoch dessen Qualifizierung als unmittelbare Rechtsgrundlage durch Teile der Wissenschaft entschieden abzulehnen. 


\section{$\underline{\text { Literaturverzeichnis }}$}

Abel, Alexander; $\quad$ Der Alien Tort Statute nach der Entscheidung des US-Supreme Court in der Sache Sosa v. Alvarez-Machain. Ein US-amerikanischer Weg zum Schutz der Menschenrechte, Diss. Jur., Universität des Saarlandes 2006, veröffentlicht: Aachen 2007 (zitiert: Abel, Der Alien Tort Statute nach der Entscheidung des US-Supreme Court in der Sache Sosa v. Alvarez-Machain)

Accioly, Hildebrando;

Responsabilité résultant d'actes de simples individus, in: Principes généraux de la responsabilité internationales d'après la doctrine et la jurisprudence, in: Collected Courses of the Hague Academy of International Law, Volume 96/1959, S. 404-441 (zitiert: Accioly, in: Collected Courses of the Hague Academy of International Law 96/1959)

Akande, Dapo/

Shah, Sangeeta;

Immunities of State Officials, International Crimes and Foreign Domestic Courts, in: European Journal of International Law, Issue 4/2010 - Volume 21, S. 815-852 (zitiert: Akande/Shah, in: EJIL 4/2010)

Alexy, Robert; Theorie der Grundrechte, Habil. Jur., Georg-August-Universität Göttingen 1984, veröffentlicht: Baden-Baden 1985

Ambos, Kai; Internationales Strafrecht: Strafanwendungsrecht, Völkerstrafrecht, Europäisches Strafrecht, Rechtshilfe, 5. Auflage, München 2018 (zitiert: Ambos, Internationales Strafrecht)

Amerasinghe,

Chittharanjan Felix; Diplomatic Protection, Oxford 2008

Anzilotti, Dionisio; Lehrbuch des Völkerrechts, 1. (einziger) Band nach der 3. italienischen Auflage von Cornelia Bruns (Hrsg.) und Karl Schmid, Berlin/Leipzig 1929

Bade, Klaus J.; $\quad$ Europa in Bewegung: Migration vom späten 18. Jahrhundert bis zur Gegenwart, München 2002

Bank, Roland/

Schwager, Elke;

Is there a Substantive Right to Compensation for Individual Victims of Armed Conflicts against a State under International Law?, in: Delbrück, Jost/Giegerich, Thomas/Zimmermann, Andreas, German Yearbook of International, 2006 - Band 49, S. 367-412 (Bank/Schwager, in: GYIL 2006)

Bautze, Kristina; $\quad$ Völkerrecht: ein Lehrbuch, Berlin 2012 (zitiert: Bautze, Völkerrecht)

Becker, Peter; Rechtsprobleme des Einsatzes von Drohnen zur Tötung von Menschen, in: Die Öffentliche Verwaltung, Ausgabe 13/2013 - Jahrgang 66, S. 493-502 (zitiert: Becker, in: DÖV 13/2013)

Becker, Peter; $\quad$ Rechtsschutz gegen verfassungswidrige Kriegsführung, in: Becker, 
Peter/Braun, Reiner/Deiseroth, Dieter (Hrsg.), Frieden durch Recht?, S. 223247, Berlin 2010 (zitiert: Becker, in: Becker/Braun/Deiseroth, Frieden durch Recht?)

Becker, Ulrich/

Hatje, Armin/

Schoo, Johann/

Schwarze, Jürgen;

Benz, Wolfgang; $\quad$ Die 101 wichtigsten Fragen - Das Dritte Reich, 3. Auflage, München 2013

Berber,

Friedrich Josef; $\quad$ Lehrbuch des Völkerrechts, 2. Band: Kriegsrecht, 2. Auflage, München 1969 (zitiert: Berber, Lehrbuch des Völkerrechts)

Bernhardt, Rudolf; $\quad$ Das BVerfG und völkerrechtliche Verträge, in: Starck, Christian (Hrsg.)/Drath, Martin, Bundesverfassungsgericht und Grundgesetz: Festgabe aus Anlass des 25-jährigen Bestehens des Bundesverfassungsgerichts, Tübingen 1967, S. 154-186 (zitiert: Bernhardt, in: Bundesverfassungsgericht und Grundgesetz)

Bianchi, Andrea; $\quad$ State Responsibility and Criminal Liability of Individuals, in: Antonio Cassese (Hrsg.), The Oxford Companion to International Criminal Justice, Oxford 2009, S. 16-24 (zitiert: Bianchi, in: The Oxford Companion to International Criminal Justice)

Blanke, Hermann-

Josef/Molitor, Claus; Der Internationale Strafgerichtshof, in: Archiv des Völkerrechts, Ausgabe 2/2001 - Band 39, S. 142-169 (zitiert: Blanke/Molitor, in: AVR 2/2001)

Bleckmann, Albert; Grundgesetz und Völkerrecht: ein Studienbuch, Berlin 1975 (zitiert: Bleckmann, Grundgesetz und Völkerrecht)

Bleckmann, Albert; Völkerrecht, Baden-Baden 2001

Bock, Stefanie; $\quad$ Zurechnung im Völkerstrafrecht, in: Zeitschrift für Internationales Strafrecht, Heft 7-8/2017 - Jahrgang 12, S. 410-427 (zitiert: Bock, in: ZIS 7-8/2017)

Bong, Shin Hae; $\quad$ Compensation for Victims of Wartime Atrocities: Recent Developments in Ja pan's Case Law, in: Journal of International Criminal Law, Issue 1/2005 - Vo lume 3, S. 187-206

Bothe, Michael; $\quad$ The Role of National Law in the Implementation of International Humanitarian Law, in: Swinarski, Christophe (Hrsg.), Studies and Essays on International Humanitarian Law and Red Cross Principles in Hunour of Jean Pictet, Dordrecht 1984, S. 301-312 (zitiert: Bothe, in: Swirarski, Studies and Essays on International Humanitarian Law and Red Cross Principles in Honour of Jean Pictet)

Boysen, Sigrid; Kriegsverbrechen im Diskurs nationaler Gerichte, in: Archiv des Völkerrechts, Ausgabe 3/2006 - Band 44, S. 363-379 (zitiert: Boysen, in: AVR 3/2006) 
Böckstiegel

Karl-Heinz;

Buchs, Gaby;

Bundesministerium

des Innern;

Cassidy, Julie;

Calliess, Christian;

Campbell,

Patrick Caroll;

Chinkin,

Christine M.;

Clapham, Andrew;

Cremer,

Hans-Joachim;

Cremer,

Hans-Joachim;

Crawford, James;

Crawford, James;
Der Staat als Vertragspartner ausländischer Privatunternehmen, Habil Jur., Universität zu Köln 1971, veröffentlicht: Frankfurt am Main 1971

Die unmittelbare Anwendbarkeit völkerrechtlicher Vertragsbestimmungen: am Beispiel der Rechtsprechung der Gerichte Deutschlands, Österreichs, der Schweiz und der Vereinigten Staaten von Amerika, Diss. Jur., Johannes Gutenberg-Universität Mainz 1993, veröffentlicht: Baden-Baden 1993 (zitiert: Buchs, Die unmittelbare Anwendbarkeit völkerrechtlicher Vertragsbestimmungen)

Allgemeine Verwaltungsvorschriften zum Aufenthaltsgesetz, Berlin 2009

Emergence of the Individual as an International Juristic Entity: Enforcement of International Human Rights, in: Deakin Law Review, Issue 2/2004 Volume 9, S. 533-572 (zitiert: Cassidy, in: Deakin Law Review 2/2004)

Staatsrecht III: Bezüge zum Völker-
2018 (zitiert: Calliess, Staatsrecht III)

$\S 220$ a StGB: der richtige Weg zur Verhütung und Bestrafung von Genozid?, Frankfurt am Main 1986 (zitiert: Campbell, § 229 a StGB)

Women's International Tribunal on Japanese Military Sexual Slavery, in: American Journal of International Law, Issue 2/2001 - Volume 95, S. 335341 (zitiert: Christine, in: AJIL 2/2001)

The Role of the Individual in International Law, in: European Journal of International Law, Issue 1/2010 - Volume 21, S. 25-30 (Clapham, in: EJIL $1 / 2010)$

Allgemeine Regeln des Völkerrechts, in: Isensee, Josef/Kirchhof, Paul (Hrsg.), Handbuch des Staatsrechts der Bundesrepublik Deutschland, Band 11: Internationale Bezüge, 3. Auflage, Heidelberg 2013, § 235 S. 369-411 (zitiert: Cremer, in: HdStR Bd. 11, § 235)

Zur Bindungswirkung von EGMR-Urteilen/Anmerkung zum GörgülüBeschluss des BVerfG vom 14.20.2004, in: Europäische Grundrechte Zeitschrift, Ausgabe 22/2004 - Jahrgang 31, S. 683-700 (zitiert: Cremer, in: EuGRZ 22/2004)

The ILC's Articles on Responsibility of States for Internationally Wrongful Acts: A Retrospect, in: American Journal of International Law, Ausgabe 4/2002 Volume 96, S. 874-890 (zitiert: Crawford, in: AJIL 4/2002)

The System of International Responsibility, in: Crawford, James/Pellet, Alain/Olleson, Simone (Hrsg.), The Law of International Responsibility, 
Oxford 2010, S. 17-25 (zitiert: Crawford, in: The Law of International Responsibility)

D'Argent, Pierre; Les réparations de guerre on droit international public: La responsabilité internationale des États à l'épreuve de la guerre, Brüssel 2002 (zitiert: D'Argent, Les réparations de guerre on droit international public)

Dahm, Georg; $\quad$ Völkerrecht, Band 1, Stuttgart 1958

Dahm, Georg/

Delbrück, Jost/

Wolfrum, Rüdiger;

Völkerrecht, Band I/2: Der Staat und andere Völkerrechtssubjekte.

Räume unter internationaler Verwaltung, 2. Auflage, Berlin 2002

(zitiert: Dahm/Delbrück/Wolfrum, Völkerrecht, Band I/2)

Dahm, Georg/

Delbrück, Jost/

Wolfrum, Rüdiger;

Völkerrecht, Band I/3: Die Formen des völkerrechtlichen Handelns. Die inhaltliche Ordnung der internationalen Gemeinschaft, 2. Auflage, Berlin 2002 (zitiert: Dahm/Delbrück/Wolfrum, Völkerrecht Bd. I/3)

Dahlgrün, Hans Martin;

Funktionen und Rechtspersönlichkeit der Internationalen Handelskammer, Diss. Jur. Johannes Gutenberg-Universität Mainz 1969, veröffentlicht:

München 1969 (zitiert. Dahlgrün, Funktionen und Rechtspersönlichkeit der IHK)

Dahm, Georg; $\quad$ Zur Problematik des Völkerstrafrechts, Göttingen 1956

De Vattel, Emer; $\quad$ Le droit des gens ou Principes de la loi naturelle appliqués à la conduite et aux auffaires des nations et des souverains, Tübingen 1959 (zitiert: De Vattel, Le droit des gens ou principes de la loi naturelle)

Deiseroth, Dieter; Innerstaatliche Gerichte und Völkerrecht, in: Roggan, Fredrik/Busch, Dörte (Hrsg.), Das Recht in guter Verfassung?, Festschrift für Martin Kutscha, Baden-Baden 2013, S. 25-41 (zitiert: Deiseroth, in: Das Recht in guter Verfassung?)

Deiseroth, Dieter;

Verstrickung der Airbase Ramstein in den globalen US-Drohnenkrieg und die deutsche Mitverantwortung - Zugleich ein Beitrag zur Bestimmung der individuellen Klagebefugnis nach § 42 II VwGO, in: Deutsches Verwaltungsblatt, Ausgabe 16/2017 - Band 132, S. 985-994 (zitiert:

Deiseroth, in: DVB1. 16/2017)

Denninger, Erhard/

Hoffmann-Riem,

Wolfgang/Schneider,

Hans-Peter/

Stein, Ekkehart; $\quad$ Kommentar zum Grundgesetz für die Bundesrepublik Deutschland, Band 2, 3. Auflage, Neuwied 2001 (zitiert: Denninger, GG) 
Derleder, Peter; $\quad$ Individualentschädigungsansprüche zur Durchsetzung des

Kriegsvölkerrechts, in: Becker, Peter/Braun, Reiner/Deiseroth, Dieter (Hrsg.), Frieden durch Recht?, S. 331-347, Berlin 2010 (zitiert: Derleder, in:

Becker/Braun/Deiseroth, Frieden durch Recht?)

Detterbeck, Steffen; Allgemeines Verwaltungsrecht: mit Verwaltungsprozessrecht, 17. Auflage, München 2019 (zitiert: Detterbeck, Allgemeines Verwaltungsrecht)

Deutscher Bundestag

und Bundesarchiv; Der Parlamentarische Rat: 1948-1949; Akten und Protokolle, Band 14, Hauptausschuss - Teilband 1, bearbeitet von Michael F. Feldkamp, München 2009 (zitiert: Der Parlamentarische Rat: 1948-1949)

Doehring, Karl; $\quad$ Das Friedensgebot des Grundgesetzes, in: Isensee, Josef/Kirchhof, Paul (Hrsg.), Handbuch des Staatsrecht der Bundesrepublik Deutschland, Band 7: Normativität und Schutz der Verfassung - Internationale Beziehungen, Heidelberg 1992, § 178 S. 687-709 (zitiert: Doehring, in: HdStR Bd. 7, § 178)

Doehring, Karl; $\quad$ Die allgemeinen Regeln des völkerrechtlichen Fremdenrechts und das deutsche Verfassungsrecht, Habil. Jur. Ruprecht-Karls-Universität Heidelberg 1962, veröffentlicht: Köln 1963 (zitiert: Doehring, Fremdenrecht)

Doehring, Karl; $\quad$ Völkerrecht: ein Lehrbuch, 2. Auflage, Heidelberg 2004 (zitiert: Doehring, Völkerrecht)

Dörr, Oliver; $\quad$ Privatisierung des Völkerrechts, in: JuristenZeitung, Ausgabe 19/2005 - Band 60, S. 905-916 (zitiert: Dörr, in: JZ 60/2005)

Dörr, Oliver; $\quad$ Kein Anspruch jugoslawischer Staatsangehöriger auf Schadensersatz für die Folgen eines Nato-Luftangriffs, in: JuristenZeitung, Ausgabe 11/2004 - Band 59, S. 572-577 (zitiert: Dörr, in: JZ 11/2004)

Dreier, Horst/

Bauer, Hartmut; $\quad$ Grundgesetz: Kommentar, Band 2: Artikel 20-82, 3. Auflage, Tübingen 2015 (zitiert: Dreier, GG)

Dutta, Anatol; $\quad$ Amtshaftung wegen Völkerrechtsverstößen bei bewaffneten Auslandseinsätzen deutscher Streitkräfte, in: Archiv des Öffentlichen Rechts, Ausgabe 2/2008 - Jahrgang 133, S. 191-234 (zitiert: Dutta, in: AÖR 2/2008)

Echterhölter, Rudolf; Die Europäische Menschenrechtskonvention im Rahmen der

verfassungsmäßigen Ordnung, in: JuristenZeitung, Ausgabe 22/1955 - Band 10, S. 689-692 (zitiert: Echterhölter, in: JZ 22/1955)

Enache-Brown,

Colleen/Fried, Ar; Universal Crime, Jurisdiction and Duty: The Obligation of Aut Dedere Aut Judicare in International Law, in: McGill Law Journal Revue de droit de McGill, Issue 2/1998 - Volume 43, S. 613-636 (zitiert: Enache-Brown/Fried, in: McGill Law Journal 2/1998) 
Epping, Volker/

Hillgruber, Christian; Grundgesetz: Kommentar, 3. Auflage, München 2020 (zitiert:

Epping/Hillgruber, GG)

Epping, Volker (Hrsg.)/

von Heinegg,

Heintschel (Hrsg.)/

Ipsen, Knut;

Völkerrecht: ein Studienbuch, 7. Auflage, München 2018 (zitiert: Ipsen, Völkerrecht)

\section{Europäischer}

Konvent;

Artikel über den Gerichtshof und das Gericht, Entwurf des Präsidiums vom 02.05.2003, CONV 734/03

Ders.

Kurzniederschrift über die Sitzung vom 04.10.2002 unter dem Vorsitz des Kommissionsmitglieds António Vitorino, CONV 350/02 sowie Schlussbericht der Gruppe II über die Charta vom 22.10.2002, CONV 354/02

Ders.

Schlussbericht des Arbeitskreises über den Arbeitskreises über die Arbeitsweise des Gerichtshofs vom 13.03.2003, CONV 636/03

Eustathiades,

Constantin Th.;

Les sujets du droit international, in: Les sujets du droit international et la responsabilité internationale: nouvelles tendances, in: Collected Courses of the Hague Academy of International Law, Volume 84/1953, S. 405-428 (zitiert: Eustathiades, in: Collected Courses of the Hague Academy of International Law 84/1953)

Falk, Richard A.; The Shimoda Case: A Legal Appraisal of the Atomic Attacks upon Hiroshima and Nagasaki, in: American Journal of International Law, Issue 4/1965 Volume 59, S. $759-793$ (zitiert: Falk, in: AJIL 4/1965)

Farahat, Anuscheh; Progressive Inklusion: Zugehörigkeit und Teilhabe im Migrationsrecht, Heidelberg 2014 (zitiert: Farahat, Progressive Inklusion)

Fassbender, Bardo; Can Victims Sue State Officials for Turture?: Reflections on Rasul v. Myers from the Perspective of International Law, in: Journal of International Criminal Justice, Issue 2/2008 - Volume 6, S. 347-369 (zitiert: Fassbender, in: JICJ 2/2008)

Felz, Daniel; $\quad$ Das Alien Tort Statute: Rechtsprechung, dogmatische Entwicklung und deutsche Interessen, Diss. Jur., Johannes Gutenberg-Universität Mainz 2016, veröffentlicht: Berlin 2017 (zitiert: Felz, Das Alien Tort Statute)

Ferdinandusse, Ward N.,

Direct Application of International Criminal Law in National Courts, Den Haag 2006

Fischer-Lescano, Andreas;

Militärbasen und militärisch genutzte Flughäfen in Deutschland: Umfang und Modalitäten des subjektiven Rechts auf Einhaltung des Verbots der Beteiligung an Angriffskriegen, Rechtsgutachten für DIE LINKE im 
Bundestag, Bremen 2008 (zitiert: Fischer-Lescano, Militärbasen und militärisch genutzte Flughäfen in Deutschland)

Fischer-Lescano, Andreas;
Subjektivierung völkerrechtlicher Sekundärregeln: Die Individualrechte auf Entschädigung und effektiven Rechtsschutz bei Verletzungen des Völkerrechts, in: Archiv des Völkerrechts, Ausgabe 3/2007 - Band 45, S. 299-381 (zitiert: Fischer-Lescano, in: AVR 3/2007)

Fischer-Lescano, Andreas/

Hanschmann, Felix; Subjektive Rechte und völkerrechtliches Gewaltverbot - Eine völker- und verfassungsrechtliche Analyse, in: Becker, Peter/Braun, Reiner/Deiseroth, Dieter (Hrsg.), Frieden durch Recht?, S. 181-200, Berlin 2010 (zitiert:

Fischer-Lescano/Hanschmann, in: Becker/Braun/Deiseroth, Frieden durch Recht?)

Fleck, Dieter (Hrsg.)/

Bothe, Michael; The Handbook of International Humanitarian Law, 3. Auflage, Oxford 2013

Fredriksen,

Halvard Haukeland; Individualklagemöglichkeiten vor den Gerichten der EU nach dem Vertrag über eine Verfassung für Europa, in: Zeitschrift für Europarechtliche Studien, Ausgabe 1/2005 - Jahrgang 7, S. 99-133 (zitiert: Fredriksen, in ZEuS 1/2005)

Friedrich, Roland; Die deutsche Außenpolitik im Kosovo-Konflikt, 2005 (zitiert: Friedrich, Die deutsche Außenpolitik im Kosovo-Konflikt, 2005)

Friesenhahn, Ernst; Der internationale Schutz der Menschenrechte, in: Schriftreihe der Niedersächsischen Landeszentrale für Politische Bildung. Reihe C, Ausgabe 6/1960 (zitiert: Friesenhahn, Der internationale Schutz der Menschenrechte)

Frowein, Jochen Abr./

Peukert, Wolfgang; Europäische Menschenrechtskonvention: EMRK-Kommentar, 3. Auflage, Kehl 2009 (zitiert: Frowein/Peukert, EMRK)

Frulli, Micaela; $\quad$ When are States liable towards Individuals for serious Violations of Humanitarian Law? The Markovic case, in: Journal of International Criminal Justice, Issue 2/2003 - Volume 1, S. 406-427 (zitiert: Frulli, in: JICJ 2/2003)

Gasser, Hans-Peter; Humanitäres Völkerrecht. Eine Einführung., Baden-Baden 2007

Gärditz,

Klaus Ferdinand; Subjektives Recht auf Überwachung von US-Drohneneinsätzen durch die Bundesregierung?, in: Deutsches Verwaltungsblatt, Ausgabe 13/2016 - Band 131, S. 849-858 (zitiert: Gärditz, in: DVB1. 13/2016)

Giegerich, Thomas; Die Verfassungsbeschwerde an der Schnittstelle von deutschem, internationalem und supranationalem Recht, in: Christoph Grabenwarter u.a. (Hrsg.), Allgemeinheit der Grundrechte und Vielfalt der Gesellschaft, Wien 1994, S. 101-128 (zitiert: Giegerich, in: Grabenwarter, Allgemeinheit der Grundrechte und Vielfalt der Gesellschaft) 
Giegerich, Thomas; Wirkung und Rang der EMRK in den Rechtsordnungen der Mitgliedstaaten, in: Grote, Rainer/Marauhn, Thilo, EMRK/GG: Konkordanzkommentar zum europäischen und deutschen Grundrechtsschutz, Tübingen 2006, S. 61-96 (zitiert: Giegerich, in: Konkordanzkommentar zum europäischen und deutschen Grundrechtsschutz)

Gollwitzer, Walter; Menschenrechte im Strafverfahren: MRK und IPBPR; Kommentar (um ein Sachregister erweiterte Sonderausgabe der Kommentierung der MRK, IPBPR in der 25. Auflage des Löwe-Rosenberg, Großkommentar zur Strafprozessordnung und zum Gerichtsverfassungsgesetz), Berlin 2005 (zitiert: Gollwitzer, EMRK)

Grabenwarter,

Christoph;

Europäische Menschenrechtskonvention: Ein Studienbuch, 6. Auflage, München 2016 (zitiert: Grabenwarter, EMRK)

Graefrath, Bernhard; Schadensersatzansprüche wegen Verletzung humanitären Völkerrechts, in: Humanitäres Völkerrecht - Informationsschriften, Ausgabe 2/2001 Jahrgang 14, S. 110-120 (zitiert: Graefrath, in: HuV-I)

Gropengießer,

Helmut/Kreicker,

Helmut (Hrsg.)/

Eser, Albin (Hrsg.); Nationale Strafverfolgung völkerrechtlicher Verbrechen - National

Prosecution of International Crimes, 1: Deutschland, Freiburg im Breisgau 2003 (zitiert: Gropengießer/Kreicker, Nationale Strafverfolgung völkerrechtlicher Verbrechen)

Gruchmann, Lothar; Justiz im Dritten Reich 1933-1940: Anpassung und Unterwerfung in der Ära Gürtner, 3. Auflage, München 2009 (zitiert: Gruchmann, Justiz im Dritten Reich)

Guzman, Andrew T.; Saving Customary International Law, in: Michigan Journal of International Law, Issue 1/2005 - Volume 27, S. 115-176 (zitiert: Guzman, in: MJIL $1 / 2005)$

Hagelberg, Juliane; Die völkerrechtliche Verfügungsbefugnis des Staates über Rechtsansprüche von Privatpersonen, Jur. Diss., Humboldt-Universität Berlin 2005, veröffentlicht: Baden-Baden 2006

Hahn, Hugo J.; $\quad$ Individualansprüche auf Wiedergutmachung von Zwangsarbeit im Zweiten Weltkrieg - Das Entschädigungsgesetz vom 2.8.2000, in: Neue Juristische Wochenschrift, Ausgabe 48/2000 - Jahrgang 53, S. 3521-3525 (zitiert: Hahn, in: NJW 48/2000)

Hauser, Mathild; Die den Ausländern in der Schweiz garantierten Freiheitsrechte, Diss. Jur., Universität Zürich 1961, veröffentlicht auch: Winterthur 1961

Hecker, Bernd; $\quad$ Europäisches Strafrecht, 4. Auflage, Berlin 2012

Hempel, Michael; Die Völkerrechtssubjektivität internationaler nichtstaatlicher Organisationen, XVI 


\section{Berlin 1999}

Henkin, Louis; $\quad$ Human Rights, in: Rudolf Bernhardt (Hrsg.), Encyclopedia of Public International Law, Amsterdam/New York/Oxford, Ausgabe 8/1985, S. 268274 (zitiert: Henkin, in: EPIL 8/1985)

Herdegen, Matthias; Die Befugnisse des UN-Sicherheitsrates: aufgeklärter Absolutismus im Völkerrecht?, Heidelberg 1998 (zitiert: Herdegen, Die Befugnisse des UNSicherheitsrates)

Heß, Burkhard; Kriegsentschädigungen aus kollisionsrechtlicher und rechtsvergleichender Sicht, in: v. Heinegg, Wolff Heintschel/Kadelbach, Stefan/Heß,

Burkhard/Hilf, Meinhard/Benedek, Wolfgang/Roth, Wulf-Henning, Entschädigung nach bewaffneten Konflikten. Die Konstitutionalisierung der Welthandelsordnung, Heidelberg 2003 S. 107-205 (zitiert: Heß, in: v. Heinegg/Kadelbach/Hilf/Benedek, Entschädigung nach bewaffneten Konflikten)

Hermsdörfer, Willibald;

Zum Anpassungsbedarf des deutschen Strafrechts an das Statut des Internationalen Gerichtshofs, in: Humanitäres Völkerrecht Informationsschriften, Ausgabe 1/1999 - Jahrgang 12, S. 22-27 (zitiert: Hermsdörfer, in: HuV-I 1/1999)

Higgins, Rosalyn; $\quad$ Problems and Process: International Law and how we use it, Oxford: Clarendon Press 1995 (zitiert: Higgins, Problems and Process)

Hillgruber, Christian; Der Nationalstaat in übernationaler Verflechtung, in: Isensee, Josef/Kirchhof, Paul (Hrsg.), Handbuch des Staatsrechts der Bundesrepublik Deutschland, Band 2: Verfassungsstaat, 3. Auflage, Heidelberg 2004, § 32 S. 929-992 (zitiert: Hillgruber, in: HdStR Bd. 2, § 32)

Hillgruber, Christian; Anmerkungen zur Entscheidung des IGH im Fall LaGrand, in: JuristenZeitung, Ausgabe 1/2002 - Jahrgang 57, S. 94-99 (zitiert: Hillgruber, in: JZ 1/2002)

Himmels, Heinz; $\quad$ Der souveräne Malteser-Ritterorden als Völkerrechtssubjekt, in: Goydke, Jürgen (Hrsg.), Vertrauen in den Rechtsstaat: Beiträge zur deutschen Einheit im Recht; Festschrift für Walter Remmers, Köln 1995, S. 213-242 (zitiert: Himmels, in: FS für Walter Remmers)

Hoffmeister, Frank; Die Bindung der Europäischen Gemeinschaft an das Völkergewohnheitsrecht der Verträge, in: Europäisches Wirtschafts- und Steuerrecht, Ausgabe 10/1998, S. 365-370 (zitiert: Hoffmeister, in: EWS 10/1998)

Hofmann, Rainer; Victims of Violations of International Humanitarian Law: Do They Have an Individual Right to Reparation Against States under International Law?, in: Dupuy, Pierre-Marie/Fassbender, Bardo/Shaw, Malcom N./Sommermann, Karl-Peter, Völkerrecht als Wertordnung/Common Values in International Law, Festschrift für Christian Tomuschat, Kehl 2006, S. 341-359 (zitiert: Hofmann, in: Dupuy, Völkerrecht als Wertordnung) 
Hofmann, Rainer/

Riemann, Frank;

Hömig, Dieter/

Wolff, Heinrich

Amadeus (Hrsg.);

Igarashi, Masabiro; Post-War Compensation Cases, Japanese Courts and International Law, in: Japanese Yearbook of International Law, 2000 - Volume 43, S. 45-82 (Igarashi, in: JYIL 2000)

Imhoof, Rodolphe S.; La personalité juridique et le statut des institutions de caractère international, exemples tirés de la pratique suisse, in: SchwJIR 1989 - Band 46, S. 98 f. (zitiert: Imhoof, in: SchwJIR 1989)

International Law Commission;

Ipsen, Hans-Peter; Gleichheit, in: Neumann, Franz Leopold (Hrsg.)/Nipperdey, Hans Carl (Hrsg.)/Scheuner, Ulrich (Hrsg.)/Bachof, Otto, Die Grundrechte: Handbuch der Theorie und Praxis der Grundrechte, Band 2: Die Freiheitsrechte, Berlin 1954, S. 111-198 (zitiert: H.-P. Ipsen, in:

Neumann/Nipperdey/Scheuner/Bachof, Die Grundrechte)

Jarass, Hans D./

Pieroth, Bodo;

Jellinek, Georg;

Jescheck, Hans-

Heinrich;

Befehl und Gehorsam in der Bundeswehr, in: Schüle, Adolf/Scheuner, Ulrich/Jescheck, Hans-Heinrich, Bundeswehr und Recht: eine Sammlung von Referaten, die die Herren [...] auf der Kommandeurstagung der Bundeswehr in München am 14. Oktober 1964 gehalten haben, Köln 1965, S. 63-91 (zitiert: Jescheck, in: Bundeswehr und Recht)

Ders./

Weigend, Thomas; $\quad$ Lehrbuch des Strafrechts: allgemeiner Teil, 5. Auflage, Berlin 1996 (zitiert: Jescheck/Weigend, Lehrbuch des Strafrechts)

Jessup, Philip Caryl; A Modern Law of Nations: An Introduction, Wien 1950 (zitiert: Jessup, A Modern Law of Nations)

Kadelbach, Stefan/

Kleinlein, Thomas;

XVIII
Grundgesetz für die Bundesrepublik Deutschland: Kommentar, 16. Auflage, München 2020 (zitiert: Jarass/Pieroth, GG)

System der subjektiven öffentlichen Rechte, 2. Auflage, Tübingen 1905
International Law - a Constitution for Mankind?: An Attempt at a Reappraisal with an Analysis of Constitutional Principles, in: Delbrück, 
Jost/Giegerich, Thomas/Zimmermann, Andreas, German Yearbook of International Law, 2007 - Band 50, S. 303-347 (zitiert: Kadelbach/Kleinlein, in: GYIL 2007)

Kahl, Wolfgang

(Hrsg.)/Waldhoff,

Christian (Hrsg.)/

Walter, Christian

(Hrsg.)/

Dolzer, Rudolf;

Ders.;

Ders.;

Ders.;

Kelsen, Hans;

Kempen, Bernhard;

Bundesrepublik Deutschland, in: Hans-Joachim Cremer, Tradition und

Weltoffenheit des Rechts: Festschrift für Helmut Steinberger, Berlin 2002, S. 179-196 (zitiert: Kempen, in: Cremer, Tradition und Weltoffenheit des Rechts)

Kessler, Birgit/

Salomon, Tim René;

Die Klagebefugnis aufgrund Völkergewohnheitsrechts im

Verwaltungsprozess am Beispiel des Gewaltverbots, in: Die Öffentliche Verwaltung, Ausgabe 7/2014 - Jahrgang 67, S. 283-291 (zitiert:

Kessler/Salomon, in: DÖV 7/2014)

Knubben, Rolf; $\quad$ Die Subjekte des Völkerrechts: allgemeine Lehre von der vollen und beschränkten völkerrechtlichen Rechts- und Handlungsfähigkeit, in der Gesamtreihe: Stier-Somlo, Fritz (Hrsg.)/Walz, Gustav Adolf/von Dungern, Otto/Ebers, Godehard Josef, Handbuch des Völkerrechts, Stuttgart 1928 (zitiert: Knubben, Die Subjekte des Völkerrechts)

Knox, John H.; $\quad$ Horizontal Human Rights Law, in: American Journal of International Law, Issue 1/2008 - Volume 102, S. 1-47 (zitiert: Knox, in: AJIL 1/2008) 
Koch, Harald; Grenzüberschreitende strategische Zivilprozesse: Ein Weg zu mehr Recht?, in: Anwaltsblatt, Ausgabe 6/2015 - Jahrgang 65, S. 454-461 (zitiert: Koch, in: AnwB1. 6/2015)

Köck,

Heribert-Franz; Die völkerrechtliche Stellung des Heiligen Stuhls: dargestellt an seinen Beziehungen zu Staaten und internationalen Organisationen, Habil. Jur., Universität Wien 1974-1975, veröffentlicht: Berlin 1975 (zitiert: Köck, Die völkerrechtliche Stellung des Heiligen Stuhls)

Kolb, Andreas/

Neumann, Thilo/

Salomon, Tim René;

Entführung deutscher Seeschiffe: Flaggenrecht, Strafanwendungsrech und diplomatischer Schutz, in: Zeitschrift für ausländisches und öffentliches Recht und Völkerrecht, 2011 - Band 71, S. 191-246 (zitiert:

Kolb/Neumann/Salomon, in: ZaöRV 2011)

Koller, Arnold; $\quad$ Die unmittelbare Anwendbarkeit völkerrechtlicher Verträge und des EWGVertrages im innerstaatlichen Bereich, Bern 1971

Kreß, Claus;

Kreicker, Helmut;

Kuhli, Milan;

Lador-Lederer, J. Josef;

Lador-Lederer, J. Josef;

Lagrange, Evelyne;
Vom Nutzen eines deutschen Völkerstrafgesetzbuchs, Baden-Baden 2000

Die Entscheidung des Internationalen Gerichtshofs zur Staatenimmunität Auswirkungen auf das (Völker-)Strafrecht? - Anmerkungen zum Urteil des IGH vom 3.2.2012 aus strafrechtlicher Sicht, in: Zeitschrift für Internationale Strafrechtsdogmatik, Ausgabe 4/2012 - 7. Jahrgang, S. 107-123 (zitiert: Kreicker, in: ZIS 4/2012)

Punishment Based on Customary Law? The Crime against Humanity of Deportation and Enforced Transfer According to $\S 7$ (1) (4) of the German Völkerstrafgesetzbuch (International Law Criminal Code), in: Zeitschrift für Internationale Strafrechtsdogmatik, Ausgabe 4/2012 - Jahrgang 7, S. 124-131 (zitiert: Kuhli, in: ZIS 4/2012)

International Non-Governmental Organizations and Economic Entities: a Study in Autonomous Organization and Ius Gentium, Leiden 1963 (zitiert: Lador-Lederer, International Non-Governmental Organizations)

Nichtstaatliche Organisationen und die Frage der Erweiterung des Kreises der Völkerrechtssubjekte, in: Zeitschrift für ausländisches öffentliches Recht und Völkerrecht, 1963 - Band/Volume 23, S. 657678 (zitiert: Lador-Lederer, in: ZaöRV 23/1963)

L'articulation constitutionnelle des normes d'origine internationale et des normes d'origine interne, in: L'efficacité des normes internationales concernant la situation des personnes privées dans les ordres juridiques internes, in: Collected Courses of the Hague Academy of International Law, Volume 356/2012, S. 372-451 (zitiert: Lagrange, in: Collected Courses of the Hague Academy of International Law 356/2012) 
Lauterpacht,

Hersch;

Leibholz, Gerhard/

Rinck, Hans-Justus/

Hesselberger, Dieter

(Hrsg.);

Ders.;

Lillich, Richard B.;

Lundstedt,

Anders Vilhelm;

MacLean, Jan;

McCorquodale, Robert;

Malanczuk, Peter;

Maunz, Theodor/

Dürig, Günter

(Begr.);
International Law and Human Rights, London 1950 (zitiert: Lauterpacht, International Law and Human Rights)

Grundgesetz für die Bundesrepublik Deutschland, Kommentar an Hand der Rechtsprechung des Budnesverfassungsgerichts, Band 2: Art. 12-69, Gesetzes- und Sachregister, Loseblattsammlung, Köln 1975 fortlaufend, 82. Aktualisierungslieferung Februar 2021 (zitiert: Leibholz/Rinck, Grundgesetz für die Bundesrepublik Deutschland)

Grundgesetz für die Bundesrepublik Deutschland: Kommentar an Hand der Rechtsprechung des Bundesverfassungsgerichts, Band 3: Art. 70-146,

Gesetzes- und Sachregister, Loseblattsammlung, Köln 1975 fortlaufend, 76. Aktualisierungslieferung Mai 2018 (zitiert: Leibholz/Rinck, Grundgesetz für die Bundesrepublik Deutschland)

The Human Rights of Aliens in Contemporary International Law, Manchester 1984 (Lillich, The Human Rights of Aliens)

Superstition or Rationality in Action for Peace?: Arguments against Founding a World Peace on the Common Sense of Justice, London 1925 (zitiert:

Lundstedt, Superstition or Rationality in Action for Peace?)

Gesetzentwurf über die Zusammenarbeit mit dem Internationalen

Strafgerichtshof, in: Zeitschrift für Rechtspolitik, Ausgabe 6/2002 - Jahrgang 35, S. 260-264 (zitiert: MacLean, in: ZRP 6/2002)

The Individual in the International Legal System, in: Evans, Malcom (Hrsg.), International Law, 5. Auflage, Oxford 2018, S. 259-288 (zitiert:

McCorquodale, in: Evans, International Law)

Akehurst's Modern Intriduction to International Law, London 1997

Grundgesetz: Kommentar, Band 2, Art. 6-16a, Loseblattsammlung, München 1985 fortlaufend, Aktualisierungslieferung Januar 2019 (zitiert: Maunz/Dürig, GG)

$\begin{array}{ll}\text { Ders.; } & \text { Grundgesetz: Kommentar, Band 3: Art. 17-28, Loseblattsammlung, } \\ \text { München } 1985 \text { fortlaufend, Aktualisierungslieferung Januar } 2019 \\ \text { (zitiert: Maunz/Dürig, GG) }\end{array}$

Ders.; $\quad$ Grundgesetz: Kommentar, Band 4: Art. 29-67, Loseblattsammlung, 
München 1958 fortlaufend, Aktualisierungslieferung Januar 2019 (zitiert: Maunz/Dürig, GG)

Mennecke, Martin; Towards the Humanization of the Vienna Convention of Consular Rights, in: Delbrück, Jost/Hofmann, Rainer/Zimmermann, Andreas, German Yearbook of International Law, 2001 - Band 44, S. 430-468 (zitiert: Mennecke, in: GYIL 2001)

Meyer, Inga; $\quad$ Der Alien Tort Claims Act: zwischen Völkerrecht und amerikanischer Außenpolitik, Diss. Jur., Rheinische Friedrich-Wilhelms-Universität Bonn 2018, veröffentlicht: Tübingen 2018 (zitiert: Meyer, Der Alien Tort Claims Act)

Milano, Enrico; Diplomatic Protection and Human Rights before the International Court of Justice, in: Netherlands Yearbook of International Law, 2004 - Volume 35, S. 85-142 (zitiert: Milano, in: NYIL 2004)

Moewes, Udo; Staatshaftungsrechtliche Implikationen automatisierter Kriegsführung, in: Robert Frau (Hrsg.), Drohnen und das Recht: Völker- und verfassungsrechtliche Fragen automatisierter und autonomer Kriegsführung, Tübingen 2014 (zitiert: Moewes, in: Frau, Drohnen und das Recht)

Mosler, Hermann; Das Völkerrecht in der Praxis der deutschen Gerichte: Vortrag gehalten vor der Juristischen Studiengesellschaft in Karlsruhe am 8. März 1957, Karlsruhe 1957 (zitiert: Mosler, Das Völkerrecht in der Praxis der deutschen Gerichte)

Mosler, Hermann; $\quad$ Die Erweiterung des Kreises der Völkerrechtssubjekte, in: Zeitschrift für ausländisches öffentliches Recht und Völkerrecht, 1962 - Band 22, S. 1-48 (zitiert: Mosler, in: ZaöRV 1962)

Münch, Fritz; $\quad$ Entscheidungen nationaler Gerichte in völkerrechtlichen Fragen, in: für ausländisches und öffentliches Recht und Völkerrecht, 1959 - Band 20, S. 186-242 (zitiert: Münch, in: ZaöRV 1959)

Nijman, Janne E.; $\quad$ Paul Ricoeur and International Law: Beyond „The End of the Subject“. Towards a Reconceptualization of International Legal Personality, in: Leiden Journal of International Law, Issue 1/2007 - Volume 20, S. 25-64 (zitiert: Nijman, in: LJIL 1/2007)

Nollkaemper, André; National Courts and the International Rule of Law, Oxford 2011

Oellers-Frahm, Karin;

Die Entscheidung des IGH im Fall LaGrand - Eine Stärkung der internationalen Gerichtsbarkeit und der Rolle des Individuums im Völkerrecht, in Europäische Grundrechte Zeitschrift, Ausgabe 11-13/2001 Jahrgang 28, S. 265-271 (zitiert: Oellers-Frahm, in: EuGRZ 11-13/2001)

Oellers-Frahm, Karin;

Die Entscheidung des IGH im Fall LaGrand - ein Markstein in der Rechtsprechung des IGH, in: Thilo Marauhn (Hrsg.), Die Rechtsstellung des Menschen im Völkerrecht: Entwicklungen und Perspektiven, Tübingen 2003, S. 21-36 (zitiert: Oellers-Frahm, in: Die Rechtsstellung des Menschen im 
Völkerrecht)

OHCHR - Committee

on Economic, Social

and Cultural Rights; General Comment No. 3 (UN-Document E/1991/23), Annex II 86, 1991

(zitiert: OHCHR - Committee on Economic, Social and Cultural Rights,

General Comment No. 3 1991)

Ossenbühl, Fritz/

Cornils, Matthias; $\quad$ Staatshaftungsrecht, 6. Auflage, München 2013

Papadimitriu,

Georgios;

Die Stellung der allgemeinen Regeln des Völkerrechts im innerstaatlichen Recht: eine rechtsdogmatische und rechtsvergleichende Untersuchung zur Stellung der allgemeinen Regeln des Völkerrechts im innerstaatlichen Recht unter Berücksichtigung der Rechtsordnungen Belgiens, der Bundesrepublik Deutschland und Griechenlands, Diss. Jur., Ruprecht-Karls-Universität Heidelberg 1971/72, veröffentlicht: Berlin 1972 (zitiert: Papadimitriu, Die Stellung der allgemeinen Regeln des Völkerrechts im innerstaatlichen Recht

Papier, Hans-Jürgen; Umsetzung und Wirkung der Entscheidungen des EGMR aus der Perspektive der nationalen deutschen Gerichte, in: Europäische Grundrechte Zeitschrift, Ausgabe 1/2006 - Jahrgang 33, S. 1-2 (zitiert: Papier, in: EuGRZ 1/2006)

Parlett, Kate; $\quad$ The Individual in the International Legal System: Continuity and Change in International Law, Cambridge 2011 (zitiert: Parlett, The Individual in the International Legal System)

Partsch, Karl Josef; Die Anwendung des Völkerrechts im innerstaatlichen Recht: Überprüfung der Transformationslehre, in: Berichte der Deutschen Gesellschaft für Völkerrecht, Heft 6/1964, S. 13-147 (zitiert: Partsch, in: Berichte der Deutschen Gesellschaft für Völkerrecht 6/1964)

Pergantis, Vasileios; Towards a „Humanization“ of Diplomatic Protection?, in: Zeitschrift für ausländisches öffentliches Recht und Völkerrecht, 2006 - Band 66, S. 351-397 (zitiert: Pergantis, in: ZaöRV 2006)

Peters, Anne; $\quad$ Jenseits der Menschenrechte: die Rechtsstellung des Individuums im Völkerrecht, Tübingen 2014 (zitiert: Peters, Jenseits der Menschenrechte)

Petersen, Niels; $\quad$ Demokratie als teleologisches Prinzip: zur Legitimität von Staatsgewalt im Völkerrecht, Diss. Jur., Goethe-Universität Frankfurt am Main 2008, veröffentlicht: Berlin 2009 (zitiert: Petersen, Demokratie als teleologisches Prinzip)

Piotrowski, G.; $\quad$ L'ordre international et la question de sujets de droit, in: Revue de droit international, de sciences diplomatiques et politiques, No. 1/1954 - Volume 32, S. 12-37 (zitiert: Piotrowski, in: Revue de Droit International, de Sciences diplomatiques et politiques No. 1/1954)

Portmann, Roland; Legal Personality in International Law, Diss. Jur., University of St. Gallen 2008, veröffentlicht: Bamberg 2009 
Reich und Länder: Bruchstücke eines Kommentars zur Verfassung des Deutschen Reiches, aus dem Nachlass des Prof. Dr. Gerhard Anschütz (Hrsg.), Berlin 1928 (zitiert: Preu $\beta$, Reich und Länder)

Quadri, Rolando; $\quad$ Diritto internazionale pubblico, 5. Auflage, Neapel 1968

Randelzhofer, Albrecht;

Rengier, Rudolf; $\quad$ Strafrecht Allgemeiner Teil, 10. Auflage, München 2018 (zitiert: Rengier, Strafrecht AT)

Roscher, Bernhard; Der Briand-Kellog-Pakt von 1928: Der „Verzicht auf den Krieg als Mittel nationaler Politik“ im völkerrechtlichen Denken der Zwischenkriegszeit, Baden-Baden 2004

Rousseau, Charles; Droit international public, Paris 1953

Rudolf, Walter; Die innerstaatliche Anwendung partikulären Völkergewohnheitsrechts, in: Marcic, René/Mosler, Hermann/Suy, Erik/Zemanek, Karl, Internationale Festschrift für Alfred Verdross zum 80. Geburtstag, München 1971, S. 435448 (zitiert: Rudolf, in: FS für Alfred Verdross)

Rudolf, Walter; $\quad$ Völkerrecht und deutsches Recht: theoretische und dogmatische Untersuchungen über die Anwendung völkerrechtlicher Normen in der Bundesrepublik Deutschland, Habil. Jur., Eberhard Karls Universität Tübingen 1967, veröffentlicht: Tübingen 1967 (zitiert: Rudolf, Völkerrecht und deutsches Recht)

Ruffert, Matthias; $\quad$ Diplomatischer und konsularischer Schutz, in: Isensee, Josef/Kirchhof, Paul (Hrsg.), Handbuch des Staatsrechts in der Bundesrepublik Deutschland, Band 10 - Deutschland in der Staatengemeinschaft, 3. Auflage, Heidelberg 2012, $\S 206$ S. 67-91 (zitiert: Ruffert, in: HdStR Bd. 10, § 206)

Sachs, Michael

(Hrsg.);

Grundgesetz: Kommentar, 9. Auflage, München 2021 (zitiert: Sachs, GG)

Safferling, Christoph/

Joecks, Wolfgang/

Miebach, Klaus

(Hrsg.);

Münchener Kommentar zum Strafgesetzbuch, Nebenstrafrecht III:

Strafvorschriften aus: AufenthG, FreizügG/EU, AsylG, StAG, WaffG,

KrWaffG, SprengG, WStG, EGWStG, VStGB, 3. Auflage, München 2018

(zitiert: Münchener Kommentar, VStGB)

Safferling, Christoph/

Kirsch, Stefan; $\quad$ Zehn Jahre Völkerstrafgesetzbuch, in: Juristische Arbeitsblätter, Ausgabe 7/2012 - Band 44, S. 481-487 (zitiert: Safferling/Kirsch, in: JA 7/2012) 
Sands, Philippe; International Law Transformed? From Pinochet to Congo...?, in: Leiden Journal of International Law, Issue 1/2003 - Volume 16, S. 37-53 (zitiert: Sands, in: LJIL 1/2003)

Satzger, Helmut; $\quad$ Das neue Völkerstrafgesetzbuch - Eine kritische Würdigung, in: Neue Zeitschrift für Strafrecht, Ausgabe 3/2002 - Jahrgang 22, S. 125-132 (zitiert: Satzger, in: NStZ 3/2002)

Ders.; Die Internationalisierung des Strafrechts als Herausforderung für den strafrechtlichen Bestimmtheitsgrundsatz, in Juristische Schulung, Ausgabe 11/2004 - Jahrgang 44, S. 943-949 (zitiert: Satzger, in: JuS 11/2004)

Ders.;

Internationales und europäisches Strafrecht: Strafanwendungsrecht, Europäi sches Straf- und Strafverfahrensrecht, Völkerstrafrecht, 8. Auflage, BadenBaden 2018 (zitiert: Satzger, Internationales und europäisches Strafrecht)

Saurer, Johannes; Der Einzelne im europäischen Verwaltungsrecht: die institutionelle Ausdifferenzierung der Verwaltungsorganisation der Europäischen Union in individueller Perspektive, Habil. Jur., Universität Bayreuth 2011, veröffentlicht: Tübingen 2014 (zitiert: Saurer, Der Einzelne im europäischen Verwaltungsrecht)

Scelle, Georges; $\quad$ Manuel de droit international public (Titre de couverture: Cours de droit international public), Paris 1948 (zitiert: Scelle, Cours de droit international public)

Ders.;

Précis de droit des gens: principes et systématique, Vol. 1, Paris 1932 (zitiert: Scelle, Précis de droit des gens)

Schack, Friedrich; Bundesverwaltungsgericht und Requisitionsentschädigung, in: Deutsches Verwaltungsblatt, Heft 21/1957 - Jahrgang 72, S. 740-745 (zitiert: Schack, in: DVB1. 21/1957)

Schaller, Christian; Die strafrechtliche Verfolgung von Piraten, in: Stefan Mair (Hrsg.), Piraterie und maritime Sicherheit: Fallstudien zu Afrika, Südostasien und Lateinamerika sowie Beiträge zu politischen, militärischen, rechtlichen und ökonomischen Aspekten, SWP-Studie, Berlin 2010, S. 91-100 (zitiert:

Schaller, in: Mair, Piraterie und maritime Sicherheit)

Schiedermair,

Stephanie;

Piratenjagd im Golf von Aden, in: Archiv des Öffentlichen Rechts, Ausgabe 2/2010 - Jahrgang 135, S. 185-220 (zitiert: Schiedermair, in: AÖR 2/2010)

Schmahl, Stefanie; Die Bekämpfung er Seepiraterie im Spiegel des Völkerrechts, des

Europarechts und der deutschen Rechtsordnung, in: Archiv des Öffentlichen Rechts, Ausgabe 1/2011 - Jahrgang 136, S. 44-94 (zitiert: Schmahl, in: AÖR 1/2011)

Schmidt-Bleibtreu,

Bruno/Klein, Franz/

Hofmann, Hans (Hrsg.)/

Henneke, Hans-Günter 
(Hrsg.);

Schneider, Peter;

Zur Rechtsstellung des Internationalen Roten Kreuzes, in: Archiv des Verwaltungsrechts 2/1955/56 - Band 5, S. 257-271 (zitiert: Schneider, in: AVR 2/1955/56)

Schorkopf, Frank; $\quad$ Staatsrecht der internationalen Beziehungen, München 2017

Schorkopf; Frank; Grundgesetz und Überstaatlichkeit: Konflikt und Harmonie in den auswärtigen Beziehungen Deutschlands, Tübingen 2007 (zitiert: Schorkopf, Grundgesetz und Überstaatlichkeit)

Schweitzer, Michael/

Weber, Albrecht/

Ahlers, Sabine;

Handbuch der Völkerrechtspraxis der Bundesrepublik Deutschland, 1. Auflage, Baden-Baden 2004 (zitiert: Schweitzer/Weber, Handbuch der Völkerrechtspraxis der BRD)

Schweitzer, Michael/

Dederer,

Hans-Georg;

Staatsrecht, Völkerrecht, Europarecht, 12. Auflage, Heidelberg 2020 (zitiert: Schweitzer/Dederer, Staatsrecht)

Seibert-Fohr Anja; Die Deliktshaftung von Unternehmen für die Beteiligung an im Ausland begangenen Völkerrechtsverletzungen: Anmerkungen zum Urteil Doe I v. Unocal Corp. des US Court of Appeal ( $9^{\text {th }}$ Circuit), in: Zeitschrift für ausländisches öffentliches Recht und Völkerrecht, 2003 - Band 63, S. 195204 (zitiert: Seibert-Fohr, in: ZaöRV 2003)

Seyersted, Finn; $\quad$ Objective international personality of intergovernmental organizations: do their capacities really depend upon the conventions establishing them?,

Kopenhagen 1963

Simma, Bruno/

Alston, Philipp;

The Sources of Human Rights Law, Australian Yearbook of International Law, Volume 12/1988/89, S. 82-108 (zitiert: Simma/Alston, in: AYIL 1988/1989)

Sivakumaran, Sandesh;

Binding Armed Opposition Groups, in: International and Comparative Law Quarterly, Issue 2/2006 - Volume 55, S. 369-394 (zitiert: Sivakumaran, in: ICLQ 2/2006)

Sodan, Helgel

Ziekow, Jan;

Verwaltungsgerichtsordnung: ein Großkommentar, 5. Auflage, Baden-Baden 2018 (zitiert: Sodan/Ziekow, VwGO)

Steger, Ruth; $\quad$ Staatenimmunität und Kriegsverbrechen - Das IGH-Urteil im Verfahren Deutschland gegen Italien vom 03.02.2012, Frankfurt 2013 (zitiert: Steger, Staatenimmunität und Kriegsverbrechen)

Steinberger, Helmut; Allgemeine Regeln des Völkerrechts, in: Isensee, Josef/Kirchhof, Paul 
Streinz, Rudolf/

Michl, Walther;

Stumpfe, Werner;

Talmon, Stefan;

Thym, Daniel;

Tomuschat,

Christian;

Tomuschat,

Christian;

Tomuschat,

Christian;

Umbach, Dieter C./

Clemens, Thomas;

Vannod, Alex;
(Hrsg.), Handbuch des Staatsrechts der Bundesrepublik Deutschland, Band 7: Normativität und Schutz der Verfassung - Internationale Beziehungen, Heidelberg 1992, 1. Auflage $§ 173$ S. 525-569 (zitiert: Steinberger, in: HdStR Bd. 7, § 173)

EUV/AEUV: Vertrag über die Europäische Union, Vertrag über die Arbeitsweise der Europäischen Union, Charta der Grundrechte der Europäischen Union, Band 57, 3. Auflage, München 2018 (zitiert: Streinz, AEUV)

Die allgemeinen Regeln des Völkerrechts im Sinne des Art. 25 des Grundgesetzes für die Bundesrepublik Deutschland vom 23. Mai 1949 und der Satz ,pacta sunt servanda“, Diss. Jur., Universität Zürich 1963, veröffentlicht: Zürich 1963 (zitiert: Stumpfe, Die allgemeinen Regeln des Völkerrechts)

Die Grenzen der Anwendung des Völkerrechts im deutschen Recht, in: JuristenZeitung, Ausgabe 1/2013 - Jahrgang 68, S. 12-21 (zitiert: Talmon, in: JZ 1/2013)

Respect for Private and Family Life under Article 8 ECHR in Immigration Cases, in: International \& Comparative Law Quarterly, Volume 57/2008, S. 87-112 (zitiert: Thym, in: ICLQ 57/2008)

Die staatsrechtliche Entscheidung für die internationale Offenheit, in: Isensee, Josef/Kirchhof, Paul (Hrsg.), Handbuch des Staatsrecht der Bundesrepublik Deutschland, Band 7: Normativität und Schutz der Verfassung Internationale Beziehungen, Heidelberg 1992, § 172 S. 483-523 (zitiert: Tomuschat, in: HdStR Bd. 7, § 172)

Deutsche Rechtsprechung in völkerrechtlichen Fragen 1958-1965. Teil A: Allgemeines Friedensvölkerrecht, in: Zeitschrift für ausländisches öffentliches Recht und Völkerrecht, 1968 - Band 28, S. 48-147 (zitiert: Tomuschat, in: ZaöRV 1968)

The Responsibility of Other Individuals: Private Individuals, in: Crawford, James/Pellet, Alain/Olleson, Simone, The Law of International Responsibility, Oxford 2010, S. 317-329 (zitiert: Tomuschat, in: The Law of Individual Responsibility)

Grundgesetz: Mitarbeiterkommentar und Handbuch, Band 1: Art. 1-37 GG, Heidelberg 2002 (zitiert: Umbach/Clemens, GG)

Fragen des internationalen Enteignungs- und Konfiskationsrechts: insbesondere nach schweizerischer Praxis, Diss. Jur., Universität Zürich 1959, veröffentlicht: Zürich 1959 (zitiert: Vannod, Fragen des internationalen Enteignungs- und Konfiskationsrechts) 
Simma, Bruno; $\quad$ Universelles Völkerrecht, Berlin 1984

von Arnauld,

Andreas;

Die moderne Piraterie und das Völkerrecht, in: Archiv des Völkerrechts, Ausgabe 4/2009 - Jahrgang 47, S. 454-453 (zitiert: v. Arnauld, in: AVR 4/2009)

von Bogdandy,

Armin/

Bast, Jürgen (Hrsg.); Europäisches Verfassungsrecht: Theoretische und dogmatische Grundzüge, 2. Auflage, Berlin 2009 (zitiert: v. Bogdandy/Bast, Europäisches

von Mangoldt, Verfassungsrecht)

Hermann/Klein, Friedrich;

Das Bonner Grundgesetz, Band 1, 2. Auflage, Berlin 1957

von Mangoldt,

Hermann/Klein,

Friedrich/Starck,

Christian/Huber,

Peter M. (Hrsg.)/

Voßkuhle, Andreas

(Hrsg.);

Grundgesetz: Kommentar, Band 2: Artikel 20 bis 82, 7. Auflage, München 2018 (zitiert: v. Mangoldt/Klein/Starck, GG)

Vermeer-Künzli, Annemarieke;

As if: The Legal Fiction in Diplomatic Protection, in: European Journal of International Law, Issue 1/2007 - Volume 18, S. 37-68 (zitiert: VermeerKünzli, in: EJIL 1/2007)

Verhoeven, Joe; La notion d'“applicabilité directe“ du droit international, in: Revue Belge de droit international, numéro 2/1980 - Volume 15, S. 243-264 (zitiert:

Verhoeven, in: Revue Belge de droit international 2/1980)

Vitanyi, Béla; $\quad$ Les position doctrinal concernant le sens de la notion de 'principes généraux de droit reconnus par les nations civilisées': Normes positives traduisant les conceptions fondamentales de l'ordre juridique, in: Revue Générale du Droit International Public, Volume 86/1982, S. 96-116 (zitiert: Vitanyi, in: Revue Générale du Droit International Public 86/1982)

Vitzthum, Wolfgang

Graf/Proelß,

Alexander;

Völkerrecht, 7. Auflage, Berlin 2016 (zitiert: Vitzthum/Proelß, Völkerrecht)

von der Groeben,

Hans/Schwarze,

Jürgen, Hatje, Armin; Europäisches Unionsrecht: Vertrag über die Europäische Union - Vertrag über die Arbeitsweise der Europäischen Union - Charta der Grundrechte der Europäischen Union, Band 4: Art. 174 bis 358 AEUV, 7. Auflage, BadenBaden 2015 (zitiert: v. der Groeben/Schwarze/Hatje, AEUV) 
von Kempen,

Bernhard/

Hillgruber, Christian; Völkerrecht, 2. Auflage, München 2012

von Münch, Ingo/

Kunig, Philip/

von Arnold, Andreas; Grundgesetz-Kommentar, Band 1: Präambel bis Art. 69, 6. Auflage, München 2012 (zitiert: v. Münch/Kunig, GG)

von Woedtke,

Niclas;

Die Verantwortlichkeit Deutschlands für seine Streitkräfte im Auslandseinsatz und die sich daraus ergebenden Schadensersatzansprüche von Einzelpersonen als Opfer deutscher Militärhandlungen, Diss. Jur., Goethe-Universität Frankfurt am Main 2009, veröffentlicht: Berlin 2010 (zitiert: v. Woedtke, Die Verantwortlichkeit Deutschlands)

Wagner, Norbert B.; Pirata hostis generi humani: Zu den rechtlichen Grundlagen der Bekämpfung von Piraterie durch Seestreitkräfte, in: Humboldt Forum Recht, Aufsatz 3/2010, S. 31-54 (zitiert: Wagner, in: HFR 3/2010)

Walter, Christian; $\quad$ Subjects of International Law, in: Rüdiger Wolfrum (Hrsg.), The Max Planck Encyclopedia of Public International Law, Volume 9: Human rights, treaties, Third-Party effect to International Organizations or Institutions, Headquarters, Amsterdam/New York/Oxford 2012, S. 634-642 (zitiert: Walter, in: Wolfrum, EPIL 9/2012)

Walz,

Gustav Adolf; $\quad$ Völkerrecht und staatliches Recht: Untersuchungen über die Einwirkungen des Völkerrechts auf das innerstaatliche Recht, Stuttgart 1933 (zitiert: Walz, Völkerrecht und staatliches Recht)

Weller,

Marc-Philippe; Die Vertragstreue: Vertragsbindung - Naturalerfüllungsgrundsatz -

Leistungstreue, Habil. Jur., Universität zu Köln 2007-2008, veröffentlicht: Tübingen 2009

Wengler, Wilhelm; Völkerrecht, Band 1: 1. und 2. Teil, Berlin 1964 (zitiert: Wengler, Völkerrecht)

Werle, Gerhard; $\quad$ Menschenrechtsschutz durch Völkerstrafrecht, in: Zeitschrift für die gesamte Strafrechtswissenschaft, Ausgabe 4/1997 - Band 109, S. 808-829 (zitiert: Werle, in: ZStW 4/1997)

Werle, Gerhard; $\quad$ Konturen eines deutschen Völkerstrafrechts. Zum Arbeitsentwurf eines Völkerstrafgesetzbuchs, in: JuristenZeitung, Ausgabe 18/2001 - Band 56, S. 885-894 (zitiert: Werle, in: JZ 18/2001)

Werle, Gerhard/

Jeßberger, Florian; Völkerstrafrecht, 4. Auflage, Tübingen 2016 
Wessels, Johannes/

Beulke, Werner/

Satzger, Helmut; $\quad$ Strafrecht, Allgemeiner Teil: die Straftat und ihr Aufbau, 48. Auflage,

Heidelberg 2018 (zitiert: Wessels/Beulke/Satzger, Strafrecht AT)

Wiefelspütz, Dieter; Die Beteiligung der Bundeswehr am Kampf gegen Piraterie, in:

Dau, Klaus/Zetsche, Holger, Neue Zeitschrift für Wehrrecht, Ausgabe 2/2009

- Jahrgang 51, S. 133-150 (zitiert: Wiefelspütz, in: NZWehrR 2/2009)

\section{Zimmermann, Andreas/}

Tams, Christian J./

Tomuschat, Christian/

Oellers-Frahm,

Karin;

The Statute of the International Court of Justice: A Commentary, 3. Auflage, Oxford 2019 (zitiert: Zimmermann/Tomuschat/Oellers-Frahm, The Statute of the ICJ)

Zegveld, Liesbeth; $\quad$ Remedies for Victims of Violations of International Humanitarian Law, in: International Review of the Red Cross, Issue 849/2003 - Volume 85, S. 497527 (zitiert: Zegveld, in: IRRC 849/2003)

Zypries, Brigitte; $\quad$ Verfassung der Zukunft. Ein Lesebuch zu 60 Jahren Grundgesetz, Berlin 2009 (zitiert: Zypries, Verfassung der Zukunft)

\section{$\underline{\text { Internetquellen }}$}

Alleingang der Trump-Regierung: USA erklären Austritt aus Pariser Klimavertrag

unter https://www.spiegel.de/politik/ausland/trump-regierung-usa-erklaeren-austritt-aus-pariserklimavertrag-a-1161486.html

(zuletzt aufgerufen am 13.06.2019)

Anger, Heike; Bundesjustizministerium plant mehr Arbeitnehmerschutz

unter https://www.handelsblatt.com/politik/deutschland/unternehmenssanktionen-bundesjustizministerium-plant-mehr-arbeitnehmerschutz/24463366.html?ticket=ST-1757917-

azVH24x5YZD1Hfa5JBYf-ap4

(zuletzt aufgerufen am 01.07.2019)

Anhörung: Experten diskutieren Anwendungsdefizite des Völkerstrafgesetzbuchs

unter https://web.archive.org/web/20160430205259/http://rsw.beck.de/aktuell/meldung/anhoerungexperten-diskutieren-anwendungsdefizit-des-voelkerstrafgesetzbuchs (zuletzt aufgerufen am 10.06.2019)

Atom-Deal: Trump verkündet Ausstieg aus Iran-Abkommen

unter https://www.spiegel.de/politik/ausland/donald-trump-verkuendet-ausstieg-aus-iran-atomabkommen-und-sanktionen-a-1206893.html

(zuletzt aufgerufen am 13.06.2019) 
Japan and South Korea agree WWII 'Comfort Women' Deal

unter https://www.bbc.com/news/world-asia-35188135

(zuletzt aufgerufen am 14.06.2019)

Raffeiner, Stefan; Italien im Dilemma zwischen Verfassungs- und Völkerrechtstreue unter https://verfassungsblog.de/italien-im-dilemma-zwischen-verfassungs-und-voelkerrechtstreue$2 /$ (zuletzt aufgerufen am 07.06.2021)

Rummel, Andreas; Der UN-Sicherheitsrat hat Syrien im Stich gelassen. Es ist an der Zeit, seine Autorität in Frage zu stellen

unter https://www.democracywithoutborders.org/de/5141/der-un-sicherheitsrat-hat-syrien-im-stichgelassen-es-ist-an-der-zeit-seine-autoritaet-in-frage-zu-stellen/

(zuletzt aufgerufen am 10.05.2021)

Samp, Rich; U.S. Supreme Court Continues To Nibble Away At Alien Tort Statute's Sweep

unter https://www.forbes.com/sites/wlf/2018/04/25/u-s-supreme-court-continues-to-nibble-away-atalien-tort-statutes-sweep/\#56764589d9fe

(zuletzt aufgerufen am 14.06.2019)

Schellenberg, Martin; Griechenland: Unbeglichene deutsche Kriegsschuld/en unter http://lernen-aus-der-geschichte.de/Lernen-und-Lehren/content/12739

(zuletzt aufgerufen am 14.06.2019)

Schreiben des ECCHR an den Bundesanwalt Ritscher vom 28.06.2016, Az. GBA 3 ARP 100/14-4 und vom 17.12.2014 (Strafanzeige),

unter https://www.ecchr.eu/de/unsere-themen/voelkerstraftaten-und-rechtliche-verantwortung/usa/verfahren-deutschland.html

(zuletzt aufgerufen am 18.10.2018)

Schreiben des Generalbundesanwaltes vom 10.03.2005, Az. 3 ARP 207/04-2,

Schreiben des Rechtsanwalts Kaleck an den Generalbundesanwalt vom 29.11.2004,

unter https://www.ecchr.eu/de/unsere-themen/voelkerstraftaten-und-rechtliche-verantwortung/usa/rumsfeld.html

(zuletzt aufgerufen am 18.10.2018)

United Nations Security Council, Statement by the President of the Security Council, UNDoc. S/PRST/2009/32,

unter https://www.securitycouncilreport.org/atf/cf/\%7B65BFCF9B-6D27-4E9C-8CD3CF6E4FF96FF9\%7D/DT\%20SPRST\%202009\%2032.pdf

(zuletzt aufgerufen am 07.06.2019)

Ulrich, Stefan; Das brutale Versagen der Vereinten Nationen,

unter https://www.sueddeutsche.de/politik/krieg-in-syrien-das-brutale-versagen-der-vereinten-nationen-1.3877937

(zuletzt aufgerufen am 10.05.2021) 